Portland State University

PDXScholar

Summer 8-21-2019

\title{
The Impact of Implementing Different Cordon Size Designs on Land Use Patterns in Portland, OR
}

Asia Spilotros

Portland State University

Follow this and additional works at: https://pdxscholar.library.pdx.edu/open_access_etds

Part of the Urban Studies and Planning Commons

Let us know how access to this document benefits you.

\section{Recommended Citation}

Spilotros, Asia, "The Impact of Implementing Different Cordon Size Designs on Land Use Patterns in Portland, OR" (2019). Dissertations and Theses. Paper 5095.

https://doi.org/10.15760/etd.6971

This Dissertation is brought to you for free and open access. It has been accepted for inclusion in Dissertations and Theses by an authorized administrator of PDXScholar. Please contact us if we can make this document more accessible: pdxscholar@pdx.edu. 
The Impact of Implementing Different Cordon Size Designs on Land Use Patterns in Portland, OR

by

Asia Spilotros

A dissertation submitted in partial fulfillment of the requirements for the degree of

\author{
Doctor of Philosophy \\ in \\ Urban Studies
}

Dissertation Committee:

Anthony M. Rufolo, Chair

Gerard Mildner

James Strathman

Miguel Figliozzi

Portland State University

2019 


\begin{abstract}
The purpose of this research dissertation is to compare the effects of using small, medium, and large cordon designs in road tolling on residential and commercial neighborhoods in Portland, Oregon. Changes in land use patterns are assessed by comparing the projected output of each cordon scenario to a "no toll" alternative in 2035. The performance of each cordon design is tested using two different prices $(\$ 1.65$ and \$8) and compared to a default scenario 25 years after the initial implementation in MetroScope's year 0, 2010. The following areas embedded within the cordon perimeter were considered in determining changes in land use: all the zones closest to the boundaries, the entire city of Portland, and the neighborhood towns surrounding Portland.

Understanding the impact of choosing the "right" cordon size on economic development and residential location choices can be of utmost interest to lawmakers when they assess economic development policies.

Unanswered questions remain regarding the impact a cordon scheme has on economic development and business location decisions, as well as its effect on the spatial pattern in the city. While studies on optimal toll pricing are abundant, there are very few studies that determine the optimal cordon location and size for a particular network. Accordingly, a critical question is whether cordon pricing will influence the centralization or decentralization of land use and affect jobs, population, and economic activities. The implementation of a cordon scheme is expected to affect areas both inside and outside of the designated perimeter and is further expected to contribute to changes
\end{abstract}


that will affect land use. Existing studies have ignored land use effects and, instead, assume a monocentric city model.

What sets this study apart is that instead of using a monocentric model to test the hypothetical cordon scenarios, the MetroScope model is used to predict changes in economy, demographics, and land use. The MetroScope model is one of only a few models that can assist in forecasting changes in both land use and prices.

This study found primary evidence that the implementation of diverse sizes of cordon designs differently affect residential and non-residential land use patterns and trends. 


\section{Acknowledgments}

I wish to express my immense gratitude to my advisor, Dr. Anthony M. Rufolo, whose hard work and dedication made the development and production of my dissertation possible. To his continuous support and commitment to excellence in guidance and his ever-ready attitude. It would have not been possible for me to take this work to completion without his incredible support and expertise. I could not have imagined having a better advisor and mentor for my doctoral study.

I wish to thank the individual members of my dissertation committee: Dr. Mildner, Dr. Strathman, and Dr. Figliozzi, for serving as my committee members and for their encouragement and knowledge.

In particular, I am grateful to my dissertation committee members for letting my defense be an enjoyable moment, and for their brilliant comments and suggestions.

A special thanks to Metro for providing me with the opportunity to use their integrated land use and transportation model MetroScope. Without precious support from Metro, it would not have been possible to conduct this research successfully.

To Arash, for his unconditional love, understanding, and encouragement through the years. I would like to thank my daughter Vittoria and my son Raphael.

Last but not least, I am truly grateful to my family for their immeasurable love and care: my mother Marina, my father Giuseppe, Mario, and nonna Danila. 


\section{Table of Contents}

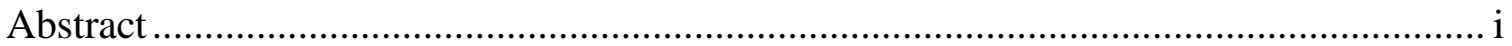

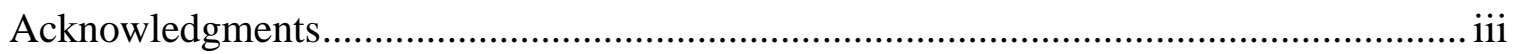

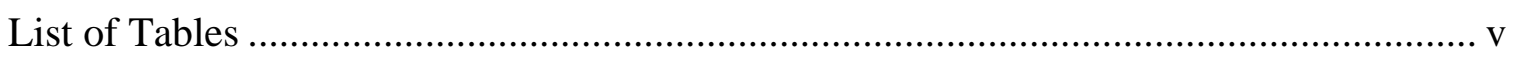

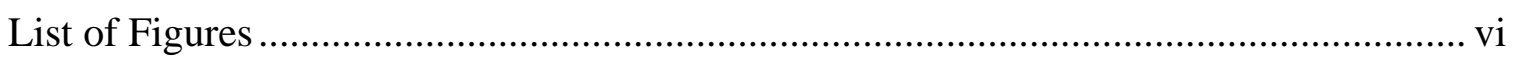

1 Introduction on Congestion Pricing Theory ………………………………......... 1

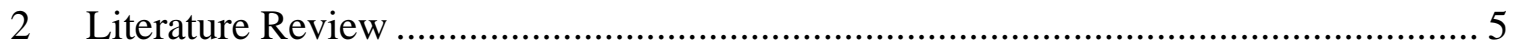

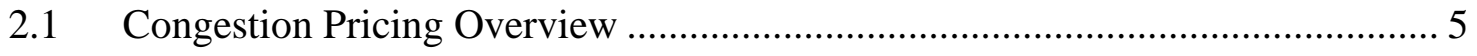

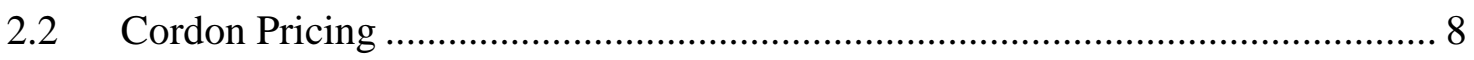

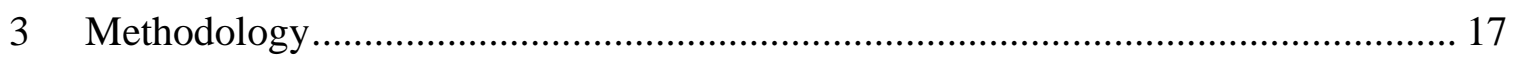

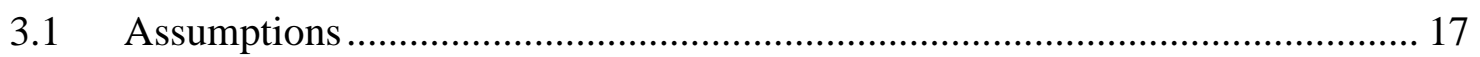

3.2 MetroScope-A Land Use Allocation Model................................................... 18

3.3 MetroScope Full Version Versus Simplified Version ........................................ 24

3.4 MetroScope versus Other Urban Models ……………………....................... 26

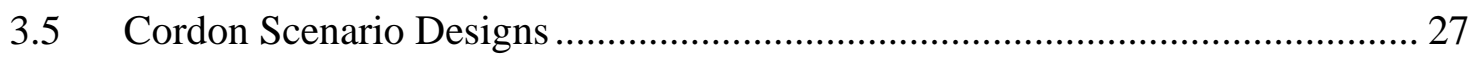

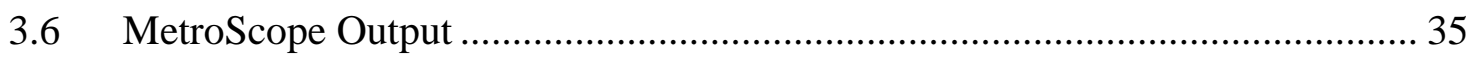

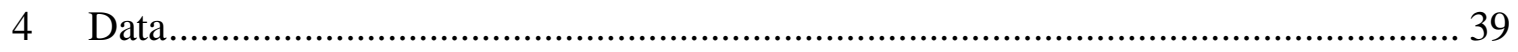

5 General Information about Technology ............................................................... 40

6 Central Business District, or Small Cordon............................................................. 42

6.1 CBD or Small Cordon Output Analysis ......................................................... 50

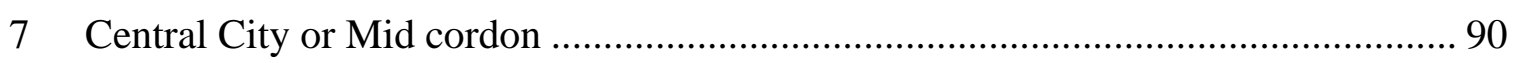

7.1 Central City or Mid Cordon Output Analysis .................................................... 97

8 Portland City Boundaries, or Big Cordon ........................................................... 147

8.1 Portland City Boundaries, or Big Cordon Output Analysis ............................ 150

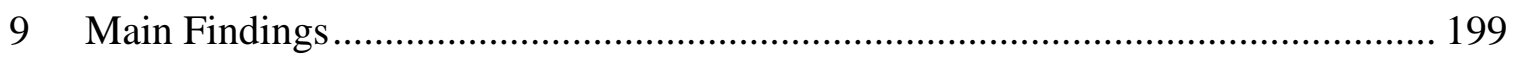

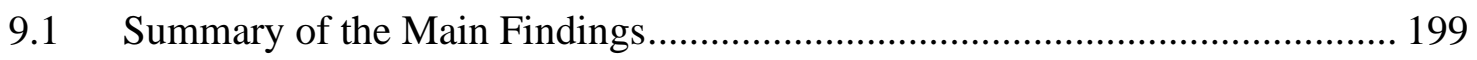

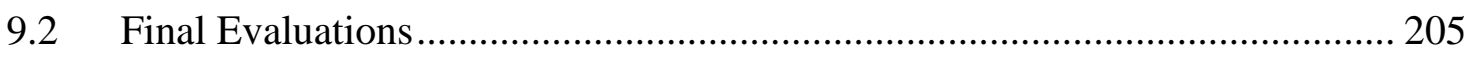

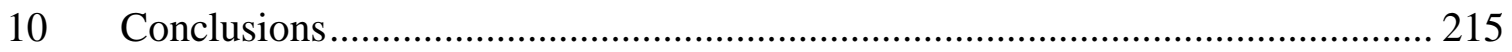

10.1 Limitations and Future Research.............................................................. 216

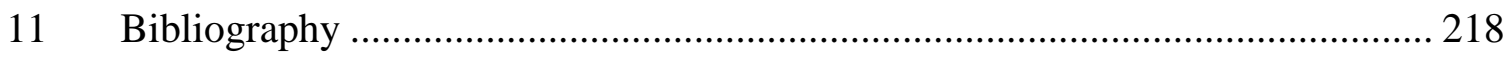


List of Tables

Table 3.1 Full Version versus Simplified Version of MetroScope Travel Model........... 25

Table 3.2 Different Cordon Scenarios Tested................................................................ 30

Table 3.3 MetroScope Years Versus Actual Years ....................................................... 35

Table 8.1 Non-residential Location Price Changes Once a Toll Cordon Is Implememnted

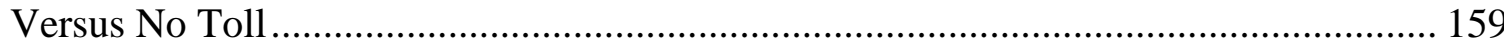

Table 8.2 Percentage Changes in Employment After the Implementation of a Cordon Toll

within Portland at the Year 2035 .............................................................................. 162

Table 8.3 Effects of the Implementation of a Cordon Toll around Portland on Non-

residential Employment in Each City, at the Year 2035......................................... 170

Table 8.4 Changes in Non-residential Household Demand (With and Without School-

Age Children) after a Toll Cordon is Implemented Versus No Toll in 2035 ................ 176

Table 8.5 Effects of the Implementation of a Cordon Toll around Portland on Non-

residential Total Supply in Each City at the Year 2035

Table 8.6 Recaps and Compares the Effect that Each Cordon Has within the Entire City of Portland After a Toll is Implemented Compared to a No Toll Alternative in 2035 ... 198 


\section{List of Figures}

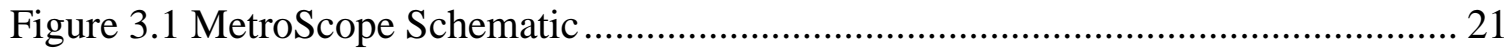

Figure 3.2 CBD Boundaries in Portland, OR ........................................................... 31

Figure 3.3 CBD or Small Cordon Boundaries in Portland, OR .................................... 31

Figure 3.4 Central City, Portland, OR ......................................................................... 32

Figure 3.5 Central City or Mid Cordon Boundaries in Portland, OR .............................. 33

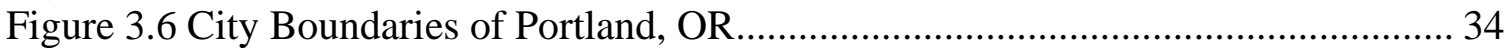

Figure 3.7 Portland City or Big Cordon Boundaries .................................................... 34

Figure 6.1 Map of Former Trimet Fareless Zone Compared to the CBD Cordon Identified

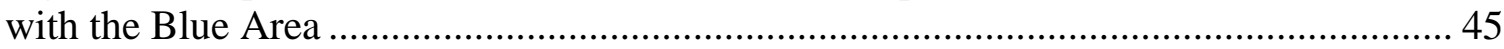

Figure 6.2 Map of the City of Portland with CBD Defined by the Blue Perimeter......... 46

Figure 6.3 CBD or Small Cordon Marked as the Blue Area Portland, OR .................... 46

Figure 6.4 Westside and Eastside Zones Outside the Cordon Line Perimeter ................. 48

Figure 6.5 City of Portland and Metro Cities Outside ............................................... 49

Figure 6.6 Percenatage of non-residential location price changes year 2035; CBD ....... 51

Figure 6.7 Percentage of non residential location prices change in 2035; Outside-

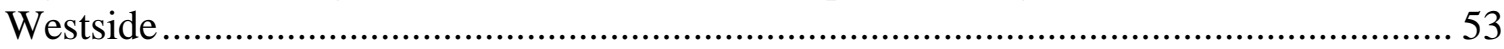

Figure 6.8 Percentage of non residential location prices change in 2035; Outside-

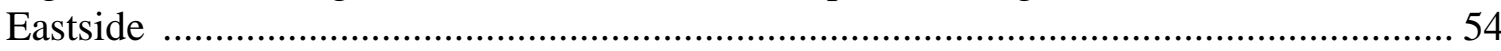

Figure 6.9 Percentage of Total employment changes year 2035; Inside the CBD .......... 55

Figure 6.10 Percentage of Total employment changes year 2035; Outside -Westside: ... 57

Figure 6.11 Percentage of Total employment changes year 2035; Outside -Eastside...... 58

Figure 6.12 Percentage of changes in HH location preferences year 2035; Inside CBD . 60

Figure 6.13 Percentage of changes in HH location preferences year 2035; Outside -

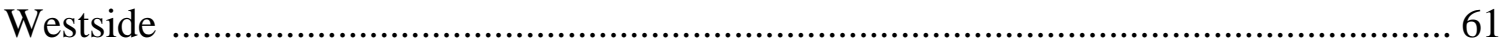

Figure 6.14 Percentage of changes in HH location preferences year 2035; Outside -

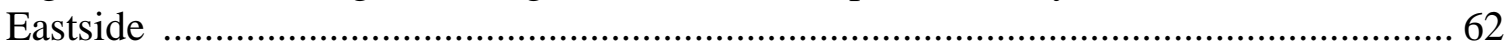

Figure 6.15 Percentage changes in Total sqft supply year 2035: Inside CBD ................ 63

Figure 6.16 Percentage changes in Total sqft supply year 2035; Outside -Westside ....... 65

Figure 6.17 Percentage changes in Total sqft supply year 2035; Outside - Eastside ....... 66

Figure 6.18 Residential location: Percentage of prices change Year 2035: Inside CBD . 68

Figure 6.19 Residential location: Percentage of prices changeYear 2035: Westside...... 70

Figure 6.20 Residential location Percentage of prices change Year 2035: (SE) Central

East Side_Belmont_Hawthorne ........................................................................ 71

Figure 6.21 Residential location Percentage of prices change Year 2035: (NE) Lloyd

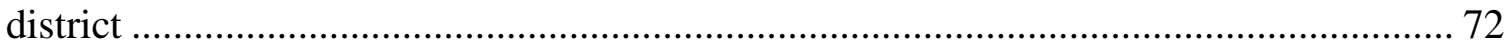

Figure 6.22 Percentage changes: Total HH supply year 2035; Inside CBD.................. 74

Figure 6.23 Percentage changes: Total HH supply year 2035; Westside ........................ 75

Figure 6.24 Percentage changes: Total HH built year 2035; (SE) Central East

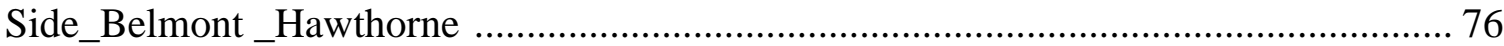

Figure 6.25 Percentage changes: Total HH built year 2035; (NE) Lloyd district .......... 77

Figure 6.26 Percentage of non-residential location price changes year 2035; Portland ... 80

Figure 6.27 Percentage of Total employment changes year 2035; Portland ................... 81 
Figure 6.28 Percentage changes in HH location demand year 2035; Portland................ 82

Figure 6.29 Percentage changes in Total sqft supply year 2035: Portland ...................... 83

Figure 6.30 Residential location: Percentage of prices change Year 2035- Portland....... 85

Figure 6.31 Percentage changes: Total HH Supply year 2035; Portland ....................... 86

Figure 7.1 Sub Areas in Portland, OR ...................................................................... 91

Figure 7.2 Central City District, Portland, OR ........................................................ 92

Figure 7.3 Zooming of the Central City District, Portland, OR .................................. 93

Figure 7.4 Central City or Mid-size Cordon: Whole Blue Area, Portland, OR............... 94

Figure 7.5 Selection of Portland Main Zones Compatible with MetroScope ezones and

rzones

Figure 7.6 Percenatage of Non-residential location price changes year 2035: Central city

Figure 7.7 Percentage of Non-residential location price changes year 2035: Outside -

Westside

Figure 7.8 Percentage of non-residential location prices change in 2035; Outside -

Eastside

Figure 7.9 Percentage of non-residential location prices change in 2035; Outside -NE 103 Figure 7.10 Percentage of non-residential location prices change in 2035; Outside -N. 105 Figure 7.11 Percentage of Total employment changes year 2035; Central city ............ 106 Figure 7.12 Percentage of Total employment changes year 2035; Outside - Westside . 107 Figure 7.13 Percentage of Total employment changes year 2035; Outside - SE .......... 109 Figure 7.14 Percentage of Total employment changes year 2035; Outside - NE.......... 110 Figure 7.15 Percentage of Total employment changes year 2035; Outside - N ............. 111 Figure 7.16 Percentage of changes in HH location demand year 2035; Central city ..... 113 Figure 7.17 Percentage of changes in HH location demand year 2035; Outside -

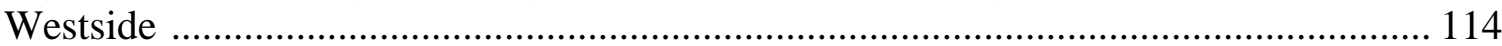
Figure 7.18 Percentage of changes in HH location demand year 2035; Outside -SE ... 115 Figure 7.19 Percentage of changes in HH location demand year 2035; Outside -NE ... 116 Figure 7.20 Percentage of changes in HH location demand year 2035; Outside -N ..... 116 Figure 7.21 Percentage changes in Total sqft supply year 2035: Inside........................ 119 Figure 7.22 Percentage changes in Total sqft supply year 2035; Outside -Westside ..... 120 Figure 7.23 Percentage changes in Total sqft supply year 2035; Outside - SE ............. 121 Figure 7.24 Percentage changes in Total sqft supply year 2035; Outside - NE ............. 122 Figure 7.25 Percentage changes in Total sqft supply year 2035; Outside - N............... 122 Figure 7.26 Residential location prices change Year 2035: Inside............................... 124 Figure 7.27 Residential location prices change Year 2035: Westside.......................... 125 Figure 7.28 Residential location Percentage of prices change Year 2035: (SE) ............ 127 Figure 7.29 Residential location Percentage of prices change Year 2035: (NE)........... 127 Figure 7.30 Residential location Percentage of prices change Year 2035: (N) ............. 128 Figure 7.31 Residential location Percentage of prices changeYear 2035: EAST Districts

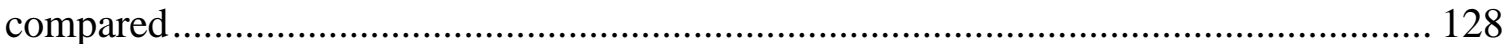

Figure 7.32 Percentage changes Total HH supply year 2035; Inside ........................... 130

Figure 7.33 Percentage changes Total HH supply year 2035; Westside ...................... 131

Figure 7.34 Percentage changes Total HH supply year 2035; (SE) ............................. 132

Figure 7.35 Percentage changes Total HH supply year 2035; (NE) ............................ 133 
Figure 7.36 Percentage changes Total HH supply year 2035; (N) 133

Figure 7.37 Percentage changes Total HH supply-year 2035; East Districts compared 134 Figure 7.38 Percentage of Non-residential location price changes-year 2035; Portland 136 Figure 7.39 Percentage of Total employment changes year 2035; City of Portland ...... 137 Figure 7.40 Percentage of changes in HH location preferences year 2035; Portland..... 138 Figure 7.41 Percentage of changes in HH location preferences year 2035; Portland..... 139 Figure 7.42 Residential location Percentage of prices changeYear 2035: Portland ....... 140 Figure 7.43 Percentage changes Total HH Supply year 2035; Portland....................... 142 Figure 8.1 Portland, OR City Boundaries ................................................................... 148 Figure 8.2 Big Cordon and Metro Areas Surrounding Portland City Boundaries.......... 149 Figure 8.3 Percenatage of Non-residential location price changes year 2035; Inside

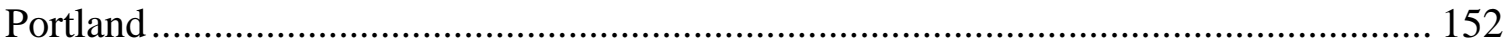
Figure 8.4 Portland vs Metro Areas Percentage of Non-residential location prices change in 2035 - Manufacturing 153 Figure 8.5 Portland vs Metro Areas Percentage of Non-residential location prices change in 2035 - Warehousing/Distribution .... 154 Figure 8.6 Portland vs Metro Areas Percentage of Non-residential location prices change in 2035 - Retail/Consumer services 154 Figure 8.7 Portland vs Metro Areas Percentage of Non-residential location prices change in 2035 - General offices. 155

Figure 8.8 Portland vs Metro Areas Percentage of Non-residential location prices change in 2035 - Medical offices 156 Figure 8.9 Portland vs Metro Areas Percentage of Non-residential location prices change in 2035 - Government offices.

Figure 8.10 Percentage of Total employment changes year 2035; Inside Portland....... 160

Figure 8.11 Percentage of Total employment changes year 2035; Gresham ................ 163 Figure 8.12 Percentage of Total employment changes year 2035; Lake Oswego.......... 164 Figure 8.13 Percentage of Total employment changes year 2035; Happy Valley/Milwaukie . 165 Figure 8.14 Percentage of Total employment changes year 2035; Tanasbourne/Bethany 166

Figure 8.15 Percentage of Total employment changes year 2035; Hillsboro/Orenco .... 167 Figure 8.16 Percentage of Total employment changes year 2035; Beaverton/Tigard.... 168 Figure 8.17 Percentage changes in $\mathrm{HH}$ location demand-year 2035; Inside Portland.... 171 Figure 8.18 Percentage changes in HH location demand-year 2035; Gresham ............ 172 Figure 8.19 Percentage changes in HH location demand-year 2035; Lake Oswego...... 173 Figure 8.20 Percentage changes in HH location demand-year 2035; Happy Valley/Milwaukie 173

Figure 8.21 Percentage changes in HH location demand-year 2035; Tanasbourne/Bethany 174

Figure 8.22 Percentage changes in HH location demand-year 2035; Hillsboro/Orenco 174 Figure 8.23 Percentage changes in HH location demand-year 2035; Beaverton/Tigard 175 Figure 8.24 Percentage changes in Total sqft supply year 2035: Portland .................... 178 Figure 8.25 Percentage changes in Total sqft supply year 2035: Manufacturing.......... 179 Figure 8.26 Percentage changes in Total sqft supply year 2035: Warehousing ............. 180 
Figure 8.27 Percentage changes in Total sqft supply year 2035: Retail/Consumer services

Figure 8.28 Percentage changes in Total sqft supply year 2035: General offices .......... 181

Figure 8.29 Percentage changes in Total sqft supply year 2035: Medical offices ......... 181

Figure 8.30 Percentage changes in Total sqft supply year 2035: Goverment offices..... 182

Figure 8.31 Residential location: Percentage of prices change Year 2035- Portland..... 185

Figure 8.32 Residential location: Percentage of prices change Year 2035- Gresham.... 186

Figure 8.33 Residential location: Percentage of prices change Year 2035- Lake Oswego

Figure 8.34 Residential location: Percentage of prices change Year 2035- Happy

Valley/Milwaukie 187

Figure 8.35 Residential location: Percentage of prices change Year 2035-

Tanasbourne/Bethany 188

Figure 8.36 Residential location: Percentage of prices change Year 2035-

Hillsboro/Orenco 188

Figure 8.37 Residential location: Percentage of prices change Year 2035-

Beaverton/Tigard 189

Figure 8.38 Percentage changes Total HH Supply year 2035; Portland. 190

Figure 8.39 Percentage changes Total HH Supply year 2035; Gresham 191

Figure 8.40 Percentage changes Total HH Supply year 2035; Lake Oswego..... 192 Figure 8.41 Percentage changes Total HH Supply year 2035; Happy Valley/Milwaukie

Figure 8.42 Percentage changes Total HH Supply year 2035; Tanasbourne/Bethany ... 193 Figure 8.43 Percentage changes Total HH Supply year 2035; Hillsboro/Orenco .......... 193 Figure 8.44 Percentage changes Total HH Supply year 2035; Beaverton/Tigard .......... 194 


\section{Introduction on Congestion Pricing Theory}

The general theory of congestion pricing involves charging road users a fee to offset the external time costs associated with adding a vehicle to a road. With the implementation of congestion pricing, all drivers would pay the difference between the costs of using the road system and the cost that, by using the system, they impose on the whole system. Congestion pricing would internalize the marginal costs of delay, but it would not internalize the marginal costs of other factors such as air pollution. Also, these costs typically remain unaccounted for in cost-benefit analyses (Eliasson, 2009).

Congestion has become progressively worse over time (Downs, 2004). From one perspective, congestion is a sign of economic activity; however, infrastructure usually does not expand with the new activities, so congestion can limit the agglomeration benefits of growth. In fact, it represents an inefficient distribution of resources. Imposing congestion pricing on a region as a solution to its systemic congestion is highly debated: while society gains a more efficient use of the system, individual drivers lose with regard to cost or a reduction in their overall usage. The cost to the driver during congestion without congestion pricing is a loss of time, which benefits no one, but with congestion

pricing the cost is actual cash, which is a transfer and could be used to benefit society as a whole. When there is a transfer of money through congestion pricing, economic theory states that the society could benefit as a result. This collected revenue could be used efficiently either by providing additional benefits and/or transportation investments or by lowering other transportation taxes. Much of the debate over the use of congestion pricing centers on the intended use of revenue. Although economic theory supports 
utilizing this revenue to provide additional benefits to the society, such as lowering taxes or making other transportation investments, part of the literature argues that the revenue should be used to subsidize transit.

From an economic viewpoint, it can be argued that transit already relies heavily on public subsidies and this could lead to inefficiencies in transit operations. Critics argue that it is inefficient to further subsidize transit, because it will leave fares below Marginal Cost (MC). When transit fare is lowered, the service cost increases because the fee is lower than MC, particularly during peak hours. This low cost also lends itself to overuse and creates the deadweight loss (DWL) associated with peak and off-peak traffic, when there is an over/underestimated use of the capacity. However, supporters argue that public transit provides offsetting benefits.

It can be said that economies of density and network characteristics are critical for transit. Today, the decentralization of housing and labor has reduced the density of a trip, making transit more costly (even if the overall density has increased) (Rufolo, 2010). Scholars argue that promoting common destinations and therefore a better balance between job and housing land uses has the potential to correct congestion while affecting land-use through giving people the option of living close to their jobs. Also, it could reduce vehicle miles traveled (VMT) since people who live and work in the same jurisdiction would more likely to take public transit, walk, or bike to work, and their car trips would be shorter. By contrast, a number of economists argue that there are many factors that prevent people from living near their workplaces. They criticize the assumption that labor is homogeneous. Indeed, labor is heterogeneous, that is, anybody cannot work any job. Different employers have different skill requirements and could 
decide to locate in response to different factors such as demand and production technologies. Additionally, workers have different skills, education, and preferences. Also, households often contain multiple workers who work in different locations, so they might decide to locate in a convenient area that guarantees access to work for all the household's employed members. Moreover, there are households with workers who have more than one job and therefore need to commute to different places.

Overall, policies designed toward raising density in order to reduce traffic congestion are likely to be more successful if the targeted areas have a good access to transit services that include areas close to downtowns (Downs, 2004). In fact, raising job density in downtowns could encourage more transit use by concentrating more destinations for workers in the same spot, making transit more efficient. Therefore, by commuting to $\mathrm{CBD}$ and hence sharing the same origin-destination pairs, workers can make mass transit more efficient while reducing the need to drive.

However, even though the topic of transit subsidies and balance between housing and transit origin-destination is an important and interesting one, it is not one that will be examined in this paper.

Overall, private citizens perceive the argument for congestion pricing as something abstract, wherein individuals incur a "loss" while the government "gains" on something they feel should be free to use. Because of this negative public perception, politicians are understandably resistant to the introduction of something that voters so clearly oppose. Overall, by charging congestion pricing, the society could, in fact, gain net benefits through the more efficient use of roads and the revenue collected, even though individual drivers will be worse off because of the cost incurred (Rufolo, 2010). 
Despite strong theoretical foundations, road pricing remains politically difficult to implement.

Another reason behind this difficulty involves the perception of freedom in driving and fairness that is critical for public acceptability of toll implementation and concerns about equity, both vertical and horizontal (Gomez-Ibanez, Tye \& Winston, 1999). Vertical equity pertains to the unequal impact from the tolling scheme across different socio-economic groups. The horizontal equity impact refers to the different geographical areas of population (this topic is further discussed in the literature review section) (Small \& Gomez-Ibanez, 1999). 


\section{Literature Review}

\subsection{Congestion Pricing Overview}

Textbooks report that congestion pricing is based on setting a price that is the difference between marginal cost and average cost at the optimal level of usage. Part of the debate over congestion pricing ties to differentiating between ideal pricing and actual pricing systems that are implemented on road networks; the actual charge applied on a road network can be different from the ideal one. The ideal pricing generates net benefits for society through a more efficient use of the road, yet often lawmakers adopt a pricing system that is different from the optimal one. However, even if the actual toll is different from the ideal one, still it could bring some benefits.

Congestion pricing could be used for different purposes, for instance, as a demand-management system aiming to lower congestion or as a revenue-generating device aiming to raise substantial amounts of revenue. However, congestion pricing can be costly to run, and policymakers have to take the costs into account when evaluating the net benefits of implementation.

There are different types of congestion pricing, such as: congestion charges only on major freeways, tolls, cordons, and area pricing where a charge is applied to enter or drive within a congested area, usually a city center. It must be noted that the difference between comprehensive congestion pricing, wherein vehicles are charged the marginal cost for each mile driven, and other various systems, like cordon pricing or area pricing, is that the latter attempts to alter behavior but are not comprehensive pricing systems. Cordon pricing is often used as a demand strategy to reduce traffic congestion and the related externalities within the area charged. 
State route 91 in California is an example of implemented congestion pricing. State route 91 has two lanes in each direction that are priced (four lanes un-priced). The price is set in advance and changed as often as every hour, although it could be argued that by setting up the prices in advance, there is a risk of underusing the capacity. If the price is set too high, the fixed charge may lead to inefficient usage (Rufolo, 2010).

Alternatively, with dynamic pricing, the toll charged varies with regards to the actual level of traffic. Dynamic pricing may be increased or decreased every few minutes to ensure that the lanes are fully utilized without a breakdown in traffic flow. An example of dynamic pricing is Interstate 15 in California, where the two reversible lanes are charged a price that varies as frequently as every six minutes (while free for highoccupancy vehicles $[\mathrm{HOV}])$ in order to maintain a free flow during periods of very high demand (Rufolo, 2010). With dynamic pricing, drivers will not know the toll charged until they enter the road, limiting their time to decide whether to enter the tolled lane or stay on the free one.

Other types of congestion pricing are cordon and area pricing, where vehicles are charged for entry into an area or for any driving in a designated area. A growing number of cities have adopted cordon and area pricing. Famous examples are Singapore (the first city to implement area pricing), London, Oslo, Stockholm, and Milan. The fee charged could be a flat fee for any vehicles that enter/drive into the designated area, such as in London, or it could be vary depending on the time of the day, such as in Singapore and Stockholm.

Cordon and area pricing have raised concerns about equity. London is an example of a system wherein horizontal equity issues arise. People are charged a daily flat fee for 
the right to drive within the designated area. However, taxis, public transit, government vehicles, and now private-hire vehicles like Uber are free of charge and residents of the area pay a lower fee. This disparity is raising equity concerns. House prices within the congestion zone have increased since some wealthier consumers were willing to pay to avoid traffic and enjoy improved environmental conditions (Short, 2018).

New York City's congestion pricing proposal is another example of horizontal equity concerns. Introduced in April 2007, New York City's pricing proposal was the first area-wide road pricing scheme proposed for a major North American city. Under the proposal, New York would have joined Singapore, London, and Stockholm as the fourth large city that charges for driving into the central city core.

There is substantial evidence that equity concerns prevented the implementation of New York's proposed system (Schaller, 2010). Some legislators raised regional equity issues related to commuters from Queens, Brooklyn, and the Bronx area who currently use the free bridges would pay the full fee (\$8 fee), while New Jersey commuters would pay little in congestion fees due to toll offsets. The most vocal opposition came from elected officials and civic groups in the four New York City boroughs outside Manhattan, centered in eastern Queens and southern Brooklyn. These areas are more auto dependent than neighborhoods closer to Manhattan and have the least rapid or convenient transit access to Manhattan jobs (Schaller, 2010).

This issue of regional equity became a significant obstacle in legislative consideration of congestion pricing. Skepticism created by these concerns led to questions related to the high cost that certain areas would have faced compared to the benefits. Also, other oppositions to the charge were from some officials who questioned 
whether funds raised from the implementation of the toll would have been spent effectively on transit improvements, while they felt that mass transit was not and would not become a viable alternative to driving. If not, opponents argued that transit riders would suffer even more from crowded trains and buses. Moreover, it can be argued that when people pay only one time to enter the area, there is no real incentive for them to limit their driving once they have paid the toll.

Overall, it cannot be ignored that the administration, implementation, and collection of congestion pricing costs money. These costs may decline in importance over time; nevertheless, they still must be taken into consideration while evaluating the net benefits of using pricing for managing congestion. Direct pricing still faces political, technological, and public acceptance conflicts, even though it could be a tool to improve the efficiency of the system and provide revenue to be used for improvements. Acceptance of congestion pricing is mainly tied to the support of voters and the availability of public transit. For example, on the day that the congestion charge was introduced in London, 300 extra buses were added to the Central London bus network to give people an alternative to driving and try to limit resistance (Budstuper, 2018). The design of the scheme proposed and how design choices could partially impact future costs are also critical concerns.

\subsection{Cordon Pricing}

This research focuses on cordon pricing. In a cordon scheme, those who drive into the charged area have to pay a toll, which is levied at specific points on the road network. Cordon based pricing schemes have been developed and applied in several cities, including Singapore, Trondheim, Oslo, and Stockholm. The toll may vary with the time 
of day or day of the week as well as on weekends and holidays. The main advantages of cordon tolls are that they are easy to understand and relatively easy to implement, with technology that has been widely tested (Maruyama \& Sumalee, 2007; Safirova et al., 2006). Also, cordon pricing is often used as a demand strategy to reduce traffic congestion (Ribalta, Gómez\& Arenas, 2018) and the related externalities within the area charged (Rufolo, 2010).

At the same time, cordon tolls have been criticized for being inflexible (since the tolling location cannot be easily changed), for creating equity and privacy issues (Schaller, 2010; Safirova et al., 2006), and for being expensive to operate (Eliasson, 2009, Prud'homme \& Bocarejo, 2005), even with swift improvements in technology. Furthermore, the introduction of an area-type pricing system is controversial; research is still lacking in predicting the effects of pricing on regional development and in identifying cost-effective ways to implement this pricing scheme.

While there are studies on how to set up optimal toll pricing, determination of optimal cordon locations on a network has received limited attention, even though this type of pricing scheme is witnessing increasing interest in the literature (Anas \& Hiramatsu, 2013; Ahmadi Azari et al., 2013; Schaller, 2010; Eliasson, 2009; Maruyama \& Sumalee, 2007; Mun et al., 2005; Ho et al., 2005; Zhang \& Yang, 2004; Mun et al., 2003).

Santos (2004) simulated and compared a single-layered cordon with a double cordon for eight English towns. The research primarily focuses on determining the optimal toll charge in the case of a single cordon boundary versus a double one, while comparing their costs and their transportation and environmental effects. However, the 
study does not discuss the optimal location of cordons, but rather focuses on the empirical estimates of toll levels and social welfare. Neither does it address the effects of land use upon the structure of cities nor how the charges might affect land use. A few studies have proposed an approach to determine the optimal toll links to achieve a system optimum. Zhang and Yang (2004) as well as Verhoef (2002) specifically examined the optimal selection of toll locations and toll levels for both one and multiple cordons in hypothetical general networks. Even though the network models can be useful for practical applications, it can be argued that the results of the study depend on the network structures specified for calculation, they are specific for the simulations examined, and, moreover, they do not address changes in land use supply.

Both Ho et al. (2005) and Mun et al. (2003) focus primarily on the effects of cordon pricing based on urban spatial models of monocentric cities. Their studies show that cordon pricing can attain an economic welfare level close to the optimum. Although Ho et al. (2005) do extend the Mun et al. model, they continue to assume that jobs are located at the center. These two studies reach a similar conclusion: the benefits captured by the optimal cordon tolling policy boost employment concentrated at the center to a larger degree. Therefore, the larger the amount of labor concentrated toward the center of an area, the more effective the cordon.

Other existing studies on cordon schemes ignore land use effects and assume monocentric city models. De Borger \& Russo (2018) and Anas \& Hiramatsu (2013) discuss the relationship between the implementation of cordon pricing and residential location, employment location, and their effects on housing and labor markets. However, in their study, land use is fixed. 
The effects of the implementation of cordon tolls on travel behavior and land use are still unknown. It cannot be assumed, nor is there evidence to support the theory, that the monocentric model accurately predicts how people and businesses will react following the introduction of a toll. It has to be researched as to whether the impact of the charge would be to cause development to move toward the core, or instead cause people to find it more desirable to decentralize activities and household locations. Therefore, the critical question becomes whether cordon pricing will influence the centralization or decentralization of land use, jobs, population, and economic activities. The implementation of a cordon area, along with the size of its boundaries, are expected to affect areas both inside and outside of the designated perimeter and to promote changes in travel behavior as well as origin-destination pairs that will affect land use and vice versa.

Evaluations of pricing schemes in general have concluded that congestion charges have been successful. However, these analyses are based on the evaluation of transportation effects alone (Eliasson, 2010; Safirova et al., 2006). Congestion pricing research is based mainly on network models and it does not address the effect on the land use structure of cities. Very little is known about the economic, transportation, and related land use effects of cordon pricing; for example, how the cordon design can affect a city's business and resident location decisions, congestion level, land use, or mode choice. Overall, scholars agree that cordon schemes need more research to better understand the economic, travel, and land use consequences.

Anas \& Hiramatsu (2013) attempt to study optimal cordon tolling for the Chicago MSA and investigate adjustments in travel, housing, and labor markets after the 
implementation of a fixed toll. They report on the performance of three hypothetical cordon scenarios. Each cordon has a different size. All three cordons charged an arbitrary $\$ 5$ fee per crossing. The report shows how narrow cordons that are focused on central areas can cause a suburban expansion and lead to urban sprawl, while real output inside the cordon zone decreased. Yet, they found that the outermost cordon, enclosing the city and the inner suburbs, had the opposite effect: centralizing jobs and residences and raising output inside the central area.

However, it should be noted that the specific cost of $\$ 5$ for the fee is an important criterion regarding the effect cost can have on travel behavior and land use. It would have been interesting to test the same cordons using different fee levels, both higher and lower than $\$ 5$, and comparing the new output with the former ones. The same cordon design could perform differently under different prices. Anas \& Hiramatsu (2013) discuss the relationship between the implementation of cordon pricing and residential location, employment location, and their effects on housing and labor markets. A limitation is that in their study land use is fixed.

There is also a lack of research examining the welfare effects of the pricing schemes, where value of time gained and other externalities (such as reduction of congestion and environmental benefits) are compared to the costs of the system. It is here where researchers often disagree on the economic benefits and costs (Eliasson; 2009). Existing studies comparing travel time and social benefits with the estimated investment and operation costs often obtain differing results.

In their cost-benefit analysis (CBA) of the London congestion charge, Prud'homme \& Bocarejo (2005) report a net yearly loss of 80 million euros, while the 
CBA of Transport for London (2003) that accounted for a net yearly benefit of 70 million euros. The explanation of such a difference in results lies in the different calculations of the time gains. While the first analysis does not include the time gains outside the area, the second study attempts to consider them along with the time changes inside of the boundaries (Eliasson, 2009).

There are still many issues and unanswered questions on the impact of the cordon scheme on economic development and business location decisions, as well as how these affect the spatial pattern in the city, land use, business activities, and employment inside and outside of the cordon area boundaries. The decision on where to draw the cordon line will affect land use, business location decisions, congestion levels, travel time, origin destination pairs, revenue from the cordon charge, and consumer choices.

As reported above, the existing literature lacks in providing a comprehensive understanding of the effects both inside and outside the cordon as a consequence of the pricing scheme. Brueckner (2014)'s analysis investigates the differences in the population distributions across zones under cordon tolling and the first-best regime, with the goal of comparing the city's spatial sizes in those two cases. The one available analytical result establishes that cordon tolling leads to a redistribution of population away from the zone immediately outside the cordon, with residents moving either to the central zone or to the suburban zone.

There is a remarkable scarcity of published results on the effects of the cordon charge on residential and non-residential land use effects after the implementation of the cordon scheme, along with drivers' travel behavior in terms of origin destination pairs. Existing research does not consider cordon charges in consumers' preferences, and it 
does not explain changes in residential or business location decisions that could be induced by the charge. One related critical question is where people go shopping. After the cordon charge is applied, some business may benefit from the charge in that it could act as a force toward the creation of new agglomeration tendencies. Other business may be better off either by relocating right outside the area line or by moving toward suburbs.

Interestingly, the Victoria Transport Policy Institute (2011) reports that some businesses consider themselves harmed from the pricing charge implemented in London in 2003, especially bulk good retailers that have private vehicle owners as their most important customers. A survey of 150 local businesses conducted in May 2007 stated that there was an average drop in business of 25 percent following the introduction of the charge. However, this survey was disputed by Transportation for London (TfL-Annual Study, 2007) and Leape (2006), which state that there had been "no overall effect" on business.

Zhang \&Shing (2006) focus on property prices in London as a measure to assess the benefit of transport innovation (they referred to Gibbons and Machin, 2003a); positive changes in transportation can be captured by property prices because if housing markets are efficient, residential property values should capture all the benefits and costs to commuters that a location offers. Better transport access would allow households easier commutes to better-paid jobs; therefore, if the cordon around London resulted in an asymmetric impact on transport access inside and outside the ring, then the impact will be picked up in the relative changes in property prices. Further, transport innovations can bring benefits to the firm as well. Zhang \& Shing (2006) find that the London congestion toll affected property prices. It can be argued that the net effect of the charge was not 
necessarily negative, since higher-value activities may be substituting for lower-value ones. It should also be considered that if the charge is applied only during weekdays, high-value businesses (such as entertainment) with major activities during the weekend would be less affected. The provided explanation is that land became highly substitutable between different purposes. Also, the increased transportation costs made the inner zone commercially less desirable; it could have been reflected in property prices. Interestingly, their study highlights how residents living closest to the boundaries experienced potential increase in traffic flows due to drivers avoiding the tolled area. Therefore, properties closer to the boundaries are less desirable. A limitation is that the hedonic model of property prices was not developed. In their findings, property prices in general were found to matter the most before the implementation of the cordon rather than afterward. Research is still needed for the determination of an optimal cordon line and its related toll level on a general network. Very little is known about the consequences of implementing different cordon lines on travel choices and land use changes. The spatial size and location of a cordon zone is critical and a change in the design and size of the cordon line could have a major impact on the congestion level, travel time, and residential and non-residential land use. A practical example of this is the city of London; after the implementation of the area charge in 2003 , the city extended the charged zone westward in 2007. Because of the redesign of the pricing area, London experienced an increase in the congestion level by 17 percent (Givoni, 2011). The change of the location and size of boundaries very likely affected the congestion level, driving preferences, mode switch, and geographic redistribution of trips, business activities, and profit from the charge. The latest evaluation of the London charge (2018) shows how the charge has 
actually been a success at deterring private vehicles from entering Central London, with a fall of 39\% in personal-use cars entering the zone between 2002 and 2014 (Ambühl, L, Loder, A., Becker H., Menendez, M., \& Axhausen, K., 2018; CityMetric, 2018). Yet no one predicted the proliferation of private-hire vehicles like Uber and Lyft. From 2013 to 2017, private vehicle registration soared by over 75\% (CityMetric, 2018). Now authorities are looking for solutions. Inspired by Stockholm, there is a consideration of expanding the boundaries of the charged zone while implementing dynamic pricing to ease traffic and improve revenue (CityLab, 2018). Again, theoretically, the size and location of a cordon is key for success.

This study will focus on cordon pricing and will try to contribute to the determination of a better understanding of implementing different cordon choices in terms of land use changes. This paper focuses on cordon pricing only. Even though cordon and area pricing schemes may appear similar, they require different modeling approaches. In fact, with regards to area pricing, there is a "path cost which is not equal to linear addition of all linear link costs" (Maruyama and Sumalee, 2007, p. 656), making the modeling approach rather diverse from the more straightforward cordon design modeling approach. 


\section{Methodology}

\subsection{Assumptions}

The ultimate goal of this study is to determine what the consequences are of implementing different cordon line choices. In particular, there is very little information on the effects of different cordons on travel choices and land use changes. To this end, different procedures have been evaluated to determine the effects of cordon location and size. In order to formulate and solve the network location problem and test the cordon feasibility requirement for the candidate links, an assumption is made on how travelers in a traffic network behave.

The approach generally adopted in the literature is based on Wardrop's user equilibrium (UE) principle and can be formulated as the equivalent optimization problem, and hence enable its application to a large-scale network (Maruyama \& Sumalee, 2007). Wardrop's UE assumes that the road user chooses his/her route to minimize his/her (generalized) travel costs. Also, the user will decide to travel as long as the economic utility of traveling between an origin-destination (O-D) pair is greater than or equal to the cost (disutility) of traveling (Sumalee, 2004). Therefore, it is implied that no travelers will choose a route with travel costs higher than the minimum travel costs between an OD pair. As a consequence, as the travel cost of the network changes, the travelers will adjust their behavior to achieve a new equilibrium. In the road pricing design problem, the road users are assumed to respond to the road pricing scheme following the UE principles.

In order to analyze the design of a road pricing scheme, it is important to model how changes in travel costs and travel time will likely affect travel network decisions as 
well as residential and non-residential land use. Real estate development, travel and economic decisions, and location choices are interdependent. People locate where they can find access to work, shopping, services, schools, and recreation. Also, they place value on neighborhoods based on such factors as price, crime rate, schooling, demographic characteristics, and so on. Similarly, businesses' location decisions are based on costs of labor and materials and accessibility to markets for goods and services relative to other areas. In turn, these decisions will affect the relative demand for development at different locations and influence land use changes over time.

\subsection{MetroScope - A Land Use Allocation Model}

MetroScope is an integrated land use and transportation model that has been developed and is used by Portland Metro (Portland, Oregon area's regional government) to model changes in measures of economic, demographic, land use, and transportation activity specifically in the Portland metro region. MetroScope seems to be the right model for investigating the consequences of implementing different cordon choices in terms of residential and non-residential land use changes in the area. In fact, this model offers one of the most comprehensive simulation systems available to address these concerns. Moreover, MetroScope is one of the very few models where land supply is flexible and not fixed.

MetroScope was designed to evaluate land use and transportation policies by showing their effects on the location of households and businesses in the region. MetroScope has the ability to forecast households, employment, and real estate development trends at a very detailed geographical scale (i.e., census tracts or TAZ) (Metro, 2009). 
The estimates extend to forecast distributions of household socioeconomics by age, income bracket, household size, and composition; the distribution of jobs by industry class; and the real estate development trends by density, building square footage, real estate prices, and general building types. Also, MetroScope provides a measure of the market's ability to supply the region's housing needs under the land availability level specified (Metro Documentation, 2004).

As an urban simulation model that integrates the residential housing model with transportation, land use, and commercial location models, MetroScope provides an accurate housing development model that incorporates the impact of households' decisions, development economics, and commuting preferences. MetroScope consists of four separate models, which interact over five-year periods.

The four models that interact within the MetroScope framework are (Metro, 2009; Figure 3.1):

1. Economic Model predicts employment by industry and the number of households in the region by demographic category. It converts the forecasted population into number of households $(\mathrm{HH})$ and groups them into 400 possible combinations of $\mathrm{HH}$ size, income categories, age of the $\mathrm{HH}$ primary person, and presence/absence of children.

2. Travel Model predicts in a generalized way the travel levels by mode and road segment and estimates travel times between transportation analysis zones (TAZs) by time of day. Also, it gives a measure of "perceived costs" by travelers in traveling between different O-Ds, which affects where people work and decide to reside. 
3. Two real estate location models for residential and non-residential locations. They predict, respectively, the location of households and employment in the future based on predictions regarding how much and where employment activity will occur, the price of housing, household income and other wealth factors, and the age of the HH. Also, they measure the land consumed by the development, the amount of built space produced, and the prices of land and built space by zone in each time period. For both residential and non-residential submodules, market forces determine both the supply and demand for real estate, and then these values are used to adjust location prices until supply equals demand.

4. GIS (geographic information system) database that contains the land and development data and tracks where and how much land will be available for development in the future. Also, it provides an inventory and accounting of developable land that is available, and its capacity for housing units and employment. 

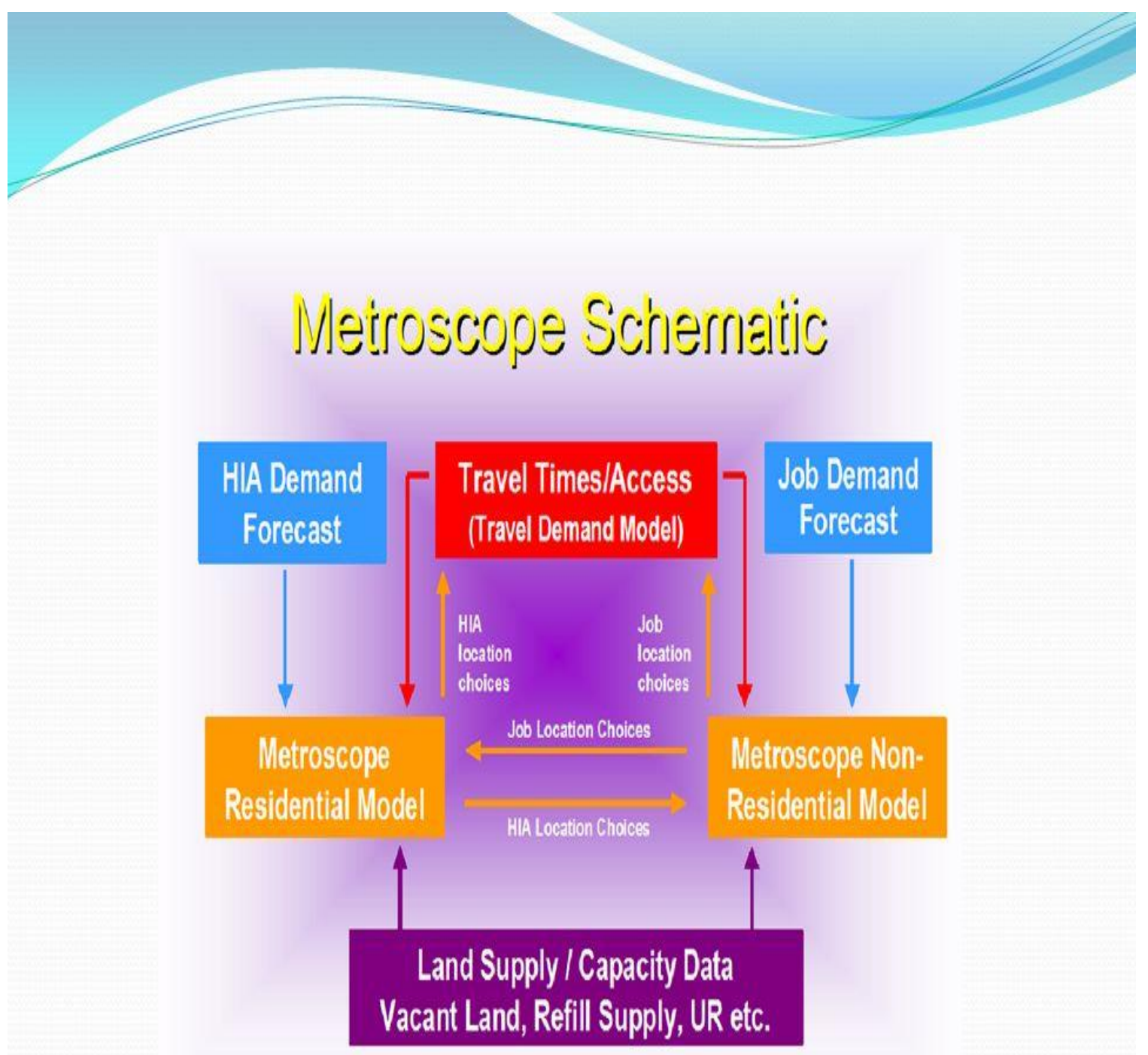

Figure 3.1 MetroScope Schematic

Source: Metro, 2009.

https://www.google.com/search?q=metroscope+general+schematic\&sa=X\&biw=1366\&bih=655\&tbm=isc

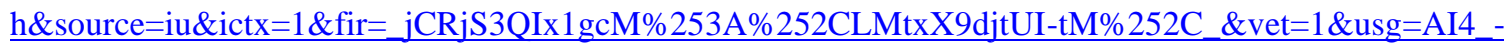
kTBANviA6TRm-1_MCbf7wx-

j33Uug\&ved=2ahUKEwjov6q2p8vhAhVIqp4KHSoHDcMQ9QEwAnoECAkQBg\# 
In more detail, MetroScope is an equilibrium model in which prices and quantities supplied and demanded of real estate product convey toward long-term market solutions. MetroScope is based on a set of assumptions with regard to supply and demand and forecasts where employment and housing are most likely to develop in the PortlandVancouver MSA (Metro, 2004):

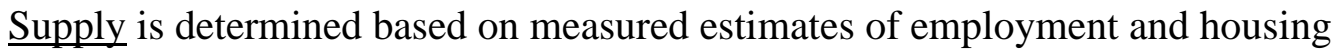
capacity. This capacity is calculated from estimates of vacant and "refill" land (Metro, 2004 2). Supply is flexible and can be accommodated by redevelopment and/or infill to meet the projected demand (Metro, 2009 7). Local zoning is overlaid on vacant and refill land to determine its status for accommodating housing and employment. Future household and employment projections will only allocate forecast growth where capacity exists to accommodate the quantity of projected growth. Supply components incorporate all the costs of developing built space, including transaction costs and development fees, permits, system development charges, and subsidies.

Demand for housing and employment real estate is derived from Metro's regional macroeconomic model that describes the region's total or overall amounts of growth in future years. MetroScope's role is to find an economically efficient distribution of this regional growth and to allocate this growth down to smaller geographic units (employment zones and census tracts).

Households' allocation to MetroScope zones are performed simultaneously to equilibrate demand for housing (with all its components) for every zone in the region given the built supply of housing for each demand type. If a zone had a 
surplus demand, real estate prices will automatically increment until demand drops and supply increases to reach an equilibrium. Consequently, households will reformulate their location preferences based on the ability to afford housing subject to their utility. Moreover, their location choice is also function of the distance to available employment opportunities (based on the primary worker). In addition to work opportunities, $\mathrm{HH}$ accessibility to other zones for recreational and commercial activities is implemented in their location choice function. MetroScope calculates the projection for households, not individual people, because people live and buy housing as a $\mathrm{HH}$ nucleus, even when the decision is made by one person (2011 2-3).

Employment allocation is related to supply and demand real estate that has to reach an equilibrium that is achieved through several iterations for each of the designated real estate types, understanding that supply and demand with not only adjust within the reference zone, but for all zones, reaching a final general equilibrium. Additionally, location choices are considered the housing choice location for workers who tend to prefer to stay closer to employment to where they already live given equal choices (Metro, 2004). Transportation accessibility among zones and housing availability are variables implemented into their location choice function. Specifically:

The demand component for housing depends on: Location and type of housing capacity, households' characteristics, proximity to work/location choices as measured by travel time, relative home prices (Metro, 2004 2). 
The market demand for employment land depends on location and amount of industrial and commercial land by employment zones (e-zones), industry characteristics, proximity to labor forces (as measured by travel time), industry clusters and agglomeration, and relative real estate prices (Metro, 2004 2).

MetroScope can be used to analyze and test alternative scenario assumptions to determine the impact from a given set of inputs on land, policy directives, demographic socioeconomic data projections, and accessibility of the transport mode. By modifying the inputs, MetroScope can test alternative development strategies to help local governments compare and assess the likely socio-economic impact of different policies.

\subsection{MetroScope Full Version Versus Simplified Version}

Metro has developed two versions of MetroScope; one version of MetroScope is modeled to run the full version of the four models (economic, travel, two land uses, and GIS), and one version interacts with an internal simplified travel demand model.

The full travel demand model version of MetroScope consists of four different modules:

1. Trip generation

2. Mode split

3. Trip distribution

4. Network assignment and the calculation of skim matrices.

The simplified version does not forecast any changes in mode choice; nevertheless, the other three modules in both versions are quite comparable (Table 4.1). 
Table 3.1 Full Version versus Simplified Version of MetroScope Travel Model

\begin{tabular}{|c|c|}
\hline $\begin{array}{c}\text { Full Version of MetroScope } \\
\text { Travel Model }\end{array}$ & $\begin{array}{c}\text { Simplified Version of MetroScope } \\
\text { Travel Model }\end{array}$ \\
\hline Zones 2200 TAZs & 450 census track zones \\
\hline \multicolumn{2}{|c|}{ Same Road Network } \\
\hline Mode choice & NO Mode choice \\
\hline 7 Different Purposes: & 3 Different Purposes: \\
\hline $\begin{array}{l}\text { 1. Home-Based Work } \\
\text { 2. Home-Based Shopping } \\
\text { 3. Home-Based Recreation } \\
\text { 4. Home-Based } \\
\text { 5. Non-Home-Based Work } \\
\text { 6. Non-Home-Based Non-Work } \\
\text { 7. Home-Based College }\end{array}$ & $\begin{array}{l}\text { 1. Home-Based Work \& College } \\
\text { combined } \\
\text { 2. Home-Based Other } \\
\text { 3. Non-Home Based }\end{array}$ \\
\hline
\end{tabular}

Although the full version of MetroScope is not available for public use, the simplified travel demand model is adequate to answer the research goals since it offers a comprehensive simulation system on forecasting the effects of a cordon scheme on land use. Generally, the Sketch Travel Model can forecast relative changes in travel time as well as changes in travelers' O-D choices for each scenario. In the case that a toll is implemented, the simplified travel model produces travel time directly, then the toll can be added as additional travel time to generate a new trip cost. 
For each scenario run, the model will produce a matrix of vehicle trips following O-D patterns that reflect accessibility to opportunities. ${ }^{1}$ Once run, MetroScope produces an allocation of households and employment to the regional landscape. This land use is imported into the simplified travel model and the process is repeated until equilibrium is achieved.

Even though the simplified travel model does not provide a specific forecast with regard to mode split on O-D pairs, Metro calibrated the model by inserting previously determined mode choice proportions from a typical scenario, so that it will reflect the proper private vehicle proportion in year 2010, even if the other modes are missing. Yet once the model runs, private vehicle proportions cannot adjust to the new policy with regard to other mode choices.

\subsection{MetroScope versus Other Urban Models}

Transportation levels of service and land use availability are two of the most important factors in determining urban development. MetroScope is designed to serve as a tool for evaluating land use and transportation levels of service by showing their effects on households and business locations in the region as well as providing information about travel time, O-D pairs, and road segments. It is critical to point out that MetroScope is one of the few models that is able to forecast changes in land use and not just in prices since land use supply is not fixed.

Moreover, MetroScope is one of the few models that is not based on monocentric assumptions, differing from other major urban models that state how the introduction of a

\footnotetext{
${ }^{1}$ The trips are assigned to a network and travel time skims (skims are full matrices of level-of-services information from production to attraction TAZs) are produced.
} 
toll has the same effects of increasing transportation costs. In this study, monocentric assumptions are not applied to cordon pricing because it cannot be assumed that there will be more compact development toward the core, nor there is evidence that people act following the urban monocentric model.

Conversely, in the bid rent model theory, increasing cost of travel to central locations would increase both land prices and density near the center. Further investigation is still needed to determine whether the impact of the charges causes development to move outside of the core instead; some activities may become more centralized while others become more decentralized. People may decide to stay outside the cordon boundaries or remain inside; it is not realistic to assume that people would want to travel from outside to the $\mathrm{CBD}$. And so, there many questions remain unanswered: how would a consumer respond to a toll? What would be the related effect on housing and labor markets? How would a business or industry located inside the cordon boundaries react to the implementation of a toll?

\subsection{Cordon Scenario Designs}

This study reports a comparison of three different cordon designs compared to the baseline scenario of no charge, assuming that, in each case, the toll charge will be the same. Keeping the toll charge constant allows comparison of the effects of alternative cordon locations. Under each cordon tolling, any car trip crossing the perimeter delineated by the cordon line in the inbound direction pays a flat cordon charge. Public transit and non-motorized means of entering the boundary are exempt from the charge. There are various factors concerning the design of a cordon scheme. The case discussed 
in this paper is limited to a single cordon line and a single mode. There will be a uniform fee rate for all points on the cordon twenty-four hours a day, seven days a week.

Each cordon tested will have a different spatial design based on a different geographic size, yet each scenario will be charged the same flat fee. MetroScope output is analyzed and compared to the default scenario after the implementation of a toll cordon around the CBD (Small), Central City (Mid) and Portland City (Big) limits. Toll rates of $\$ 1.65$ and $\$ 8$ are tested in each scenario for crossing inbound.

It is important to highlight how this study proposes three different designs that respectively represent three very different area sizes; in fact, the difference in the design is critical in providing a better understanding of how the spatial design combined with different pricing could affect land use patterns, and hence whether or not tolling contributes to centralizing or decentralizing economic activities, the labor market, and households' location decisions.

Each of the three cordon scenarios charges an arbitrary $\$ 1.65$ (or 5 additional minutes) and $\$ 8$ (or 25 additional minutes) fees per crossing inbound for private vehicles twenty-four hours a day, seven days a week. These uniform tolls allow for a comparison of the effects of alternative cordon designs. In detail, the monetary toll is converted into additional travel time by adding minutes to the areas embedded within the theoretical cordon line; every time a private vehicle crosses the boundaries will be charged the additional costs (or minutes). Households and businesses would not experience the additional time associated with the toll if located inside the tolled perimeter. The time would only be added to the zone pairs with an origin zone outside the cordon and a destination zone inside. The estimation of value of time was provided by Metro as the 
one used in their modelling associated with the Columbia River Project (CRP) in 2010 dollars. Overall, Metro estimated an average value of $\$ 20$ per hour $^{2}$ for private vehicles.

The rationale behind such different tolls lies on the idea that very different charges allow testing of whether different cordon sizes function more or less effectively under different prices. Moreover, the rationale for such arbitrary dollar amounts was done after the observation of toll cordons already employed. These examples of existing tolls are: Milan, Italy with a flat fee of $€ 5$, Stockholm, Sweden with fees varying from about $\$ 1.5$ to $\$ 3$ depending on the day and/or time, with a maximum toll of $\$ 5$. Singapore's fees are between $\$ 2$ and $\$ 15$ depending on the congestion level. And London, England has an area scheme with a fee of $£ 11.50$ per day, plus a $£ 10$ extra charge for vehicles that do not meet certain fuel standard requirements.

It seemed realistic to charge flat $\$ 1.65$ and $\$ 8$ fees. The dollar amount of each fee is converted into an additional travel time -5 minutes for a $\$ 1.65$ toll, and 25 minutes for a $\$ 8$ toll based on the value of time provided by Metro. Certainly, it is important to remember that charges may vary with the time of the day and/or weekdays versus weekend and holidays; however, the simplified version of MetroScope does not allow any charge variation.

Each of the three cordon designs will be defined and discussed individually in the next chapters. The MetroScope model has been designed to have a total of 425 residential zones (rzones) inside the Portland region, but it has only 72 non-residential zones (ezones) within the same region. The mismatch of the sizes of residential and non-

\footnotetext{
${ }^{2}$ From Metro (email): “autos were $\$ 19.61 / \mathrm{hr}$. in peak periods and $\$ 15.27 / \mathrm{hr}$. in off-peak periods. For trucks, the value was $\$ 39 / \mathrm{hr}$. All of these are in 2010 dollars. $\$ 20 / \mathrm{hr}$. is a nice round number to be used for private vehicles.
} 
residential zones was a challenge in designing the perimeter of each cordon scenario. The selection of residential and non-residential zone boundaries had to perfectly overlap to avoid location error and bias in the results. The same challenge applied to the selection of the areas outside the cordon, so that the results analyzed and compared refer to the same geographical range.

Table 3.2 Different Cordon Scenarios Tested

\begin{tabular}{|c|c|c|}
\hline \begin{tabular}{c} 
1) $\begin{array}{c}\text { Small Cordon } \\
\text { CBD }\end{array}$ \\
\hline NO TOLL
\end{tabular} & $\begin{array}{c}\text { 2) } \\
\text { Central City }\end{array}$ & $\begin{array}{c}\text { 3) } \\
\text { Portland City Limits }\end{array}$ \\
\hline Toll $=\$ 1.65$ & NO TOLL & NO TOLL \\
\hline Toll $=\$ 8$ & Toll $=\$ \mathbf{1} .65$ & Toll $=\mathbf{\$ 1 . 6 5}$ \\
\hline
\end{tabular}

\section{1) Small Cordon or Central Business District Cordon:}

The small cordon (areas in blue in Figures 3.2 and 3.3) is designed around the Central Business District (CBD) of Portland, where the CBD is largely in line with the former Trimet (Tri-County Metropolitan Transportation District of Oregon) fareless square: more precisely, the small cordon is designed to overlap the $\mathrm{CBD}$, plus the Northwest District and minus the Lloyd District. 


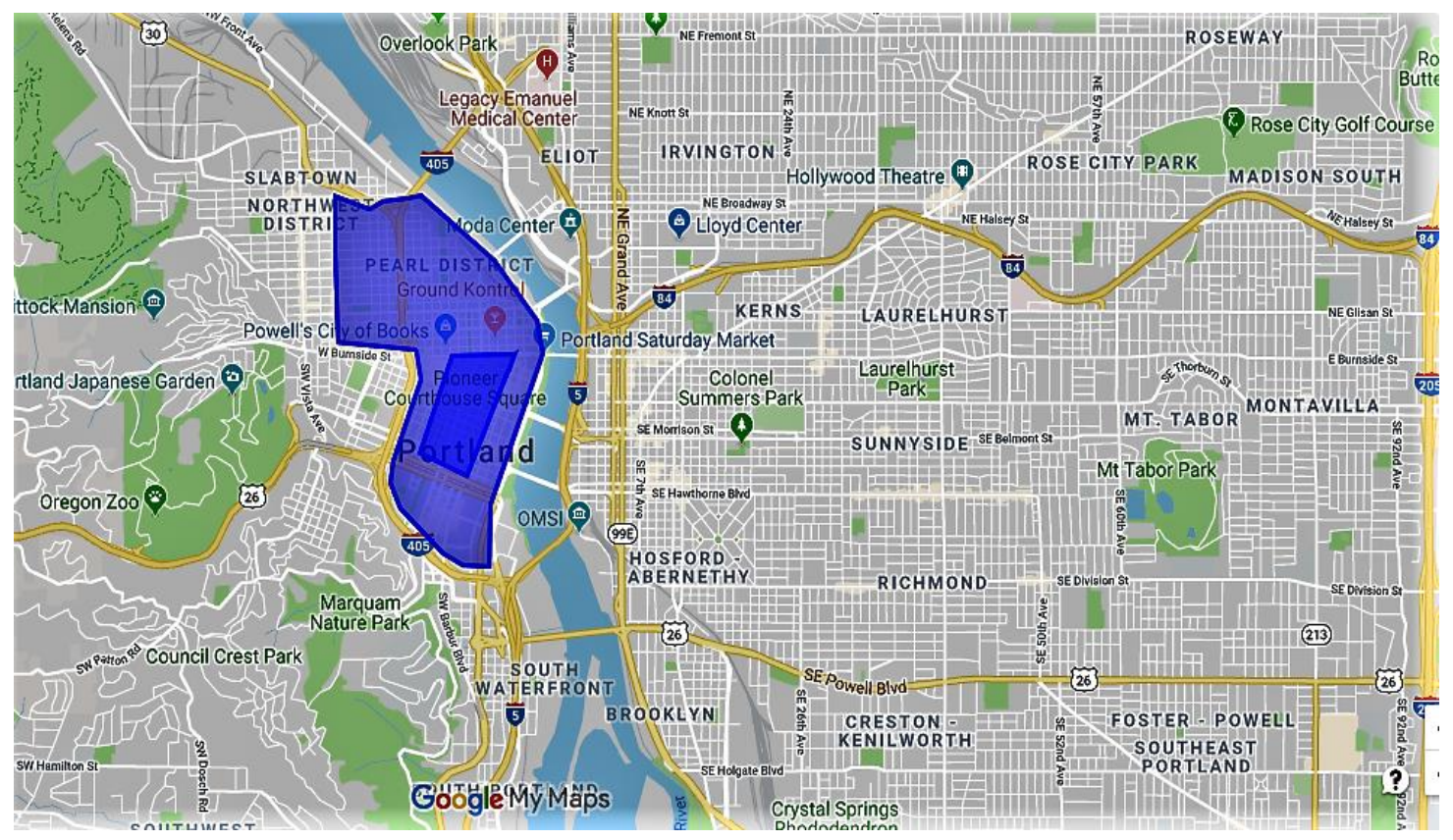

Figure 3.2 CBD Boundaries in Portland, OR

Source: google map (downtown Portland, OR)

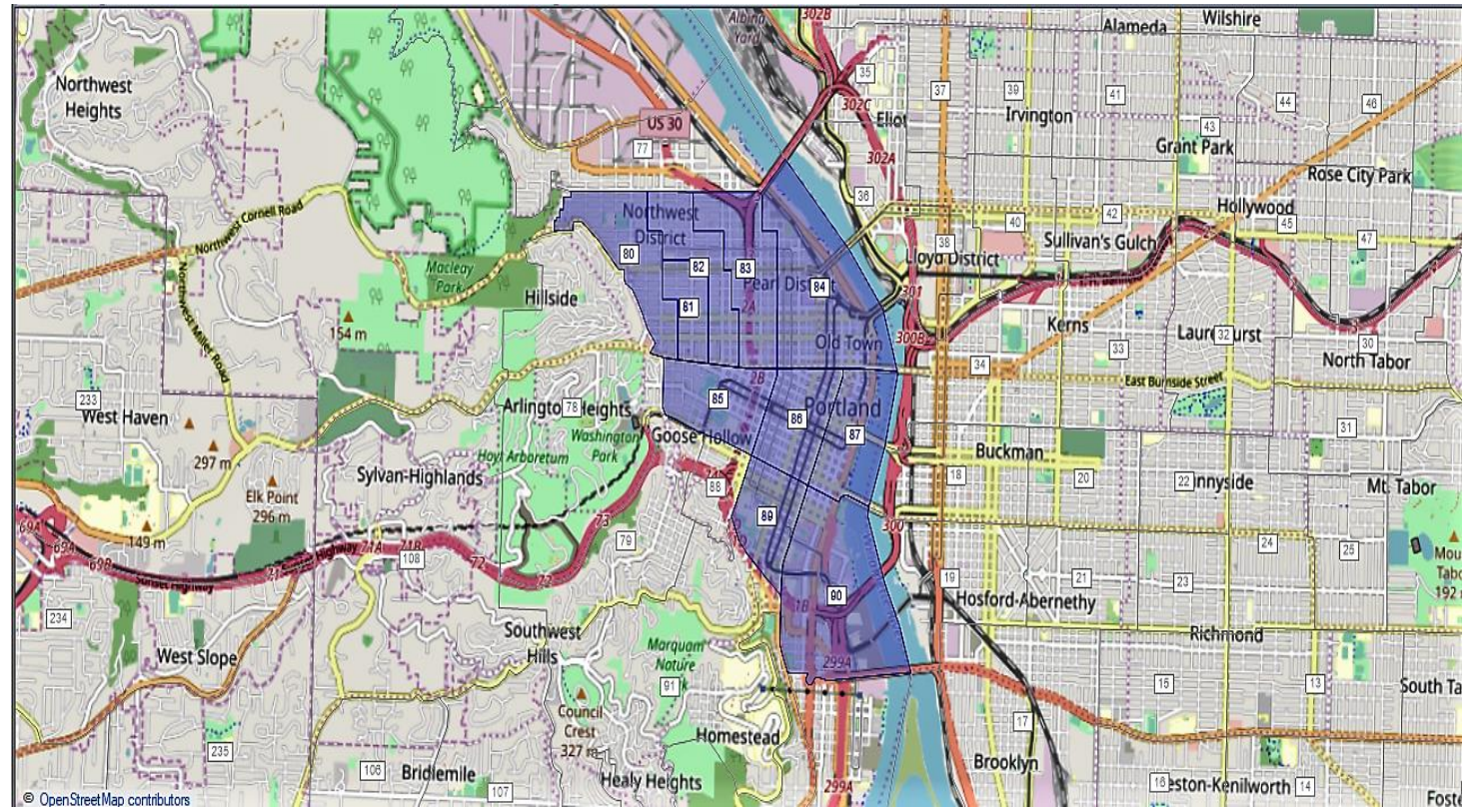

Figure 3.3 CBD or Small Cordon Boundaries in Portland, OR

Source: PTV Visum 


\section{2) Mid-size Cordon or Central Business District Cordon:}

The mid-size cordon is mainly designed around the central city of Portland as defined from Metro, the city of Portland, and the Bureau of Planning and Sustainability (2011), as shown in Figure 3.4. Figure 3.5 highlights this area in blue. In detail, this cordon includes the CBD plus the areas across the Willamette river; the North Lloyd District and zones from the Southeast Waterfront up to SE 29th Avenue (the furthest point). The mid-size cordon perimeter is about double the size of the CBD ring.

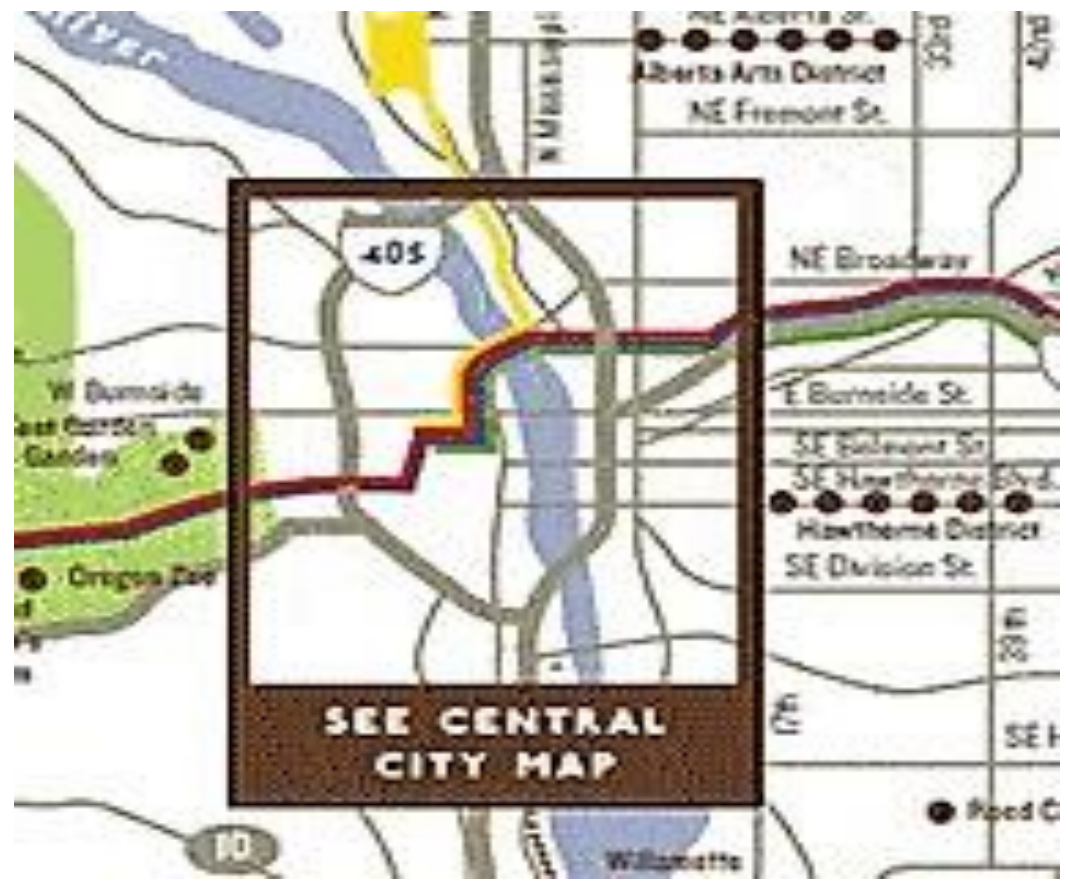

Figure 3.4 Central City, Portland, OR

Source: The Portland Plan (2011). 


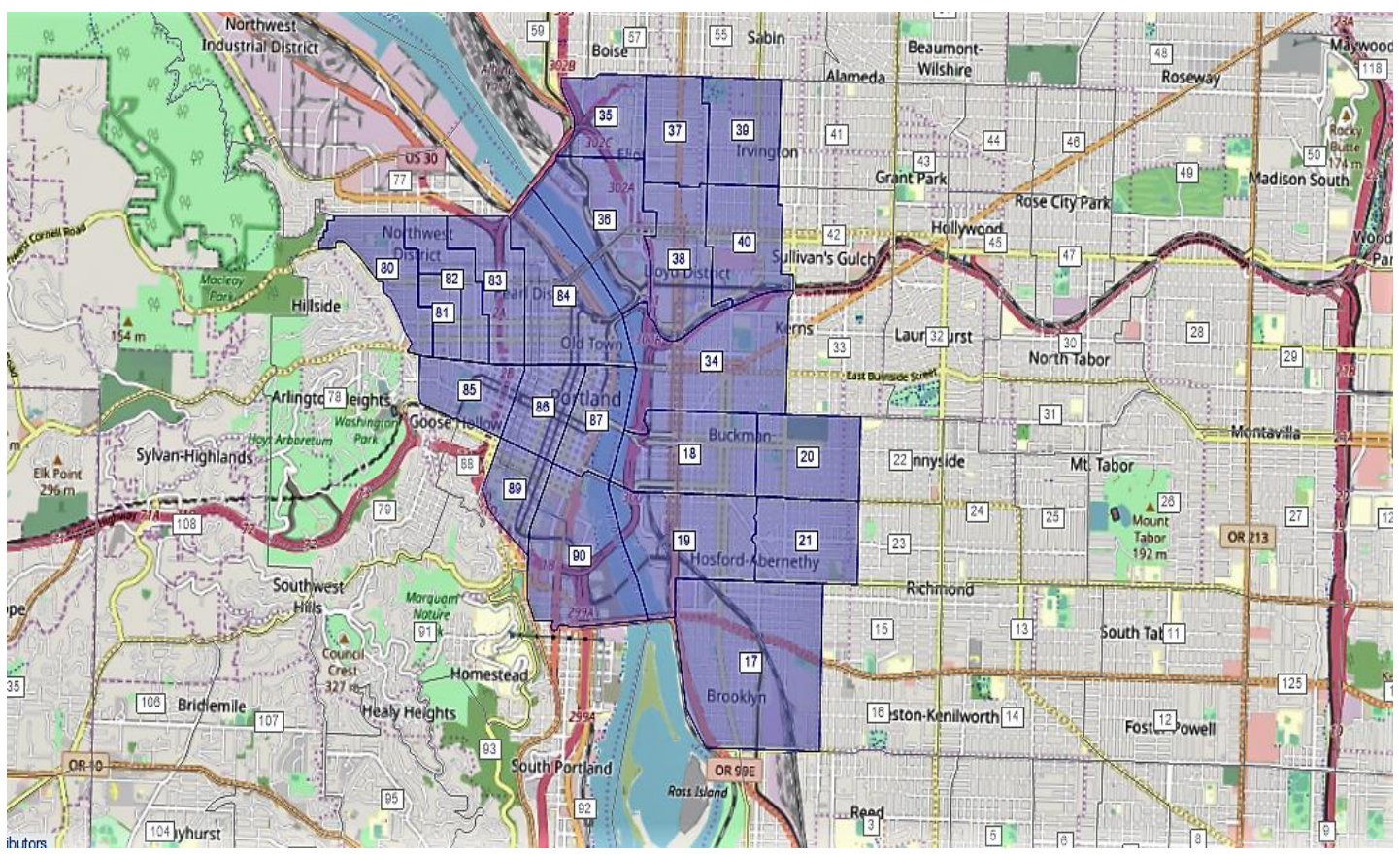

Figure 3.5 Central City or Mid Cordon Boundaries in Portland, OR

Source: PTV Visum

\section{3) Big Cordon or Portland City Boundaries Cordon:}

The Big cordon is designed around the boundaries of the city of Portland, Oregon, as shown in Figure 3.6 and defined by the blue area in Figure 3.7. 


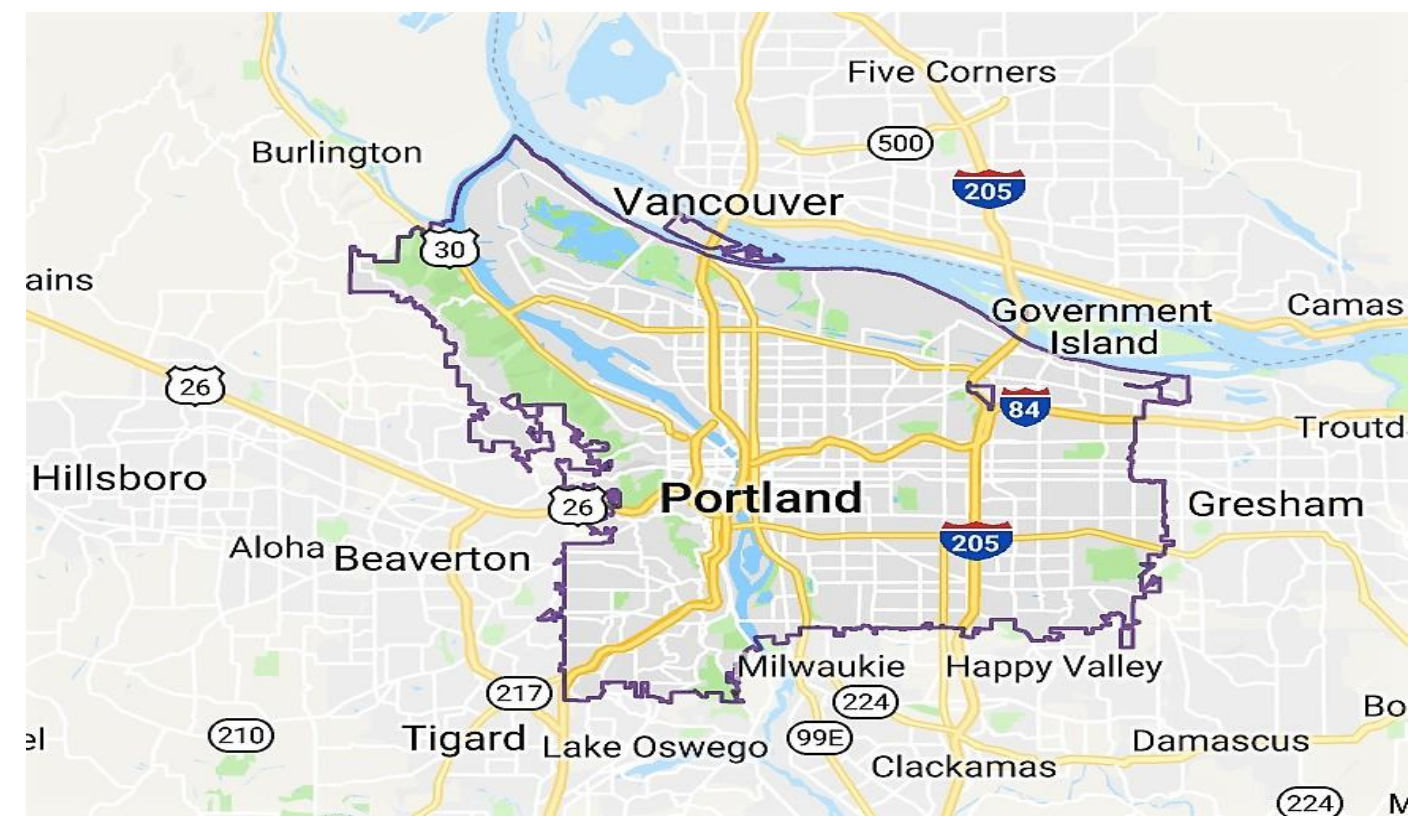

Figure 3.6 City Boundaries of Portland, OR

Source: map data @2019 Google

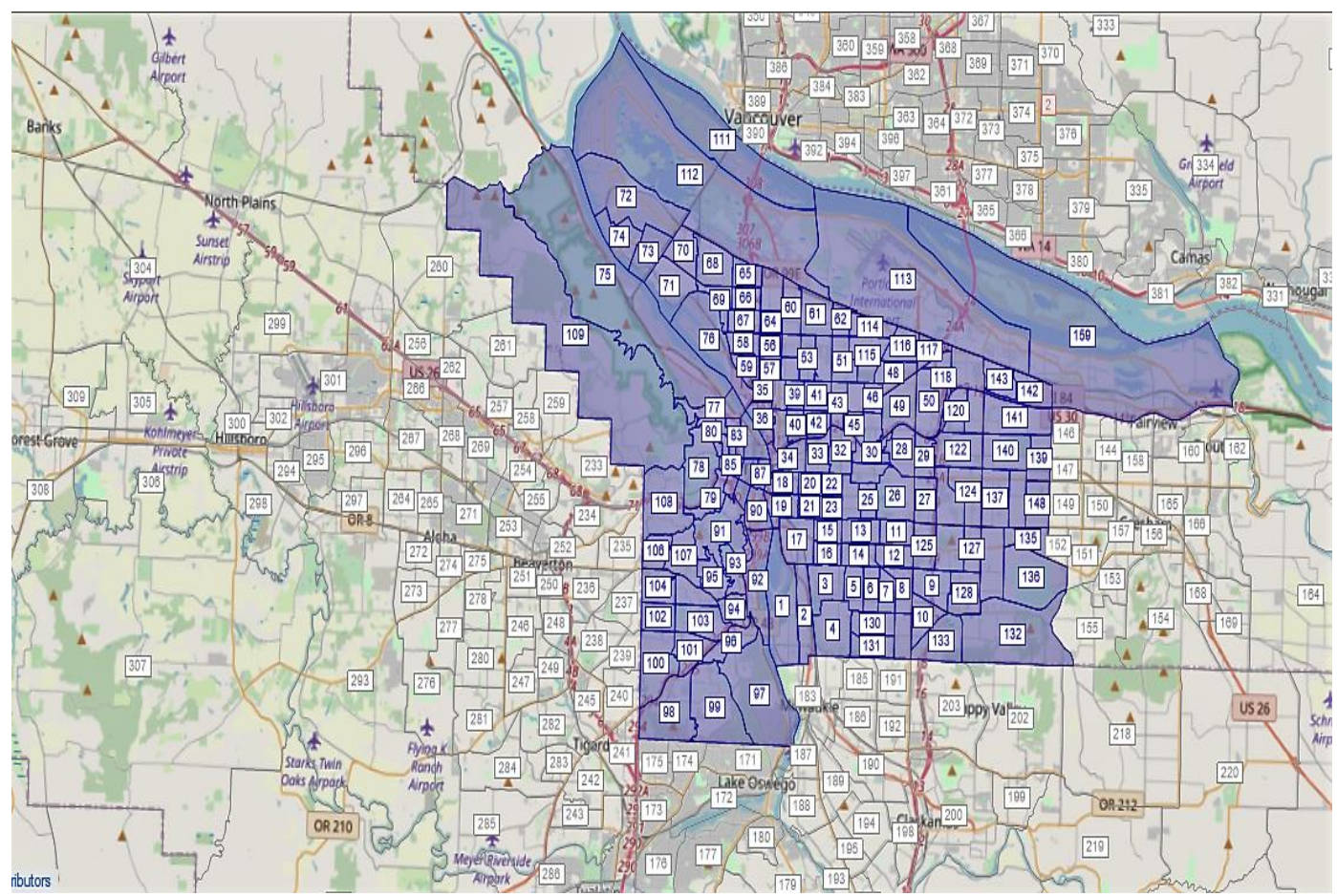

Figure 3.7 Portland City or Big Cordon Boundaries

Source: PTV Visum 


\subsection{MetroScope Output}

MetroScope interacts in five-year periods until 2035, with a baseline of year 2010.

Each model run produced the same output updated every 5 years; each MetroScope year equals 5 actual years, for instance MetroScope year 1 means 5 years have passed, so if MetroScope year 0 is actual year 2010, then MetroScope year 1 equals to actual year 2015 and so forth, as shown in Table 3.3.

Table 3.3 MetroScope Years Versus Actual Years

\begin{tabular}{|c|c|}
\hline MetroScope Year & Actual Year \\
\hline \hline Year 0 (Baseline) & 2010 \\
\hline \hline Year 1 & 2015 \\
\hline \hline Year 2 & 2020 \\
\hline \hline Year 3 & 2025 \\
\hline \hline Year 4 & 2030 \\
\hline \hline Year 5 & 2035 \\
\hline \hline
\end{tabular}

MetroScope produces a vast amount of output. ${ }^{3}$ In the model, land use output is divided into two main categories: non-residential and residential land use classes.

The performance of each given scenario is evaluated in terms of:

From non-residential land use: changes in demand and land value for different industries, changes in total employment by different employment classes, changes in

\footnotetext{
${ }^{3}$ Example: MetroScope produces a huge amount of output, for instance, for residential there are 425 Rzones x 34 Zoning classes x 5 Land sources x 3 designs types equal to 216,750 possible combinations of land consumption for one housing type. Considering that there are 4 housing types the combination increases to 867,000 possibilities (Metro, 2009, pg. 10-13).
} 
location choices for different household types (from the labor market), and changes in total sqft supply.

From residential land use: changes in location demand and land value for different real estate classes, and changes in total supply.

MetroScope divides each year's output into residential and non-residential classes. Both real estate classes' outputs are produced in each 5-year forecast period: to be clear, each real estate type in each 5-year period "inherits" the old real estate from the previous 5-year period.

On the non-residential side, there are 15 employment classes occupying 6 different real estate types in 72 employment zones (ezones). Non-residential land use takes a 6-county estimate of employment in 15 classes and allocates it to ezones and 6 real estate types within ezones (Metro, 2013). In detail, the 6 real estate types on the demand side are supplied from 3 different land sources: 1) Manufacturing and Warehousing real estate types draw from the industrial land base; 2) Retail and Services are supplied from Commercial land; and 3) Medical and Social/Government are supplied from the institutional land base (Metro, 2009-p.28).

On the non-residential side, the 15 employment classes are:

1) Agriculture/timber

2) Construction

3) Non-durable manufacturing

4) Durable manufacturing, metals, paper

5) High tech manufacturing

6) Transportation and warehousing 
7) Communication and utilities

8) Wholesale trade

9) Retail trade

10) Finance, insurance and real estate

11) Consumer services

12) Health services

13) Business, professional services

14) Other government

15) K-12 education

The 6 non-residential real estate types identified in MetroScope are:

1) Manufacturing

2) Warehousing/distribution

3) Retail/consumer services

4) General office/other commercial

5) Medical/social/institutional (non-government)

6) Government

MetroScope has 400 residential classes (divided into households' size, income classes, age of household head, and school-age children presence), occupying 4 different residential real estate types in 425 residential zones (rzones).

There are 4 types of residential real estate, each defined by a minimum and a maximum lot of sizes per dwelling unit:

1) Owner single family (osf)

2) Owner multifamily (omf) 
3) Renter single family (rsf)

4) Renter multi-family (rmf)

Single family includes 1-unit single-family attached, detached, and mobile home units. Multifamily includes apartments with two or more units. 


\section{Data}

The data used in this study is provided by Metro. The Metro Data Resource center coordinates with Metro's regional partners such as counties, cities, the Oregon

Department of Transportation, TriMet, Port of Portland, and private-sector clients in order to collect and combine data into a comprehensive database. The main data can be found in the following websites:

http://www.oregonmetro.gov/index.cfm/go/by.web/id=24905

http://www.oregonmetro.gov/index.cfm/go/by.web/id=24906

http://www.oregonmetro.gov/index.cfm/go/by.web/id=24876 


\section{General Information about Technology}

This study will not be examining the cost or type of the technology necessary to implement the cordon scheme, nor any related issues. In fact, thanks to the improvement in toll collection, including electronic toll detection and satellite surveillance, detecting and collecting fees has become easier. In a city where the charge is already applied, the congestion toll is collected at one or multiple cordons located at specific sites. In fact, with the installation of cordon gantries, public agencies can detect vehicles passing through the cordon and the tolls can be electronically charged from pre-paid cards without slowing traffic.

A popular device to charge for congestion pricing is an electronic device called transponder or "tag" (U.S. Department of Transportation-Federal Highway System, 2013) that is read by overhead antennas. There are different types of tags, from simple (where they can provide an identification number by using incoming radio frequencies) to highly sophisticated devices (battery-powered and processing power and memory).

Also, a Global Positioning System (GPS) could be used to collect tolls; an invehicle device records charges incurred based on its location as identified by the GPS unit in the vehicle. In this case, all the payment information will stay in the vehicle that will be update periodically by the owner to a processing center. However, a GPS system could be expensive.

Cameras are essential complements to tag and GPS devices to gather a record about the identity of the vehicles that do not have a working tag or GPS installed (U.S. Department of Transportation-Federal Highway System, 2013). Also, cameras can detect toll violators and impose a penalty on them. Further, cameras are being improved 
in their capabilities, and some argue that toll collection could theoretically rely only on video.

Because technology is improving at such a fast rate, there may soon be further alternatives that may be selected to implement an even more efficient way of collecting individual tolls. The intention of this paper is not to further discuss technological devices that could be used for collecting tolls and their related issues.

It is well understood that the number and locations of access points and the type of technology chosen could impact the cost of establishing and operating the cordon network. 


\section{Central Business District, or Small Cordon}

The small cordon is mainly designed around the CBD of Portland, where the CBD is largely identified with the former Trimet fareless square (minus the Lloyd District) (Figure 6.1). More precisely, the small cordon is designed to overlap the CBD plus the NW district (area in blue) as shown in Figures 6.2 and 6.3.

The design of the cordon areas has been quite challenging. The main reason is that the MetroScope model has been designed to have a total of 425 rzones inside the Portland region, but it has only 72 ezones within the same region. The mismatch of the sizes of residential and non-residential zones was a challenge at the time of designing the perimeter of each cordon scenario. The selection of residential and non-residential zone boundaries had to perfectly overlap to avoid location error and bias in the results. The same challenge applied to the selection of the areas outside the cordon, so that the results analyzed and compared refer to the same geographical range.

Another challenge was the massive amount of output produced. ${ }^{4}$ Each model run produced the same output updated every 5 years; each MetroScope year equals 5 actual years. For instance, MetroScope year 1 means that 5 years have passed, so since MetroScope year 0 is actual year 2010, then MetroScope year 1 equals actual year 2015 and so forth, as shown in Table 3.3.

In MetroScope, land use output is divided into two different categories, residential and non-residential land use (both classes were explained in the previous chapter). Metro

${ }^{4}$ Example: MetroScope produces a huge amount of output, for instance, for residential there are 425 rzones x 34 zoning classes x 5 land sources x 3 designs types equal to 216,750 possible combinations of land consumption for one housing type. Considering that there are 4 housing types the combination increases to 867,000 possibilities (Metro, 2009 10-13). 
$(2009,5)$ suggests "the best way to begin the analysis of the results and the quickest way to have an idea on how the model performed is to start analyzing residential and nonresidential location prices, since that it is considered an index of the match between supply and demand". Metro explains $(2009,5)$ "that if there is competition for real estate in each given zone, the unmet potential demand is reflected in a higher location price. The produced values indicate how the land supply will converge to its demand and can predict whether supply is falling behind real estate demand, resulting in higher location prices".

MetroScope's only output with regards to residential and non-residential land use prices is the price index. The real estate price index is generated as a component of real estate allocation. In more detail, location value is not a price, but an index measuring the housing price relative to 2010 calculated on a "hedonic" table that is matrixed with the actual price paid for housing in 2010 dollars. The hedonic table is something only Metro has access to.

Any increase or decrease in property price is a relative adjustment in value to strike a balance between supply and demand.

As Metro explains (Metro email, May 17, 2019), "The way to think about location price index it is that each model iteration has two steps: 1) compare supply and demand and change prices accordingly, then 2) use the new prices to calculate new supply and demand. The supply and demand calculations do not directly affect each other, but only indirectly through the location price. To clear the market in each iteration, only two things can happen: either higher demand plus lower construction, or lower demand plus higher construction." For example, "an excess demand will generate a relative upward 
price movement which will induce for more construction in the reference zone in response to the relative lower supply until supply meets demand" (Metro, 2004 7). Therefore, "as a price increases (or decreases) the amount of construction will rise (or fall) accordingly" (Metro, 2004 7).

Therefore, it would seem that prices would increase even in the cases where the price index declines.

Two different pricing charges have been tested — the first is a $\$ 1.65$ toll and the second is an $\$ 8$ toll (that are the equivalent of a five-minute toll and a twenty-five-minute toll). The results are analyzed at 15 years and 25 years (that are the equivalent of year 3 and year 5 in MetroScope) from the time of the implementation of the toll in 2010. If the results after 15 years follow the same trend of the output after 25 years, then only the output at MetroScope year 5 (or after 25 years) is reported.

For a complete understanding of the effects that the introduction of different cordon tolls has on residential and non-residential real estate, the results of the toll scenarios are compared with a no toll scenario at projected year 2035. 


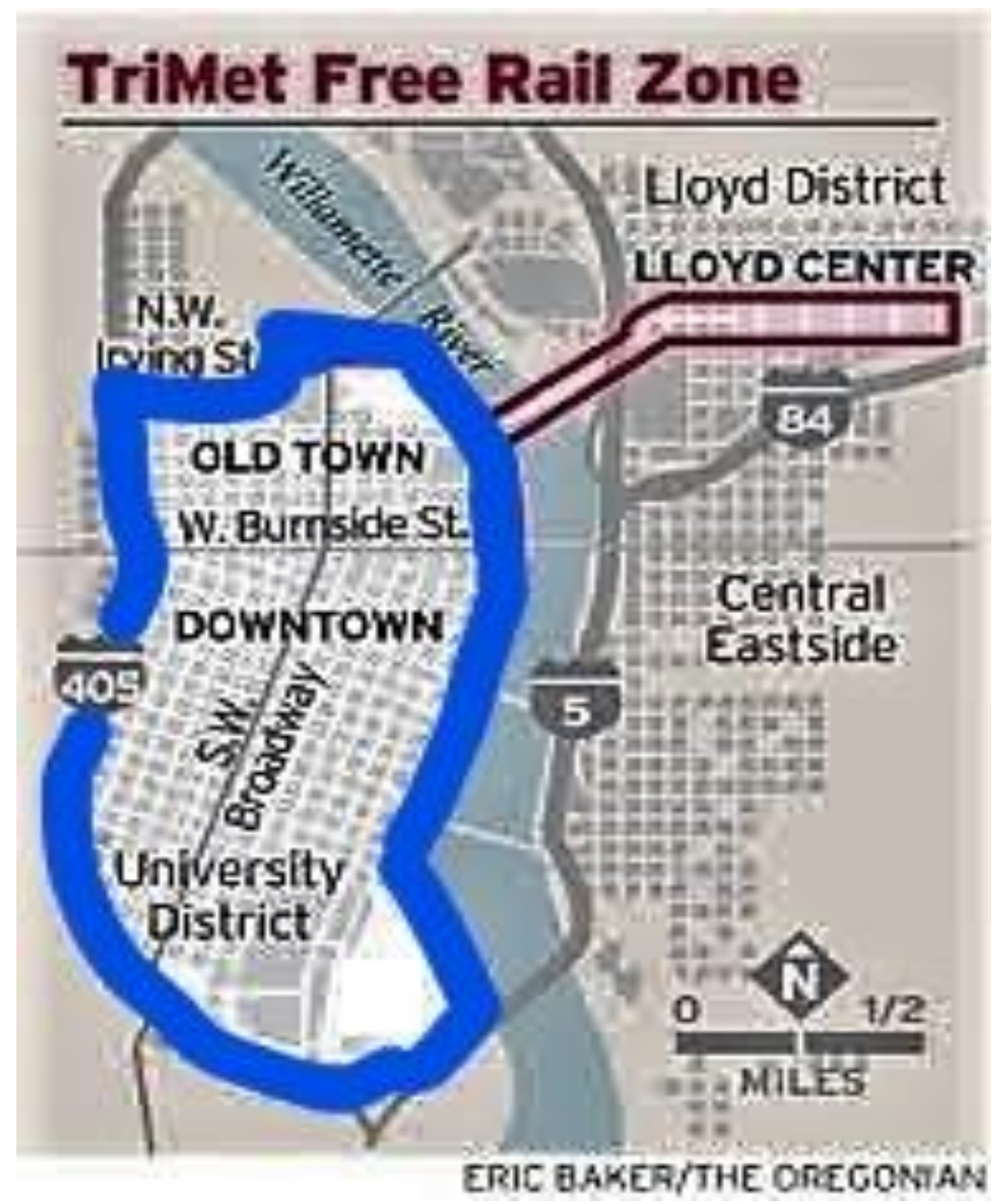

Figure 6.1 Map of Former Trimet Fareless Zone Compared to the CBD Cordon Identified with the Blue Area

Source: The Oregonian 


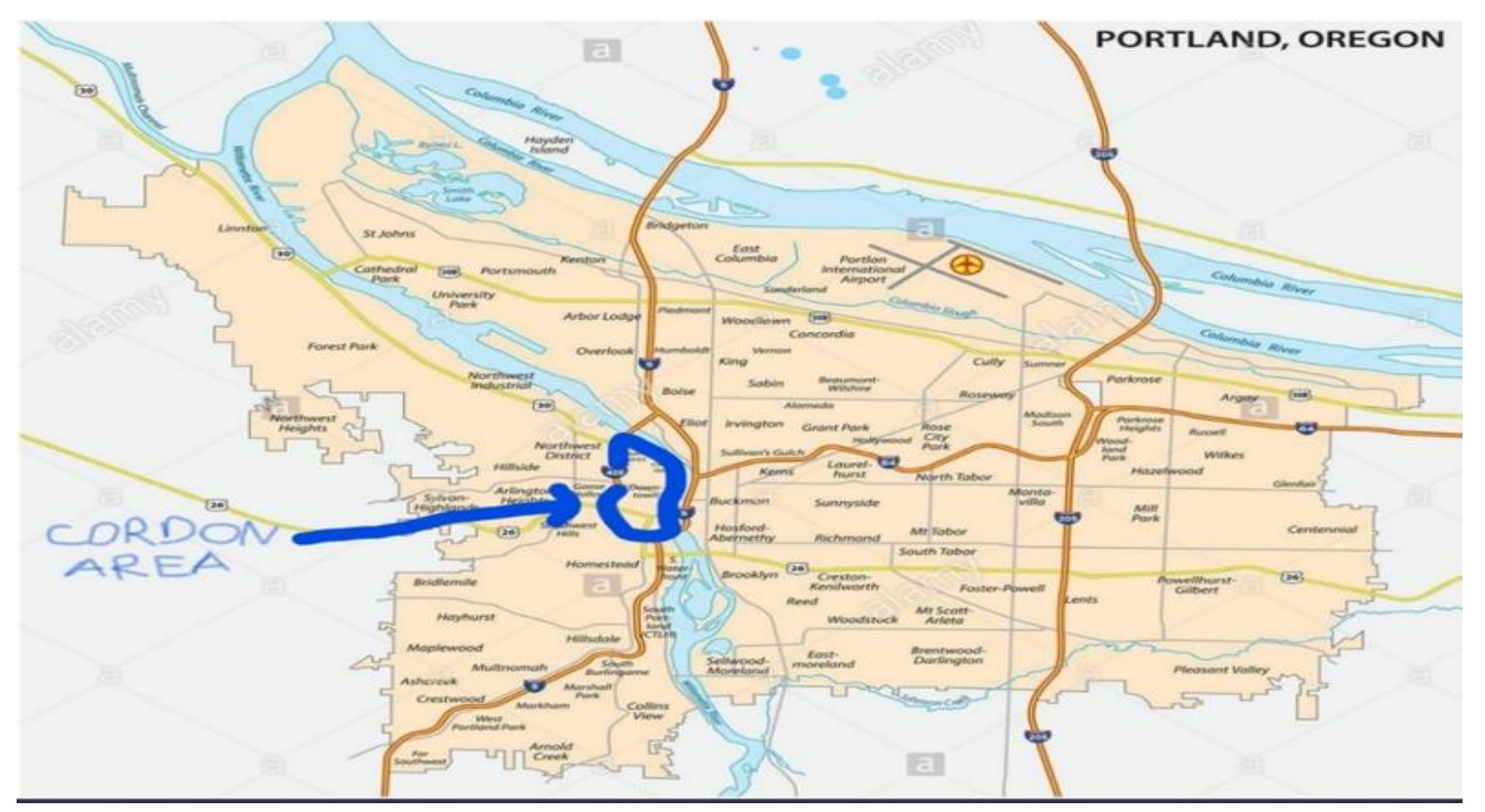

Figure 6.2 Map of the City of Portland with CBD Defined by the Blue Perimeter

Source: www.alamy.com

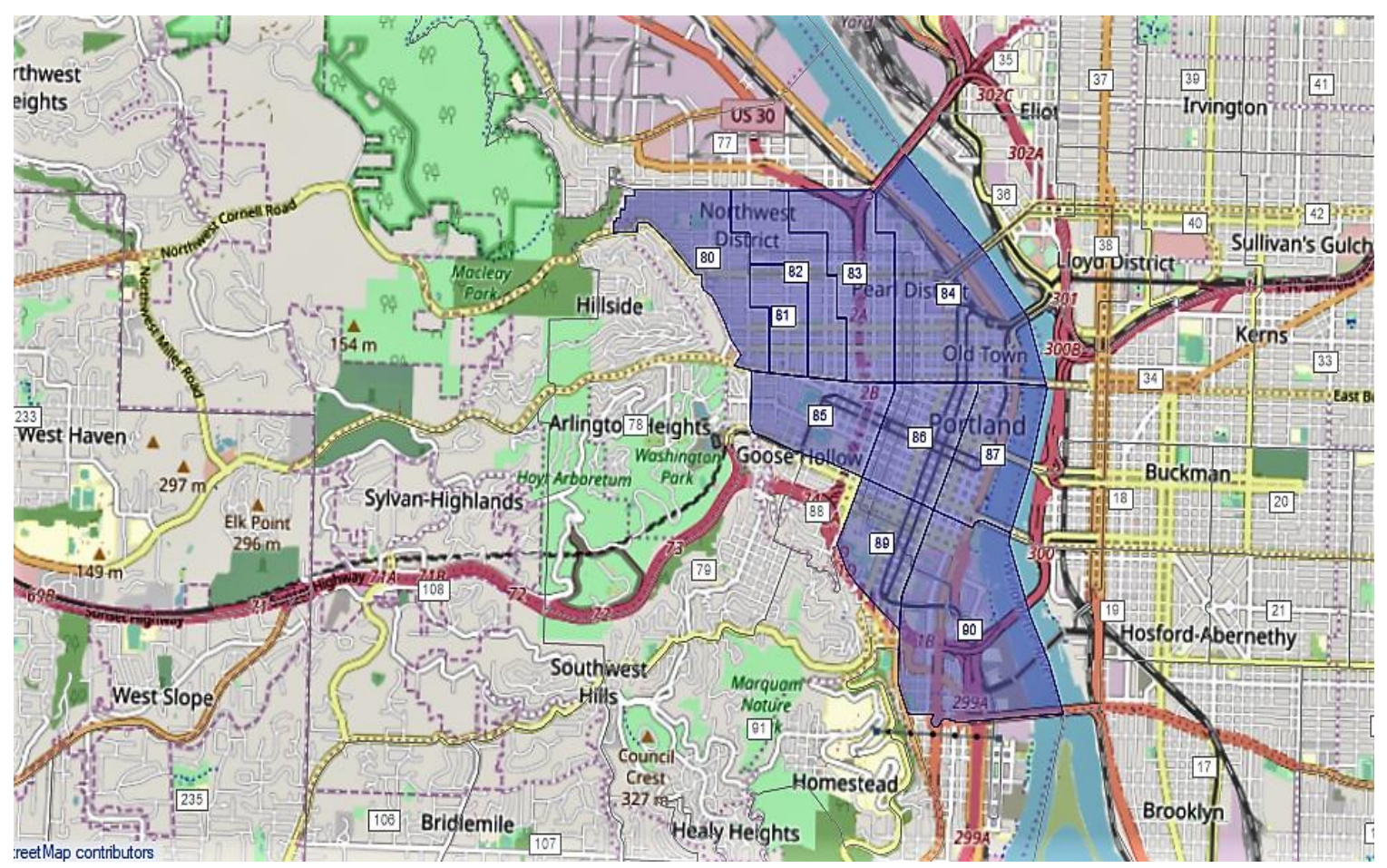

Figure 6.3 CBD or Small Cordon Marked as the Blue Area Portland, OR

Source: PTV Visum (MetroScope) 
To better understand the effects of the implementation of a cordon toll on land use, the output is divided into 4 main parts when analyzed.

1. Land use changes inside the cordon area (Figure 7.4).

2. Land use changes outside the toll boundaries, focusing on the zones directly outside the cordon perimeter:

2.1. Zones bordering with the west side of the cordon line.

2.2. Zones bordering with the east side of the cordon line, across the Willamette River.

2.2.1. Central East Side and Belmont-Hawthorne area (Figure 7.4, area circumscribed within the light green perimeter).

2.2.2. Lloyd district (Figure 7.4, area circumscribed within the dark green perimeter).

3. Land use changes in the whole city of Portland, Oregon (Figure 7.5, blue area).

4. Land use changes in the metro cities outside of Portland (Figure 7.5). 


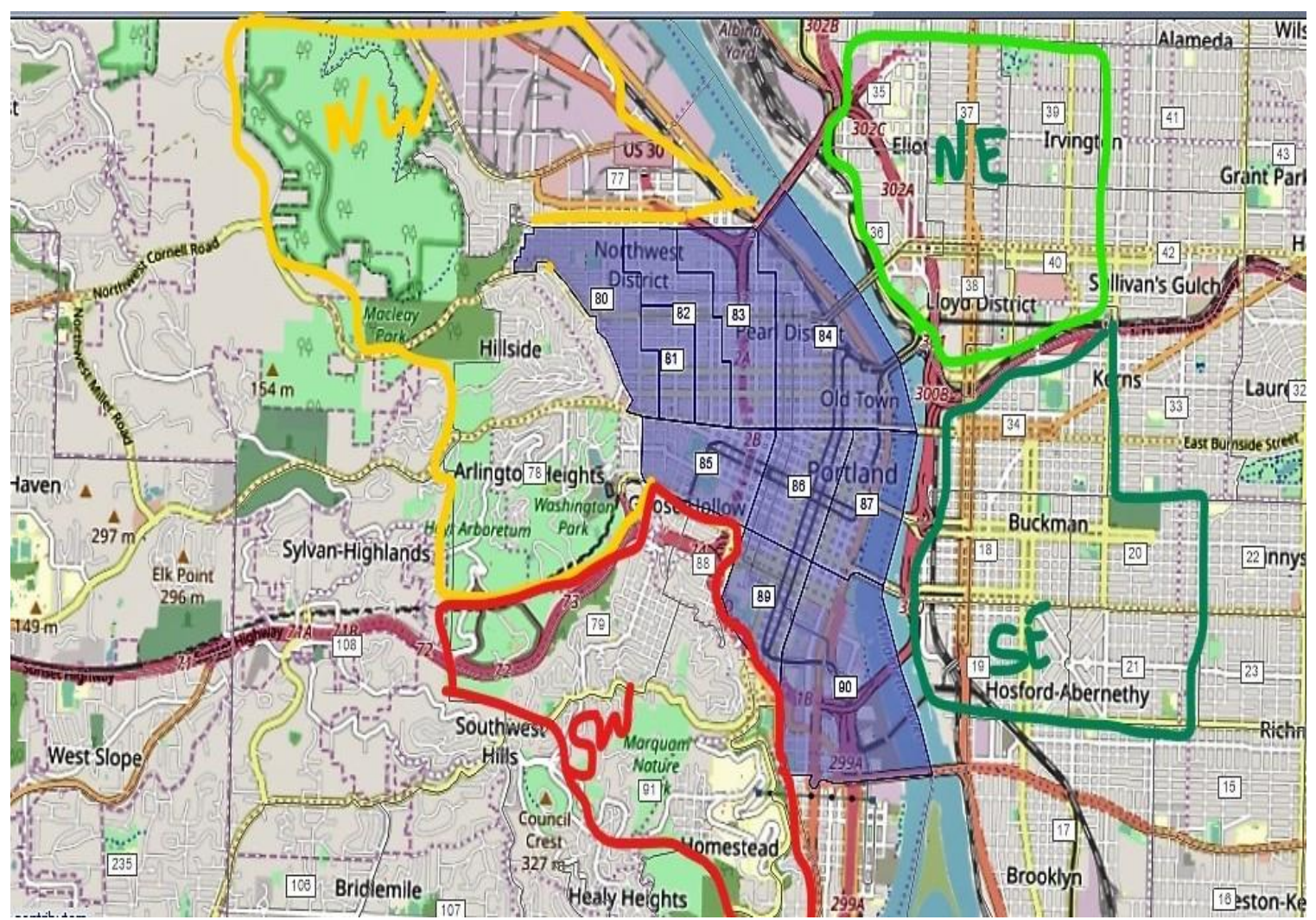

Figure 6.4 Westside and Eastside Zones Outside the Cordon Line Perimeter

Source: PTV Visum (MetroScope)

From Figure 6.4

$>$ Cordon zone is the blue area.

Westside:

$>$ Mainly Northwest of Portland, OR

Mainly Southwest of Portland, OR

Eastside:

Lloyd District, Northeast of Portland, OR

Central East Side and Belmont-Hawthorne, mainly Southeast of Portland, OR 


\section{From Figure 6.5}

Portland city boundaries: blue area.

Metro cities outside the cordon perimeter:

Dresham: area within the purple boundary.

Milwaukie and Happy Valley: areas within the green boundary.

Lake Oswego: area within the yellow boundary.

Beaverton and Tigard: area within the red boundary.

Bethany and Tanasbourne: area within the brown boundary.

Hillsboro and Orenco: area within the turquoise boundary.

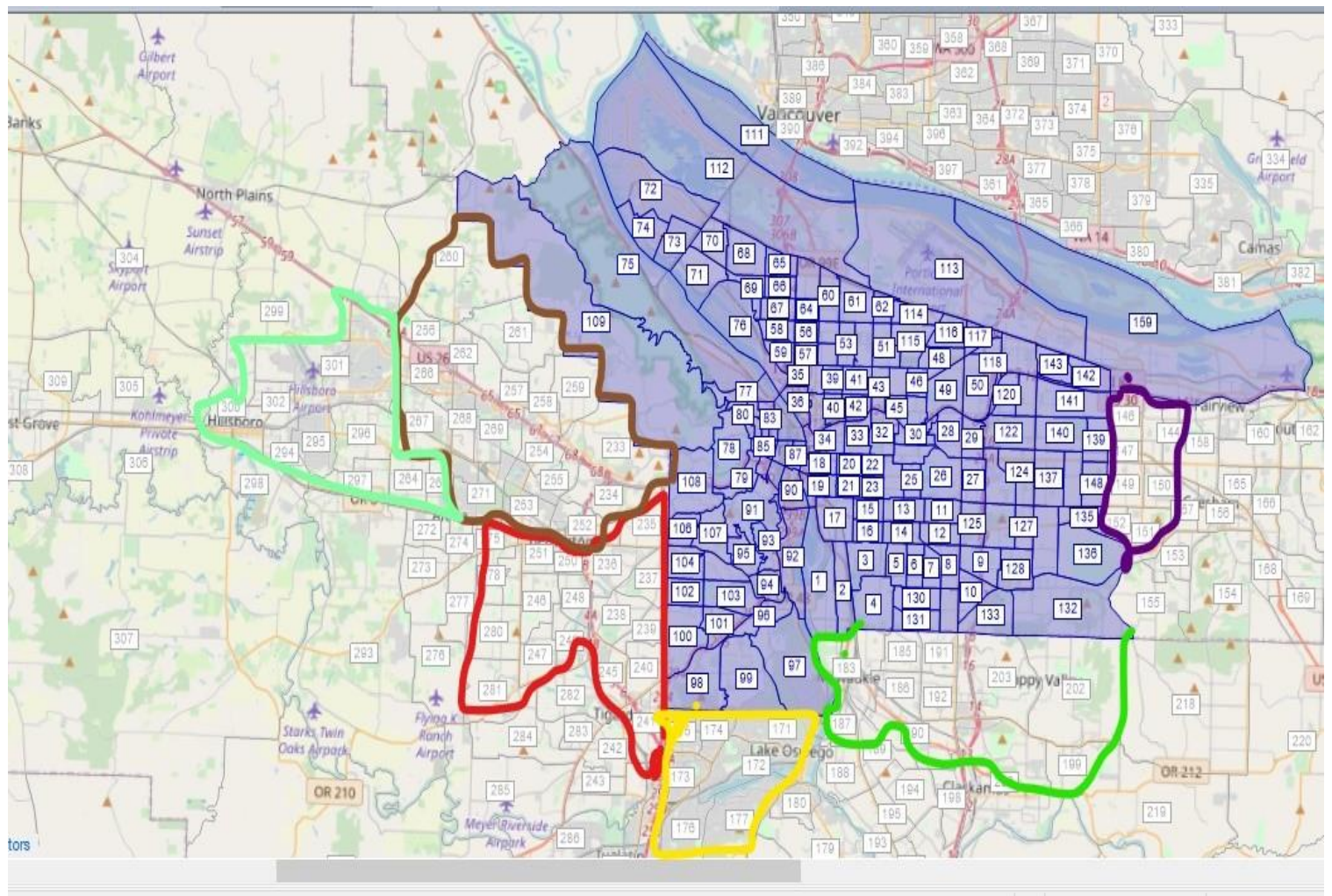

Figure 6.5 City of Portland and Metro Cities Outside

Source: PTV Visum (MetroScope) 


\subsection{CBD or Small Cordon Output Analysis}

MetroScope divides each year's output into residential and non-residential classes. ${ }^{5}$ On the non-residential side, there are 15 employment classes occupying 6 different real estate types in 72 ezones. Both real estate classes' outputs are produced in each 5-year forecast period: to be clear, each real estate type in each 5-year period "inherits" the old real estate from the previous 5-year period.

Non-residential land use takes a 6-county estimate of employment in 15 classes and allocates it to ezones and 6 real estate types within the ezones (Metro, 2013).

The analysis of the output focuses on the 4 geographical areas described above.

From the non-residential real estate side, the first variable analyzed is the percentage changes in location price (as Metro suggests), followed by total employment percentage changes, percentage changes of total household and school-age households' location demand, and non-residential total sqft supply.

Regarding residential real estate, the variables considered are the percentage changes in location prices and in total household supply.

The analysis starts with the percentage changes in non-residential location prices for different industries before and after the implementation of a cordon toll (of either $\$ 1.65$ or $\$ 8$ ) around the $\mathrm{CBD}$, followed by the report of the areas right outside the cordon, the whole city of Portland, and the metro cities in 2035.

${ }^{5}$ For a more in-depth description of non-residential and residential real estate categories, refer to Chapter 3.6. MetroScope output. 


\section{Non-Residential Land Use:}

Inside the CBD:

Figure 6.6 shows non-residential location price's response to the implementation of $\$ 1.65$ and $\$ 8$ cordon tolls designed around the CBD compared to a no toll scenario in 2035.

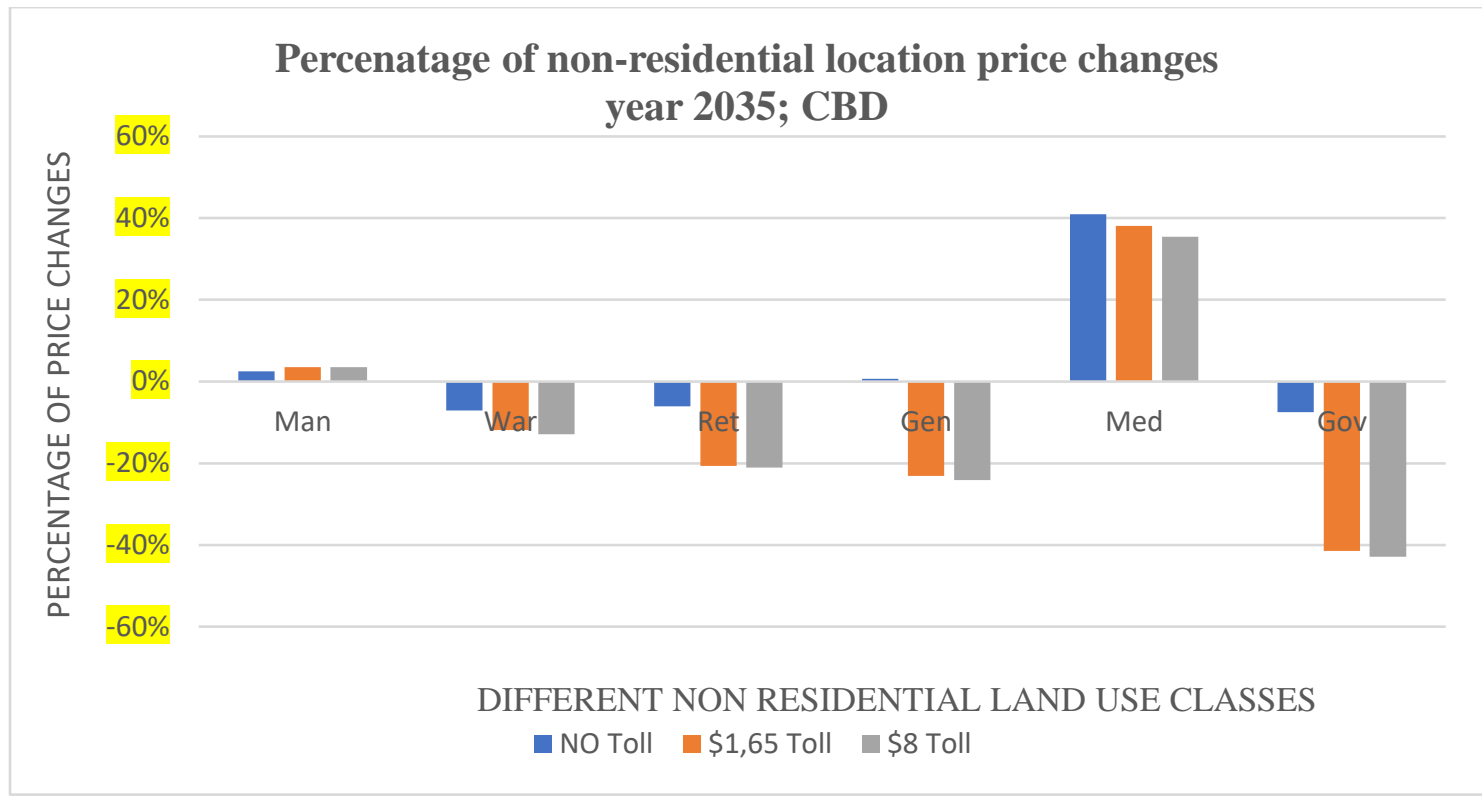

Figure 6.6

Under a no toll scenario, Medical/social/institutional real estate has relative price appreciation (41\%); demand for Medical/social/institutional is growing more than the supply, triggering a relative price appreciation that is reflected in the following period for each scenario. Government, Warehousing, and Retailers report a relative price depreciation in 2035.

Compared to no toll, the implementation of $\$ 1.65$ and $\$ 8$ toll cordons strongly influences prices: Government offices report an additional relative price decline of 35\%; 
for General offices and Warehousing, the relative additional price drop are 23\% and $5.5 \%$, respectively; and for Retailers the decline is $15 \%$.

Medical/social/institutional offices are still projected to a relative price increase but at a smaller percentage under tolls versus no toll.

In general, the implementation of tolls it is reflected in relative lower location prices for the majority of real estate.

A question remains whether some businesses will relocate right outside the cordon boundaries, trying to agglomerate in an area free from the toll but still close to the city core, or whether they might choose to decentralize and disperse further away.

Right outside the CBD boundaries:

It is reasonable to assume that the implementation of tolls affects the prices of non-residential real estate classes in those areas right outside the boundaries. Figures 6.7 and 6.8 report the effects after $\$ 1.65$ and $\$ 8$ tolls are implemented on location prices versus a no toll scenario in 2035 . 


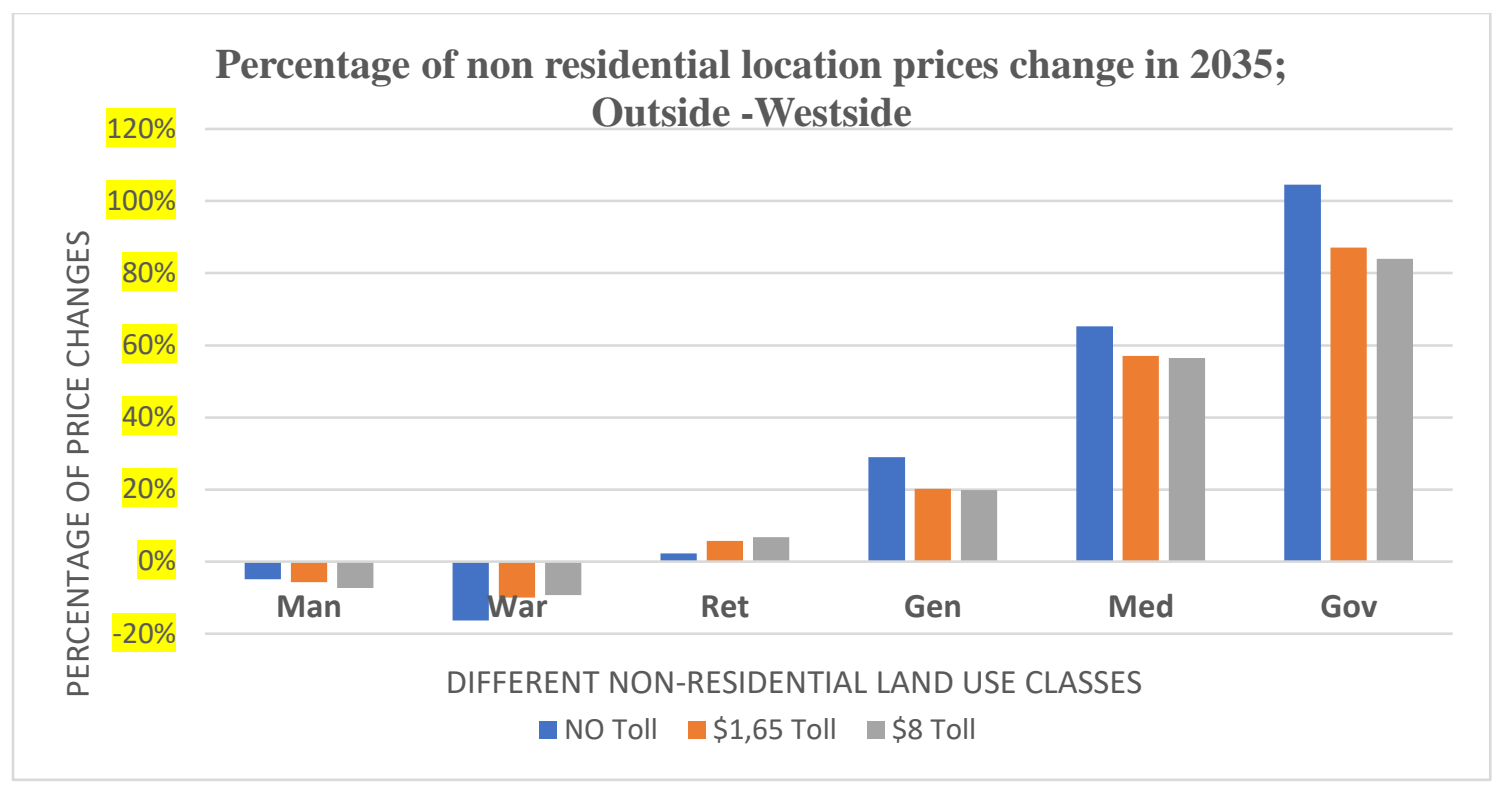

Figure 6.7

Westside: As shown in Figure 6.7, in a no toll scenario, Government offices' relative price has doubled over time. Also, Medical offices are projected to a large increase in relative value, as well as General offices, but at a smaller percentage. Retailer/services don't show any significant price variation. Contrarily, Industrial real estate's relative prices drop.

Once toll cordons are implemented, Government offices still have the relatively biggest price appreciation, although at a smaller percentage (about 20\% less) compared to no toll.

Similarly, Medical and General offices have a relatively smaller price appreciation while Manufacturing and Warehousing report a smaller price depreciation compared to no toll.

It can be speculated that tolls negatively affect demand for higher-value economic activities outside the west side of the cordon, with the exception of Retail real estate, 
which instead is positively affected by tolls compared to no toll. Perhaps this is because Retailer activities are sensitive to population movements.

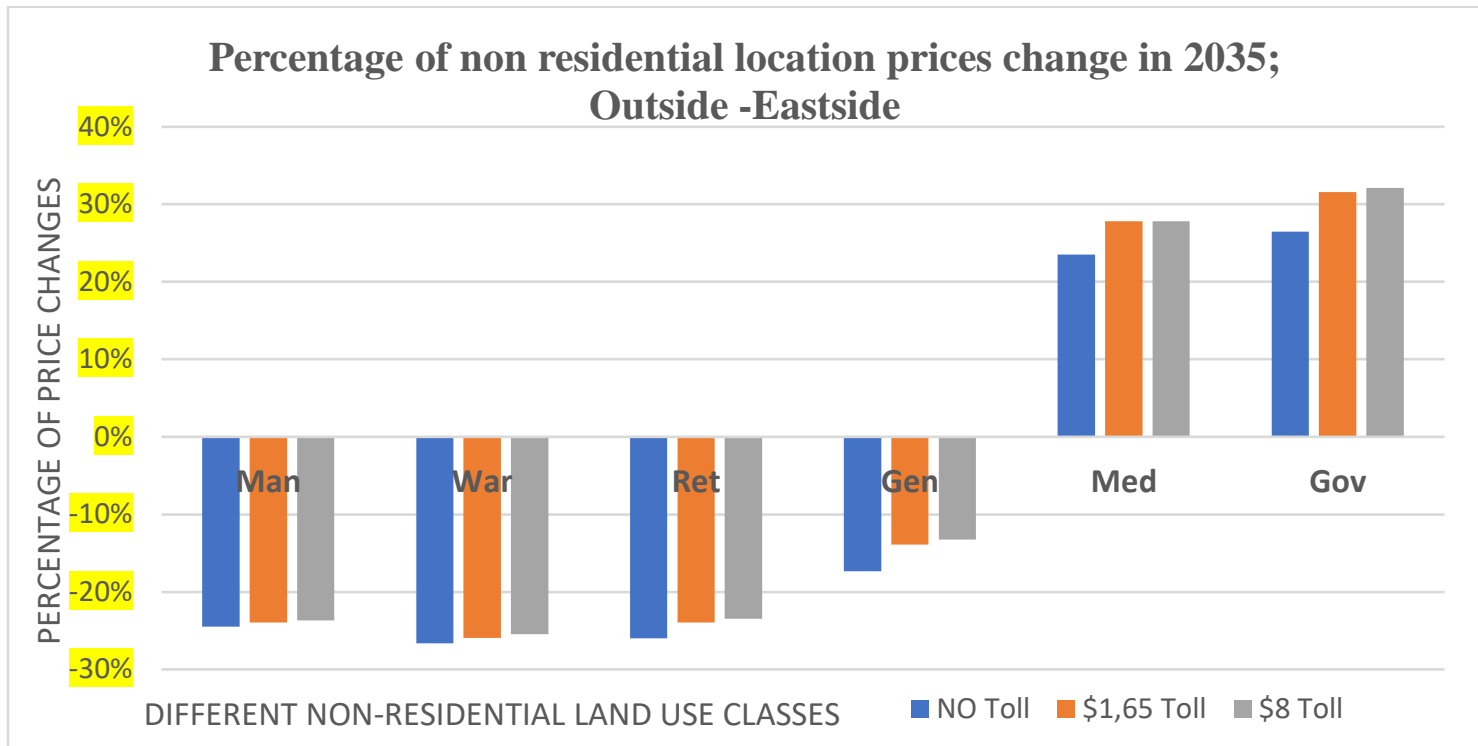

Figure 6.8

Eastside: In a no toll scenario, Government and Medical offices are the only two real estate classes projected to a relative price increase, while all other real estate reports a relative price depreciation in 2035 .

Once \$1.65 and \$8 tolls are implemented, Government and Medical real estate relative values increase an additional $5 \%$ and $4 \%$, respectively, compared to a default scenario. All the other industries report a similar change in real estate price index with a smaller relative price depreciation compared to no toll.

Tolls positively affect relative prices for higher-value activities, especially right outside the eastside boundaries, versus no toll.

The next non-residential variables analyzed are changes in employment, total household and school-age household demand (by employment zones), and nonresidential total supply. 


\section{Total Employment Changes}

Inside the CBD:

Figure 6.9 shows changes in the percentage of total employment inside the cordon before and after toll implementation in 2035.

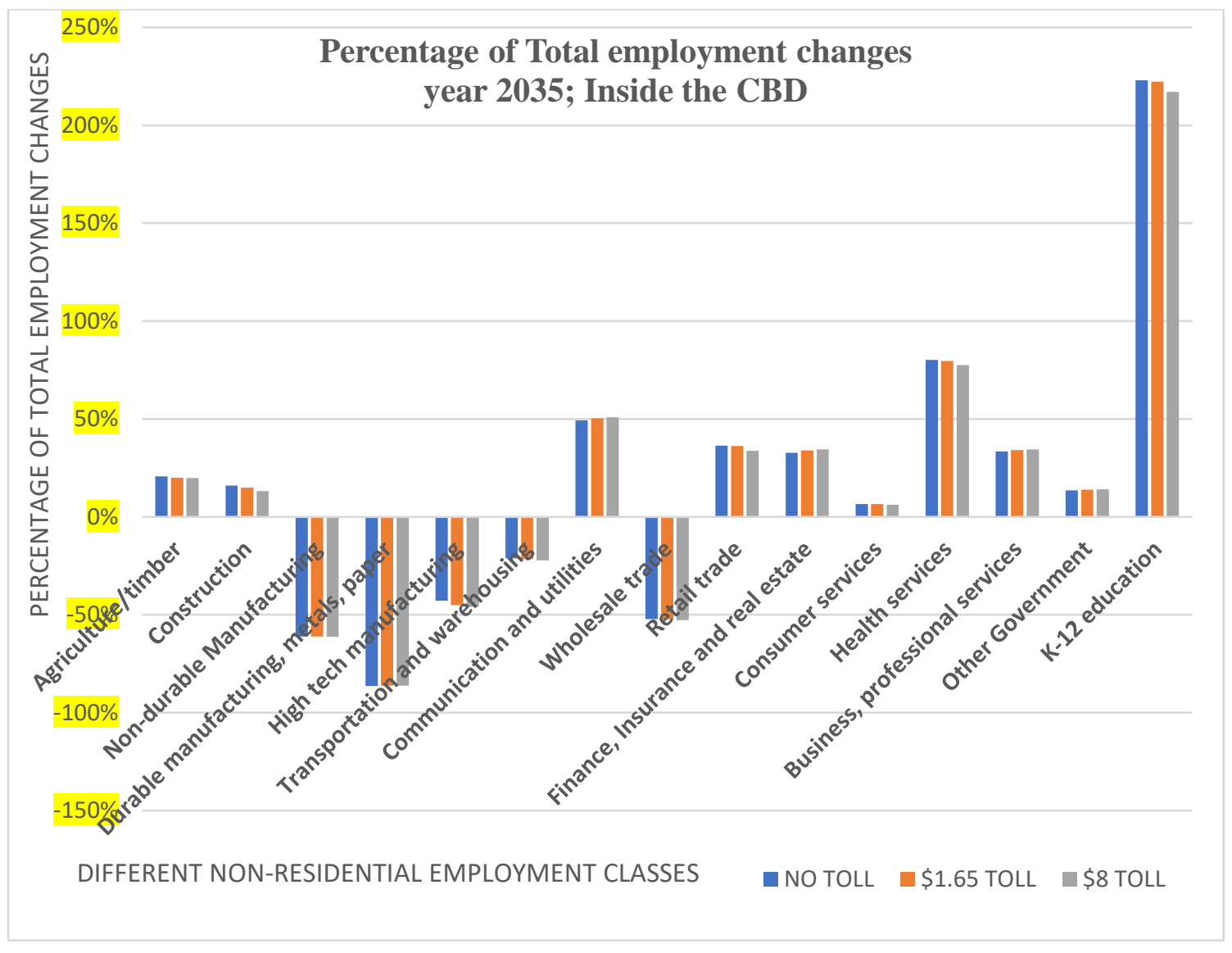

Figure 6.9

In a no toll scenario, K-12 education has an exponential increase in employment, followed by increases in Health services, Communication/Utilities, Retail trade, and Finance/Insurance/Real estate. Smaller growth in employment, below 20\%, is projected for Agriculture/timber, Construction, and Consumer services. Differently, all Manufacturing classes, Wholesale trade, and Transportation/warehousing have a decline in their employment. 
After the implementation of toll cordons, employment behaves similarly to the no toll scenario in 2035. Employment for business and commercial activities has a minor increase compared to no toll. Generally, the toll stimulates (if marginally) employment in high-value activities inside the cordon. The higher the toll, the (slightly) larger the effect.

Differently, K-12 employment still grows exponentially, but at a smaller degree compared to no toll. Similarly, employment in Construction grows at a smaller pace if tolls are implemented compared to no toll.

Overall, it can be stated that the toll stimulates (even though marginally) employment in many high-value activities inside the cordon area-the higher the toll, the (slightly) larger the effect—while it decreases employment for low-value activities in 2035.

$\underline{\text { Right outside the CBD boundaries: }}$

Figures 6.10 and 6.11 show changes in total employment before and after toll cordon implementation versus a no toll alternative in 2035, for the Westside and Eastside (respectively). 


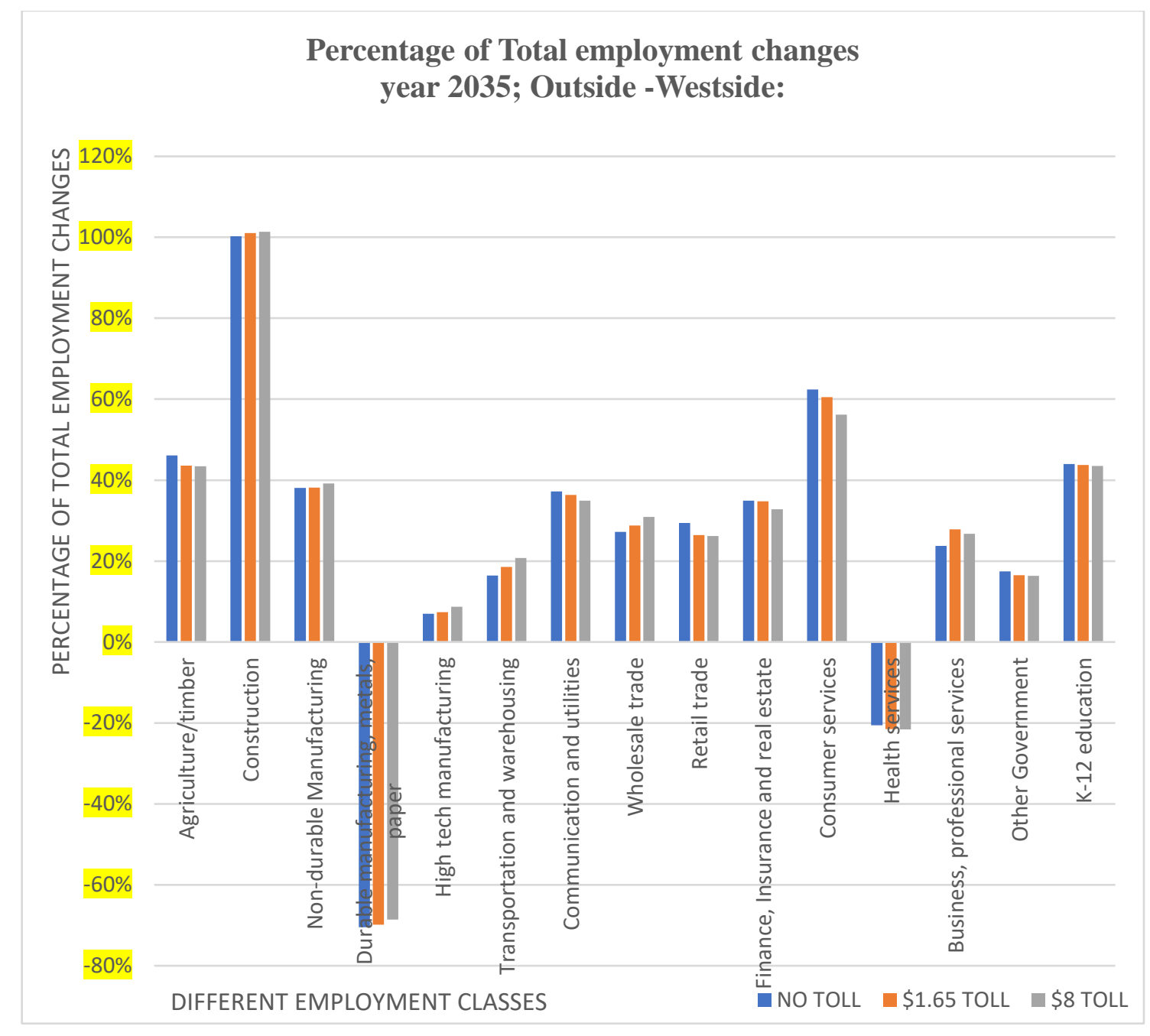

Figure 6.10

Westside: In a no toll scenario, Construction is projected to double its employment. Employment in Consumer services is also projected to a substantial increase (62\%). All economic activities report a growing employment, with the exceptions of Durable manufacturing and Health services.

Tolls push employment for Construction to an additional increase compared to no toll. Moreover, tolls positively affect employment for Business/professional services, Wholesale trade, Transportation/Warehousing, and High-tech manufacturing. On the other hand, tolls significantly reduce employment in Consumer services, Finance, Retail 
trade, and Communications/Utilities. Overall, the implementation of a toll increases or decreases employment by an average of $2.5 \%$.

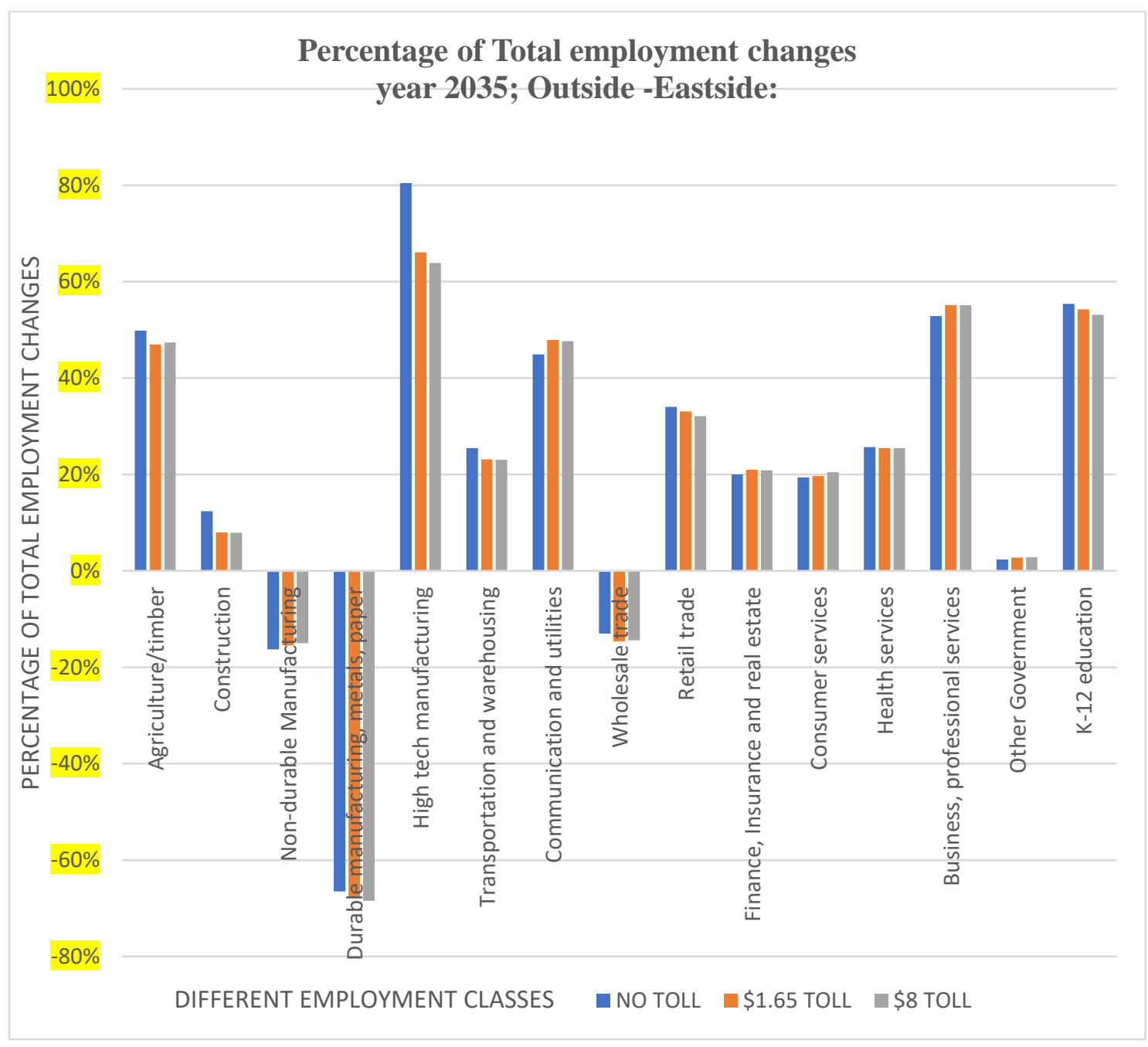

Figure 6.11

Eastside: In a no toll scenario, High tech manufacturing is the employment that increases the most (and it is the most affected by tolls as well). Overall, only Durable/Non-durable manufacturing and Wholesale trade are projected to a decline in their employment. 
Once \$1.65 and \$8 tolls are implemented, employment in High-tech manufacturing has a large drop compared to a no toll alternative; nevertheless, its employment is still very high.

Generally, total employment slightly increases in high-value activities such as Business/professional services, Consumer services, Communication and utilities, and Finance/insurance/real estate after tolls compared to no toll. Also, Health services have a percentage demand growth that is the same across all the scenarios (versus a decline on the Westside).

There is a further decline in employment for Durable manufacturing and wholesale trade after the toll cordon implementation.

Overall, total employment estimates follow the same type of response whether the tolls are implemented or not; the main difference is that under the tolls the percentage changes differ in magnitude with regards to the nature of the employment class compared to the no toll scenario.

\section{Percentage of Changes in HH Location Preferences}

Inside the CBD:

Another demand-side variable analyzed is non-residential household (hh) demand for total households and households with school-age children (from the residential model) to understand whether the presence of school-age children would matter in terms of changes in demand for housing as a reaction to a toll cordon. 
Figure 6.12 shows the percentage changes in non-residential demands for total hh and hh with school-age children before and after the toll cordons by non-residential zones within the CBD in 2035.

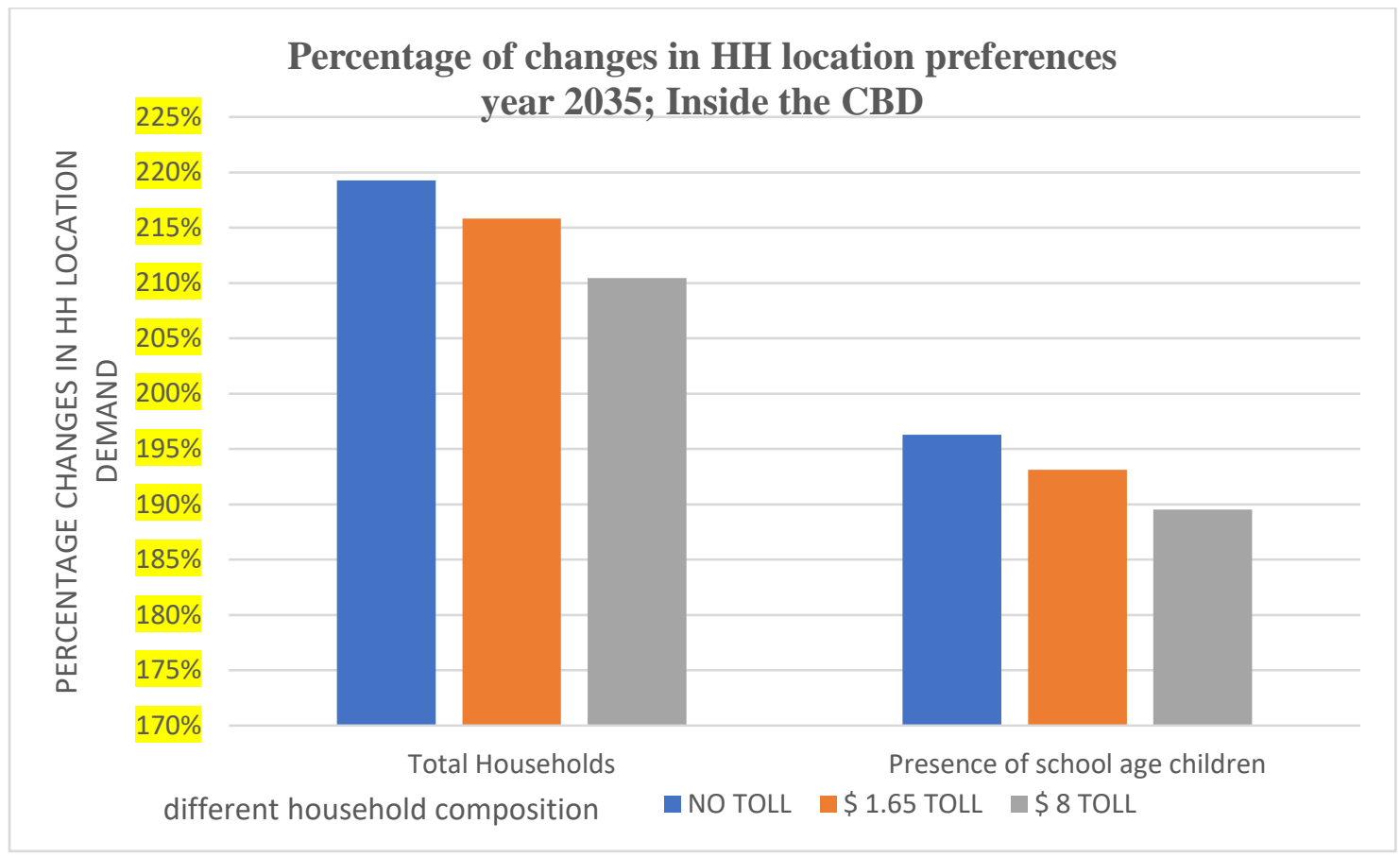

Figure 6.12

Under no toll, there is noticeable exponential growth in demand for housing for all the household types.

Once \$1.65 and \$8 tolls are implemented, total hh demand still increases over time, yet at a smaller degree- $3.5 \%$ and $9 \%$, respectively, less than under no toll.

The same trend applies to school-age hh, which account for a smaller growth (3\% and $7 \%$, less, respectively) versus no toll. Therefore, in general, tolls reduce the demand for housing for all household types inside the cordon area. The higher the toll, the larger the decline in hh demand. 


\section{Right Outside the CBD Boundaries:}

Figure 6.13 shows changes in housing demand for both hh classes before and after toll cordons on the outside of the West boundaries in 2035.

Figure 6.14 shows changes in housing demand for both hh classes before and after the toll cordons on outside of the East boundaries in 2035.

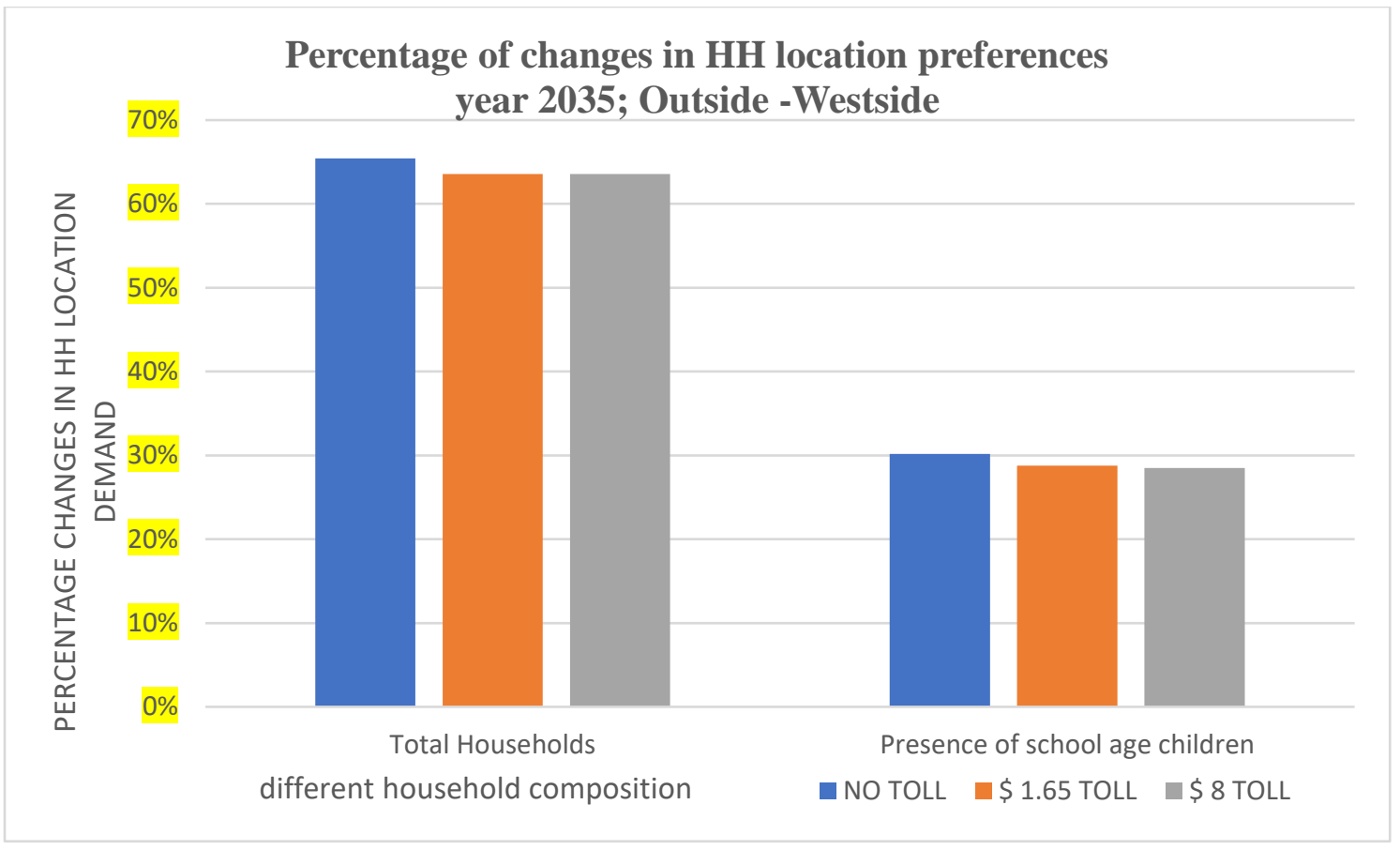

Figure 6.13

Westside: Under no toll, there is a growth in demand for housing for all household classes.

Once $\$ 1.65$ and $\$ 8$ tolls are implemented, demand for housing for both hh types decreases $2 \%$ and $3 \%$, respectively, more than under no toll. In general, the implementation of tolls has a larger negative effect on demand for housing within the CBD. 


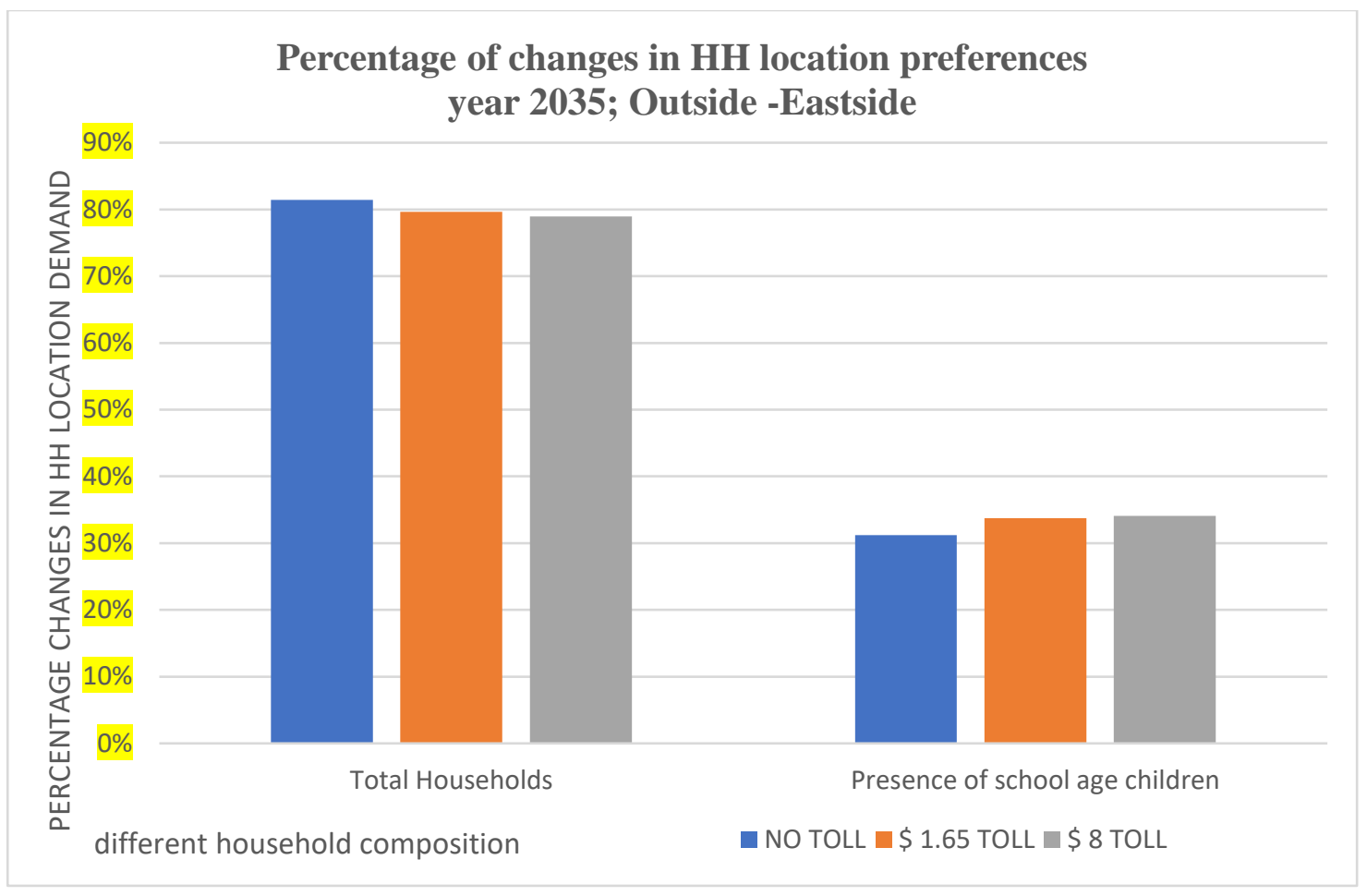

Figure 6.14

Eastside: Under no toll, there is a substantial growth in total hh demand for housing, about three times bigger than demand for housing for school-age hh.

Once $\$ 1.65$ and $\$ 8$ tolls are implemented, total hh demand still is forecasted to grow, but at $2 \%$ and $3 \%$ less, respectively, than under no toll. On the contrary, school-age hh demand for housing increases compared to no toll.

In general, toll increases school-age hh demand for housing on the Eastside, while it negatively affects housing demand within the CBD and on the Westside.

After analyzing land variables from the demand side, the next step is to focus on the supply side by looking at percentage changes in total sqft supply in 2035. A no toll scenario is compared toll cordon alternatives.

Generally, with regard to supply's assumptions in the model, Metro (2013) clarifies that any space by any employment type directly responds to the price for real 
estate classes being considered and the prices of all the competing classes. For instance, "this allows any warehouse space to be occupied by say a dance studio or any insurance claims adjuster - just two of many enterprising uses of unused industrial space" Metro (2013 28). It means that in areas such as the Central Eastside where commercial demand is high, and manufacturing is low, non-industrial uses move into industrial-type space.

\section{$\underline{\text { Total sqft Supply }}$}

Inside the CBD:

Figure 6.15 shows percentage changes in total sqft supply inside the CBD before and after introducing \$1.65 and \$8 tolls versus a default scenario in 2035.

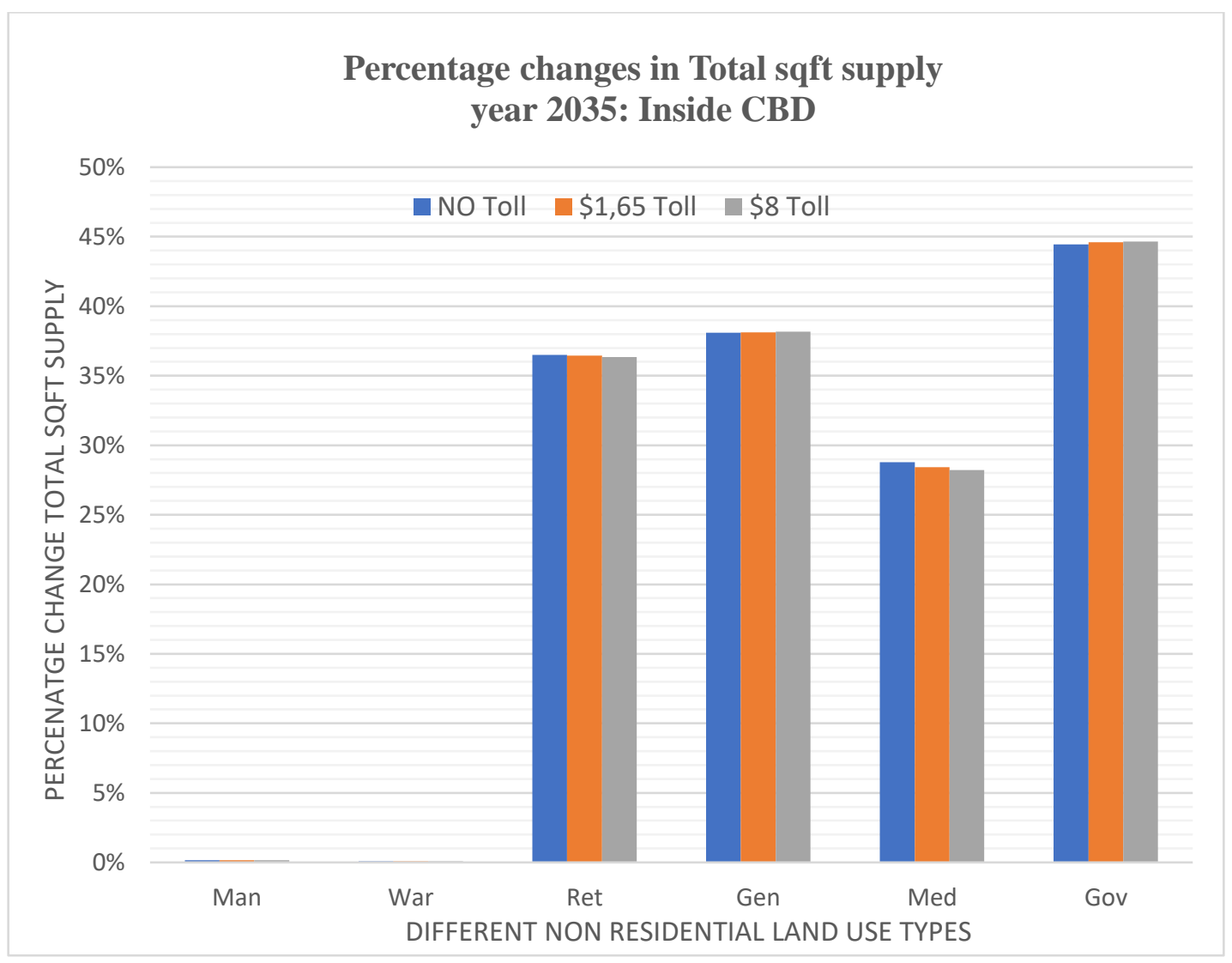

Figure 6.15 
In a no toll scenario, supply for Institutional space increases by $44 \%$, followed by General offices, Retailers, and Medical offices with growth of 38\%, 36\%, and $29 \%$, respectively.

After introducing $\$ 1.65$ and $\$ 8$ tolls, there are almost no changes in all the nonresidential real estate types. The difference in total sqft supply before and after a toll implementation is (+ or -) $1 \%$ percent.

It is reasonable to say that the implementation of the tolls has a stronger effect on demand for real estate than supply. Generally, it can be said that Supply is inelastic so that changes in demand most affect prices. It can be assumed that the presence of the UGB makes supply less reactive, behaving as almost fixed.

\section{Right Outside the CBD Boundaries:}

Figure 6.16 reports percentage changes in sqft supply for the zones outside the West boundaries before and after toll cordons are implemented in 2035.

Figure 6.17 reports the percentage changes in sqft supply for the zones outside the East boundaries before and after toll cordons are implemented in 2035. 
Westside:

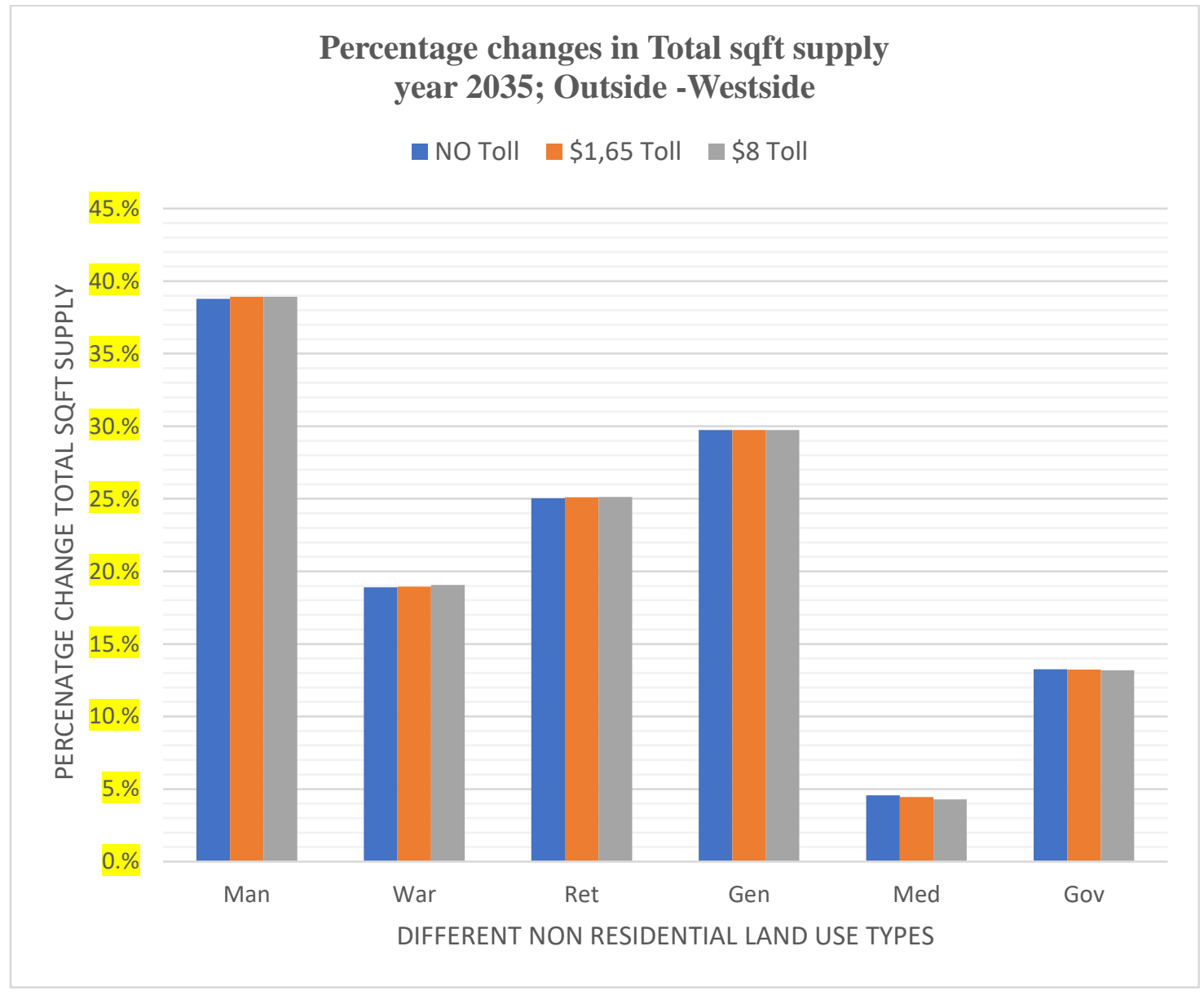

Figure 6.16

In a no toll scenario, all the real estate types show an increase in supply. The class with the biggest growth is Manufacturing (38\%), followed by General offices (29\%) and Retailers (25\%). The real estate type that has the smallest growth is Medical.

After tolls are implemented, there is not statistically significant changes in the percentage of sqft available; in fact, the percentage change is below $1 \%$ percent before and after toll cordons in 2035 in all scenarios. 
Eastside:

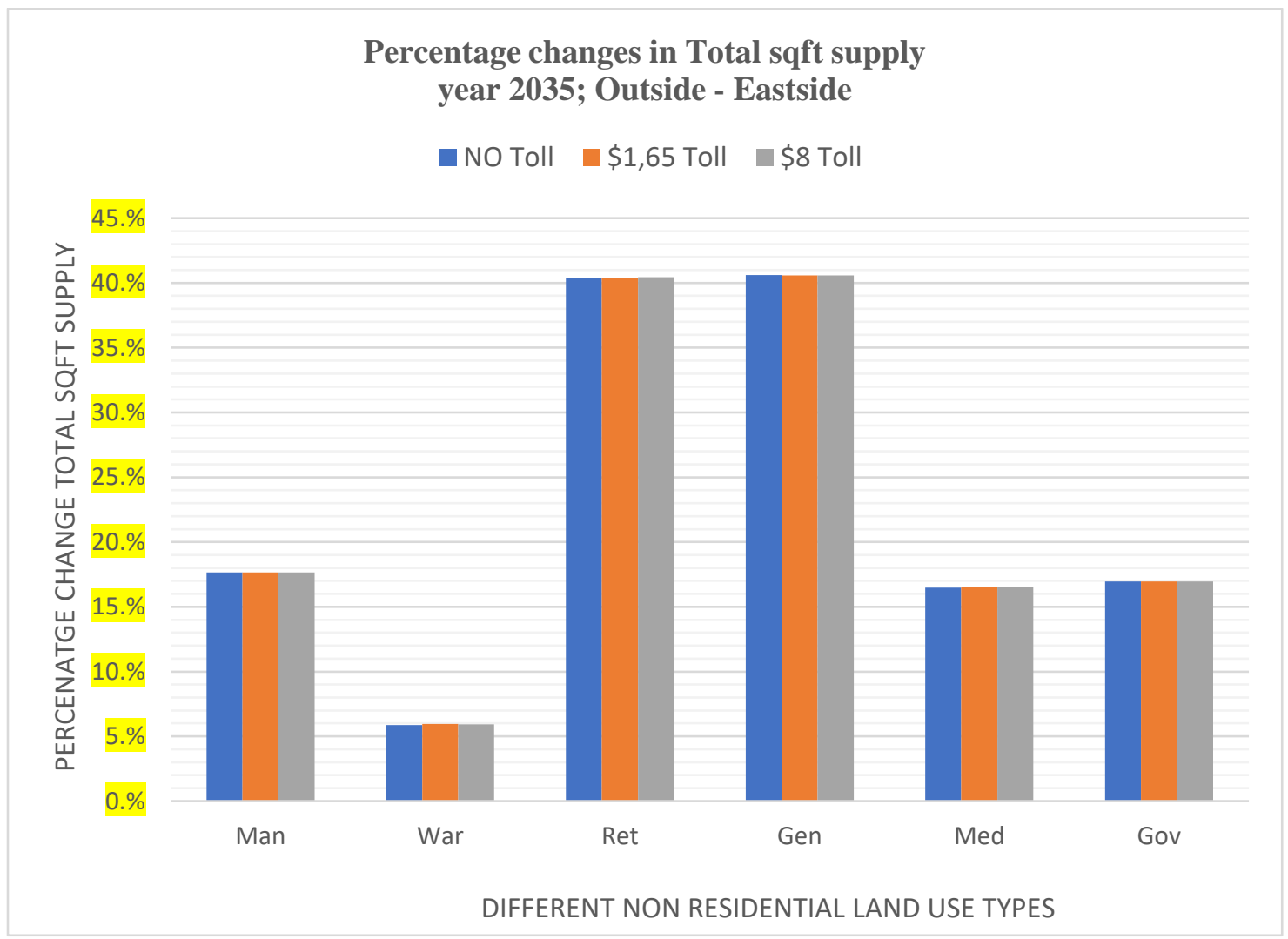

Figure 6.17

In a no toll scenario, all the real estate types show an increase in supply; the industry projected to the biggest growth is General offices (40.6\%), then Retailers $(40.3 \%)$. The real estate type with the smallest percentage increase in sqft supply is Warehousing (5.8\%).

Once tolls are implemented, there are no visible changes in the percentage of sqft supply available compared to no toll in 2035. Again, it is assumed that the presence of the UGB in Portland makes supply appear "fixed."

\section{Residential Land Use:}

In order to better interpret residential land use changes, Metro provides some details about the residential model. As explained in a previous section, the MetroScope 
residential model recognizes 4 classes of real estates: osf, omf, rsf, and rmf. While ownership and rental categories are clearly defined, Metro (2009 13) explains a single family as a dwelling unit that "you can walk around without walking around another person's house," and multifamily as "everything else;" therefore, row houses and 2 to 3 attached units go into the multifamily category. There are 425 rzones derived from the 2010 census.

With regard to the residential model and households' location decisions, Metro (2009) explains that households start with a primary place of work. From each of the 72 ezones, households then select a place of residence from among the 425 rzones according to their indirect utility functions embedded in MetroScope. Therefore, there is a connection between housing stock and place of employment (based on their willingness to pay and consumer surplus).

As Metro (2009) recommended, the first output analyzed for the residential model is the percentage changes in residential location prices. First, the percentage changes for residential real estate prices is analyzed under no toll, then the results are compared to the output generated after the implementation of \$1.65 and \$8 tolls in 2035 .

The price is not a value, but it is an index of the match between supply and demand. "When there is a competition for real estate in each given zone, the unmet potential demand is reflected in a higher location price. The produced values indicate how the land supply will converge to its demand and can predict whether supply is falling behind real estate demand, resulting in higher location prices" (Metro 2009, 5). Household allocation to MetroScope zones is performed simultaneously to equilibrate demand for housing (with all its components) for every zone in the region, given the built 
supply of housing for each demand type. If a zone had a surplus demand, real estate prices will automatically increment until demand drops and supply increases to reach an equilibrium. Then households will reformulate their location preferences based on the ability to afford housing subject to their utility function (Metro, 2009).

\section{$\underline{\text { Residential Location prices }}$}

Inside the CBD:

Figure 6.18 shows percentage changes in price before and after the implementation of $\$ 1.65$ and $\$ 8$ toll cordons in 2035 .

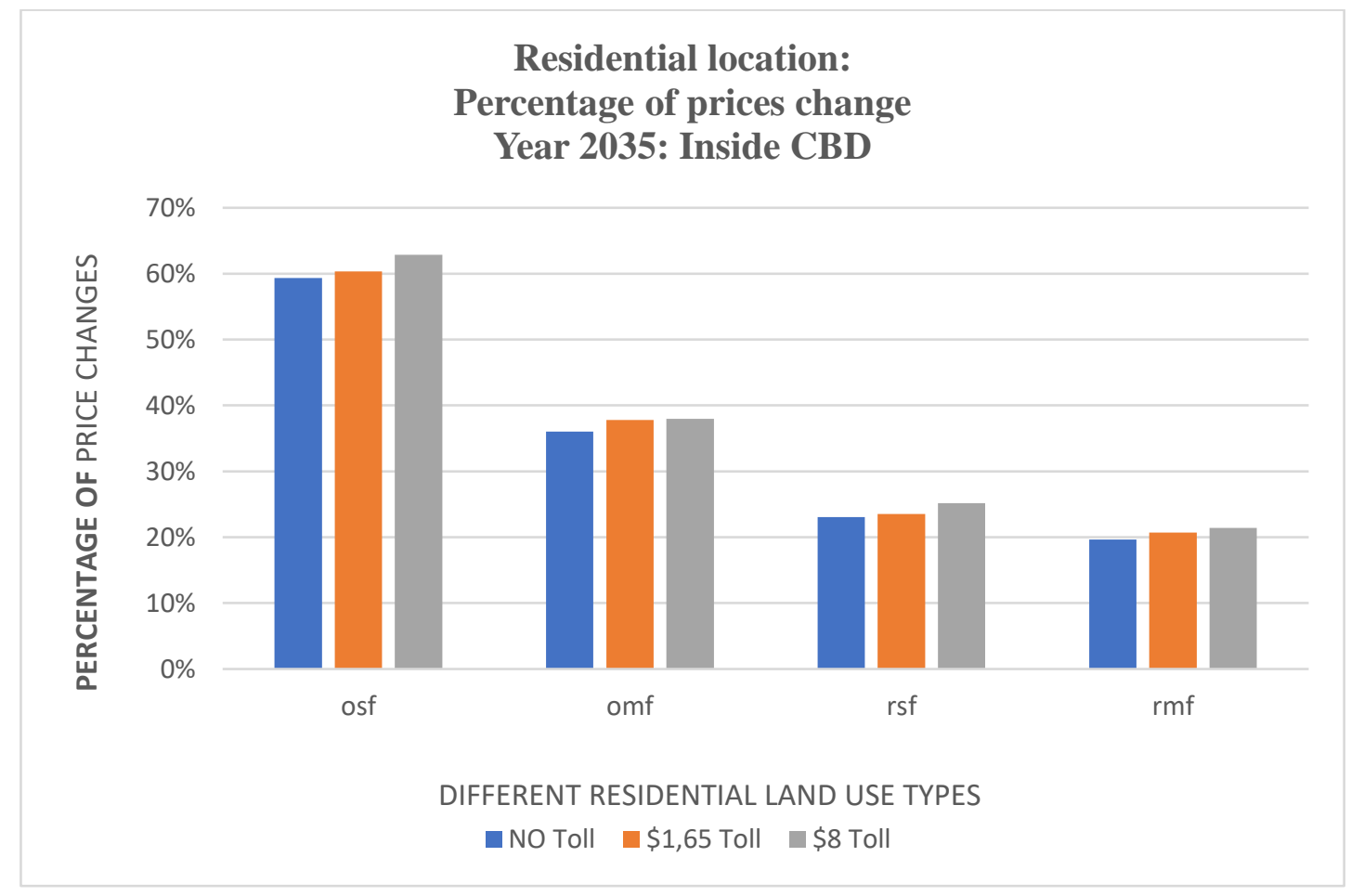

Figure 6.18

In a no toll scenario, all the residential real estate types show a large increase in relative property values, particularly for osf. 
After the implementation of $\$ 1.65$ and $\$ 8$ tolls, all the residential real estate classes show an additional relative price appreciation for all the housing types compared to no toll.

Generally, the higher the toll, the larger the relative price appreciation over time.

$\underline{\text { Right Outside the CBD Boundaries: }}$

An important question is whether households choose to relocate right outside the CBD once the cordon is implemented.

As reported at the beginning of this chapter, the analysis of the outside zones is divided into Westside, a predominantly residential and commercial neighborhood, and Eastside, where northeast is mainly industrial, and southeast is more a residential and commercial neighborhood.

Westside:

Figure 6.19 shows the percentage changes in prices under the three different scenarios for the zones outside the Westside boundaries in 2035. 


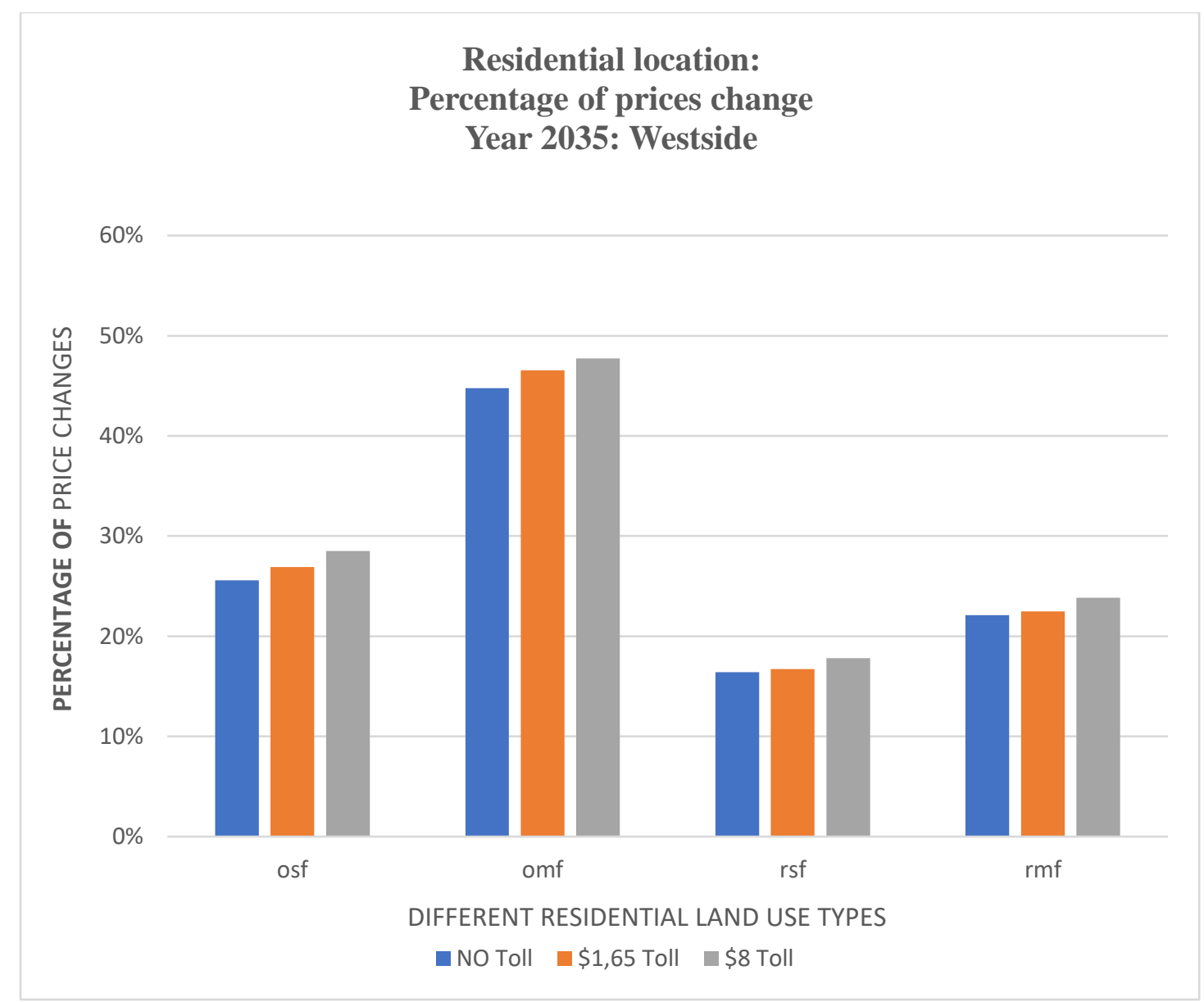

Figure 6.19

In a no toll scenario, ownership classes have the largest relative price increases, in particular multifamily units. However, generally all the residential real estate types show a relatively large increase in property values.

After the implementation of $\$ 1.65$ and $\$ 8$ tolls, all the residential real estate classes show an additional relative price appreciation for all the housing types compared to no toll. Generally, the higher the toll, the larger the relative price appreciation at the projected year. 
Eastside:

Figure 6.20 shows the percentage changes in residential location price, comparing the different scenarios for the zones outside the SE boundaries in 2035.

Figure 6.21 shows the percentage changes in residential location price comparing the different scenarios for the zones outside the NE boundaries in 2035 .

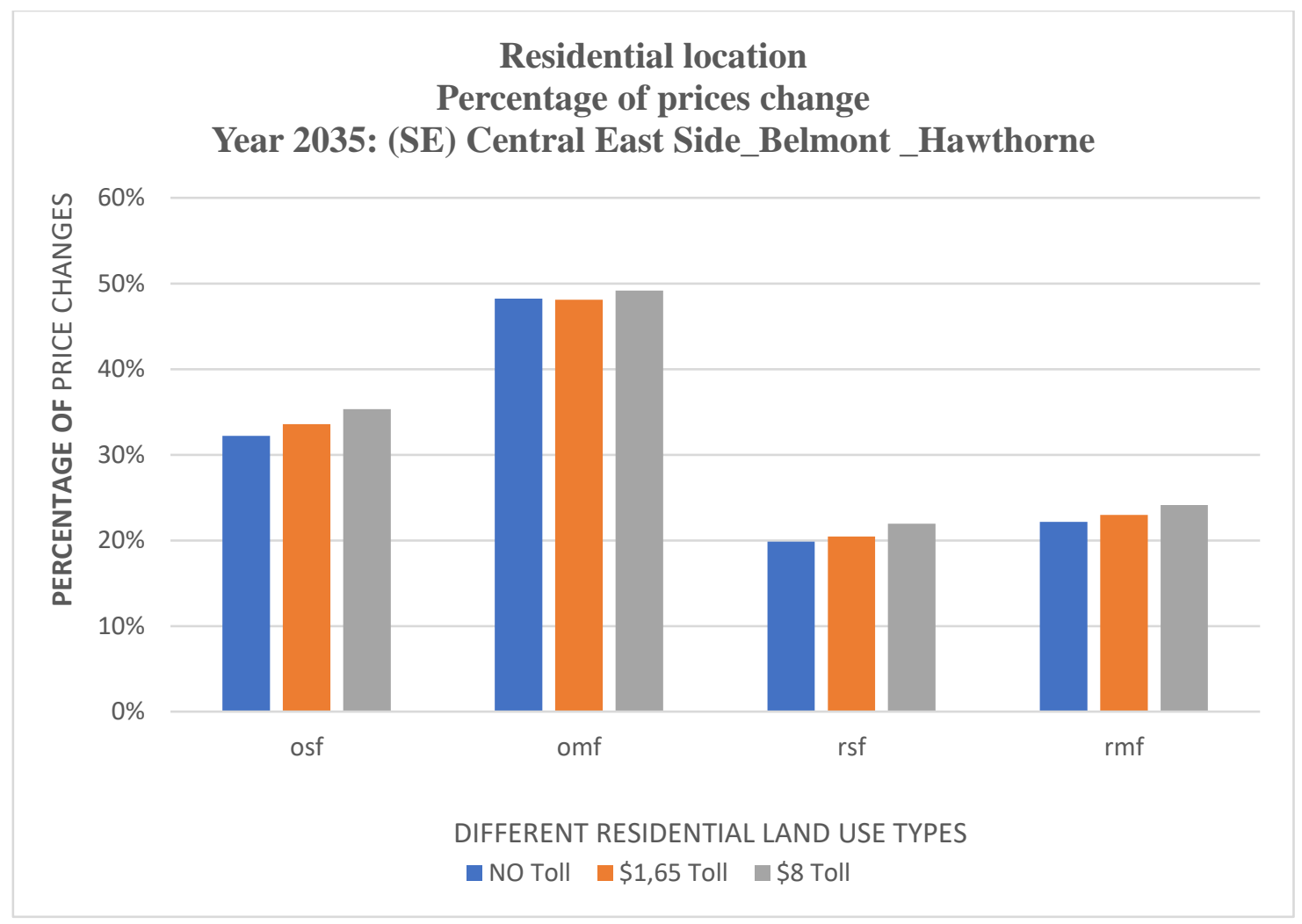

Figure 6.20 


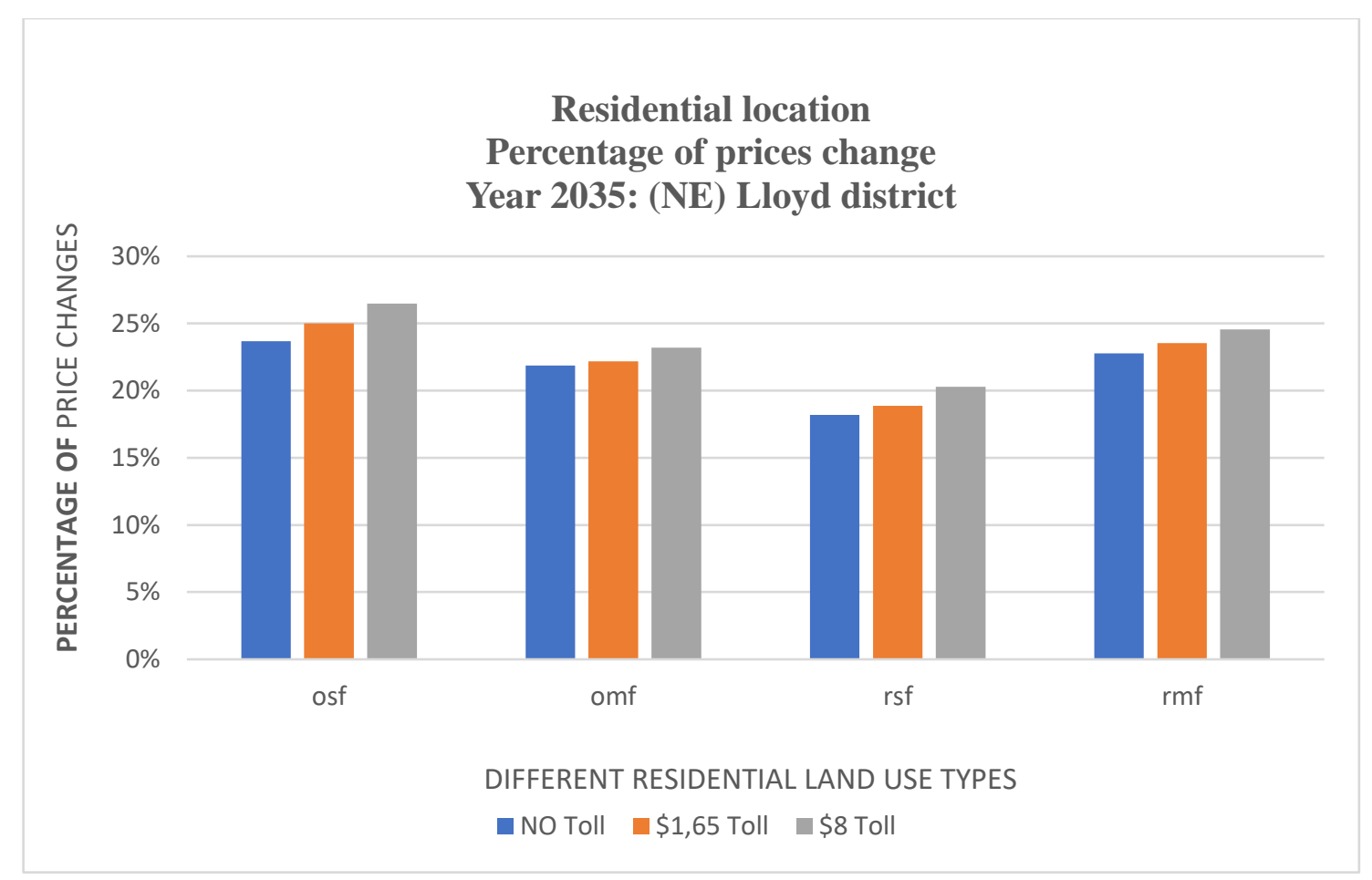

Figure 6.21

(SE) Central East Belmont/Hawthorne accounts for a relative price increase in all 4 real estate classes; ownership of multi-family homes is the real estate class with the highest price appreciation, followed by ownership of single-family homes.

Generally, ownership classes have the largest relative price increase.

After the implementation of $\$ 1.65$ and $\$ 8$ tolls, price indexes for all types of housing still increase compared to no toll. Generally, the higher the toll, the larger the increase in the price index compared to no toll in 2035. 
Similarly, in a no toll scenario, (NE) Lloyd district accounts for a relative price increase in all 4 real estate classes, but at a smaller magnitude than in the southeast. Price indexes increase in all 4 real estate classes.

After the implementation of $\$ 1.65$ and $\$ 8$ tolls, relative prices for all types of housing still increase compared to no toll, but when compared to the southeast, one can see that ownership of multifamily units increases about half.

Overall for all the real estate classes, there is a relative price appreciation; the higher the toll, the larger is relative price increase compared to no toll in 2035.

\section{Total Households' Supply}

In order to have a comprehensive view of changes in the residential location patterns, the next output analyzed is changes in the percentage of total households' supply before and after the implementation of toll cordons in 2035 . Inside the CBD:

Figure 6.22 shows the percentage changes in total households' supply inside the cordon boundaries after the implementation of toll cordons versus no toll in 2035 . 


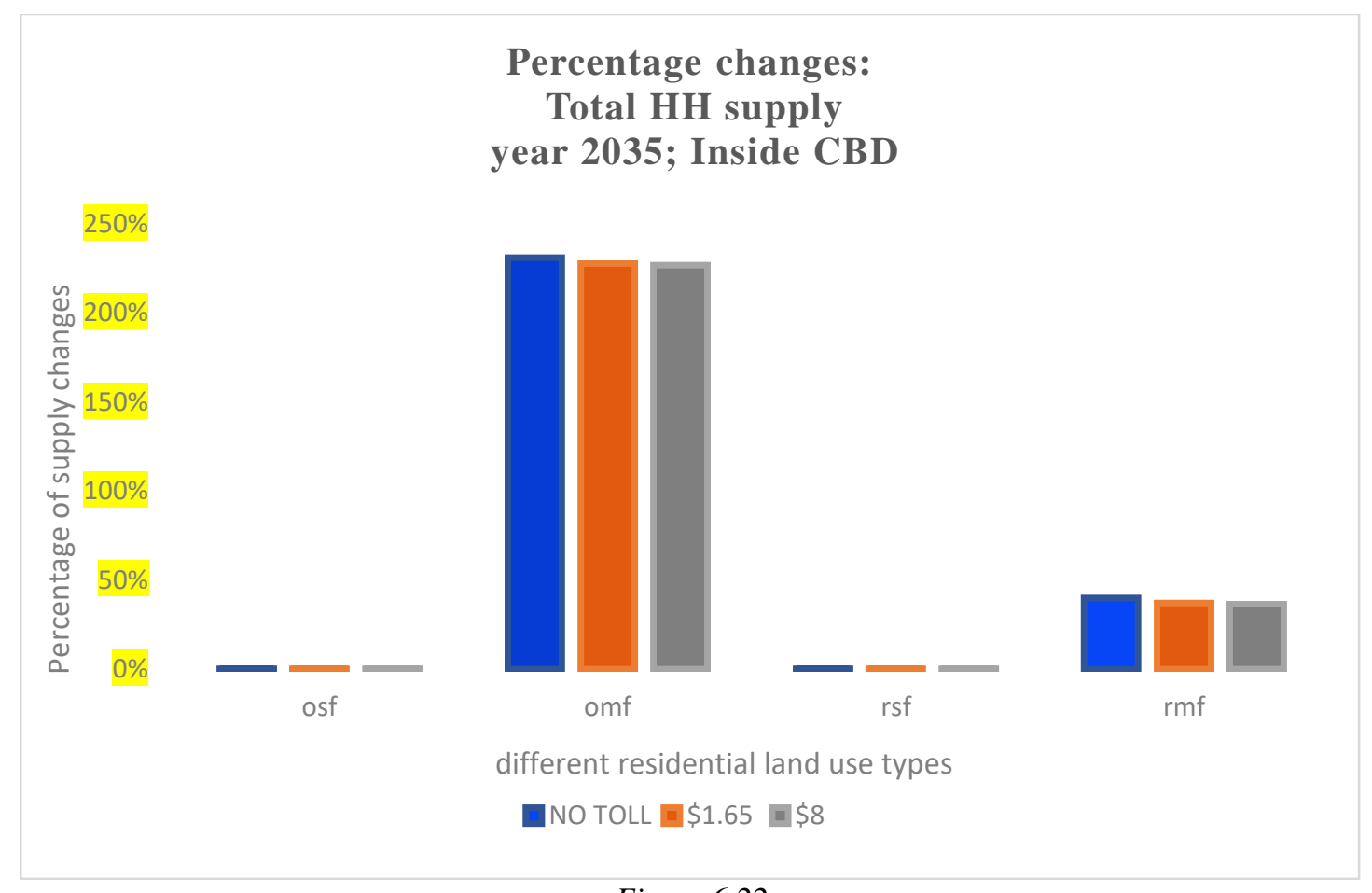

Figure 6.22

Under no toll, the CBD is projected to a growth in hh supply for owner-occupied multifamily housing units in a default scenario. Rental of multifamily housing increases only $40 \%$, compared to a $203 \%$ increase in the omf class. The increase in ownership supply of single-family homes is minimal, especially for osf.

After implementing toll cordons, it is noticeable how omf supply is forecasted to a drop that gets proportionally larger along with the toll price. Generally, the higher the price of the toll, the larger the negative effect on supply of multifamily units (owned and rentals) compared to no toll in 2035 . The supply of single-family housing basically does not change, with or without tolls. 


\section{Westside:}

Figure 6.23 shows the percentage changes in total households' supply for the zones outside the Westside boundaries after the implementation of toll cordons versus no toll in 2035.

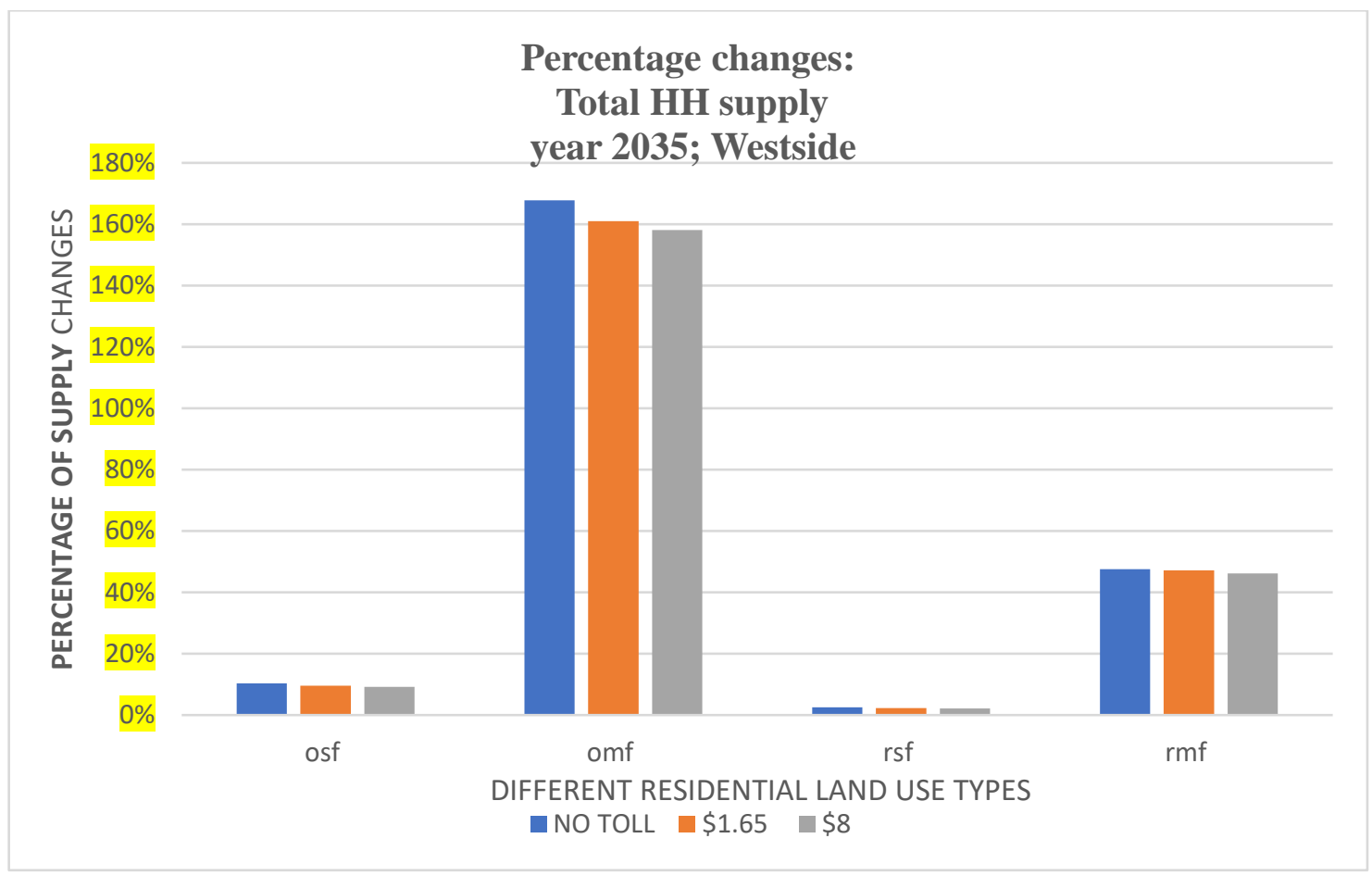

Figure 6.23

In a no toll scenario, supply of ownership multifamily housing grows exponentially. Rental of multifamily housing increases only by $50 \%$, compared to a $167 \%$ increase in omf. The increase in single-family-unit supply is minimal for both ownership and rentals.

After implementing toll cordons, it is noticeable how rmf supply is anticipated to drop; owner multifamily units has the largest decline in supply after an $\$ 8$ toll is implemented compared to a $\$ 1.65$ toll. Generally, the higher the price of the toll, the 
larger the negative effect on total supply compared to no toll. Toll reduces the supply for the other real estate classes as well, but the percentage drop is extremely small.

Eastside:

Figure 6.24 shows the percentage changes in total households' supply for the zones outside the SE boundaries after the implementation of toll cordons versus no toll in 2035.

Figure 6.25 shows the percentage changes in total households' supply for the zones outside the NE boundaries after the implementation of toll cordons versus no toll in 2035.

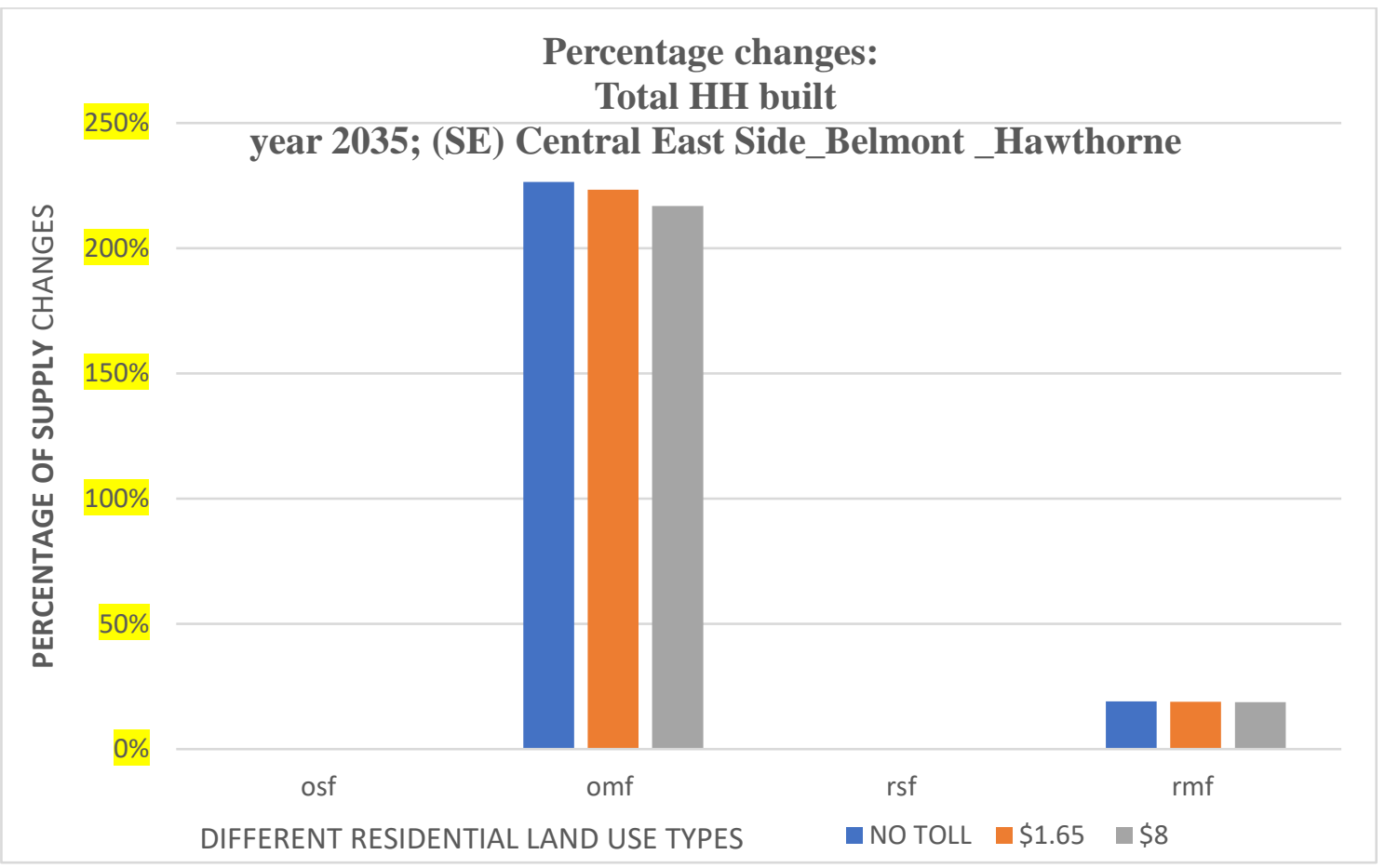

Figure 6.24 


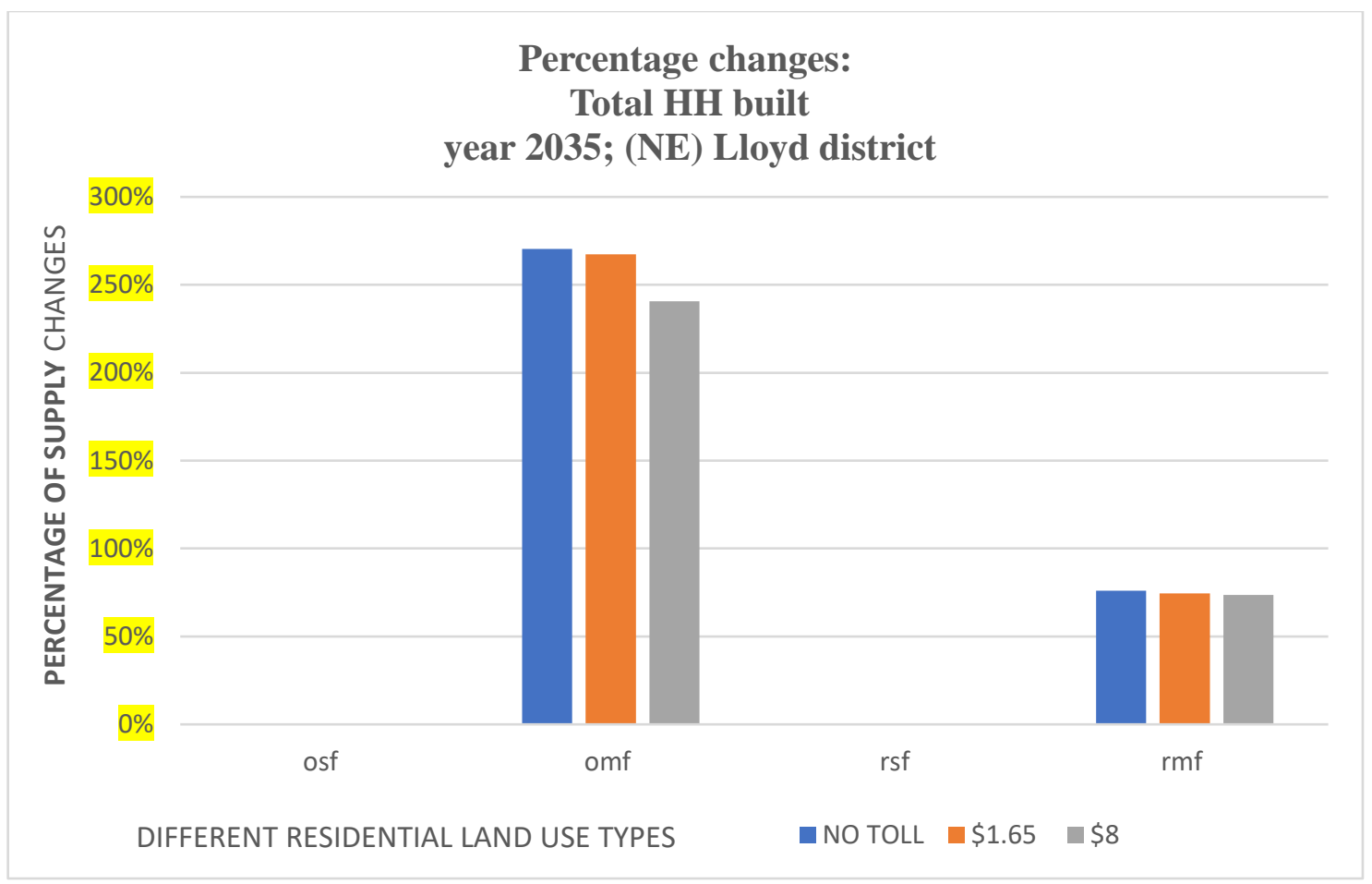

Figure 6.25

(SE) Central East Belmont/Hawthorne: in a no toll scenario, supply of ownership of multifamily housing grows exponentially. Rental of multifamily housing increases only by $19 \%$, compared to a $227 \%$ increase in omf. The increase in single-family-unit supply is minimal for both ownership and rentals.

After implementing toll cordons, the drop in rmf supply is noticeable; owner multifamily units have the largest decline in supply after an $\$ 8$ toll is implemented compared to a $\$ 1.65$ toll. Generally, the higher the price of the toll, the larger the decline in supply compared to no toll. Tolls reduce the supply for the other real estate classes, but the percentage drop is extremely small.

(NE) Lloyd District: in a no toll scenario, supply of ownership of multifamily housing grows exponentially. Rental of multifamily housing grows only by $76 \%$, 
compared to a $270 \%$ increase in omf. The increase in single-family-unit supply is minimal both for ownership and rentals.

After implementing toll cordons, it is noticeable how rmf supply is projected to decline; owner multifamily units has the larger decline in supply after $\$ 8$ toll is implemented compared to $\$ 1.65$. Generally, the higher the price of the toll, the larger the magnitude decline in supply compared to no toll. Tolls reduce the supply for the other real estate classes, but the percentage drop is extremely small.

Generally, it can be stated that the implementation of a cordon design within the CBD of Portland has an impact on non-residential and residential land use patterns. Tolls impact real estate demand, employment, and household demand, and land use patterns both inside the CBD and in the areas right outside the boundaries.

Demand is more sensitive to the implementation of toll cordons than supply. Supply is inelastic, so that changes in demand mostly affect prices. Supply is assumed to be less reactive because of the existence of an UGB in Portland, which causes supply to act fixed.

The presence and size of a cordon caused alterations in residential and nonresidential land use patterns, although the similarity of the $\$ 1.65$ and $\$ 8$ toll results is very interesting. Such different charges nevertheless generate very similar outcomes. One assumption is that MetroScope mitigates the impact of such different tolls by changing the distribution of the trips that are impacted by the tolls. Overall, after the implementation of a Small cordon, non-residential location demand, employment, and household demand are projected to decline compared to the default alternative in the area inside the CBD and right outside the West side of the cordon. Nevertheless, the same 
variables are forecast to an overall increase across the Willamette River, in the zones bordering the east part of the cordon. Households with children show an increase in demand for housing only in the east part of the cordon.

Residential location prices increase within the cordon as well as outside of it in the West and East zones. It could be assumed that there could be a shift of commercial activities (businesses and Communications specifically) and household demand for housing toward the East side of Portland as a consequence of the implementation of a cordon around the CBD. Nevertheless, it could create new agglomerations or dispersion of activities beyond those areas or merely create a redistribution effect initiated by the toll.

The next section will provide an overview of land use changes within the whole city of Portland, to investigate whether there is a net improvement in economic growth and residential demand or merely a redistribution of activities and population from one area to another.

This analysis could be of foremost interest for the city of Portland by representing a first step toward the evaluation of a toll cordon as a policy aimed to support economic development for the city.

\section{Inside the Entire City of Portland:}

$\underline{\text { Non-Residential Land Use: }}$

Figure 6.26 shows changes in non-residential location price indexes in Portland after the implementation of $\$ 1.65$ or $\$ 8$ toll cordons around the CBD compared to a no toll scenario in 2035. 


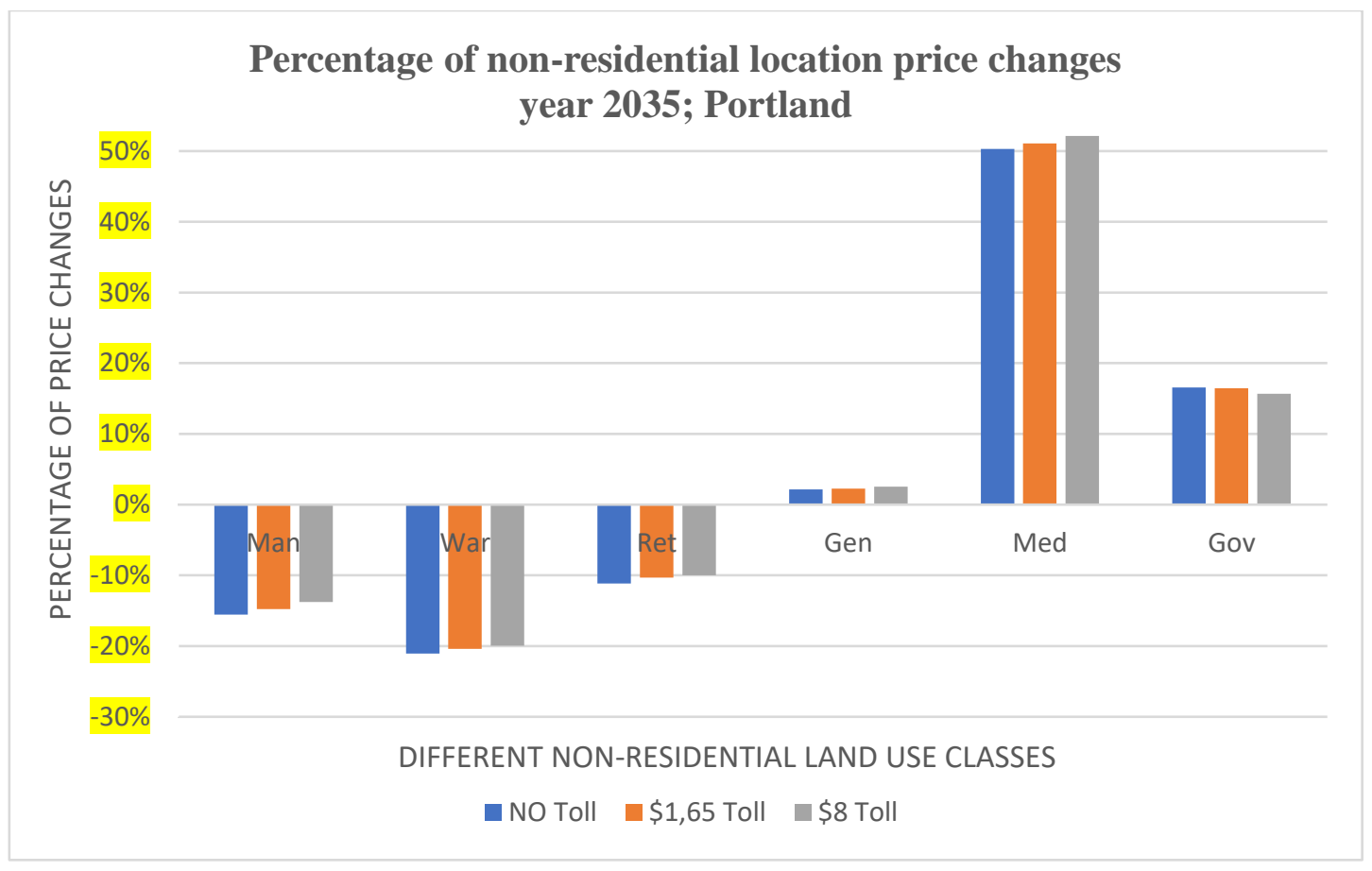

Figure 6.26

Under a no toll scenario, only Medical, Government, and General offices are projected to a relative price appreciation. Industrial activities show a relative decrease in prices over time.

Once $\$ 1.65$ or $\$ 8$ tolls are implemented, price indexes for all the types of industries still grow, with the only exception of Government office. Medical services report a further relative value appreciation, while Manufacturing and Retailers' relative price depreciation is dampened an average of $2 \%$ by the toll in 2035 .

\section{Total Employment Changes}

Figure 6.27 shows changes in employment within the entire city of Portland after the implementation of $\$ 1.65$ and $\$ 8$ toll cordons around the CBD compared to a no toll scenario in 2035. 


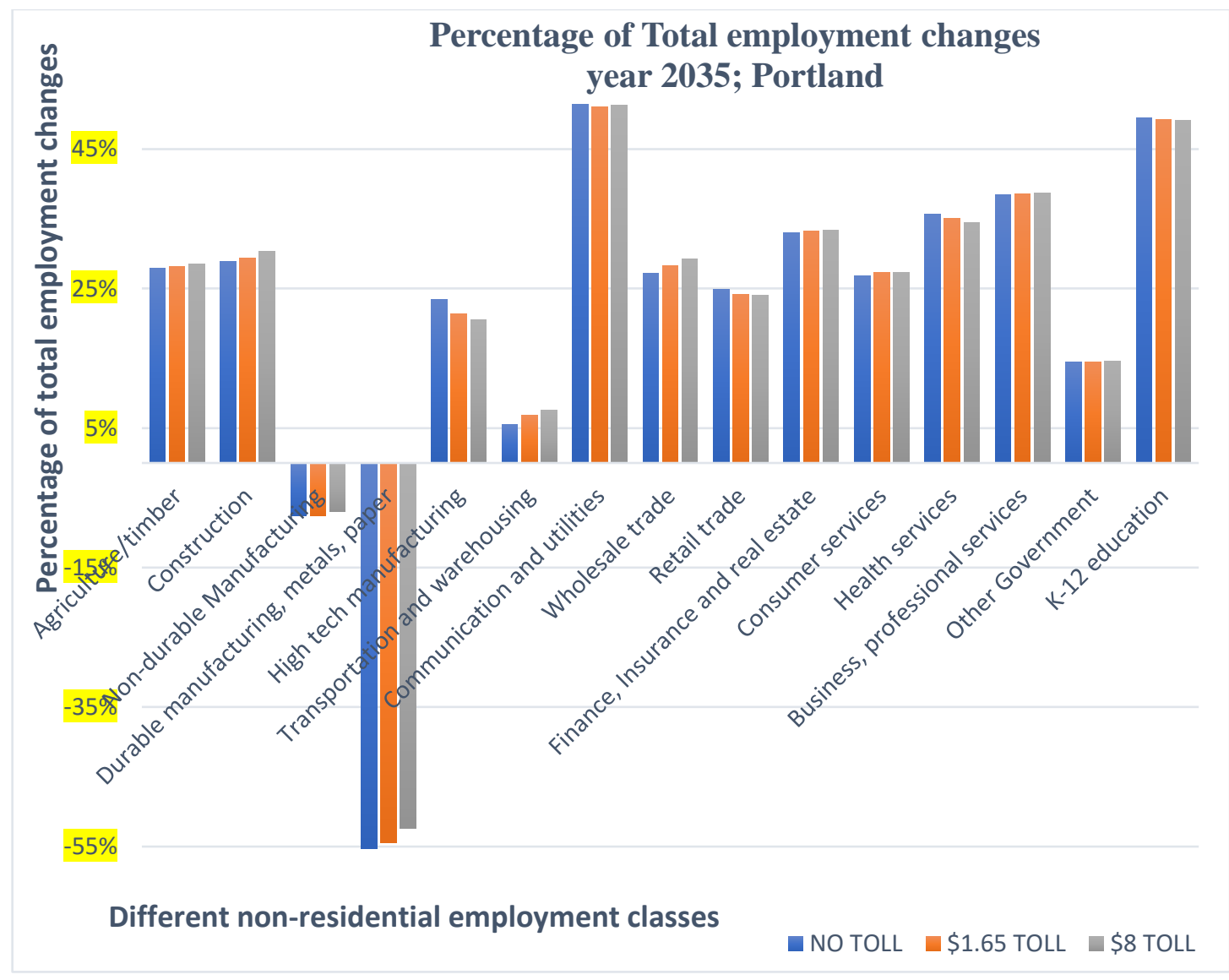

Figure 6.27

Under no toll, only Durable and Non-durable manufacturing industries are projected to a decline in employment, with a loss of $7.6 \%$ and $56 \%$, respectively. All the other employment classes have an increase. Employment grows $49.5 \%$ in K-12 education and $51.5 \%$ in Communication/Utilities, while the class with the smallest demand surge is Transportation/Warehousing (5.5\%). Overall, higher-value economic activities are projected to larger increases over time.

After toll cordons are implemented, employment for High-tech manufacturing has the largest decrease compared to a default scenario. Employment decreases only in few more industries, such as Retailers, Health services, and K-12, under tolls compared to no tolls, although the percentage of difference between the scenarios is very small. 
Employment in all the other industries is positively influenced by tolls compared to no toll in 2035.

Overall, a toll cordon seems to positively move up employment for the majority of industries within the entire city, increasing the likelihood of possible economy agglomeration outside the cordon perimeter but still within Portland.

\section{Percentage Changes in HH Location Demand}

Figure 6.28 shows how a Small cordon influences location demand for families without and with school-age children inside the entire city of Portland compared to no toll in 2035.

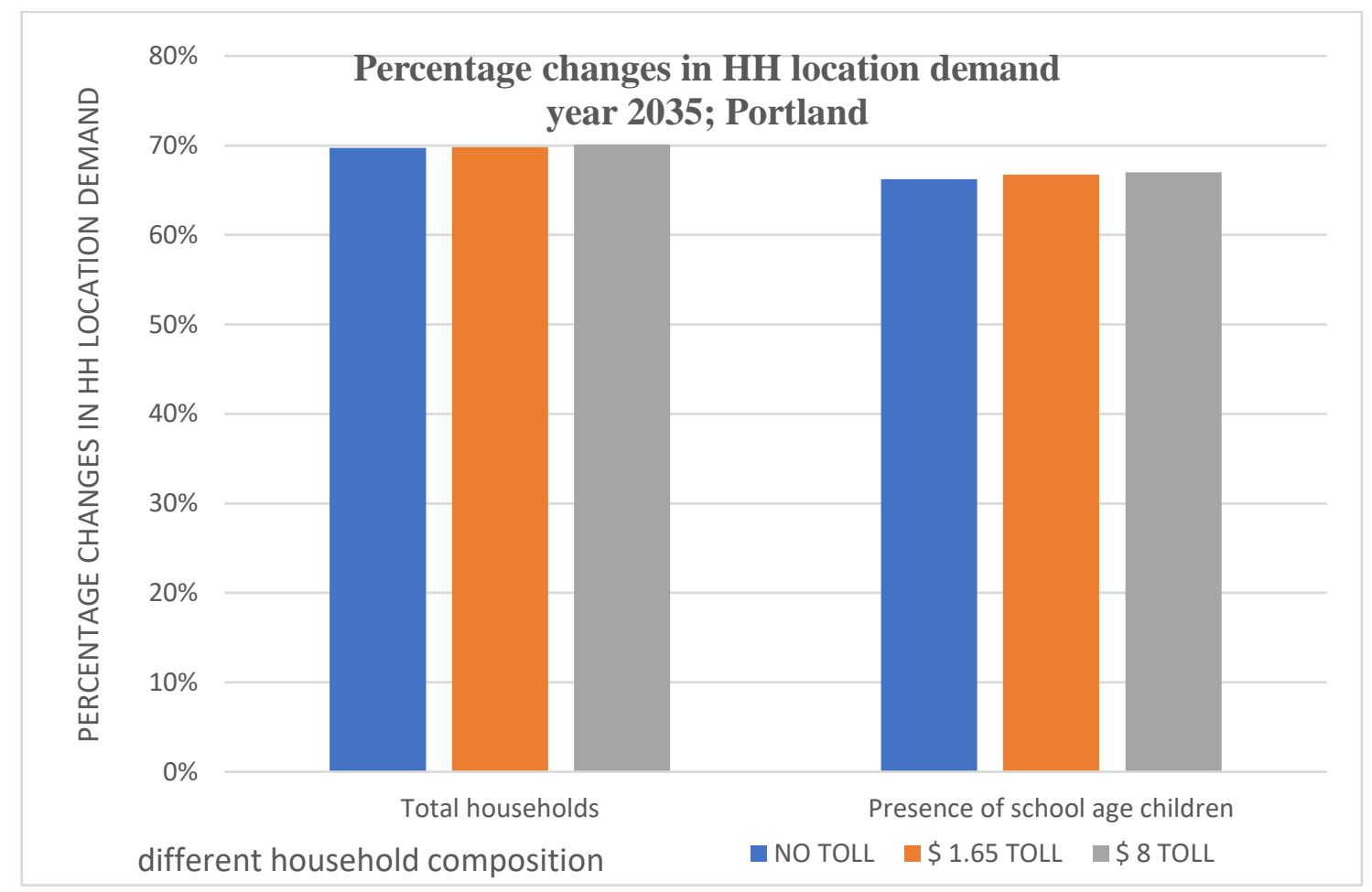

Figure 6.28

In a no toll scenario, total households' demand for housing grows over time. Once that toll cordons are implemented, total household demand (with and without children) is 
projected to a minor $1.5 \%$ additional demand growth that is slightly larger as the toll increases, compared to the default scenario. Generally, a toll cordon increases hh demand for housing inside Portland.

\section{Total sqft Supply}

Figure 6.29 shows how a Small cordon influences total sqft supply inside the entire city of Portland compared to no toll in 2035.

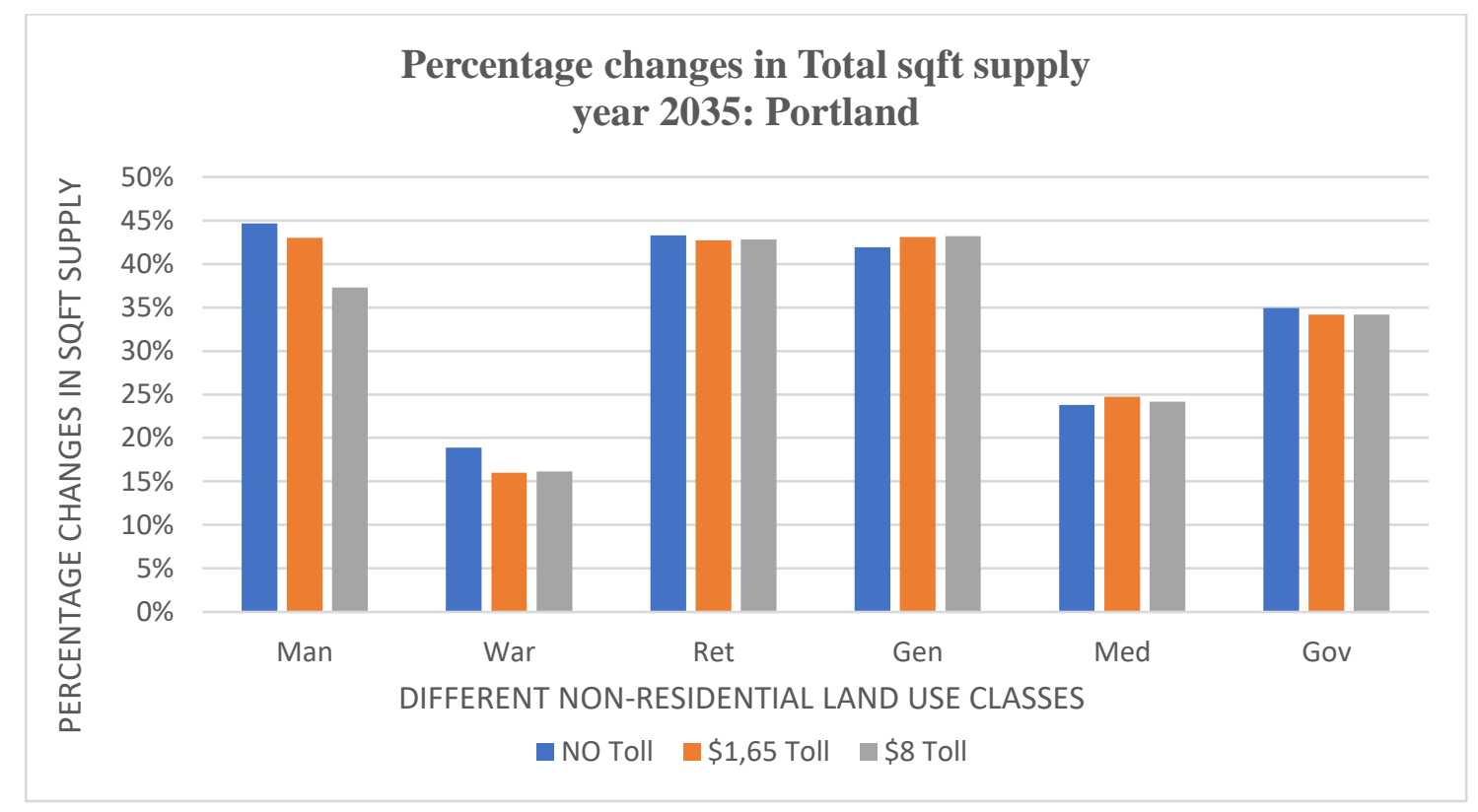

Figure 6.29

Under no toll, Manufacturing, Retailers, and General offices are projected to the largest increase in sqft supply (above 40\%), while Warehousing has the smallest growth at slightly below $20 \%$.

Once a cordon is implemented, only Manufacturing is forecast to a big decline in sqft supply as a consequence of the toll; the higher the toll, the larger the decline in sqft supply. 
Warehousing shows a small drop in total sqft available as a consequence of the toll, while the other industries are only marginally affected by the tolls compared to no toll in 2035 .

It is important to point out how changes in sqft supply are very similar for all nonresidential real estate types (except for Manufacturing) after the implementation of two different tolls, \$1.65 and \$8.

Generally, the implementation of the tolls does not significantly influence sqft supply compared to no toll. A toll cordon has a greater influence on demand more than supply variables. Possibly, the presence of an UGB in the region makes supply behave as fixed.

\section{$\underline{\text { Residential Location Prices }}$}

Figure 6.30 shows changes in residential location price within the entire city of Portland after the implementation of $\$ 1.65$ and $\$ 8$ toll cordons around the CBD compared to a no toll scenario in 2035 . 


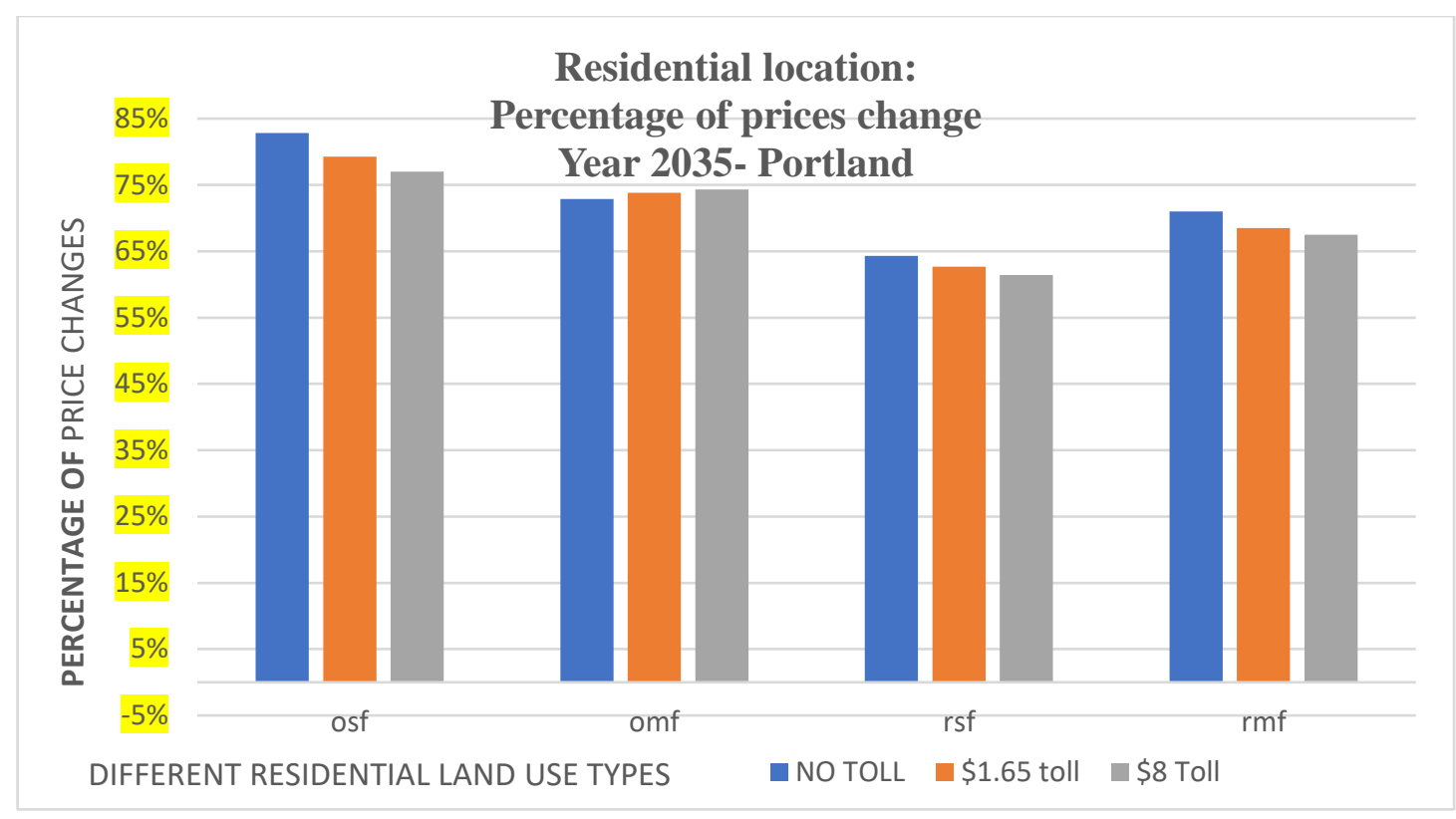

Figure 6.30

In a no toll scenario, ownership classes have the larger relative price increases, in particular osf. Although, generally, all the residential real estate types show a large increase in property value index within the entirety of Portland.

After the implementation of $\$ 1.65$ and $\$ 8$ toll cordons around the CBD, relative prices still appreciate but at a lower proportion than no toll; all 4 real estate classes have a relative loss in value compared to the default scenario. Generally, the higher the toll, the larger the relative price depreciation compared to no toll after 25 years.

\section{Total Households Supply}

Figure 6.31 shows changes in residential supply within the entire city of Portland after the implementation of $\$ 1.65$ and $\$ 8$ toll cordons around the $\mathrm{CBD}$, compared to a no toll scenario in 2035 . 


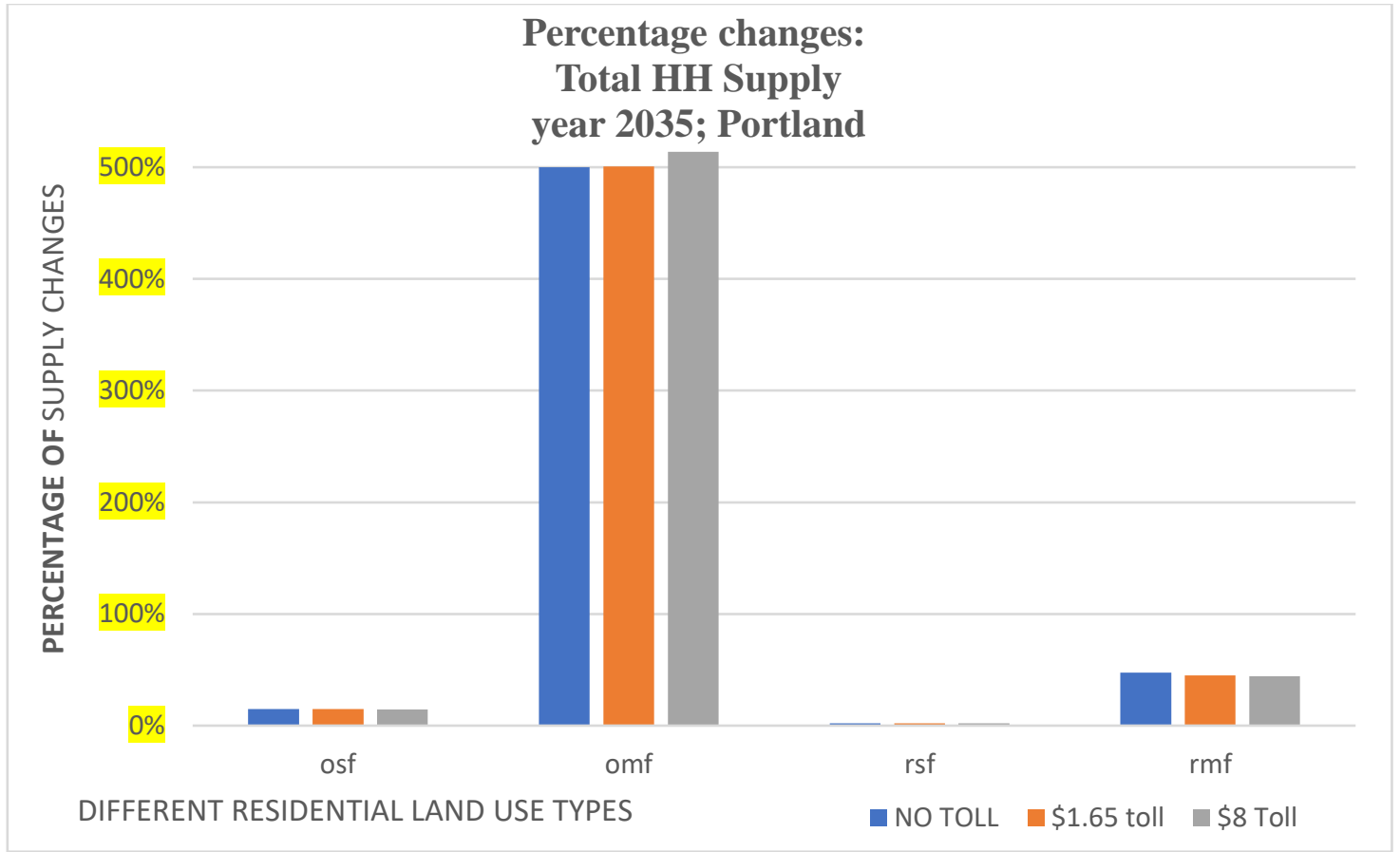

Figure 6.31

In 2035, the entire city of Portland is projected to a maximum growth in hh supply for owner-occupied multi-family housing units in a no toll scenario. Rental of multifamily housing increases only $47 \%$, compared to a $499 \%$ increase in omf. Supply increases for single-family units is minimal.

After implementing toll cordons, it is noticeable how rmf supply is forecasted to a further $14 \%$ growth under an $\$ 8$ toll.

\section{Summarizing the Effects of the CBD Cordon}

Generally, the implementation of a toll cordon around the CBD has a positive effect on commercial property demand within the entire city of Portland (with the exception of Government properties) compared to no toll. Relative prices for industrial and commercial activities increase, as does employment for many industries after a toll 
cordon is implemented compared to the default scenario at the city level. Total $\mathrm{HH}$ demand for housing increases as well.

Differently, residential location price indexes are projected to an overall decline within the entire city, with the exception of omf. Nevertheless, in the zone close to the East side of the boundary, residential values grow over time, indicating a change in residential land use patterns that could lead to a speculation about a household relocation trend.

Generally, Business, Financial/Insurance/Real estate, and consumer activities are projected to an increase in their employment both in the East and in the entire city of Portland. It seems that changes in employment in the East of Portland follows the lead of changes at the city level.

It can be speculated that tolls boost Service and Commercial activities, while other industries, such as Retail, High-tech manufacturing, Health services, and K-12 education, have a decline compared to no toll in 2035.

Land supply shows substitutivity between purposes and industries.

Since this paper focuses on the city of Portland, these results could be of great interest for politicians in evaluating different alternatives to boost development, or just to support development in targeted areas.

\section{Metro Areas Outside of Portland, OR}

The last part of the analysis focuses on land use changes in the metro cites surrounding Portland after the implementation of the CBD cordon compared to a no toll alternative in 2035 . 
It is not the main target of this study to provide a comprehensive analysis of the metro area; this research focuses on the city of Portland. However, a brief overview of the effect outside of Portland gives a broader understanding of the land use effects after the implementation of a cordon around the CBD compared to no toll in 2035. After the Implementation of Toll Cordons Compared to a Default Alternative:

Generally, non-residential location prices relatively increase for many industries in the West part of the metro area. Tanasbourne/Bethany is projected to experience a relative price appreciation in each industry, followed by Hillsboro/Orenco and Beaverton/Tigard, which report drops in relative value only for General offices and Government activities, respectively.

In the East side, Happy Valley/Milwaukie is projected to a relative price drop in all industries but Manufacturing and Government activities, while Gresham has a relative decline only in Manufacturing and General offices.

Lake Oswego has a relative price drop for commercial properties, though at a very small degree, after the implementation of a Small cordon.

Hillsboro/Orenco has the largest number of industries projected to an increase in employment after the implementation of tolls compared to no toll. Employment grows in almost all economic activities, with the exception of Business services and K-12 education. In detail, Transportation/Warehousing and Wholesale trades report the largest percentage increase in employment after a cordon is implemented compared to no toll.

Also, Happy Valley accounts for a large number of industries forecast to a growth in employment. 
All the other cities display an overall negative effect on employment once a cordon is implemented around the CBD compared to no toll in 2035.

HH location demand increases only in Tanasbourne/Bethany and Gresham, as does residential location demand for all housing types; especially ownership of singlefamily units, which has the largest decrease in relative value.

Sqft supply does not contain any important changes after a toll implementation, except in Happy Valley/Milwaukie there is a larger decline in sqft avalaiblity for Warehousing and General office after the Small cordon is implemented versus no toll in 2035.

Generally, there is a decline in residential supply for the ownership of multifamily family units in the entire metro area as a result of a toll implementation. 


\section{Central City or Mid cordon}

The Mid-size cordon is mainly designed around the Central city of Portland as defined from Metro, the city of Portland, and the Bureau of Planning and Sustainability (2011). After evaluating many different Mid-size cordon options, the most suitable one to satisfy the research goal and to match the MetroScope zoning partition map is identified with the Central city of Portland. As explained in a previous chapter, the main goal of this research is to compare three different sizes of cordon areas (Small, Mid-size, and Big) coupled with different charges to understand the effects that the implementation of a cordon line has on residential and non-residential land use and economic development. The criteria used to define Central city, as well as other surrounding areas, derive from Metro's (2011) identification and grouping of relatively permanent geographies of Portland into six "subareas,"

${ }^{6}$ The six Portland subareas are listed below (Portland Plan, p.18, 2011) as shown in map 1:

1. Portland Central Area - while MetroScope uses the term "CBD" for "Central business district," this subarea includes only these parts of the Central City plan district: the downtown core, Pearl District and other areas within the I-405 freeway loop on the west side of the river; east of the river, the Rose Quarter transit and entertainment area north of Interstate 84.

2. Northeast Portland - north of I-84, west of Vancouver Avenue: most of the NE quadrant of the city.

3. East Portland - primarily east of I-205, south of Sandy Boulevard.

4. Southeast Portland - west of I-205, south of I-84, and including the Central Eastside industrial sanctuary (which is a subdistrict of the Central City plan district)

5. West Portland - west of the I-405 freeway loop, and south of Forest Park and the Route 30/industrial sanctuary area along the river.

6. North Portland - the northern "quadrant" of the city plus the Forest Park/Route 30/industrial sanctuary area southwest of the river but not included in the West subarea. 


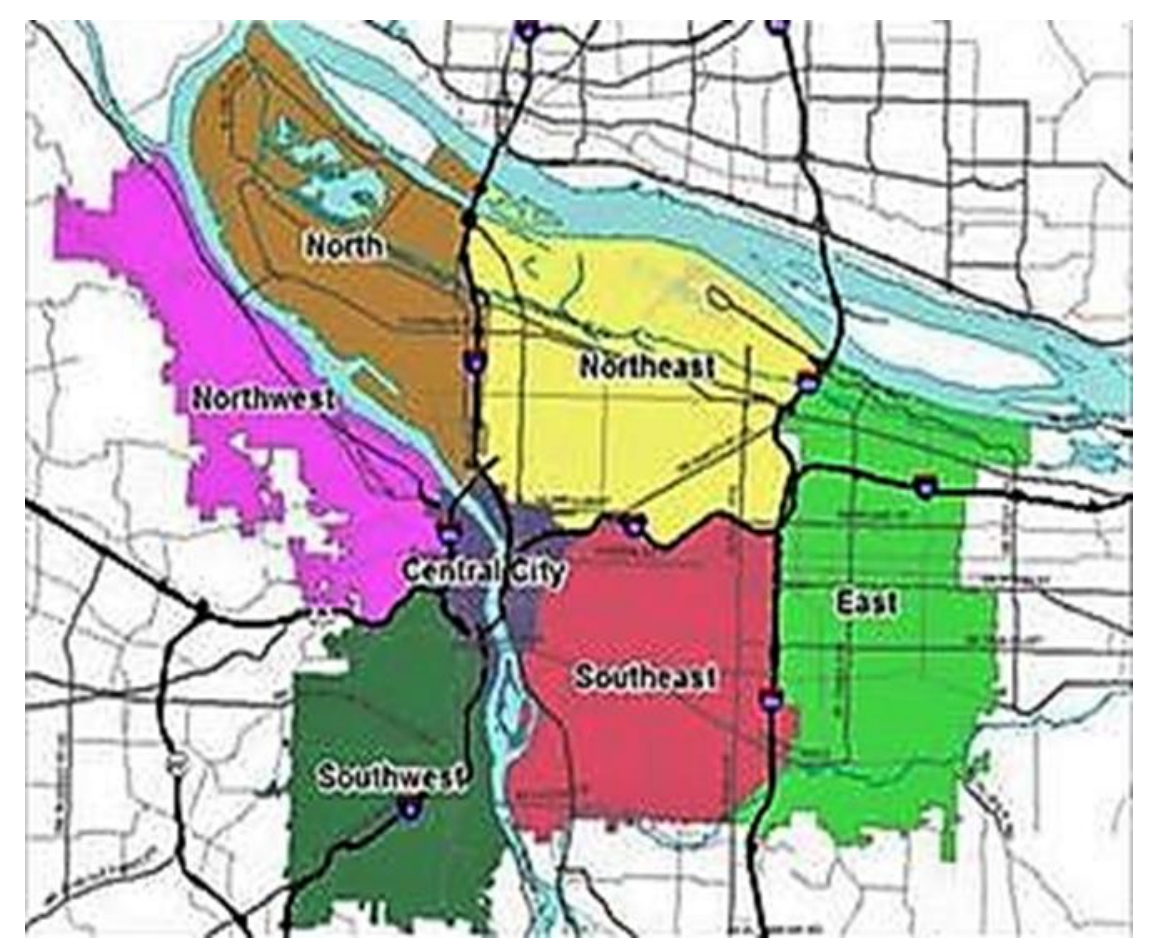

Figure 7.1 Sub Areas in Portland, OR

Source: The Portland Plan

The design of the Mid-size cordon was quite a challenge (same as it was for the Small cordon). MetroScope's application of the six subarea boundaries to Portland matches with neither the City of Portland's planning districts nor with its neighborhood association boundaries, and therefore it should not be mistaken with these designations. Rather, "the model's subarea boundaries are combinations of Census data tracts, because much of the data in the forecast originates in Census data" (The Portland Plan, p.17, 2011). Even so, the six subareas can be easily understood as five basic quadrants of the city surrounding the transportation and business hub at the center. Therefore, it felt natural to identify the Mid-size cordon with the Center of the city. See Figure 7.2. 


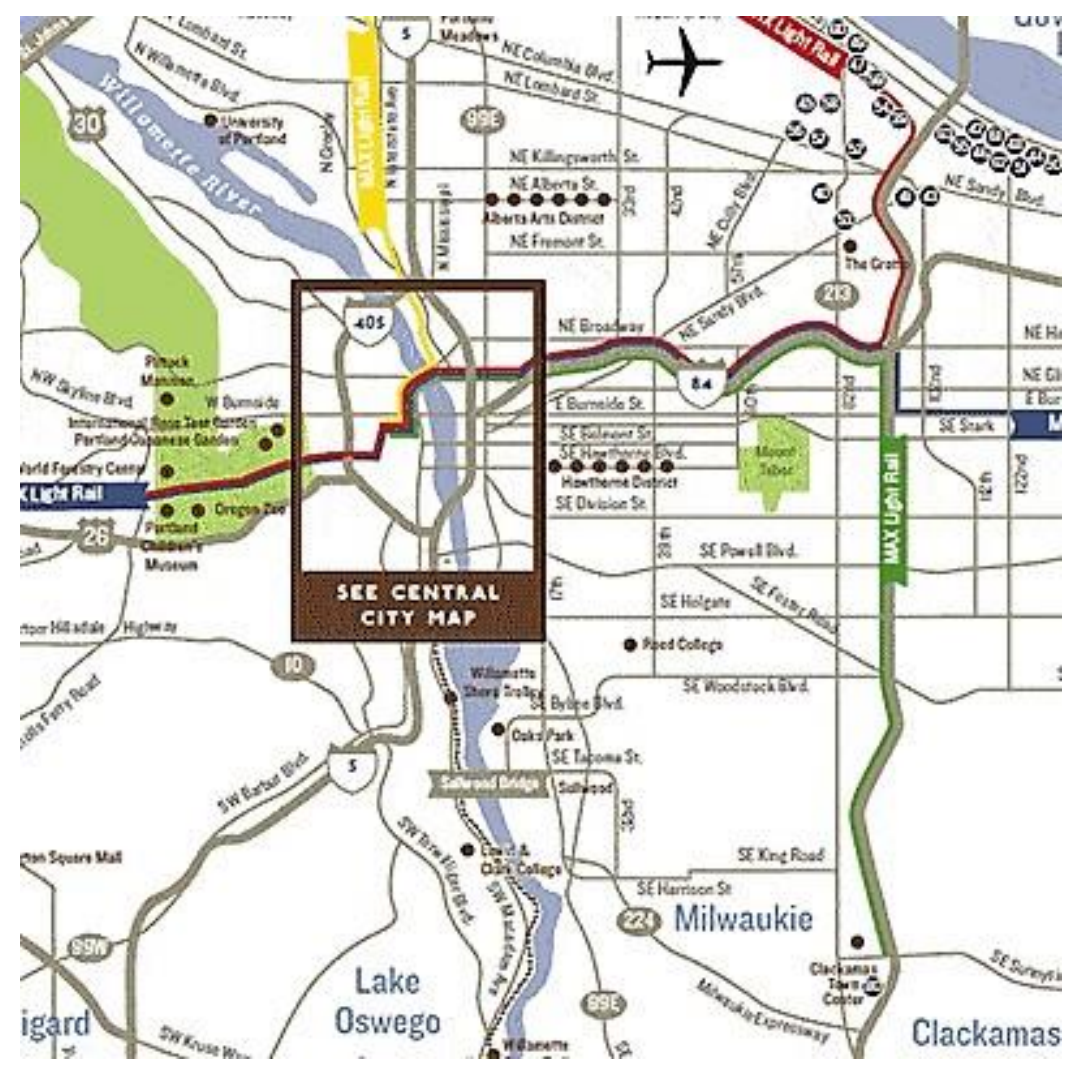

Figure 7.2 Central City District, Portland, OR

Source: The Portland Plan

Although, because of the lack of coordination between the city's designated planning boundaries and MetroScope subarea boundaries, the Central City district does not perfectly overlap with the Mid-size cordon, though they are similar in geographical boundaries, as show in Figure 7.3. The Mid-size cordon is defined by the red line boundaries, while the Central City subarea is the whole dark grey area (within which the red line of the Mid-size cordon is embedded) labeled as "Central City". 


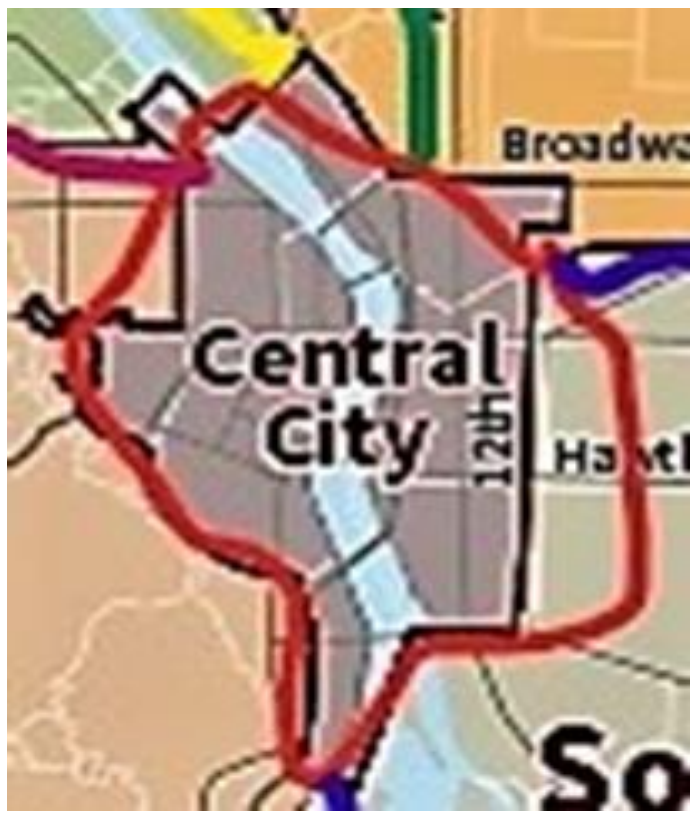

Figure 7.3 Zooming of the Central City District, Portland, OR

Source: The Portland Plan

The same challenge faced during the selection of the Small cordon design applied to the selection of the Mid-size cordon boundaries, as the MetroScope model has been designed to have a total of 425 residential zones inside the Portland region, but it has only 72 non-residential zones. The discrepancy of the sizes of residential and non-residential zones was a challenge at the time of designing the limits of each cordon scenario. The choice of residential and non-residential zone boundaries had to perfectly overlap to avoid any bias in the results. The same issue applied to the selection of the areas outside the cordon, so that the results compared are from an identical geographical area.

In detail, the Mid-size cordon is shown in Figures 7.3, 7.4, and 7.5 at different scale dimensions (the areas inside the red line). 


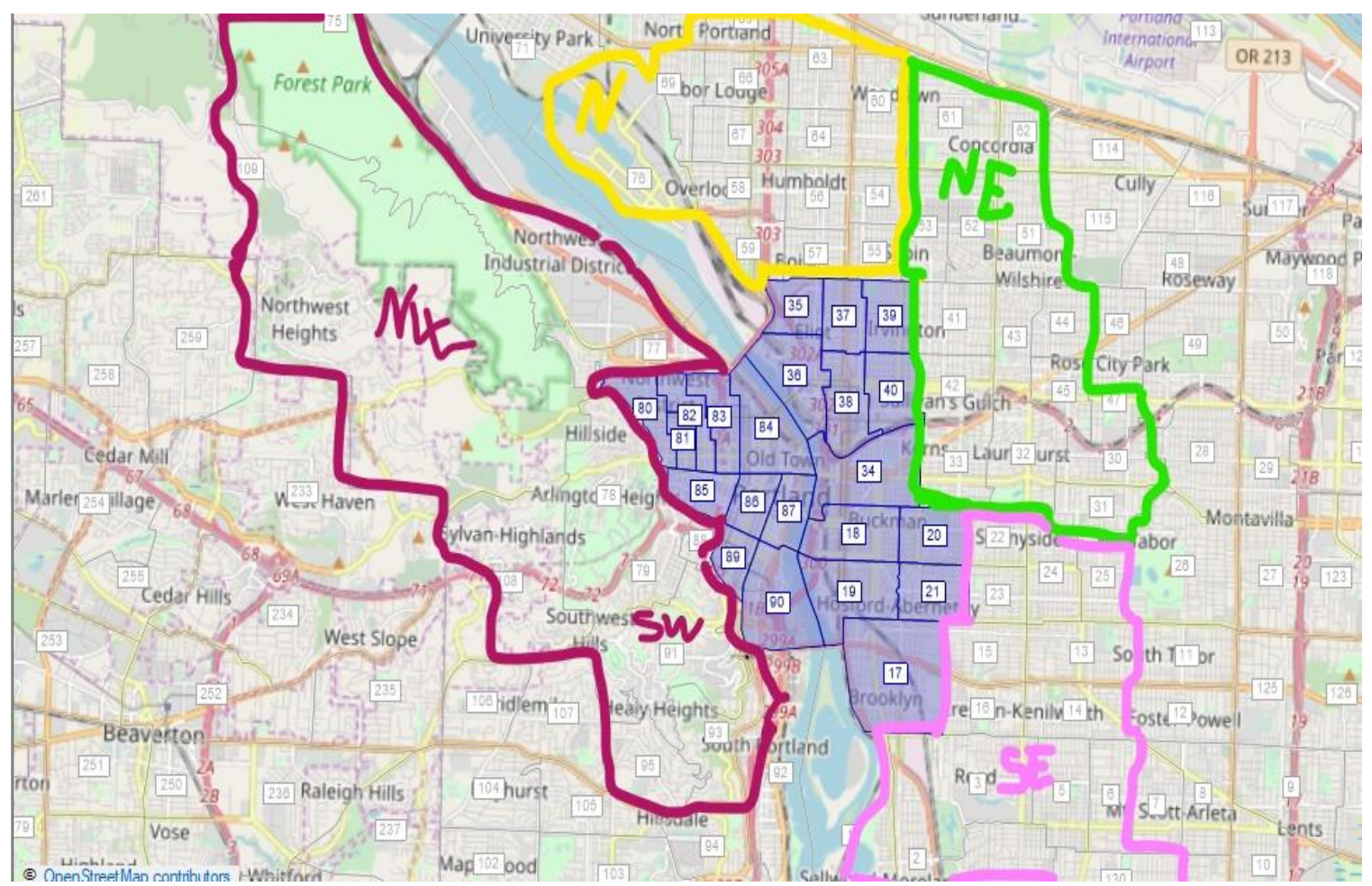

Figure 7.4 Central City or Mid-size Cordon: Whole Blue Area, Portland, OR

Source: PTV Visum (MetroScope)

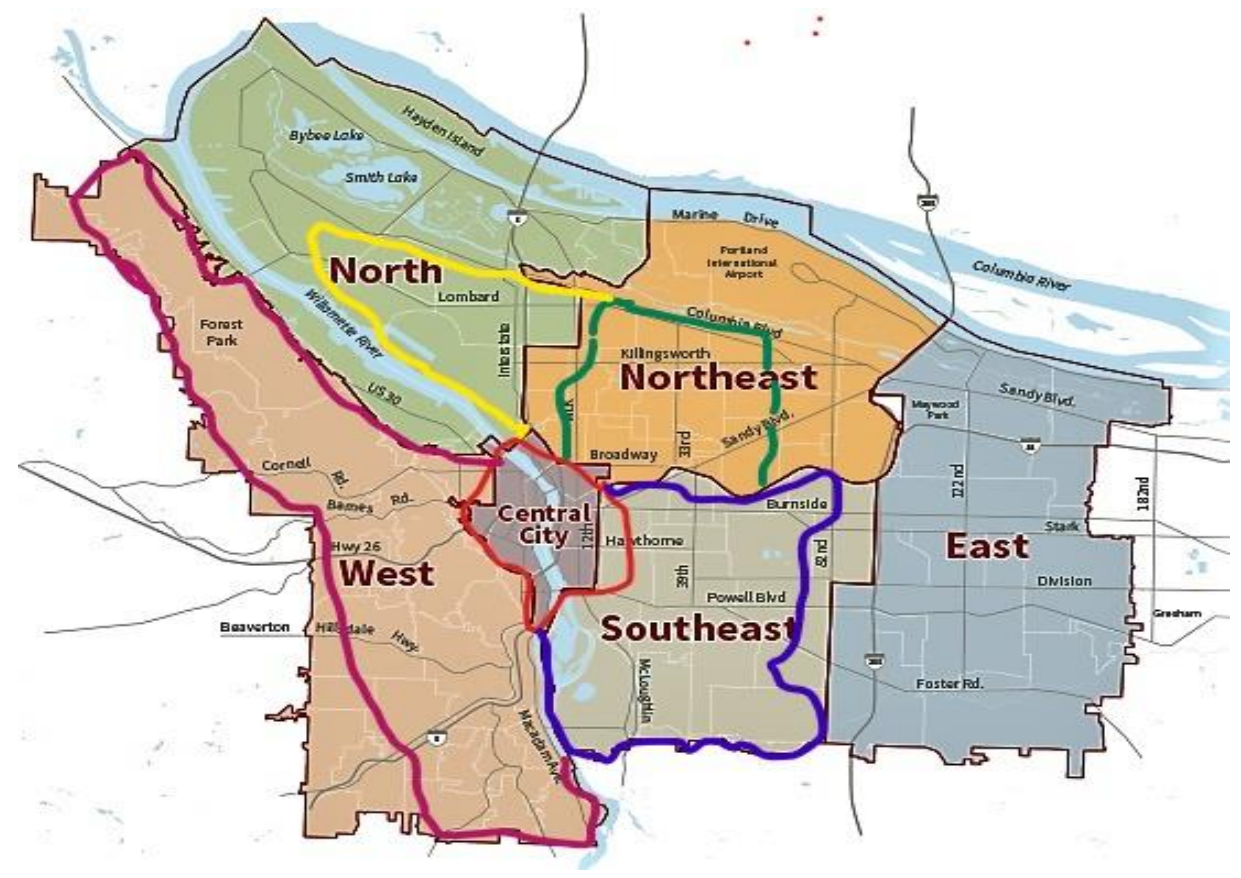

Figure 7.5 Selection of Portland Main Zones Compatible with MetroScope ezones and rzones

Source: The Portland Plan 
To better understand the effects of the implementation of a cordon toll on land use, the output analyzed is divided into 5 main zones, as shown in Figure 7.5.

1. Land use changes inside the cordon area or "Central City."

2. Land use changes outside the cordon, focusing on the zones that border with the cordon on the Westside. Mainly, West Portland bordering with the Small cordon (Figure 7.5, area circumscribed within the purple perimeter that sums up Northwest and Southwest is labeled WEST). Note that West Portland is the same area used in the small cordon analysis.

3. Land use changes outside the cordon, focusing on the zones that border with the cordon on the Eastside.

3.1 Southwest Portland (see Figure 7.5, area circumscribed within dark blue and labeled as SOUTHEAST (SE).

3.2 Northeast Portland (see Figure 7.5, area circumscribed within dark green and labeled as NORTHEAST (NE).

3.3 North Portland (see Figure 7.5, area circumscribed within yellow and labeled as NORTH (N).

4. Land use changes within the entire city of Portland.

5. Land use changes in the cities outside of Portland (Figure 6.5, in chapter 6).

The sub-areas inside Portland were selected with regard to MetroScope's unique zoning design (Figures 7.4 and 7.5):

Inside:

Cordon zone: Central city in the Mid-size cordon is the area within the red line. In detail, Central City includes the CBD plus the areas across the Willamette river, the north 
Lloyd district, and zones from SE Waterfront up to SE 29th Avenue. It is a transportation and business hub with some residential areas.

Outside:

Westside:

The area within the purple perimeter line: Northwest and Southwest of Portlandthe same Westside outside zones defined for the Small cordon boundaries. This area is mainly residential and commercial.

\section{Eastside:}

- The area within the blue/pink perimeter line is the Southeast of Portland. From SE 30th and SE Stark Street to the Belmont, Hawthorne, Sunnyside, and Reed neighborhoods plus Sellwood to SE 72nd Avenue. These are diverse neighborhoods, more upscale than, for instance, Sunnyside.

- The area within the green perimeter line is the Northeast of Portland. It primarily includes Alameda and Hollywood Districts toward the Columbia River. Also, a few blocks of SE Laurelhurst are incorporated to match ezones and rzones. This is mainly a residential and commercial/entertainment area.

- The area within the yellow perimeter line is the North of Portland, from NE 15th Avenue to the Columbia River and continuing west along N Columbia Boulevard to meet N Delaware Avenue (including Kenton Park), plus the Swan Island basin area. North Portland contains mainly industrial areas. 


\subsection{Central City or Mid Cordon Output Analysis}

As a reminder, each MetroScope year equals 5 actual years, where MetroScope year 0 is the baseline, year 2010. The outputs are analyzed 15 years and 25 years from the time of the implementation of the toll. If the results after 15 years follow the same trend of the output after 25 years, then only the output after 25 years is discussed, as was done in the Small cordon analysis, to make the two scenarios comparable. The output of the tolled scenarios is compared to the no toll alternative for all the real estate categories after the implementation of $\$ 1.65$ and $\$ 8$ toll cordons in 2035 .

The variables investigated are the same as the ones used in the analysis of the Small cordon, to make the two scenarios comparable.

From the non-residential real estate side, the first variable analyzed is the percentage changes in location price (as Metro suggests), followed by total employment percentage changes, percentage changes in total household and school age households' location demand, and non-residential total sqft supply.

For residential real estate, the variables considered are the percentage changes in location prices and in total household supply.

As a reminder, MetroScope does not use property prices directly, but instead uses an index that reflects the match between supply and demand. Supply and demand together determine price a quantity. Refer to section 6 for a more detailed explanation. 


\section{Non-Residential Land Use:}

Inside the Central City:

Figure 7.6 shows the percentage of non-residential location price changes after the implementation of $\$ 1.65$ and $\$ 8$ tolls compared to a no toll scenario in 2035 .

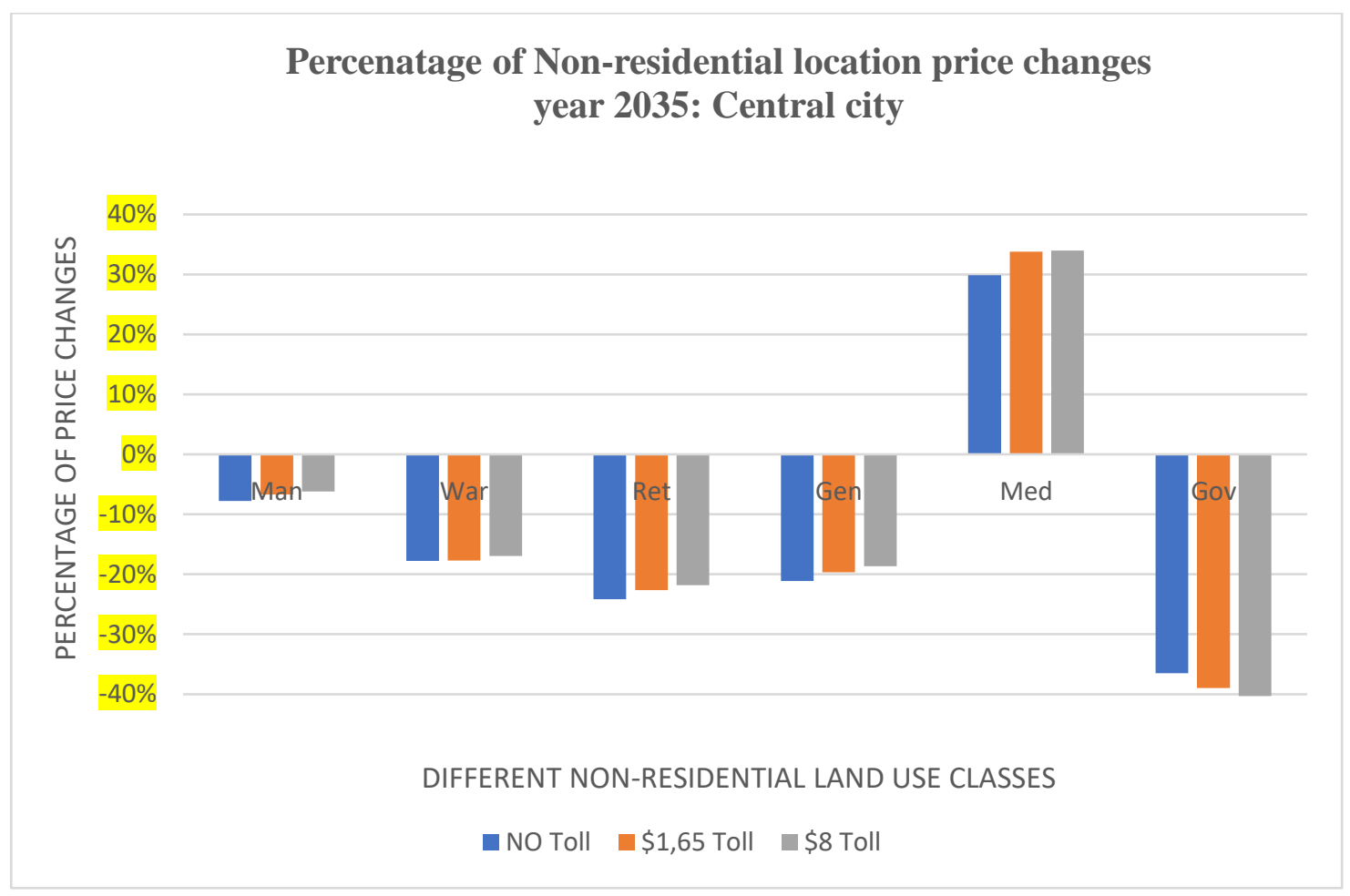

Figure 7.6

Under a no toll scenario, only Medical offices report a relative price appreciation (30\%). All the other real estate categories show a relative loss in values. Institutional real estate has the largest decline across all classes.

Under $\$ 1.65$ and $\$ 8$ toll cordons, demand for Medical offices further increases relative to supply, generating an additional 5\% and 5.5\% increase, respectively, in the price index compared to no toll. Government offices report an additional $2 \%$ and $4 \%$ decrease, respectively, in the price index. All the other real estate classes report a minor relative price increase versus no toll. 
To gain a more comprehensive understanding of the effect of charges both inside and outside the cordon, it is necessary to study changes in non-residential location prices directly outside the boundaries as well.

Directly Outside the Central City Boundaries

\section{Westside:}

In the Westside, the geographical area right outside the Mid-cordon analyzed for changes in land use patterns is the same geographical area analyzed for the Small cordon (refer to Figure 7.4). As explained at the beginning of this chapter, the Mid-size cordon embeds the CBD on the West (that is, the Small cordon), plus the Eastside zones. By selecting the same geographical zones outside the West boundaries, it is possible to directly compare the effects each cordon scheme has on the selected zones.

Figure 7.7 shows non-residential real estate percentage changes in relative price after $\$ 1.65$ and $\$ 8$ tolls are implemented versus no toll in 2035 . 


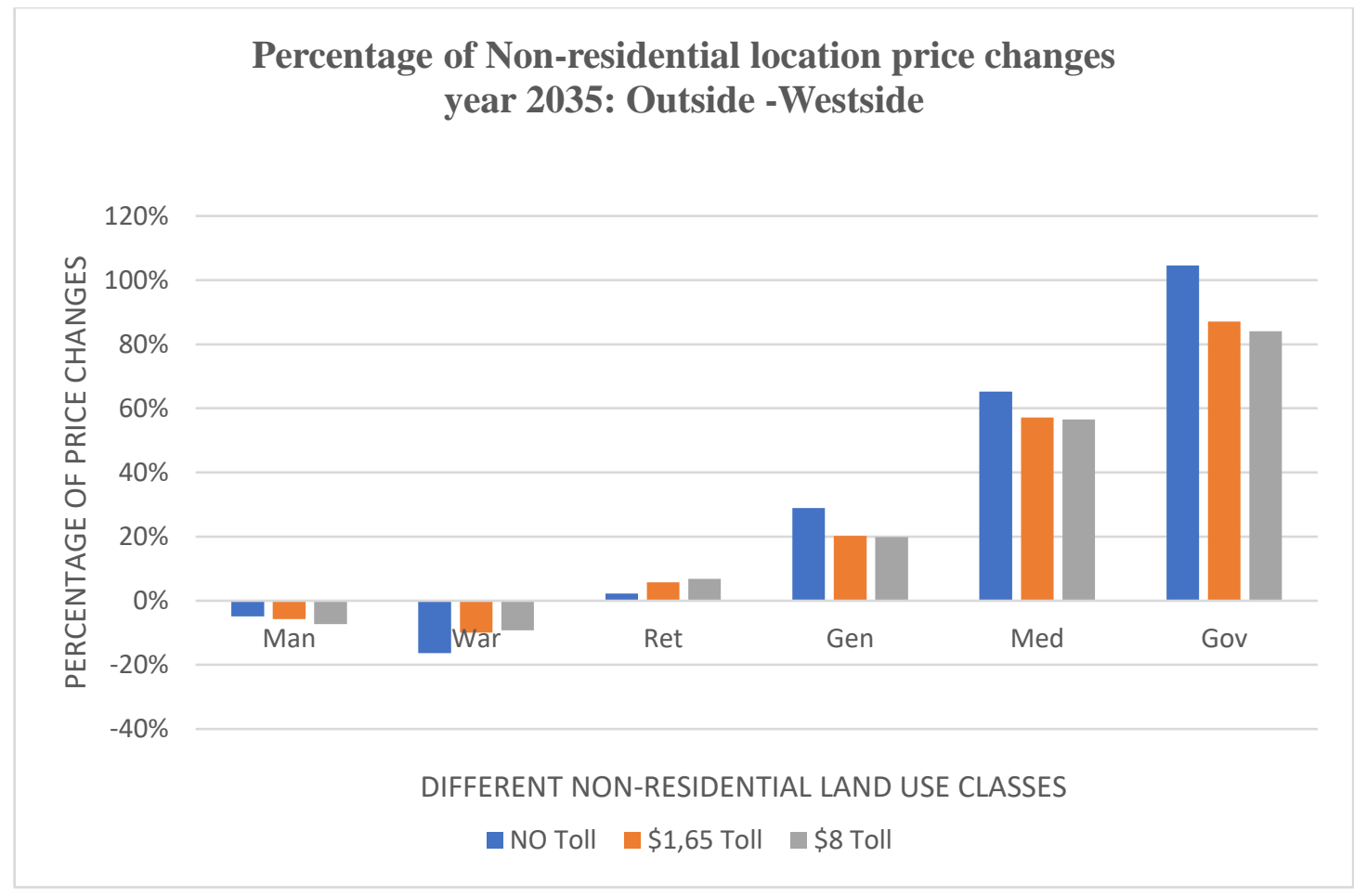

Figure 7.7

Under no toll, there is an increase in relative location prices for all the highervalue activities and decline for the lower-value ones. The largest increase in relative value is in Institutional real estate, which is projected to double in 2035. Also, in the following order, price indexes for Medical, General offices, and Retailers grow. Contrarily, Manufacturing and Warehousing experienced a decline in their relative prices. Under \$1.65 and \$8 tolls, price indexes for high-value economic activities still increase, but at a smaller pace compared to no toll. Tolls are responsible for dampening relative price appreciation for higher-value activities, with the exception of Retail, which instead has a further relative increase in price. Differently, price index for Manufacturing further declines while price index for Warehousing real estate further increases compared to no toll. Generally, tolls are responsible for dampening relative price appreciation for higher-value activities. 
The proximity to the West entrance of the cordon may not be attractive enough for businesses to relocate and increase their investment there. Geographically, West Portland is encompassed between Forest Park and residential hills on one side and the cordon perimeter on the other side. Access to and from other areas of Portland without crossing the cordon line is improbable. It could be speculated that because of the geographic location, proximity and accessibility to the tolled area are not enough to stimulate investments outside the cordon. The additional transportation costs that have to be paid to reach other areas such as East Portland seem to act as a disincentive.

Differently, East Portland is better connected to other metro areas located outside the cordon charge. Will more development occur there? Could we expect a shift of economic activities (and, if so, which type of activities) there?

Southeast:

Figure 7.8 shows the percentage of relative price changes for non-residential locations after $\$ 1.65$ and $\$ 8$ tolls are implemented versus no toll in Southeast (SE) Portland in 2035. 


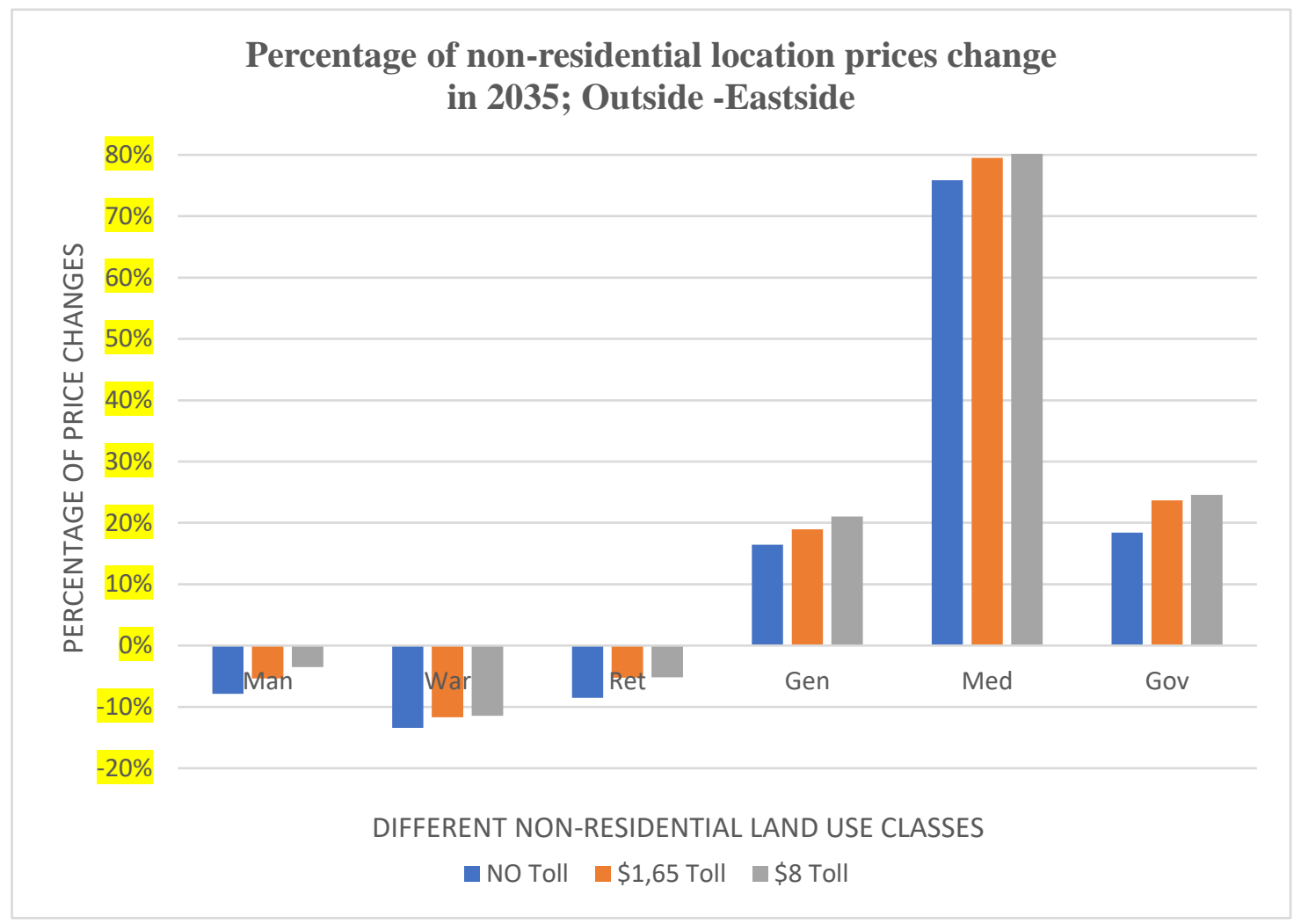

Figure 7.8

In a no toll scenario, SE Portland is projected to a relative price appreciation for Medical (75\%), General (16\%), and Government offices (18\%), while all the other real estates' values decline.

Once cordon charges are implemented, all the high-value activities are projected to a relative price appreciation: the higher the toll, the bigger the relative increase in real estate values. Additionally, Retailers' relative price depreciation becomes smaller as the toll is more expensive. The same behavior is observed in lower-value activities such as Manufacturing and Warehousing, which denote a smaller price depreciation once tolls are in place. 
Clearly, tolls push demand to grow more than supply, triggering a relative price appreciation that is reflected in each real estate class.

Possibly, the SE zone benefits from the proximity to the cordon but without paying the additional price of the toll. Further, SE provides free access to and from NE and $\mathrm{N}$ areas and the metro region; economic and transportation activities between those areas are not subject to a cordon charge.

Northeast:

Figure 7.9 shows non-residential location relative price changes after $\$ 1.65$ and \$8 tolls are implemented versus no toll in Northeast (NE) Portland in 2035.

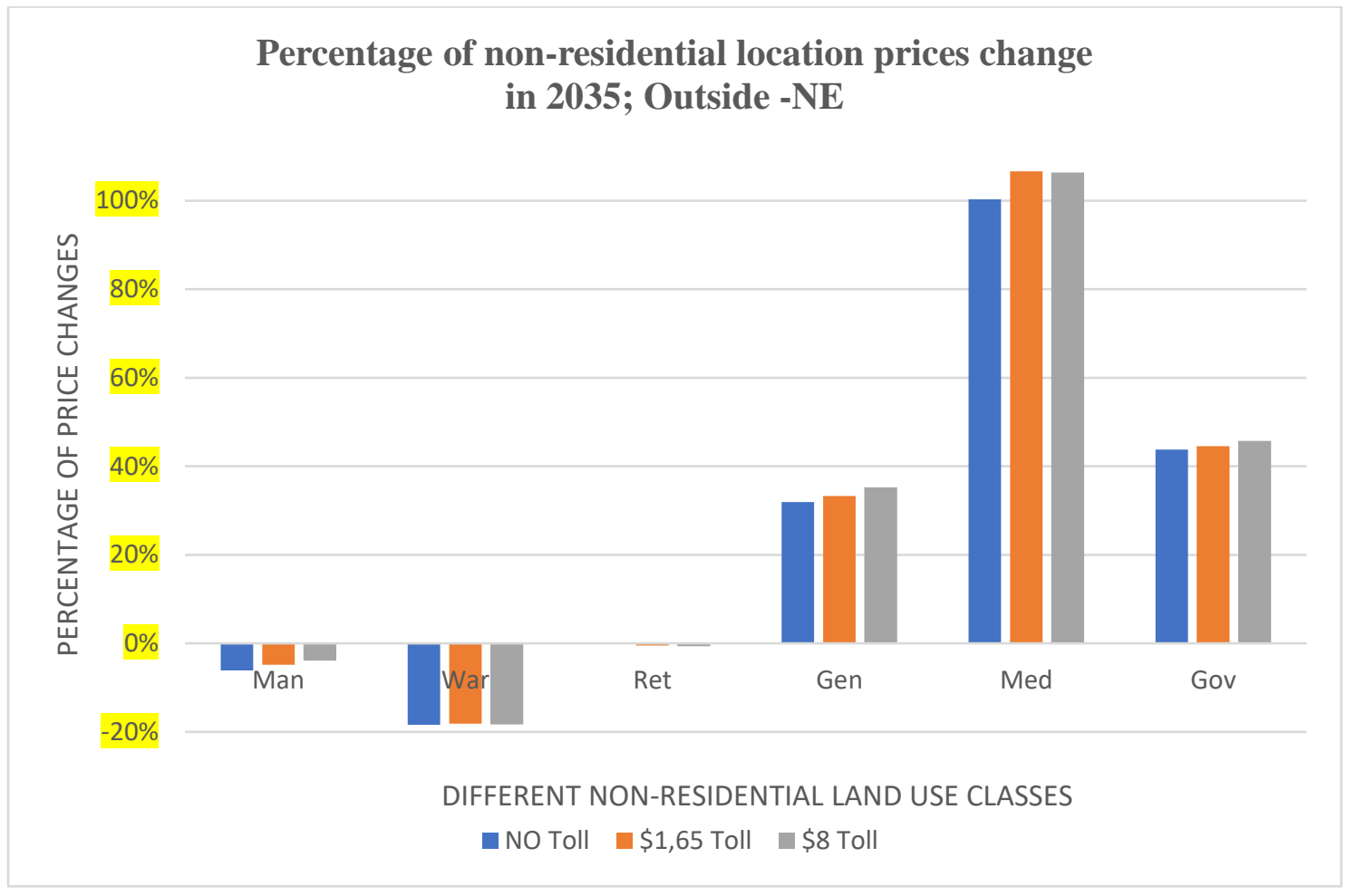

Figure 7.9

In a no toll scenario, Medical services are projected to double their price resulting from an excess demand relative to supply. Also, Government and General offices show a relative price appreciation of $43 \%$ and $31 \%$, respectively. On the other hand, 
Warehousing and Manufacturing relative prices depreciate as demand for their real estate declines relative to supply. Retailers do not show any significant changes.

After the implementation of $\$ 1.65$ and $\$ 8$ tolls, high-value economic activities are projected to a further increase in relative property values. Warehousing and Retailers do not account for any significant price changes with the implementation of tolls compared to no toll.

Generally, toll increases relative prices for Medical, Government, and General real estate and also positively affects value for Manufacturing real estate. The same consideration regarding accessibility before and after the tolls in and to SE Portland are true for NE zones as well.

North:

Figure 7.10 shows the percentage of price changes for non-residential locations after \$1.65 and \$8 tolls are implemented versus no toll in North (N) Portland in 2035. 


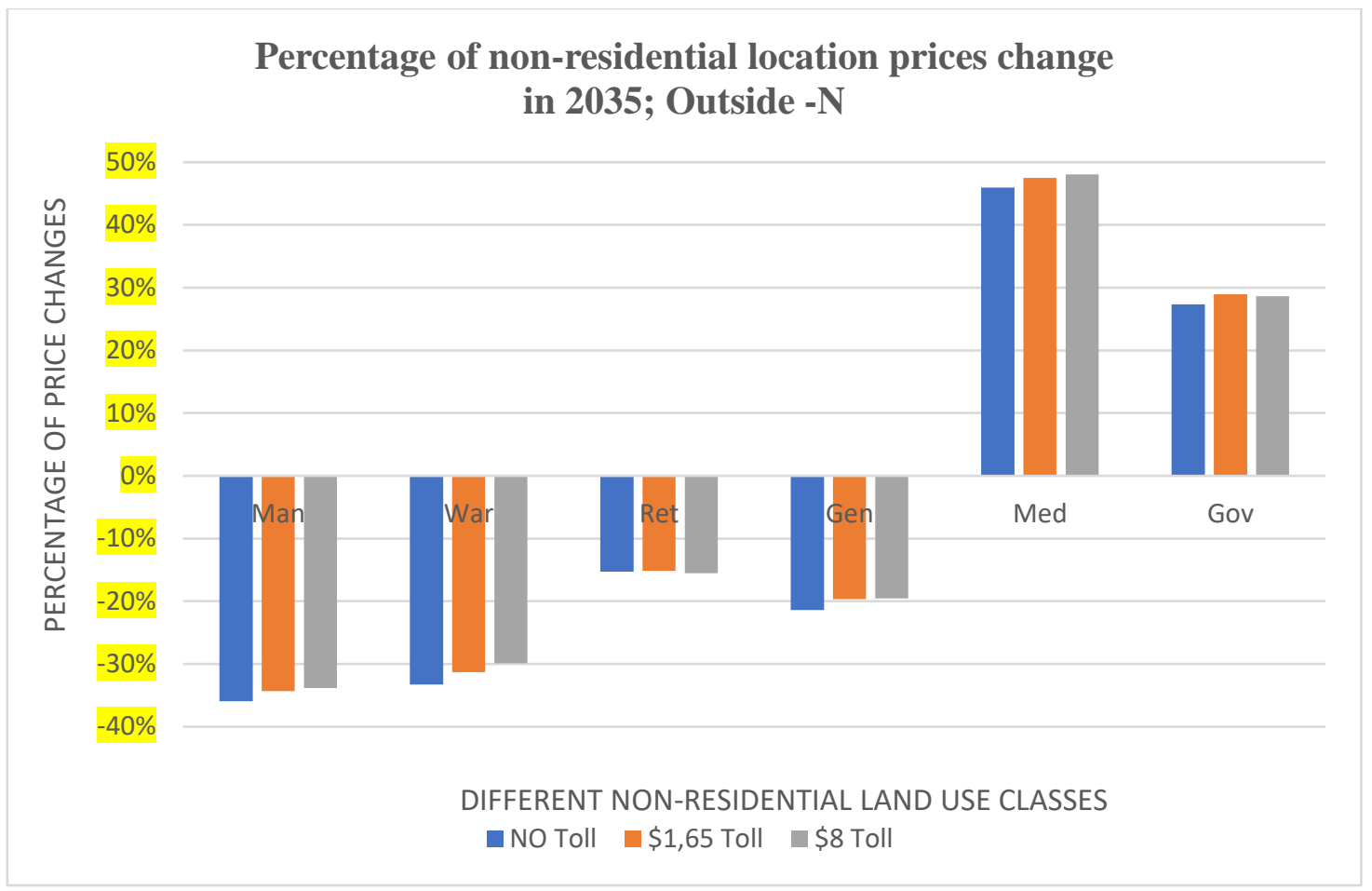

Figure 7.10

Under no toll, price indexes increase only for Medical and Government real estate, while price indexes fall for all other real estate. Under cordon schemes, tolls further boost demand for Medical and Government real estate relative to existing supply, causing a relative price increase, and tolls dampen price depreciation for Manufacturing and Warehousing real estate compared to no toll after 25 years.

Overall, the implementation of a cordon charge around the Central City increases non-residential real estate price indexes in the zones right outside the cordon on the Eastside, prompting relative price appreciation for high-value activities and dampening relative prices depreciation for Manufacturing and Warehousing compared to no toll after 25 years. 


\section{$\underline{\text { Total Employment Changes }}$}

Inside the Central City:

From the demand side, another output analyzed is total employment.

Figure 7.11 shows changes in percentage of total employment inside the cordon area, comparing the tolled scenarios versus no toll in 2035.

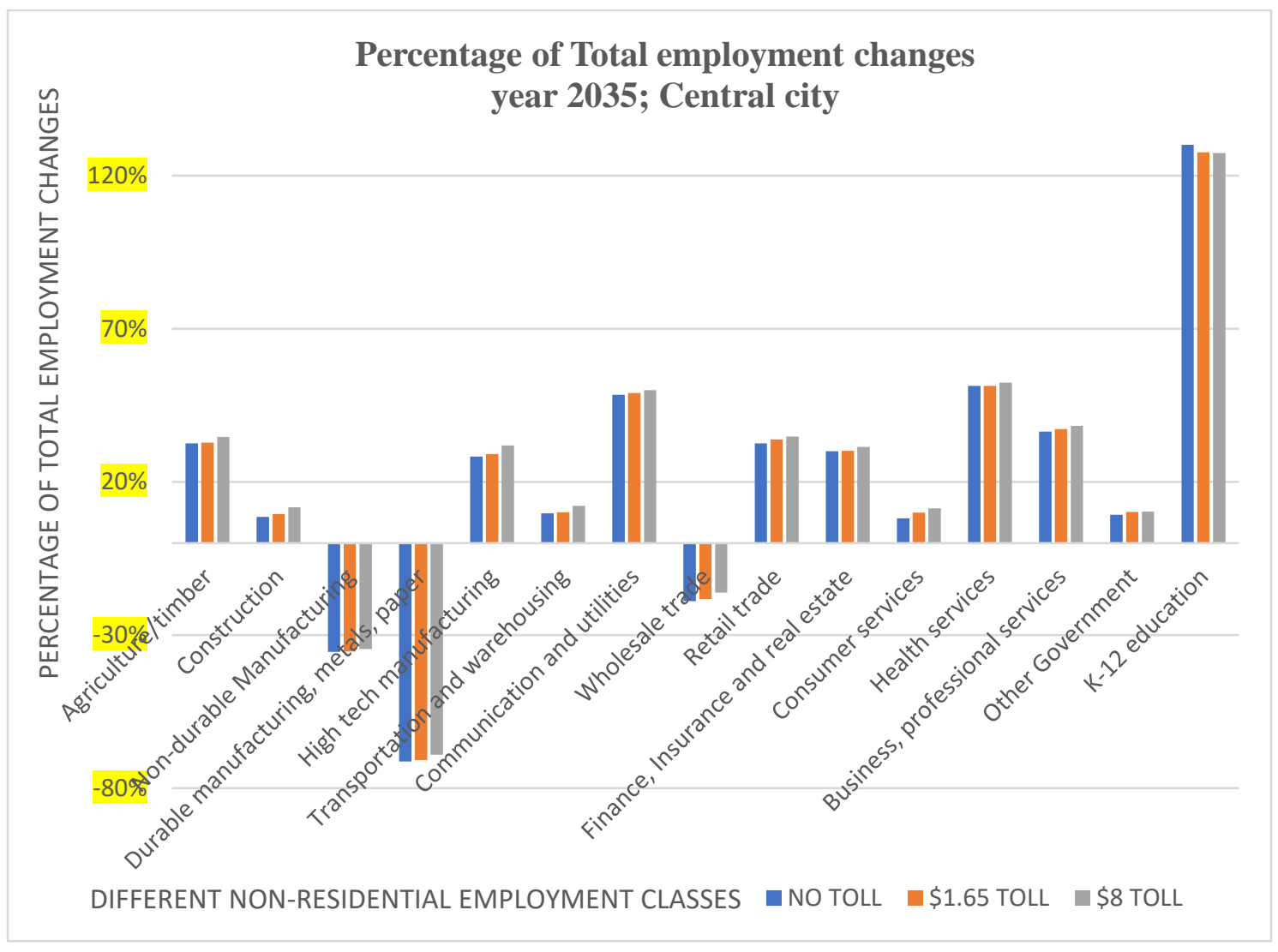

Figure 7.11

Under no toll, employment in K-12 education exponentially increases. Generally, employment increases for almost all industries but Manufacturing (Durable and Nondurable) and Wholesale trade. 
Tolls positively affect employment in all industries, with the exception of employment in K-12 education, which reports smaller growth than in a no toll scenario. Generally, the higher the toll, the (slightly) larger the effect on employment.

Right Outside the Central City Boundaries:

Westside:

Figure 7.12 shows percentage changes in employment within the Westside after the implementation of the cordon tolls versus no toll in 2035 .

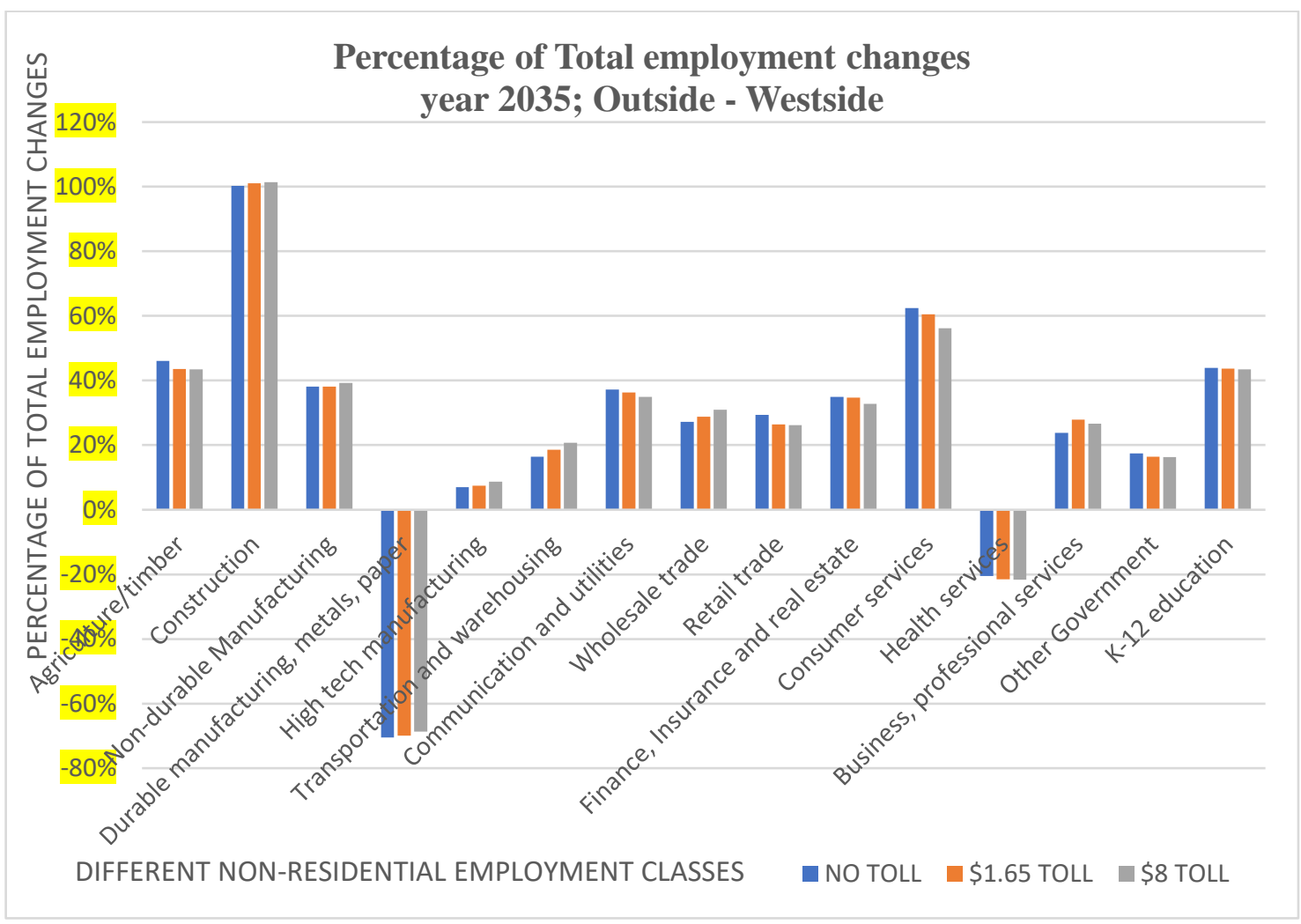

Figure 7.12

As explained at the beginning of this chapter, the area outside the West of the boundaries is the same as the of the Small cordon. Under no toll, construction has the 
largest increase in employment, while Durable manufacturing is projected to the largest decrease.

Overall, tolls affect employment, in particular boosting employment for Business/Professional services, Wholesale trade, and Transportation/Warehousing. On the other hand, tolls significantly reduce employment in Consumer services, Finance, Retail trade, and Communications/Utilities.

The areas right outside the Westside boundaries have to pay the toll to access East Portland as well as transportation hubs located there since there are not alternatives routes; therefore, the decreased accessibility to the East markets is perceived as a disincentive to investments from the majority of industries.

Eastside:

Figures $7.13,7.14$, and 7.15 show the percentage changes in total employment in SE, NE, and N Portland, respectively, before and after the tolls in 2035. 


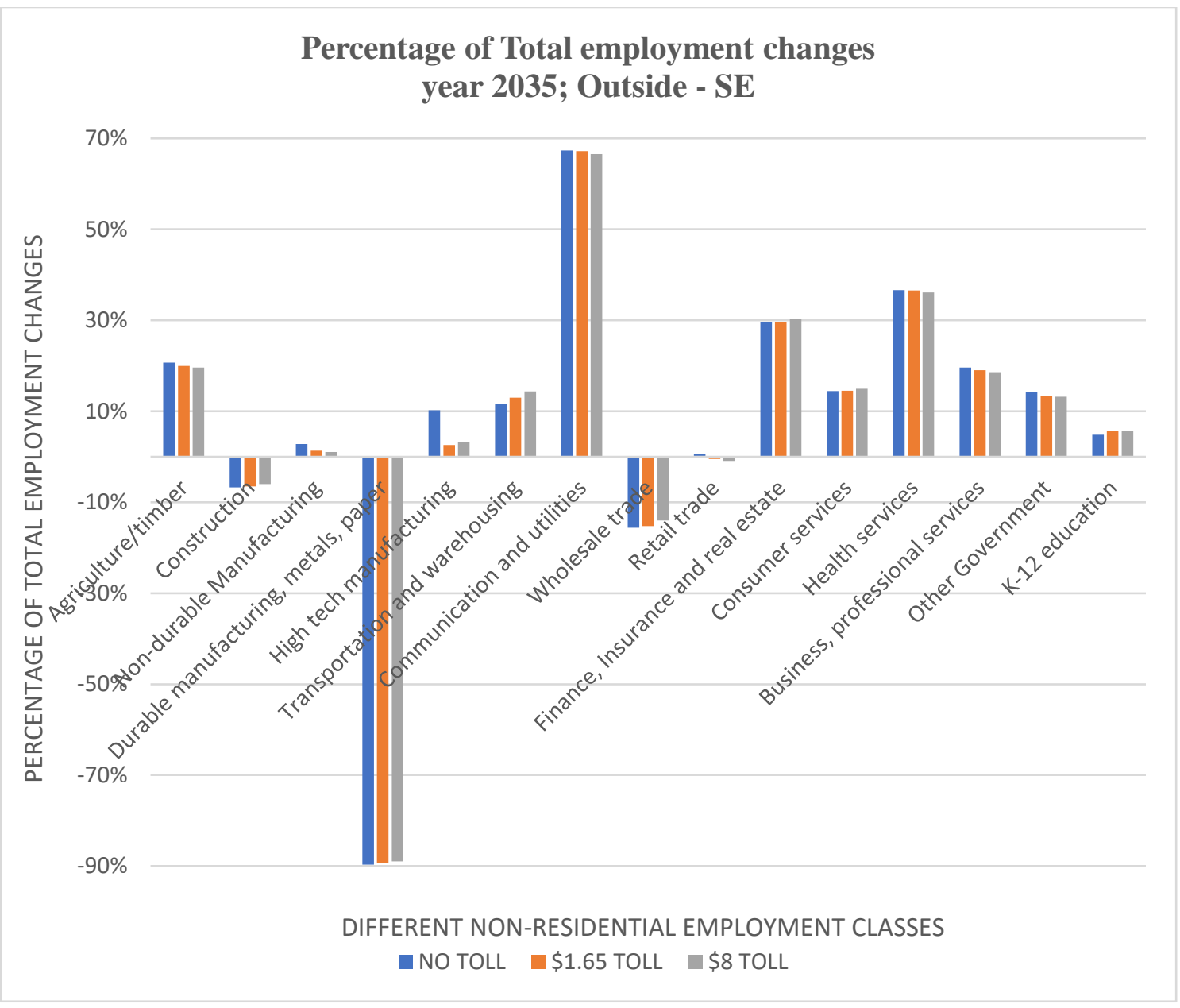

Figure 7.13

Under no toll, SE Portland is projected to a significant raise in employment for Communication and Utilities (67\%), followed by Health services and Finance/Insurance real estate. The main drop in employment is for Durable manufacturing (89\%), while employment is positive for Non-Durable and High-tech manufacturing. Industries that are projected to a decline in their employment are Durable manufacturing, Wholesale trade, and Construction. All the other activities are projected to increase over time.

Under \$1.65 and \$8 tolls, High-tech manufacturing has the largest decline in employment, while Wholesale trade has the largest increase. 


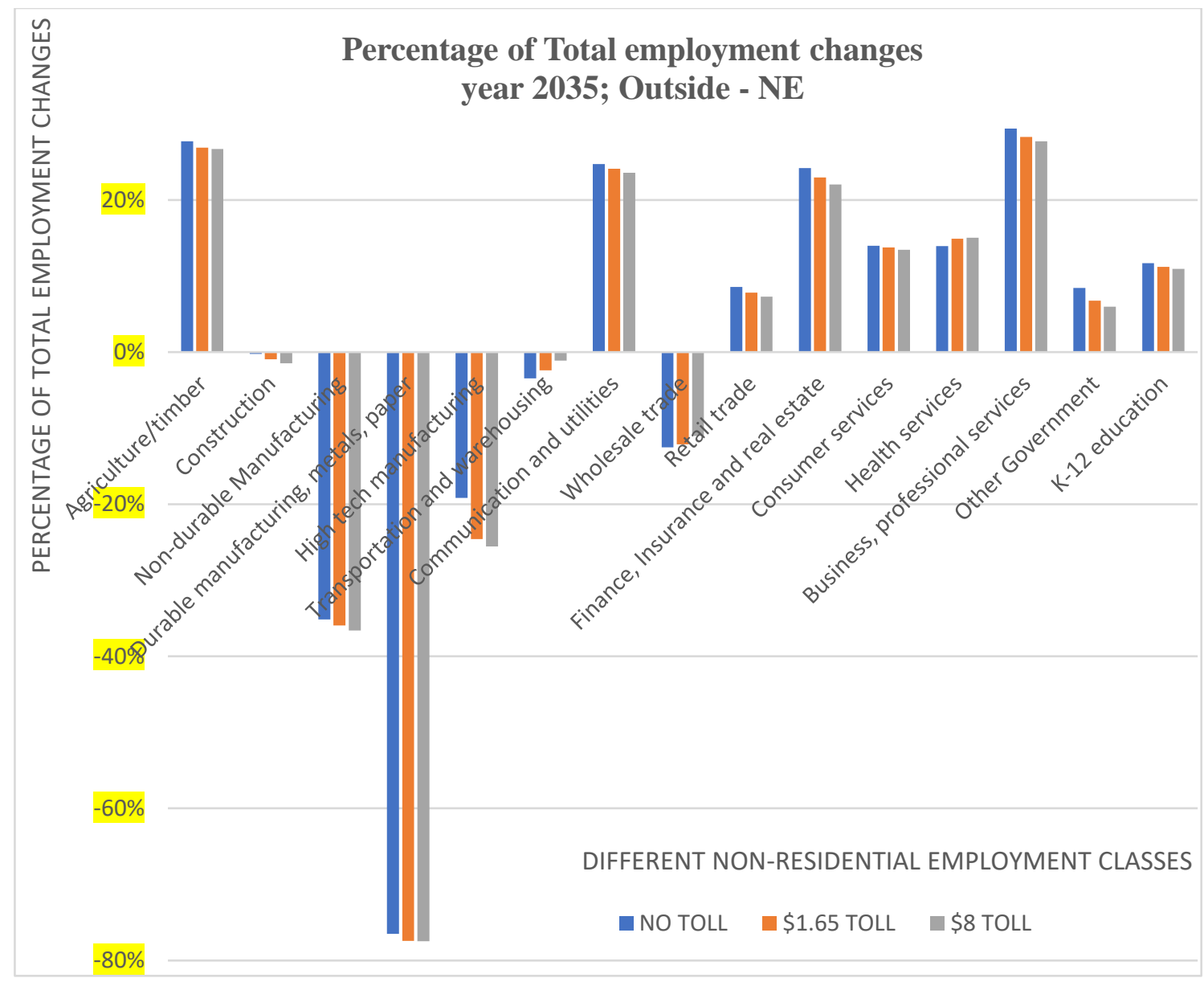

Figure 7.14

In a no toll scenario, employment for all the Manufacturing classes is projected to significantly decline over time, as is demand for Wholesale trade and Transportation/Warehousing. On the other hand, Business/Professional services and all the other higher-value economic activities are projected to a significant increase in employment, as is Agriculture/Timber.

With the implementation of $\$ 1.65$ and $\$ 8$ tolls, all Manufacturing activities show an even larger drop in their employment, while all other economic activities have smaller growth. Health services are the only class projected to slightly increase in their employment over time. 
Generally, a Mid-size cordon toll discourages employment for any types of economic activities but Health services in NE Portland.

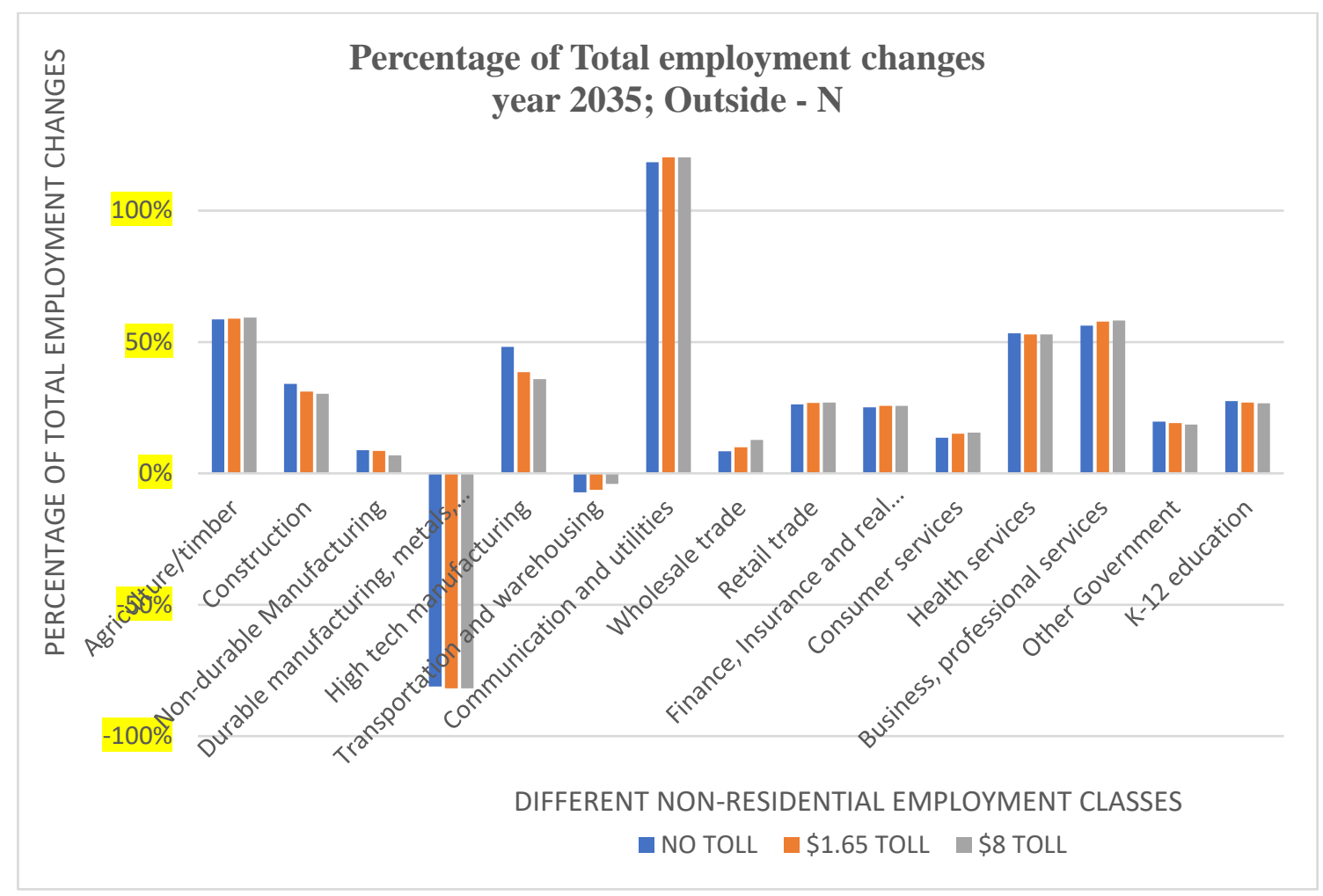

Figure 7.15

Under no toll, only two industries have a decline in their employment: Durable Manufacturing, with a drop of $81 \%$, and Transportation/Warehousing, with a drop of $7 \%$. All the other economic activities are projected to an increase in employment over a 25 year period.

The implementation of tolls discourages employment for all Manufacturing and Construction activities; specifically, High-Tech manufacturing reports the largest drop (13\%). Tolls boosts employment for Communication/Utilities, Wholesale trade, and 
Business/Professional services. Tolls also diminish the decline in Transportation/Warehousing's employment over time.

Under the cordon scenarios, some economic activities are projected to move away from NE Portland toward either SE or N Portland. It could be speculated that economic activities tend to move farther away from the cordon area.

Tolling discourages employment for almost all the lower values. Instead, other activities (such as Retailers, Construction, Transportation/Warehousing) are projected to increase in employment as they move away from the City Center toward the SE once that tolls are implemented.

The following variable analyzed is Non-residential household (hh) demand for total households and households with school-age children (from the residential model) to understand whether the implementation of a cordon charge will affect location choices for them.

\section{Percentage of Changes in HH Location Demand}

\section{Inside the Central City:}

Figure 7.16 shows the percentage changes in non-residential demands for housing for total hh and hh with school-age children inside the cordon versus no toll in 2035. 


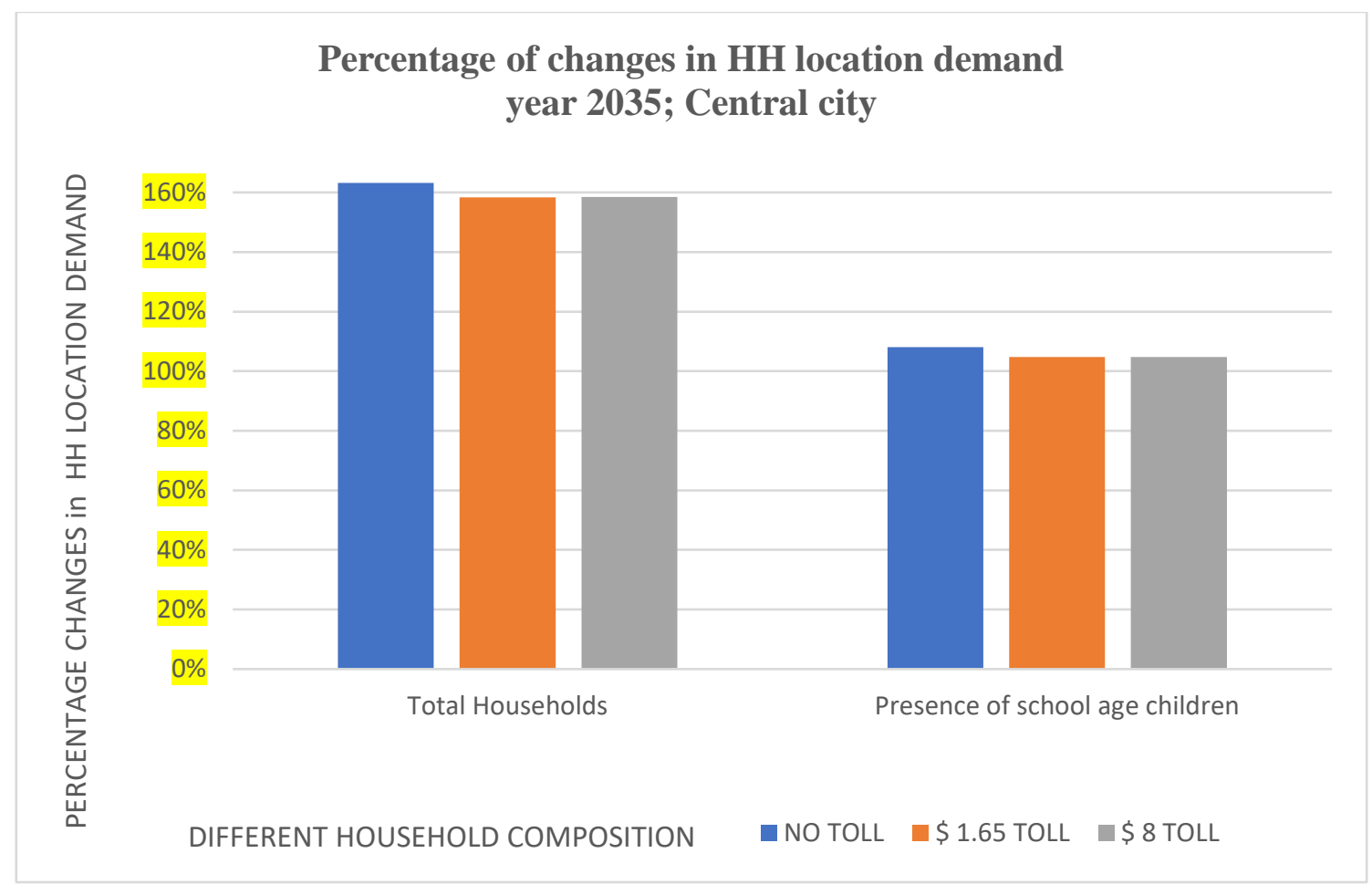

Figure 7.16

Under no toll, there is an exponential growth in total hh demand. Also, hh with school-age children demand more than doubled over 25 years.

Once \$1.65 and \$8 tolls are implemented, total hh demand still increases over time, yet at a smaller degree compared to no toll. Also, school-age hh demand has smaller growth (4\% on average) once tolls are implemented.

Generally, toll reduces the demand to locate inside the cordon area for households with and without children. Tolls at $\$ 1.65$ and $\$ 8$ produce very similar results; their outcome differs only by $0.5 \%$ on average. The assumption is that the model mitigates the impact of different tolls by changing the distribution of the trips that are impacted by the charges. Since that tolls are calculated as an increase in travel minutes, households adjust their trips to the higher transportation costs, triggering a change in distribution of all trips. 
The implementation of a Mid-size cordon does negatively influence household demand for housing within the boundaries of the cordon.

\section{Right Outside the Central City Boundaries:}

Westside:

Figure 7.17 shows the percentage changes in demand for total hh and hh with school-age children after tolls are implemented versus no toll in 2035.

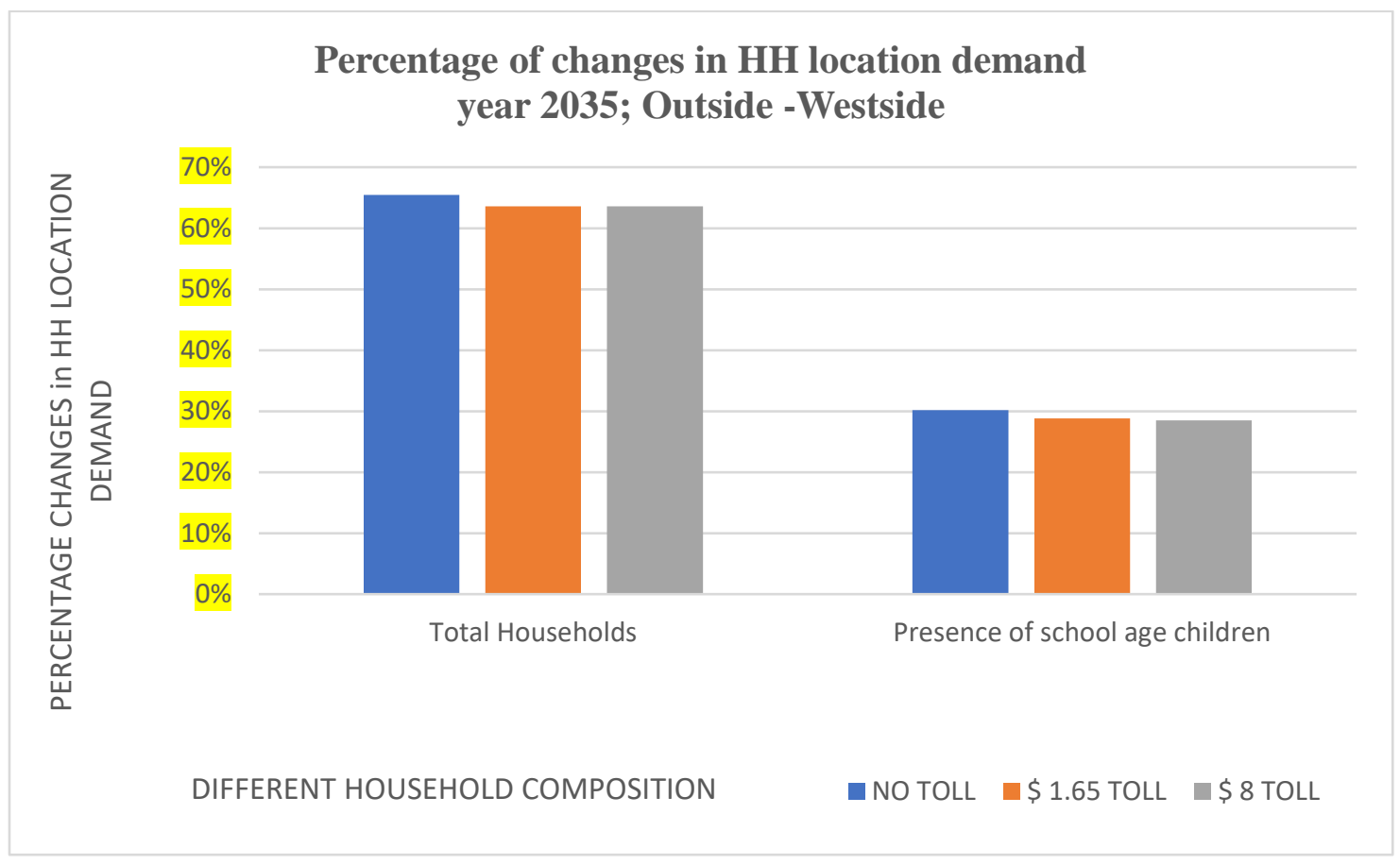

Figure 7.17

Under no toll, both households with and without children report an increase in their demand in 2035.

After the implementation of $\$ 1.65$ and $\$ 8$ tolls, household demand declines relative to the no toll scenario for both classes. 
Eastside:

The next step is to evaluate changes in total household demand in East Portland before and after $\$ 1.65$ and $\$ 8$ tolls are implemented in 2035 . Would the design of a cordon around the Central City affect household demand for those zones right outside the eastern boundaries? If yes, is the presence of children a critical factor in affecting demand changes?

Figures 7.18, 7.19, and 7.20 show the percentage changes in non-residential demands for total hh and hh with school-age children in SE, NE, and N Portland, respectively, after a toll cordon is implemented compared to no toll in 2035.

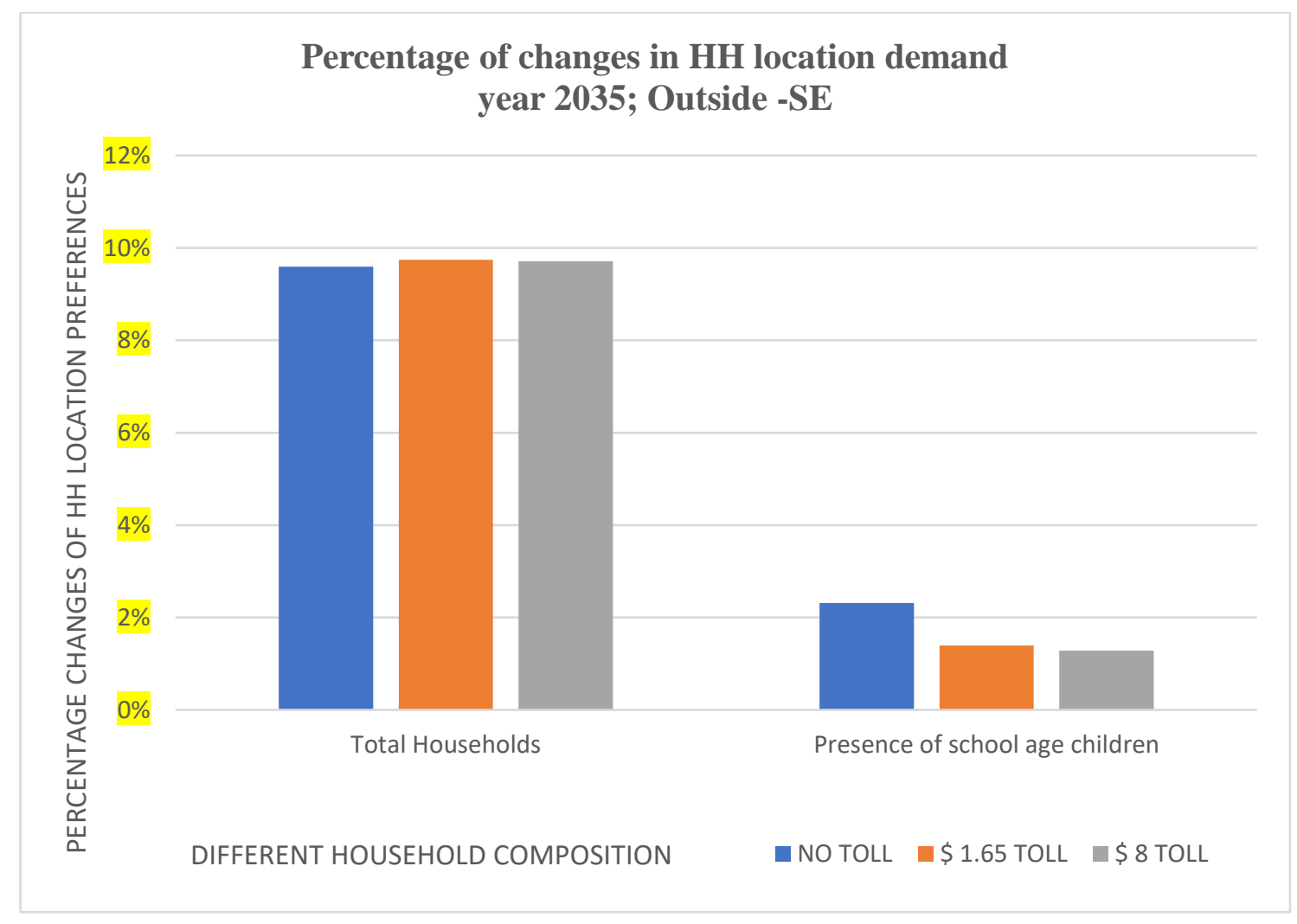

Figure 7.18 


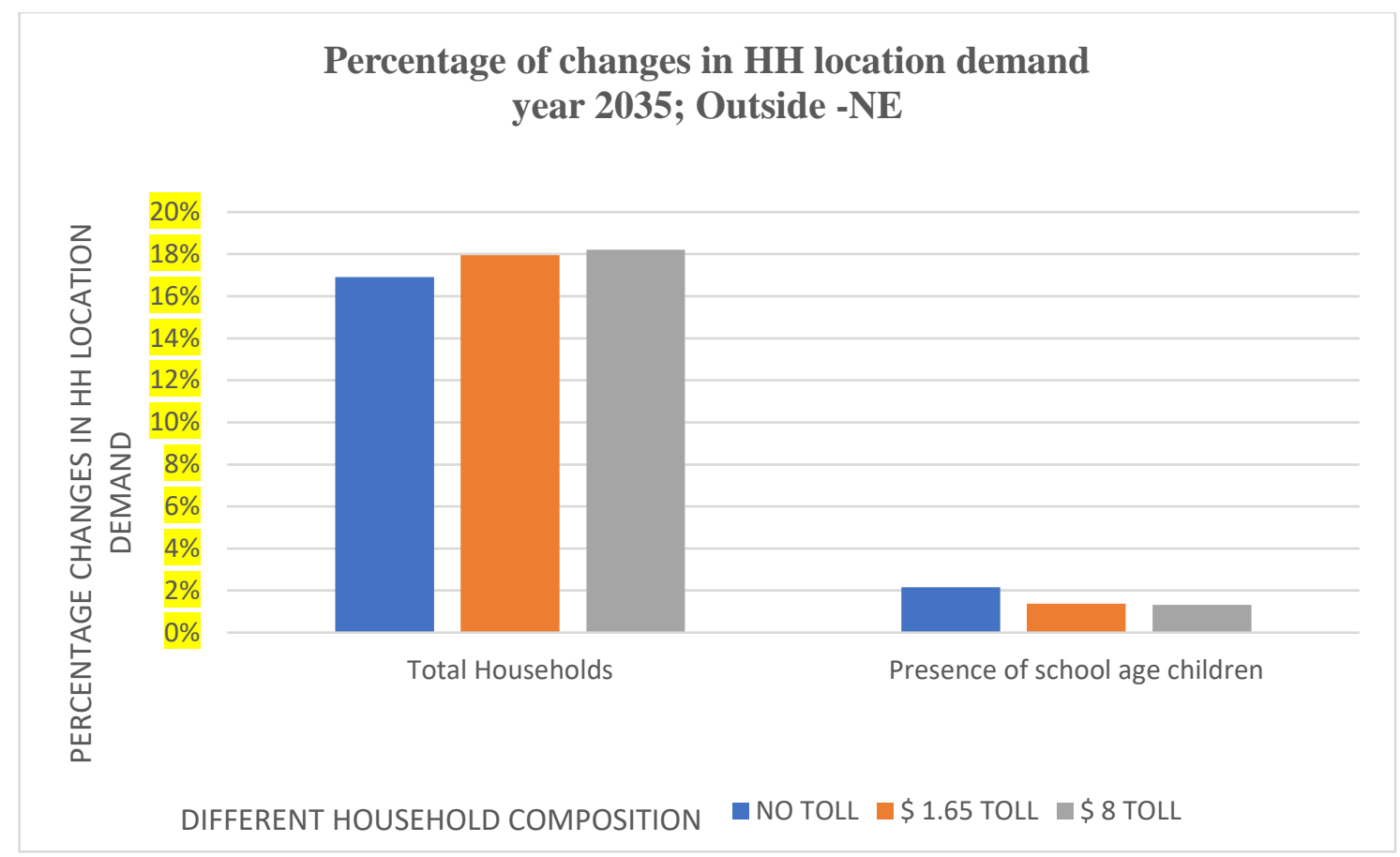

Figure 7.19

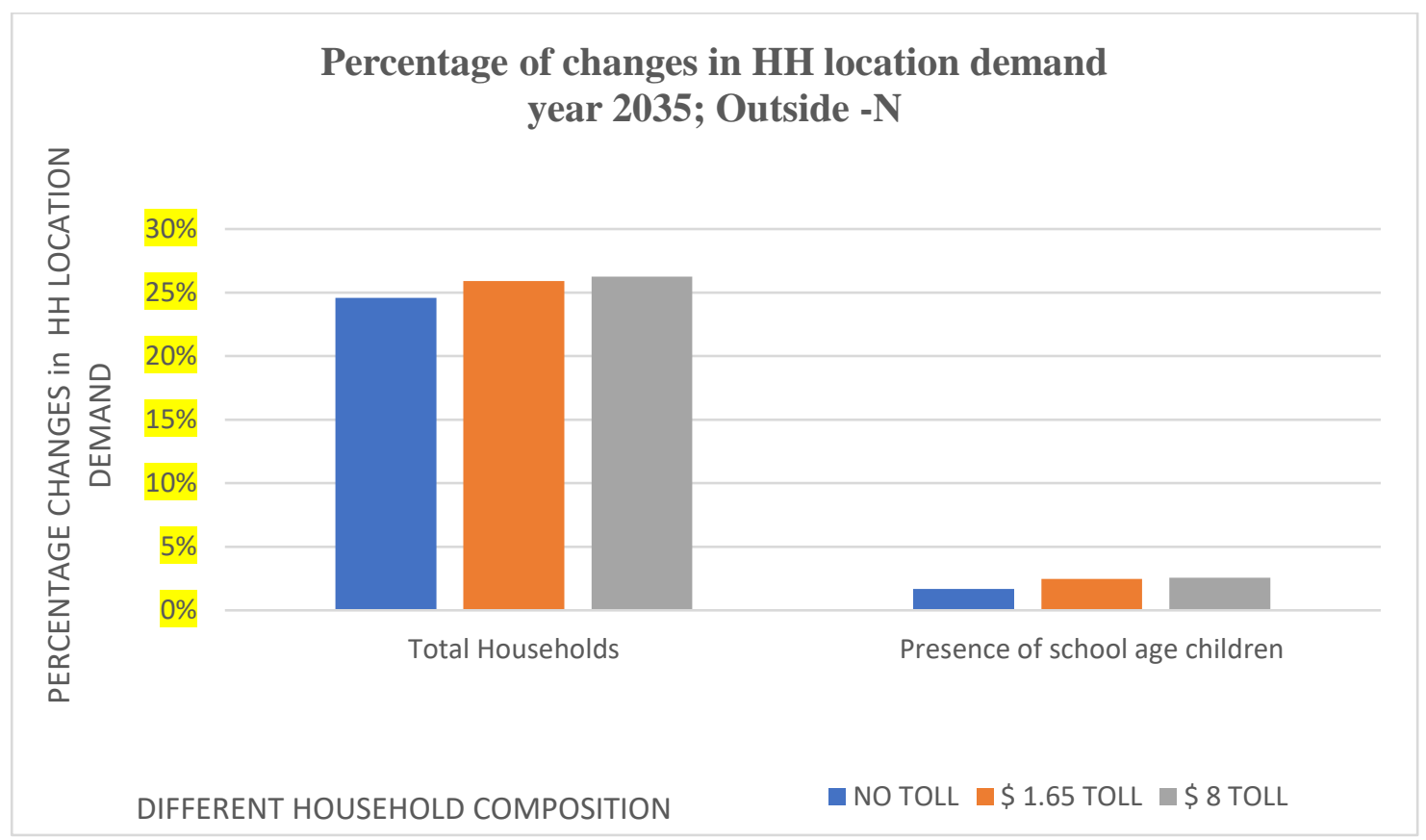

Figure 7.20 
Under no toll, the overall Eastside (SE, NE, and N) is projected to an increase in demand for both household classes. In detail, N Portland has the largest increase in demand for total hh, followed by the NE, and, lastly, by SE Portland with the smallest growth in household demand. Conversely, demand for households with school-age children is projected to a small growth overall; in fact, SE Portland is projected to reach 2.61\% growth, followed by NE Portland with a $2.17 \%$ increase, while North Portland shows only $1.68 \%$ surge in demand.

With the implementation of $\$ 1.65$ and $\$ 8$ tolls, total hh location demand has the largest upsurge in N Portland, followed by the NE and lastly by the SE districts. Demand for households with school-age children increases only in N Portland, while it declines in NE and SE Portland compared to no toll.

Generally, toll promotes total household demand growth in East Portland, especially in N Portland and secondly in NE Portland. Differently, toll promotes demand for households with school-age children only in N Portland (nearby Alameda neighborhood) when children are present. ${ }^{7}$

The higher the toll, the larger the magnitude effect on hh demand within in East Portland over time.

It has to be remembered that the model assumes that households will locate where they can access employment opportunities but also zones for recreation and commercial activities, while considering school districts for children. When a cordon charge is implemented, households' response positively to the implementation of a toll only in the

\footnotetext{
${ }^{7}$ One of the dimensions used in MetroScope for hh housing preferences is "child friendly neighborhood score" that is implemented in the model and operates as an addition to the neighborhood score only for households that have school children presents (Metro, 2013).
} 
Eastside. By relocating on the East, households could avoid the additional transportation costs of the cordon toll, while still having access to other residential and business areas.

\section{Total sqft Supply}

The following output analyzes changes in total sqft supply, comparing a default scenario against $\$ 1.65$ and $\$ 8$ cordon alternatives in 2035 . As explained in the previous section, with regard to available supply, non-residential employment type activities (i.e., K-12 education, construction, business services, etc.) may locate in any of the 6 real estate categories identified in MetroScope, so that the use of any space by any employment type directly responds to the price for real estate classes being considered and the prices of all the competing classes (Metro, 2013). For example, any warehouse space can be occupied by a different work activity than originally intended. It means that in areas where commercial demand is high, and manufacturing is low, non-industrial uses move into industrial-type space. Therefore, supply is substitutable between purposes. Inside the Central City:

Figure 7.21 shows changes in total sqft supply percentage inside the Central City before and after introducing \$1.65 and \$8 tolls against the default scenario in 2035 . 


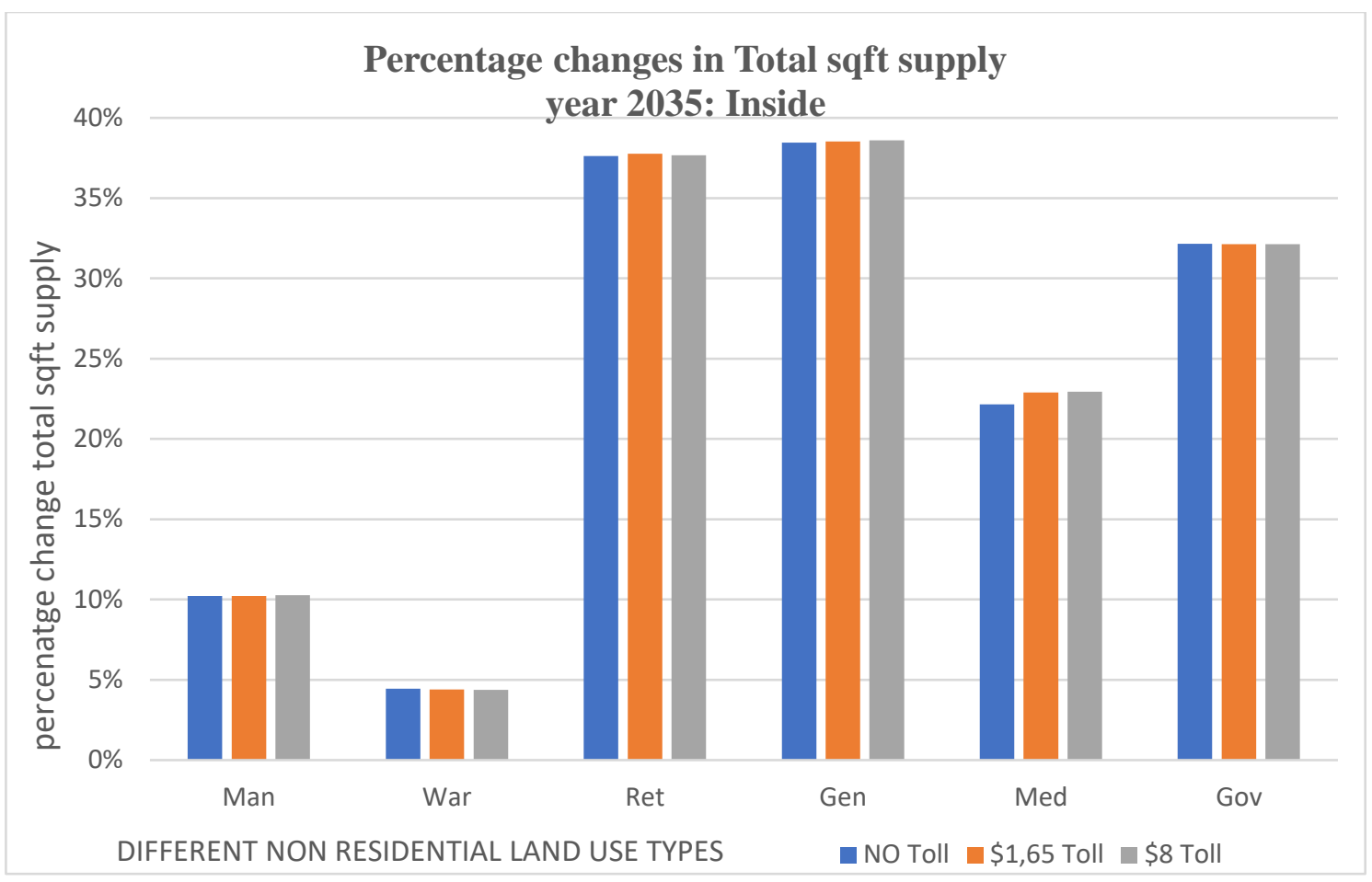

Figure 7.21

All the high-value economic activities show an increase in additional sqft supply under no toll.

By introducing $\$ 1.65$ and $\$ 8$ tolls, it is noticeable that there are almost no changes in all the 6 non-residential real estate types. The difference in sqft supply is about (+ or -) $1 \%$ between the toll scenarios versus no toll. The implementation of the tolls does not significantly influence sqft supply. It is reasonable to say that that an increase in total sqft supply will negatively affect location prices.

The implementation of the tolls has a stronger effect on location prices than on non-residential total sqft supply. Supply is inelastic, so that changes in demand have the most effect on prices. Also, supply is assumed to be less reactive because of the UGB; supply could be considered as almost fixed. 


\section{$\underline{\text { Right Outside the Central City Boundaries }}$}

Westside:

Figure 7.22 reports percentage changes in total sqft supply for non-residential land in West Portland after toll cordons are implemented compared to no toll in 2035.

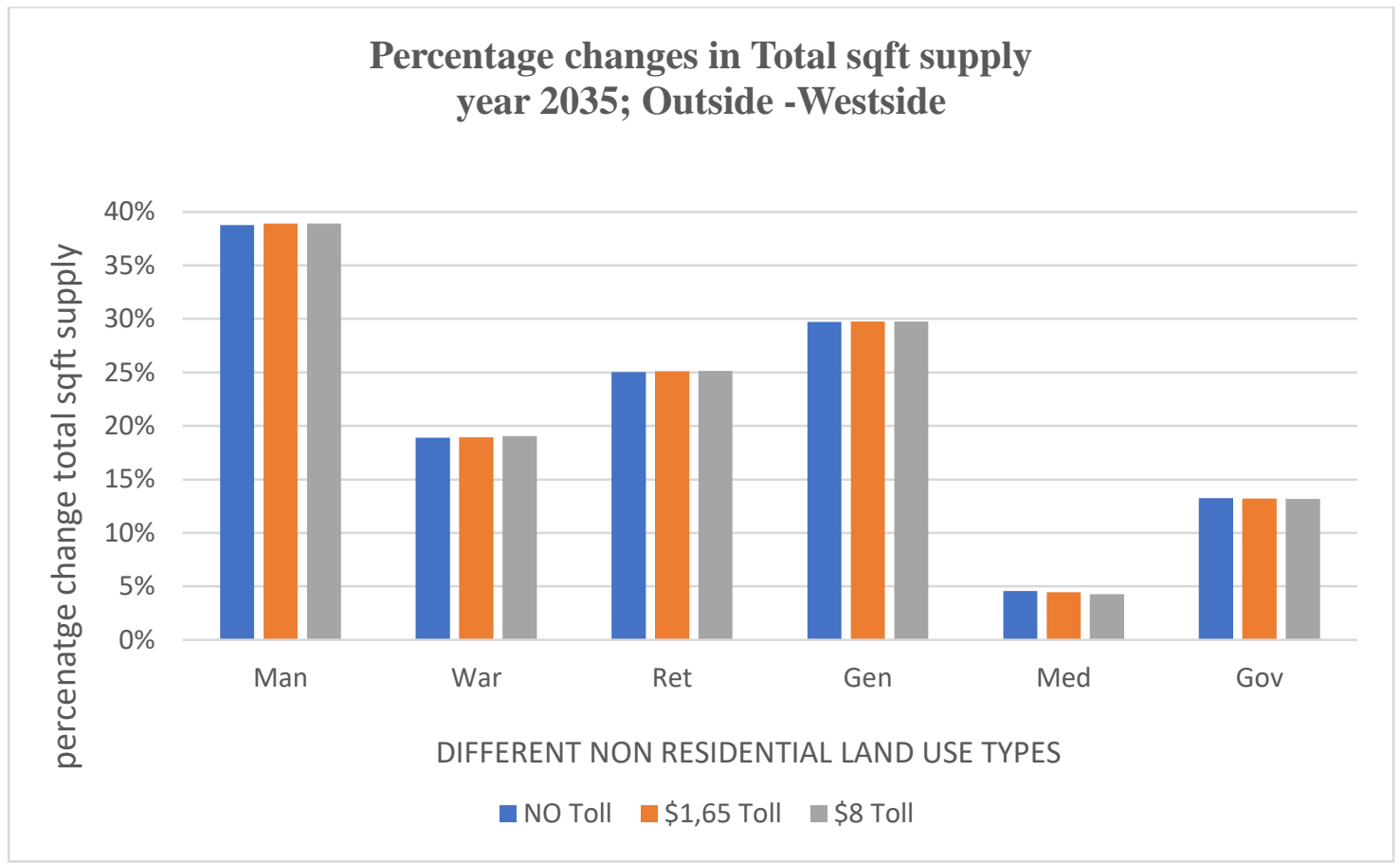

Figure 7.22

If no toll is implemented, all the real estate classes are projected to an increase in their sqft supply; in particular, Manufacturing (38\%), followed by General offices (29\%) and Retailers (25\%). The real estate types with the smallest increase in sqft supply is Medical (4.5\%).

Once tolls are implemented, no significant changes in sqft supply occur; in fact, the percentage change is on average 1\% compared to no toll at year 2035 .

Again, supply is assumed to be less reactive because of the UGB around the Portland metro area. 
Eastside:

Figures $7.23,7.24$, and 7.25 report the percentage changes in total non-residential sqft supply in SE, NE, and N Portland, respectively, comparing no toll against cordon scenarios in 2035 .

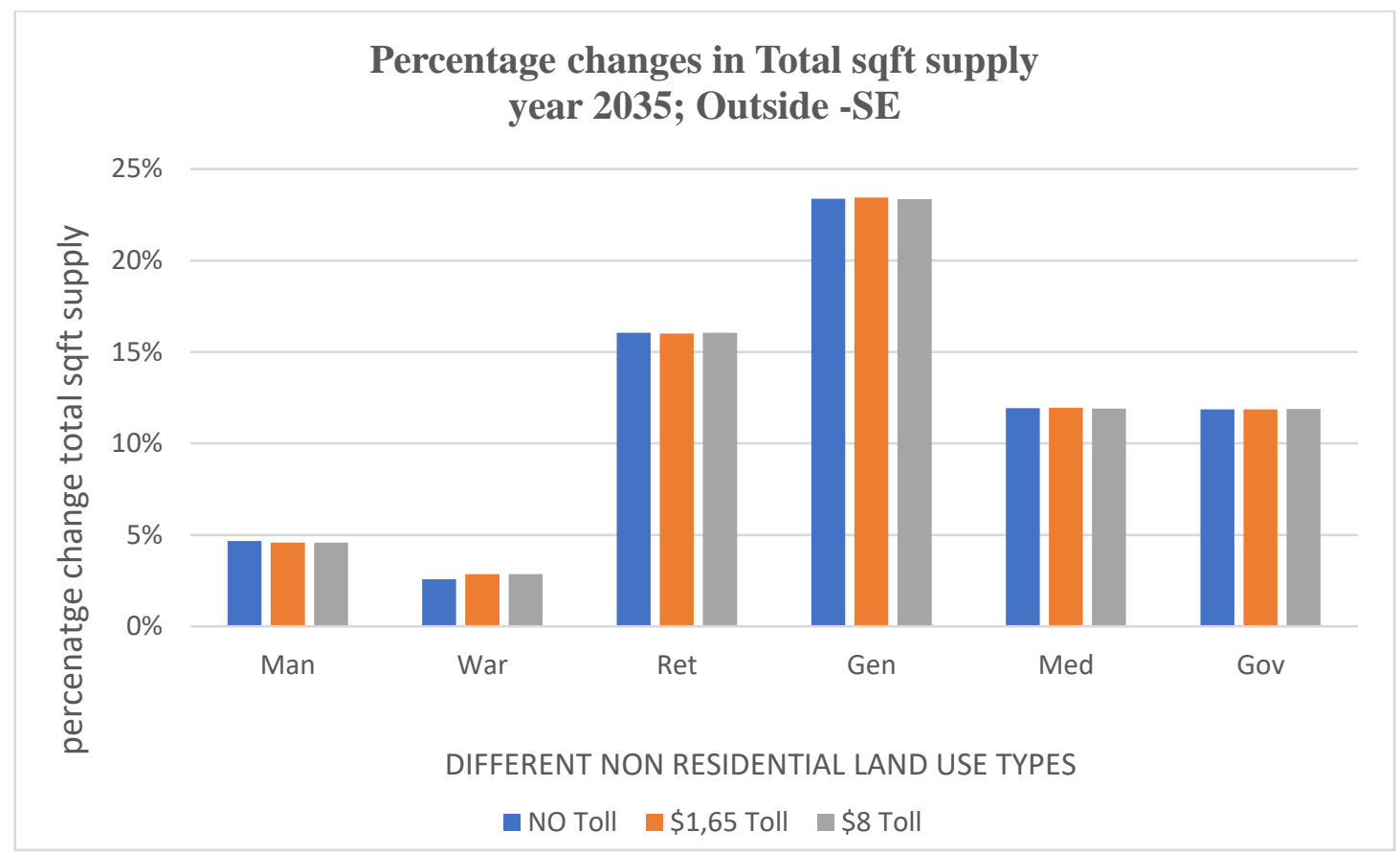

Figure 7.23 


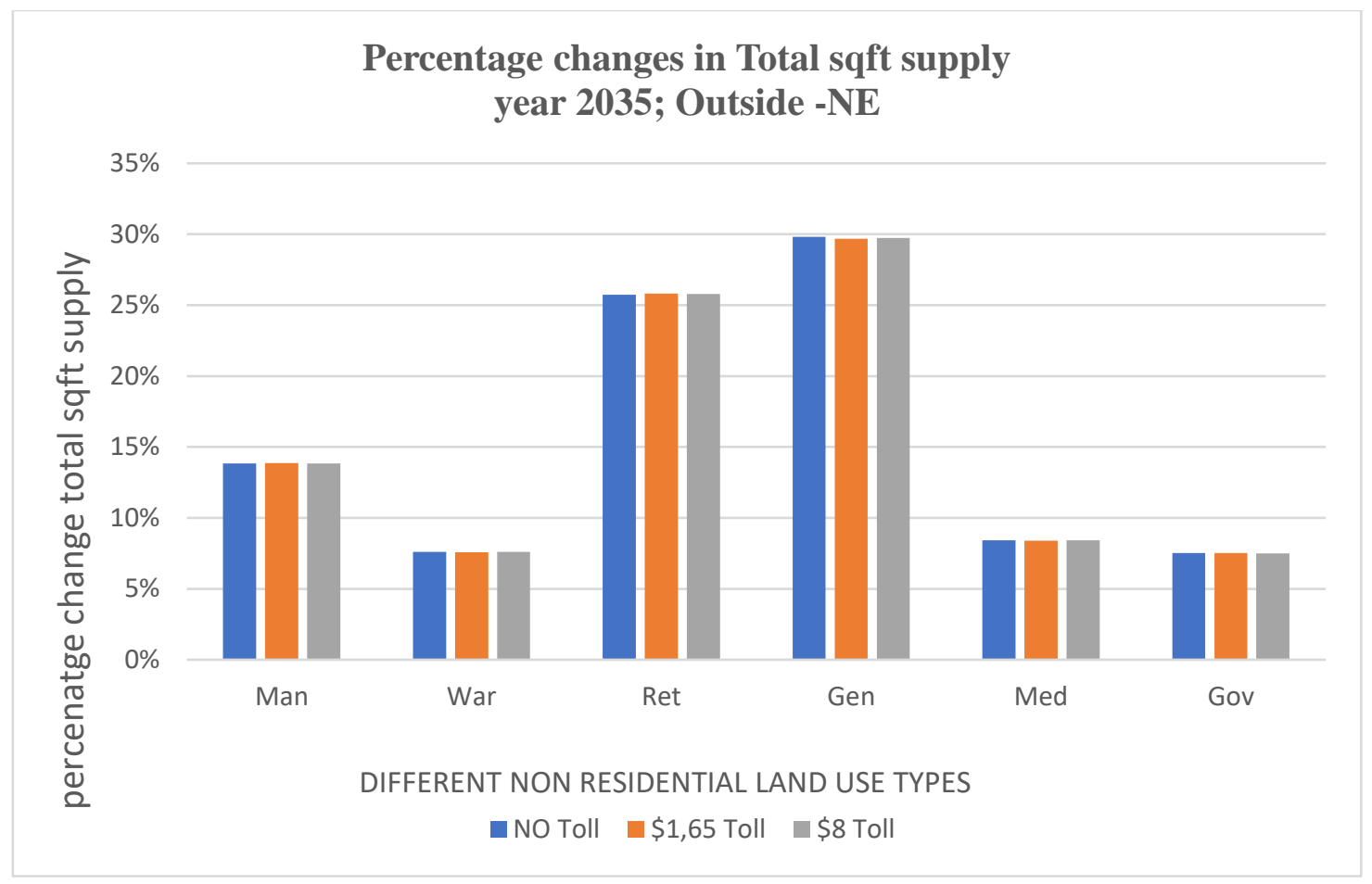

Figure 7.24

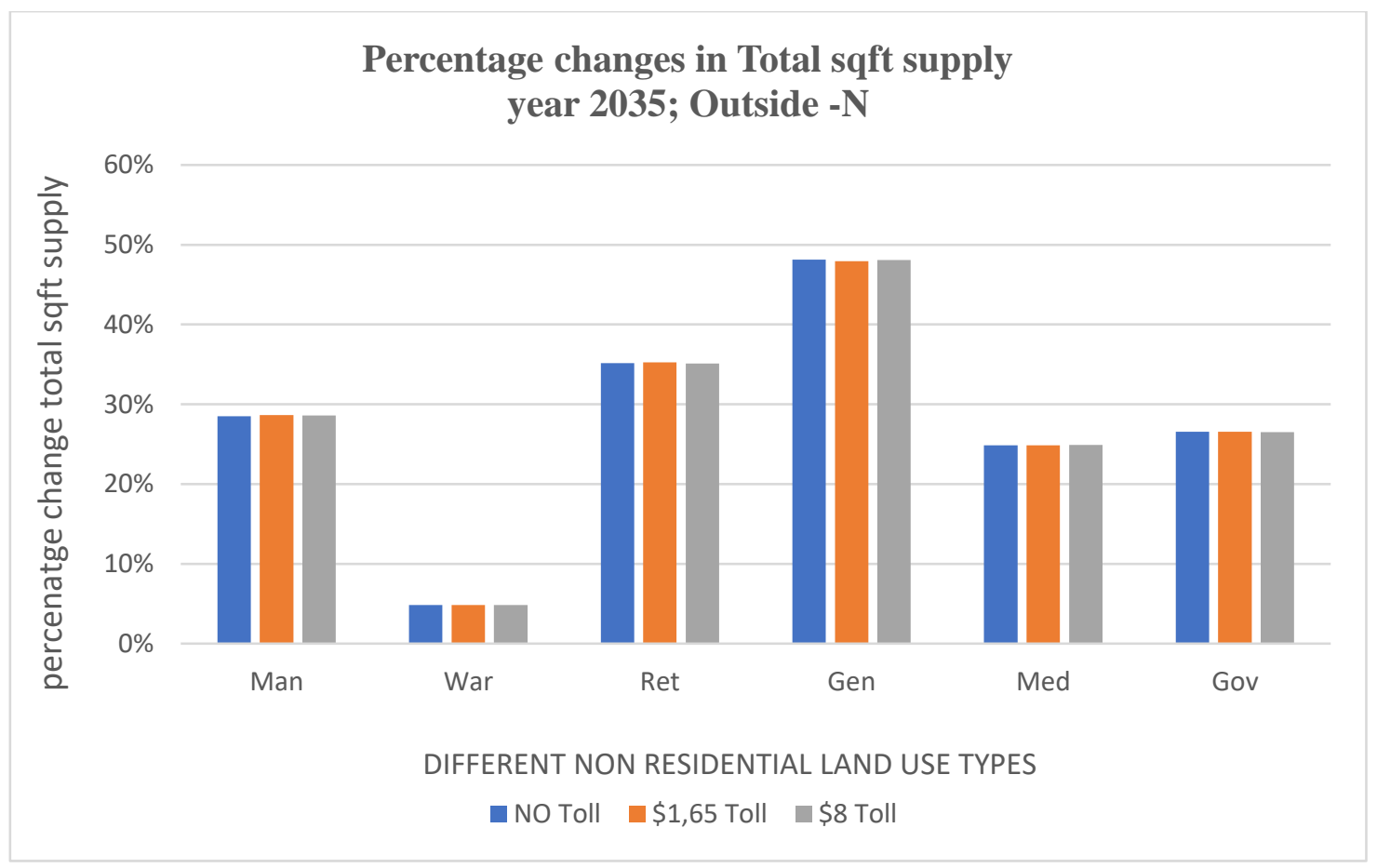

Figure 7.25 
Under no toll, it is noticeable how in the SE there is the lowest sqft supply available overall. If one looks at specific real estate classes, Warehousing space is projected to have the least sqft supply growth in SE Portland, and further, Warehousing is the real estate class with the lowest available supply overall. N Portland is projected to have the highest sqft supply for all the economic activities except Warehousing.

Once $\$ 1.65$ and $\$ 8$ tolls are implemented, there are not significant changes in total sqft supply compared to the no toll alternative. In fact, the percentage changes is within $1 \%$ in each economic activity.

Again, due to the UGB, supply acts as fixed within the Portland region.

\section{Residential Land Use:}

Residential land use recognizes 4 classes of real estates: osf, omf, rsf, and rmf, as explained in the previous chapter. Households are assumed to locate where they can access a primary place of work. From each of the 72 ezones, households select a place of residence from among the 425 rzones according to their indirect utility functions embedded in MetroScope. Therefore, there is a connection between housing stock and place of employment (based on their willingness to pay and consumer surplus).

\section{$\underline{\text { Residential Location Prices }}$}

Inside the Central City:

Figure 7.26 shows percentage of changes in residential location prices inside the Mid-cordon before and after the toll cordon schemes in 2035. 


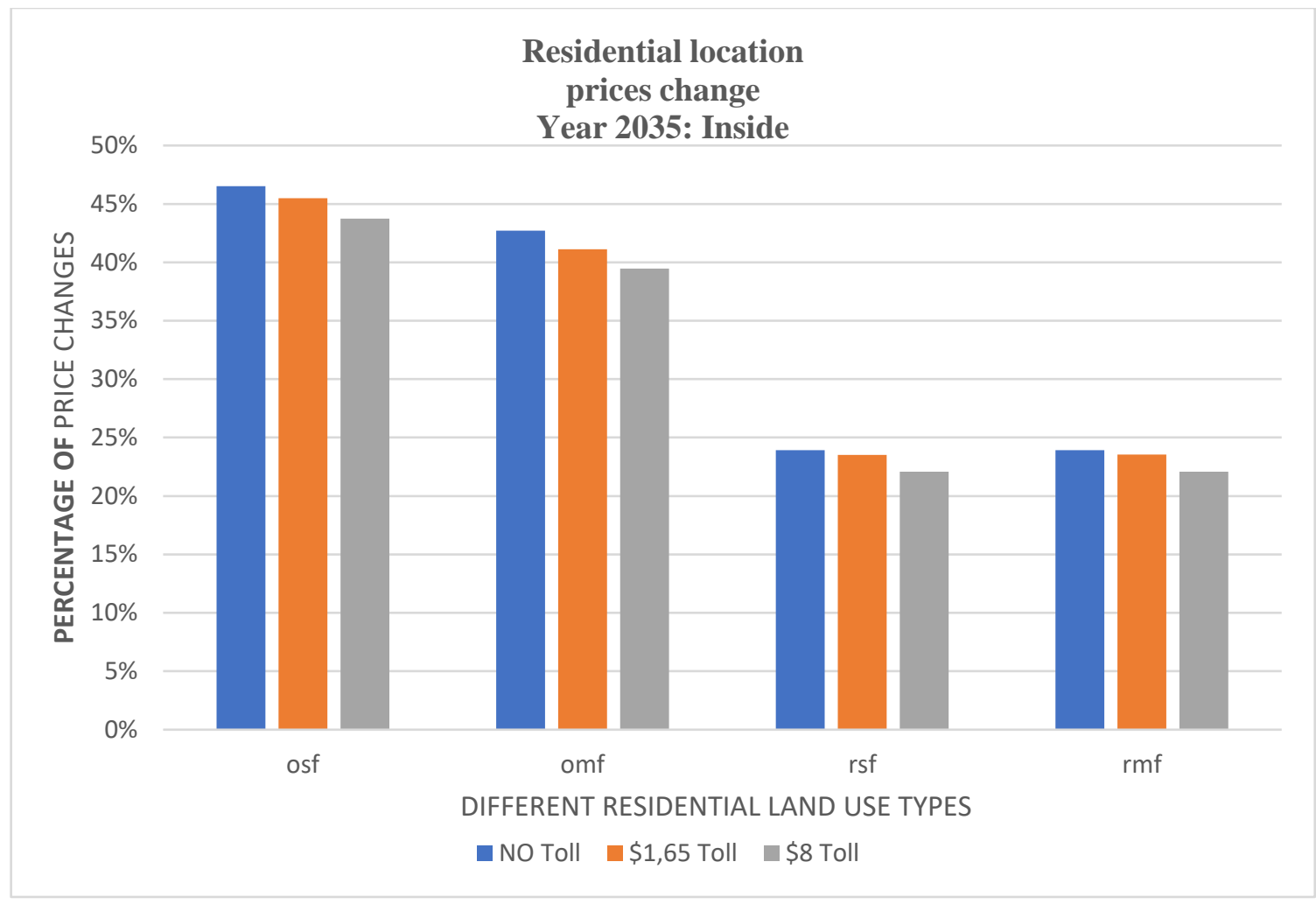

Figure 7.26

Under no toll, the ownership price index is projected to appreciate about double compared to rental units inside the Central City in 2035.

After the implementation of $\$ 1.65$ and $\$ 8$ tolls, all prices report a relative appreciation, but at a lower percentage than under a no toll scenario. Generally, the higher the toll, the less the prices will appreciate compared to no toll after 25 years.

A comparison between the Small cordon and the Mid-size cordon shows that while toll stimulates price appreciation for all the real estate classes within the CBD, toll is projected to slow price growth within the Mid-cordon Central City.

It could be assumed that the increased size of the cordon is the key variable in negatively influencing location price index for residential real estate once that cordon is place. Further, the higher the toll, the smaller is the price appreciation inside the Mid-size 
cordon. It could be speculated that the implementation of a cordon scheme around Central City is favorable to the development of higher-value economic activities, yet household demand for housing is declining within the tolled area.

Westside:

Figure 7.27 shows percentage changes in residential location prices for the area right outside the Central City cordon before and after toll cordon schemes are implemented in 2035 .

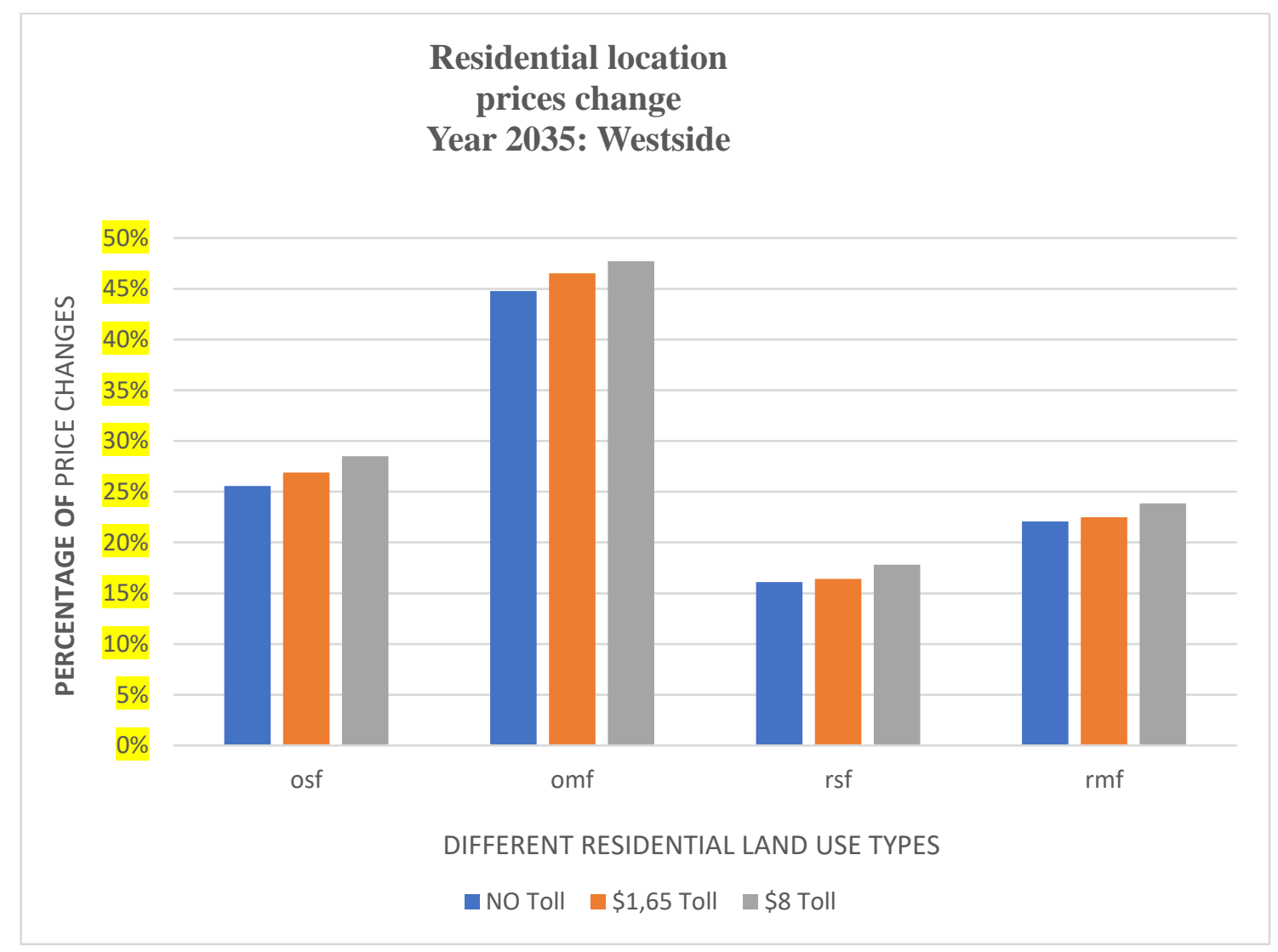

Figure 7.27 
In a no toll scenario, demand for all residential real estate appreciates, triggering a relative price growth until demand meets supply. Omf is the residential class with the largest price appreciation in 2035.

Once $\$ 1.65$ and $\$ 8$ tolls are implemented, omf price indexes increase an additional $2 \%$ and $3 \%$. Also, for other residential real estate, the price index grows about the same percentage as for omf compared to no toll.

Overall, tolls boost demand for residential real estate, as is reflected in a relative appreciation of prices as response to the increased demand relative to supply.

West Portland is a residential area with a concentration of higher-income households (City of Portland, 2011); therefore, the cost that those households will have to pay to access the Central City is assumed to be less significant in affecting their demand for housing. If from one side, households that live in West Portland are facing the cost of crossing the cordon line to enter the city center or going to East Portland, from the other they seem to appreciate locating in residential suburbs. Also, some households might not be affected by the tolls if the workplace of the primary household is in the West metro areas in cities such as Hillsboro where worldwide corporations are located.

\section{Eastside:}

Figures 7.28, 7.29, and 7.30 show the percentage changes in location price in SE, NE, and N Portland before and after the implementation of tolls after a 25 -year period. Figure 7.31 is a summary of the previous graphs and compares the percentage of price changes of the three East districts before and after the tolls in 2035. 


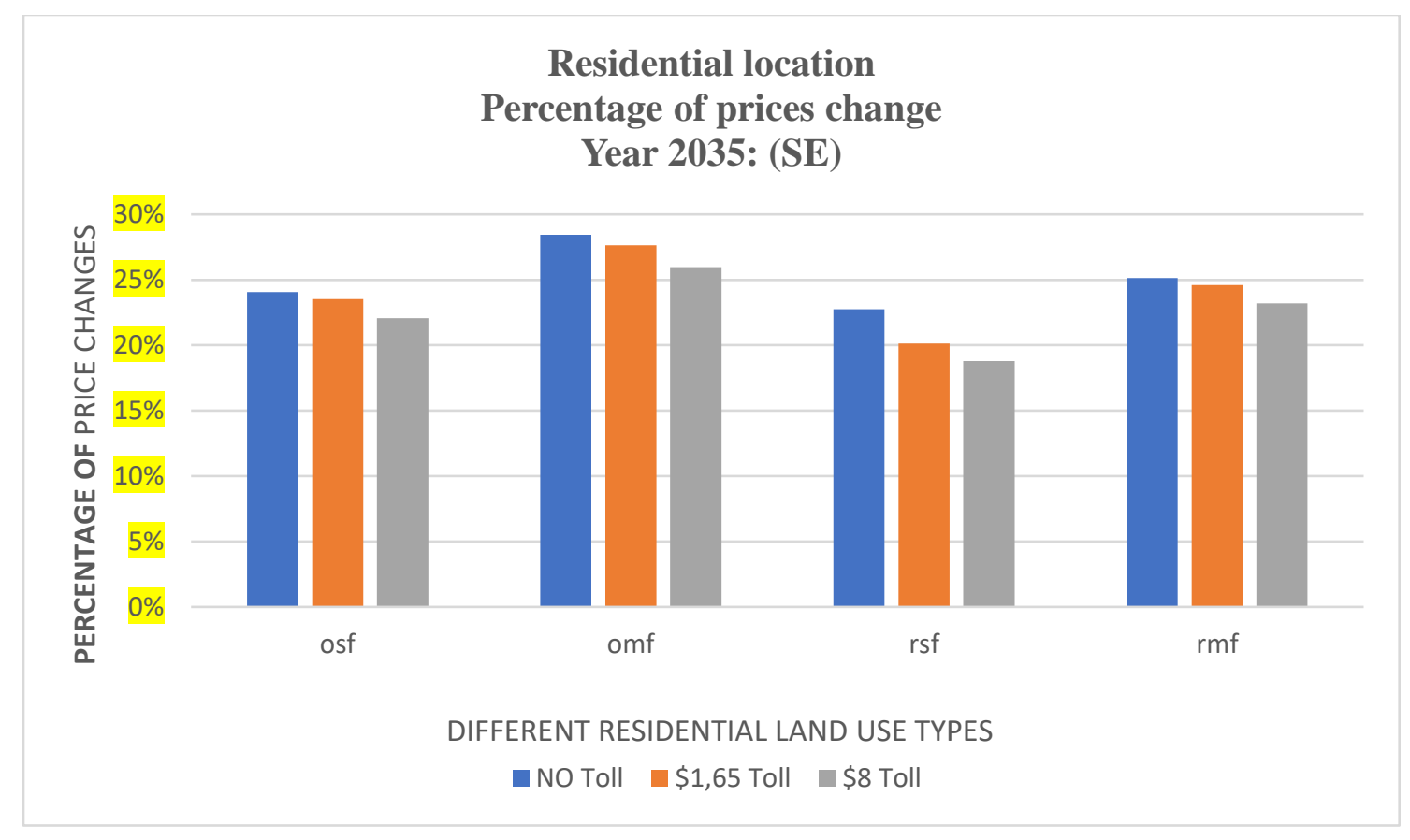

Figure 7.28

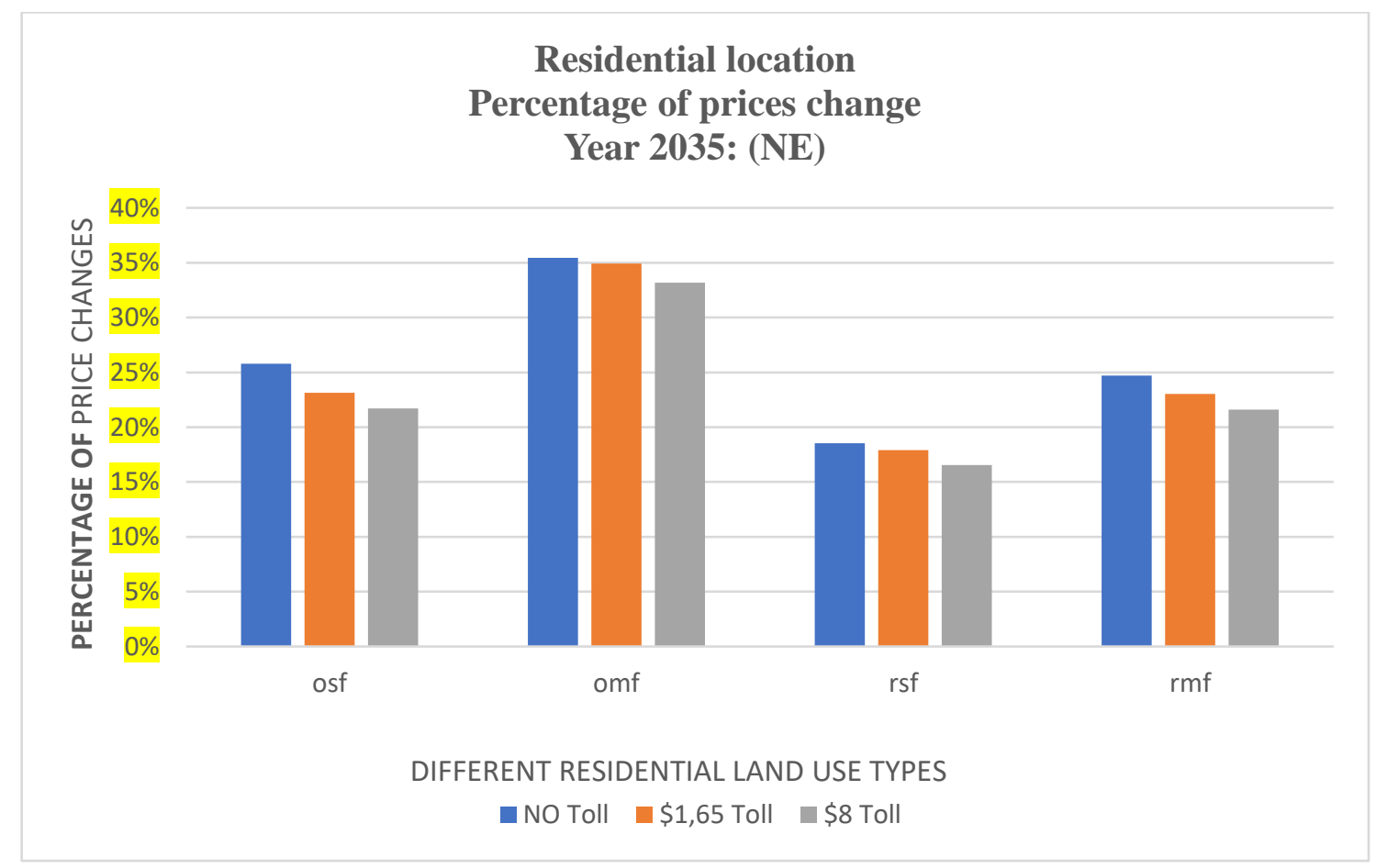

Figure 7.29 


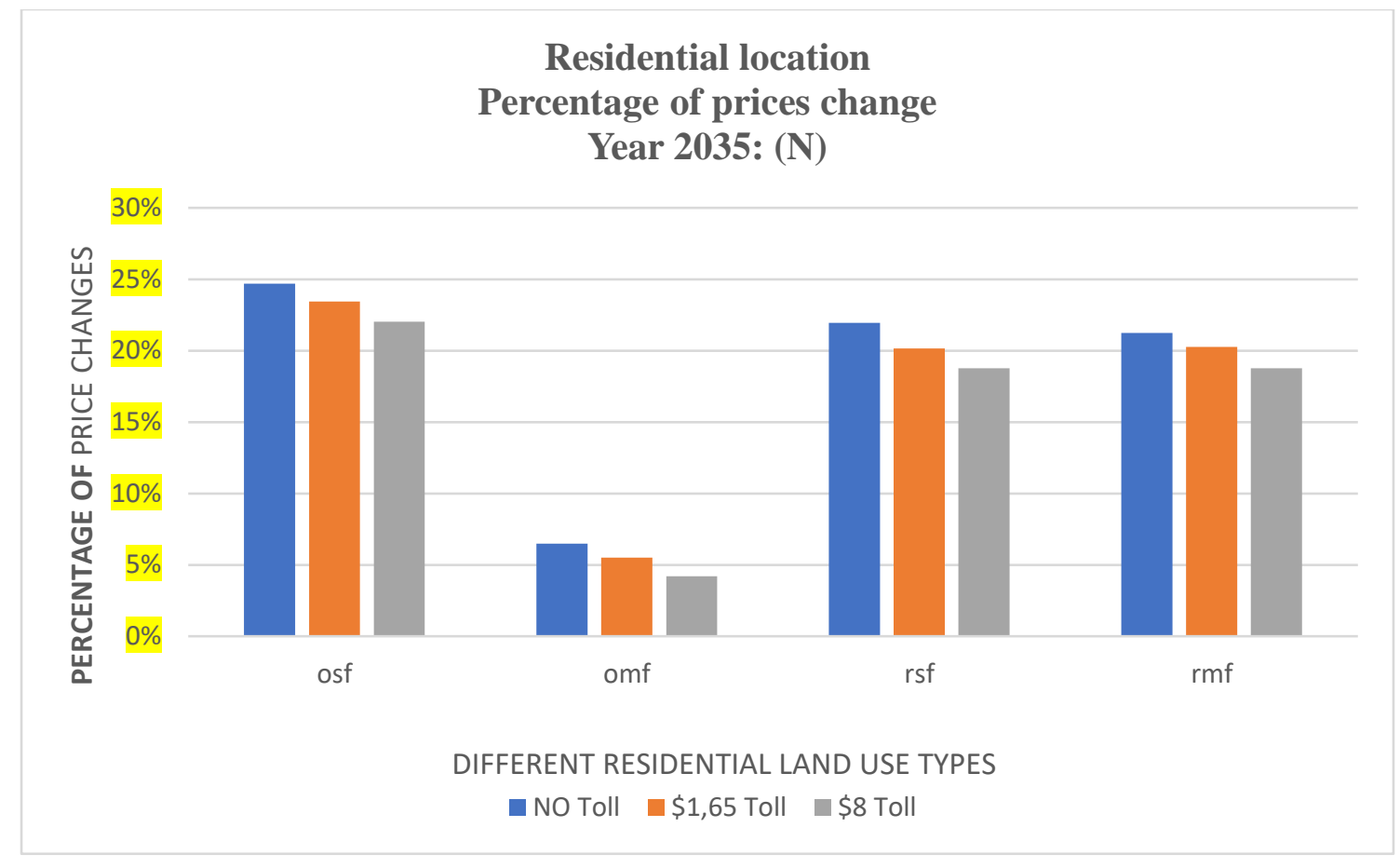

Figure 7.30

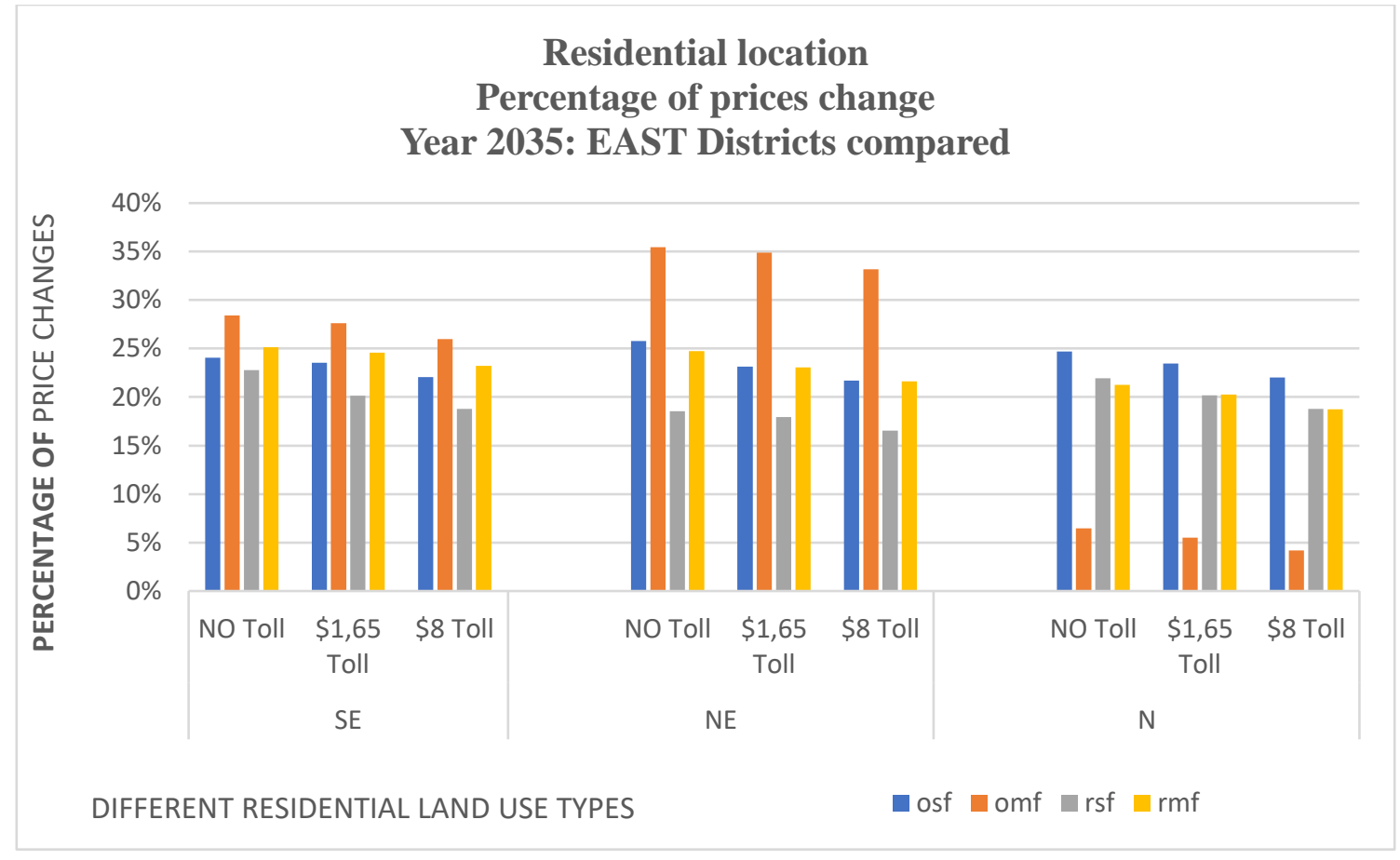

Figure 7.31 
Under no toll, demand for omf is projected to increase the most in NE, followed by SE, Portland. While in the NE, ownership housing (osf and omf) is preferred and shows an increase in relative price, in the SE, multifamily housing is preferred regardless if owned or rented. $\mathrm{N}$ Portland is projected to have the smallest increase in relative value for omf across all the Eastside.

After the implementation of $\$ 1.65$ and $\$ 8$ tolls, price indexes for all types of housing fall. Further, the higher the toll, the larger the decline in the price index compared to no toll. Generally, toll reduces relative prices for housing in East Portland between $2 \%$ and $4 \%$, depending on the selected neighborhood.

It could be speculated that some households might decide to move to some other neighborhoods beyond the areas studied or further way in the metro area outside of Portland.

\section{Total Households Supply}

The next output analyzed is changes in the percentage of total households' supply inside the Central district and right outside the cordon boundaries before and after the cordon's implementation in 2035.

\section{Inside the Central City:}

Figure 7.32 shows the percentage changes in total households' supply within the Central City, comparing a no toll scenario versus two different cordon alternatives 25 years after the implementation. 


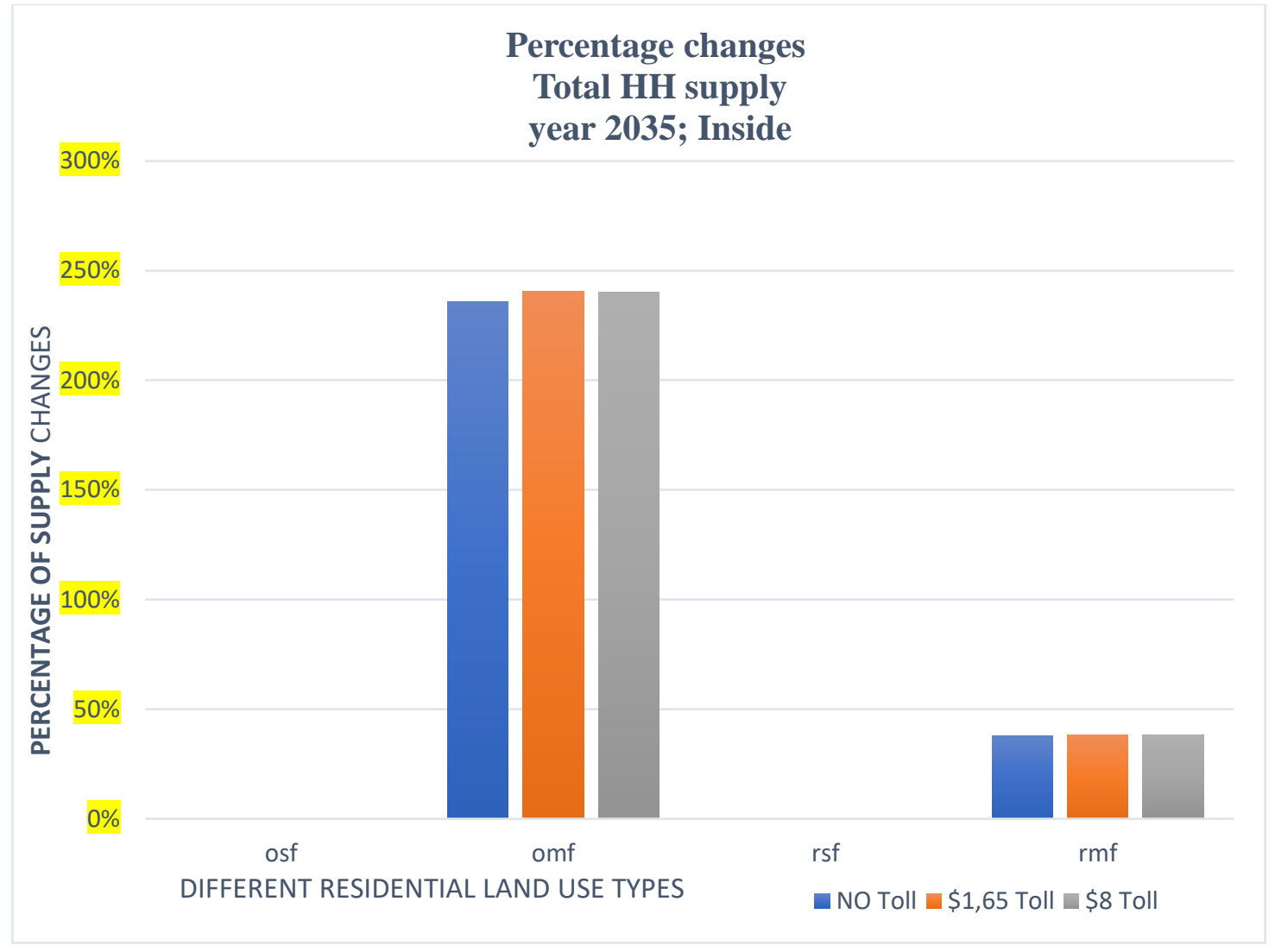

Figure 7.32

Supply of ownership of multifamily hh increases exponentially, followed by a much smaller increase in supply of rental of multifamily hh. Supply of single-family hh stays almost unchanged.

Under $\$ 1.65$ and $\$ 8$ tolls, total supply is projected to increase within all classes, especially for omf. Generally, the dollar amount charged is not significant in affecting total hh supply; instead, whether a cordon is implemented or not is important in influencing the quantity of total hh supply at the projected year. Overall, toll has the effect of increasing total hh supply versus demand; location prices go down within the cordon area, as reported in Figure 7.26. 


\section{$\underline{\text { Right Outside the CBD Boundaries }}$}

Westside:

Figure 7.33 shows the percentage changes in total households' supply in the West, comparing no toll versus two different cordon scenarios after 25 years.

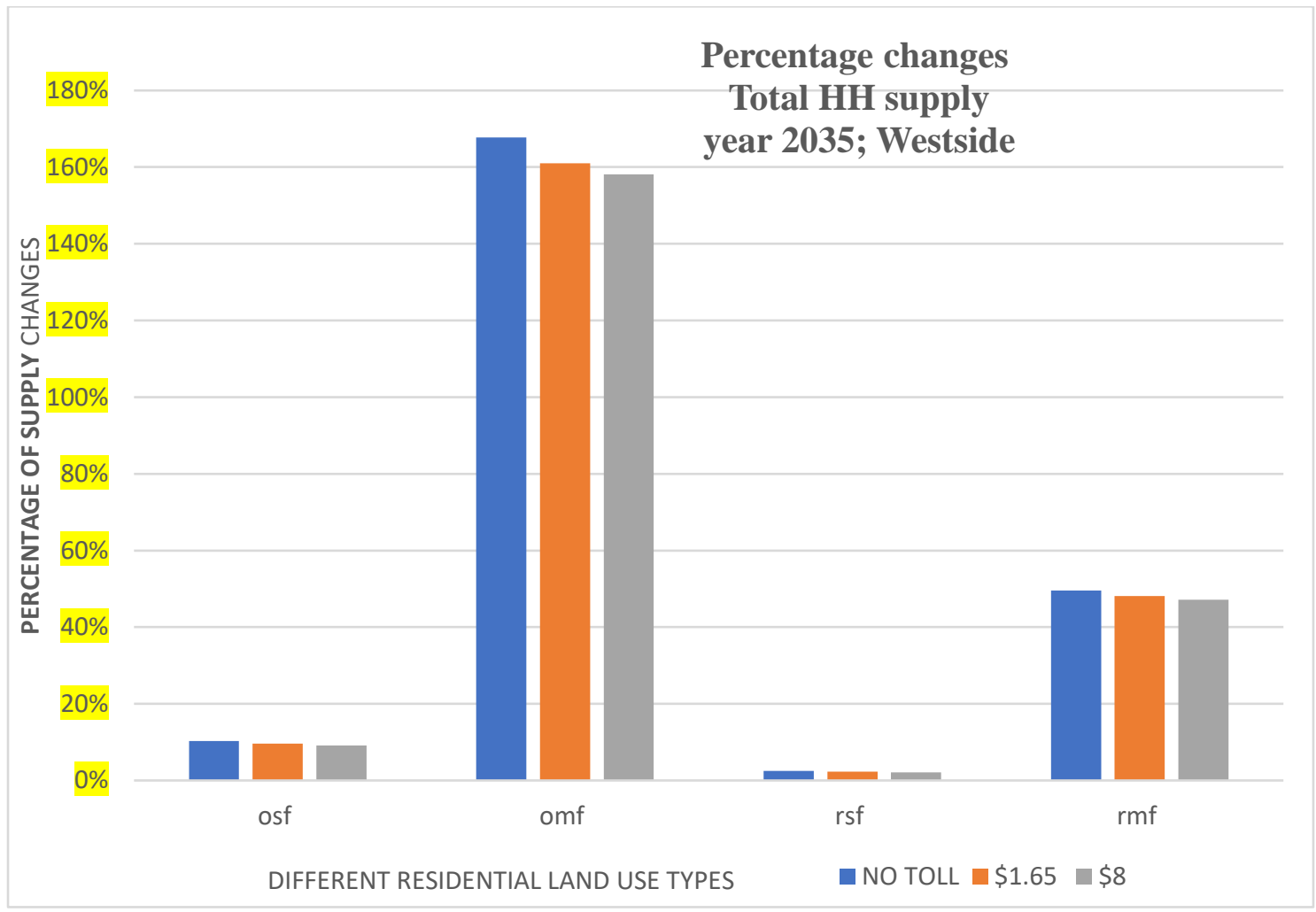

Figure 7.33

Under no toll, ownership of multifamily units is projected to a very large increase in household supply; overall, multi-family real estate is showing a larger increase in supply compared to single-family real estate.

Under \$1.65 and \$8 tolls, multi-family hh supply is projected to a minor decrease in both ownership and rental classes, while single-family hh supply shows almost no changes compared to no toll 25 years after the cordon implementation.. 
Eastside:

Figures $7.34,7.35$, and 7.36 show the percentage changes in total hh supply in SE, NE, and N Portland before and after the implementation of the tolls in 2035.

Figure 7.37 compares total hh supply changes in the East districts before and after the tolls in 2035 .

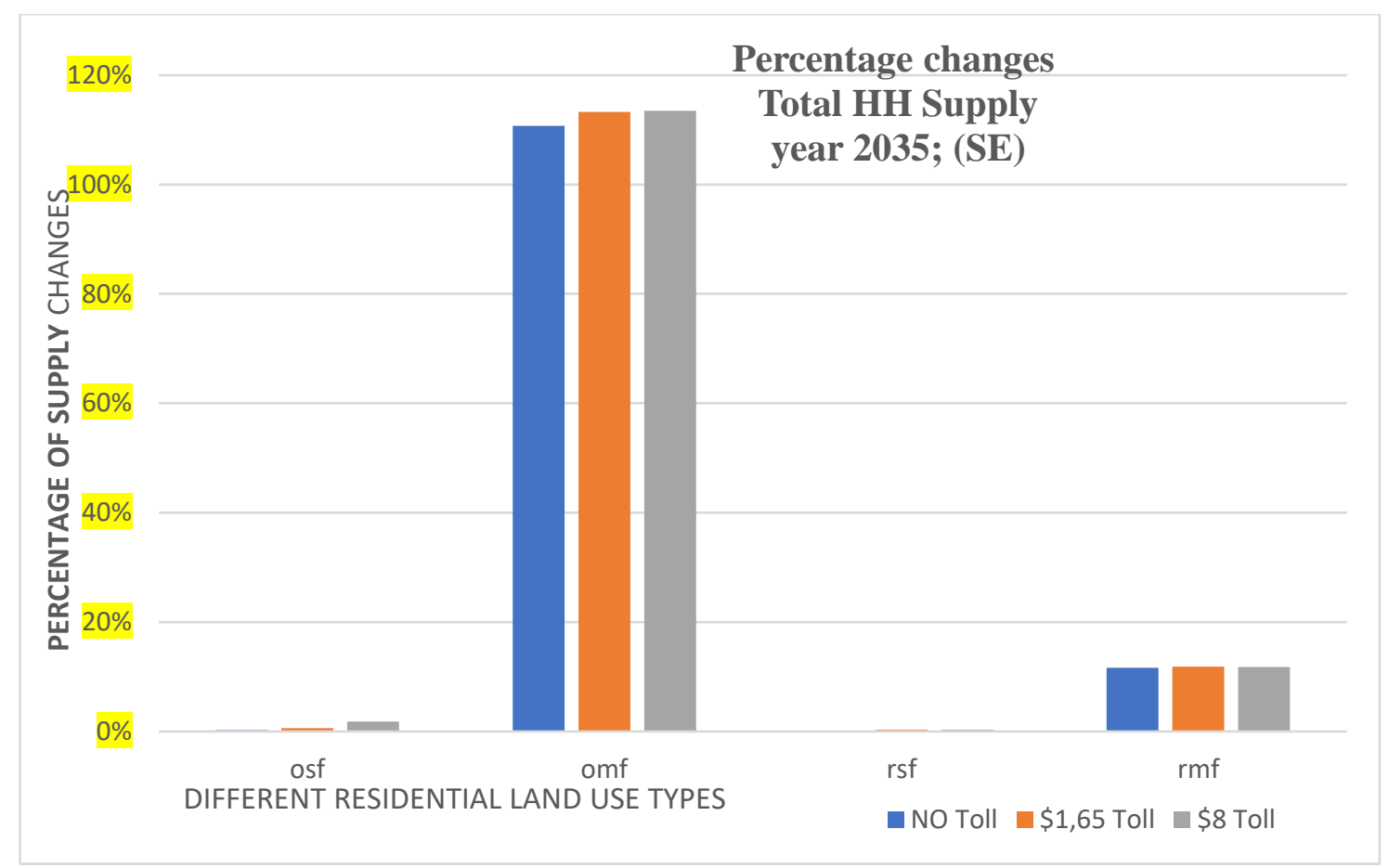

Figure 7.34 


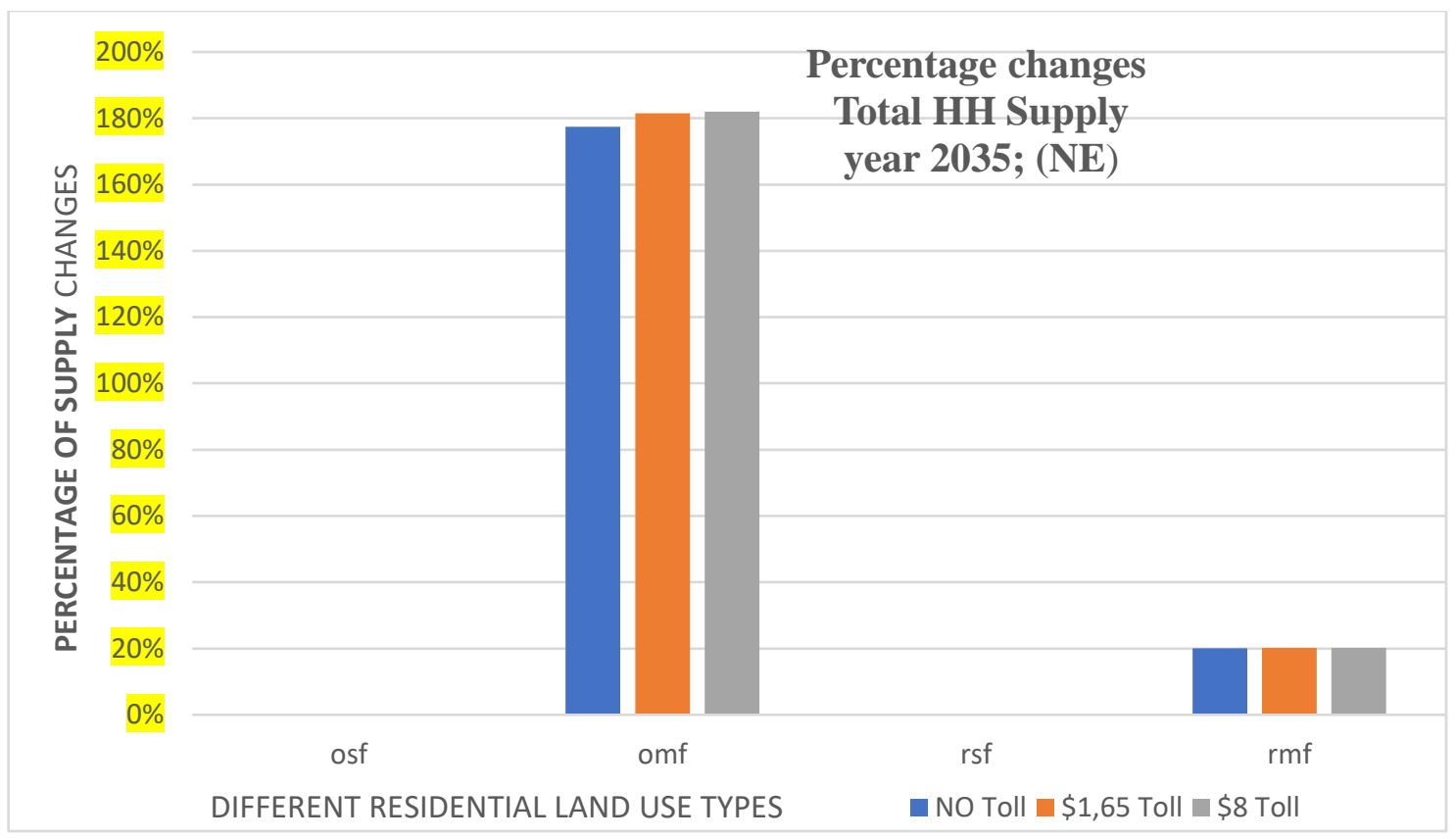

Figure 7.35

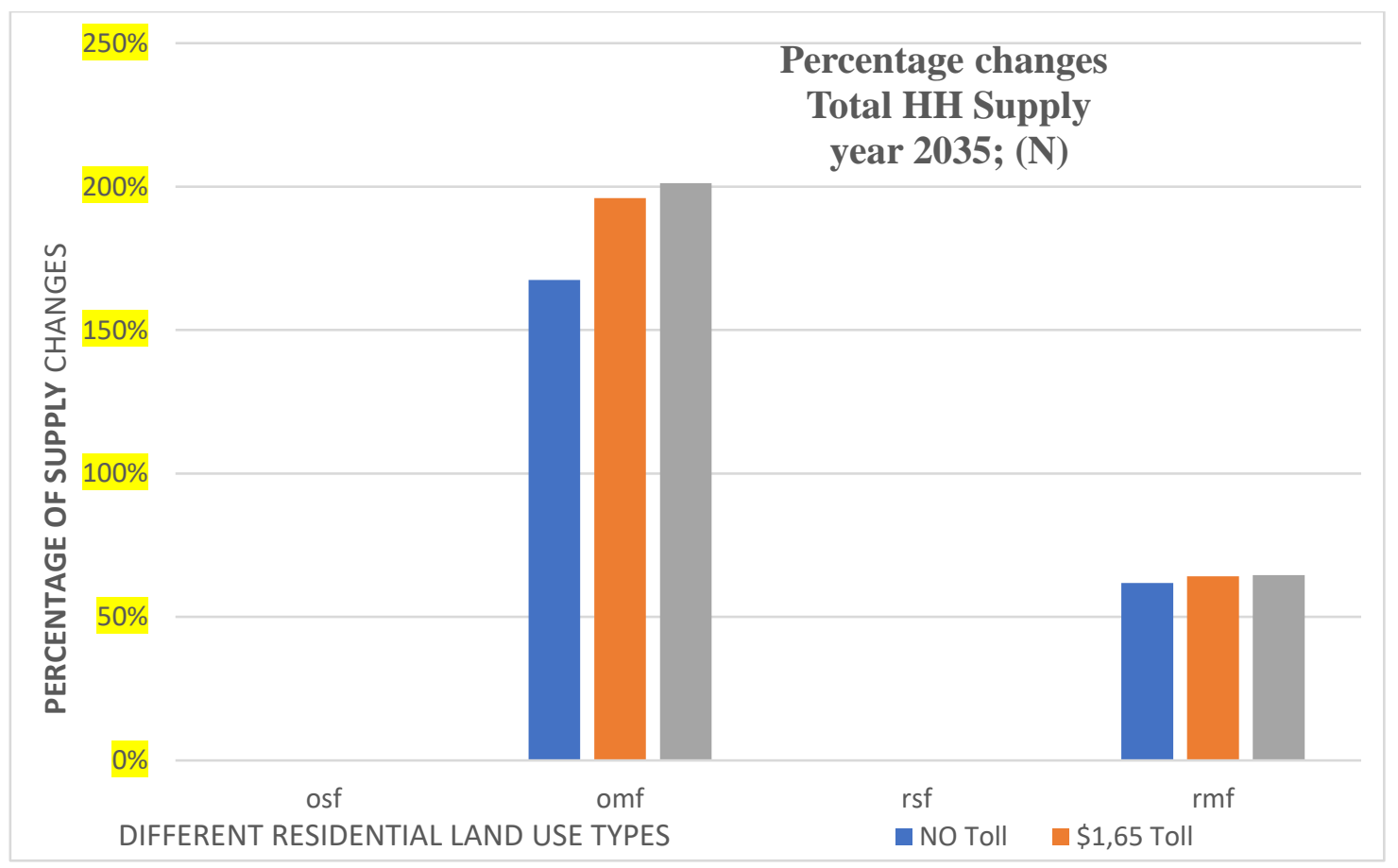

Figure 7.36 


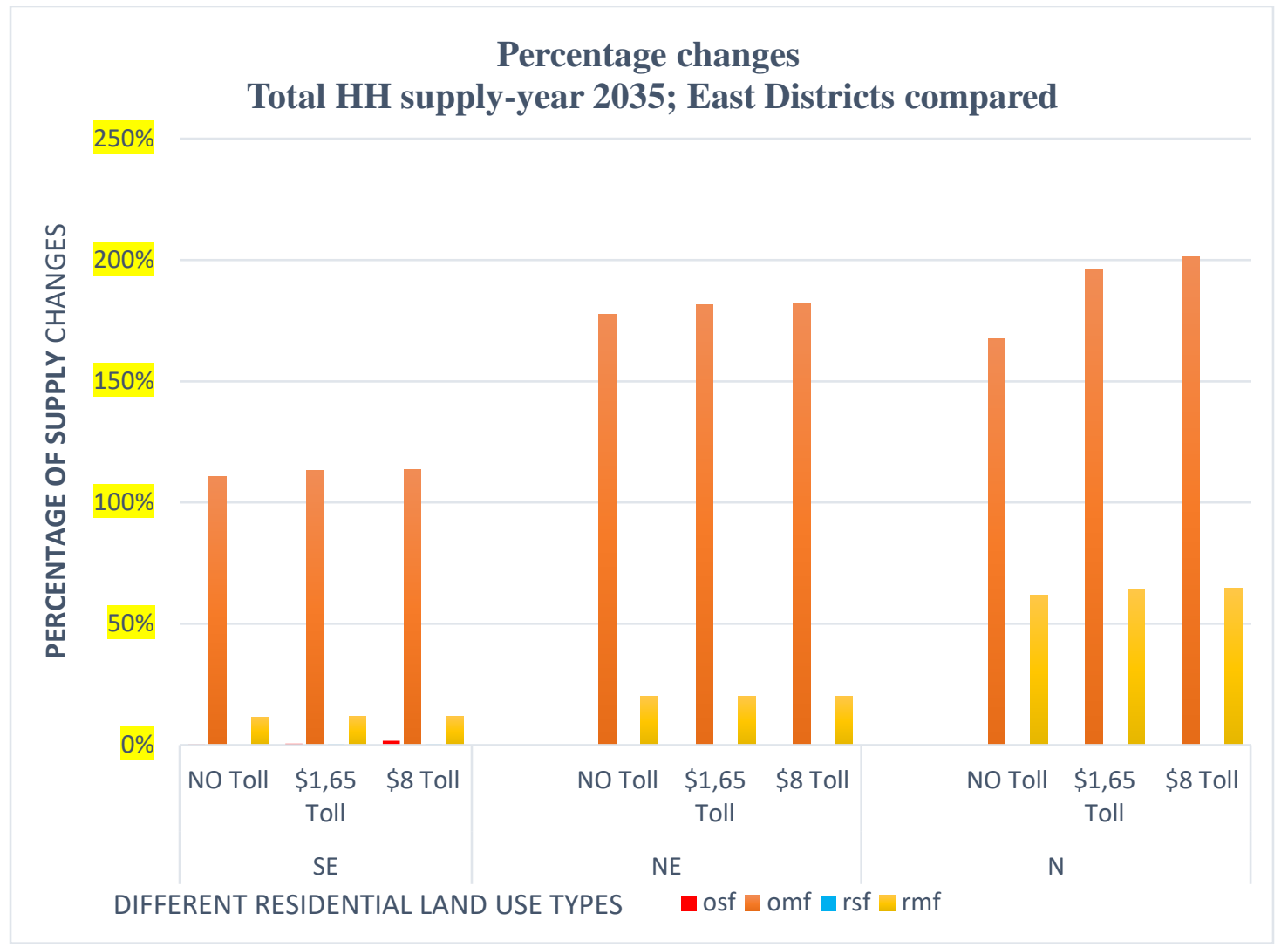

Figure 7.37

Under no toll, total household supply is projected to increase exponentially for ownership of multifamily units in East Portland, predominantly in NE and N Portland, respectively. Also, rental of multifamily houses increases in the East districts, specifically in N and NE Portland. Single-family homes do not show any significant changes in total hh supply over time.

Once $\$ 1.65$ and $\$ 8$ tolls are implemented, household supply for multifamily units is projected to further increase over time, especially in $\mathrm{N}$ and NE Portland (on average $4 \%$ in each area). Also, rmf supply increases the most in $\mathrm{N}$ Portland, but increases within the other East districts as well. Single-family supply does not show any significant changes over time. 
Generally, it can be stated that the implementation of a toll cordon design within the Central City of Portland impacts non-residential and residential real estate location patterns and resulting in changes in prices. Demand is more sensitive to the implementation of tolls than supply, which acts as fixed because of the UGB that limits the available supply of land in the region. Also, supply can become substitutable between purposes.

The dollar amount charged to enter the cordon, whether is $\$ 1.65$ or $\$ 8$, generally affects only the magnitude of the outcome produced; the higher the toll, the slightly bigger the magnitude of the effect on land use.

Also, it is noteworthy to highlight how the increased size of the cordon design impacts non-residential and residential land use patterns differently than the implementation of a smaller cordon around the CBD only. A more detailed comparison of the effects that each cordon size design has on land use patterns is provided in the final chapter of this paper.

The next section will provide an overview of land use changes within the entire city of Portland if a Mid-cordon is implemented, to explore whether there is a net improvement in economic growth and residential demand at the entire city level, or a merely redistribution of activities and population from one area to another.

\section{Inside the Entire City of Portland:}

Non-Residential Land Use:

Figure 7.38 shows percentage changes in non-residential location price for the entire city of Portland after the implementation of $\$ 1.65$ and $\$ 8$ toll cordons around the Central City compared to a no toll scenario in 2035. 


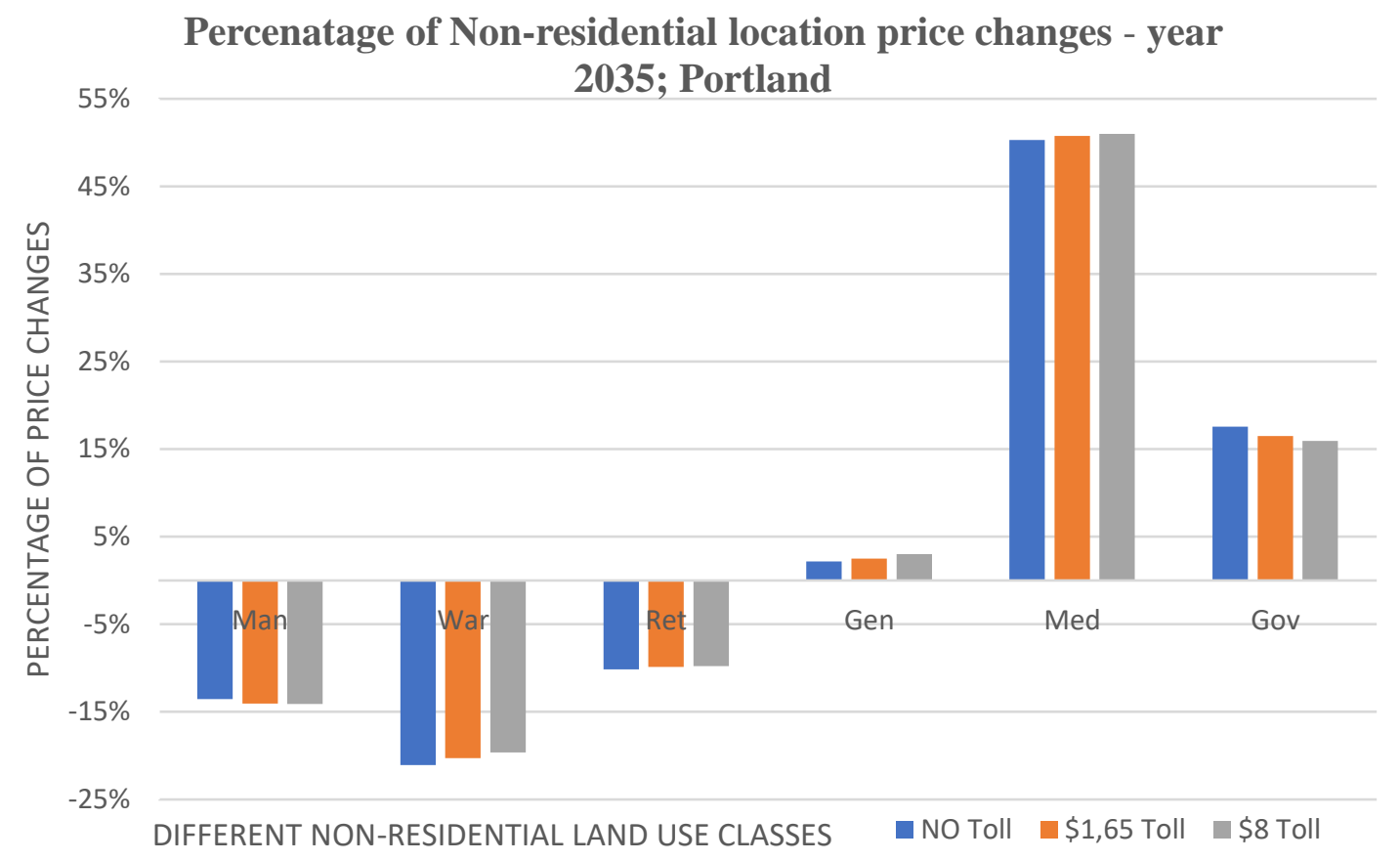

Figure 7.38

Under a no toll scenario, only Medical, Government, and General real estate are projected to a relative price appreciation. Industrial activities and Retailers show a decrease in demand relative to supply that negatively affects prices over time.

Once $\$ 1.65$ or $\$ 8$ tolls are implemented, all the industries, with the exceptions of Government offices and Manufacturing, report an increase in demand relative to supply that is reflected to an increase of the price index in 2035.

\section{$\underline{\text { Total Employment Changes }}$}

Figure 7.39 shows changes in employment within the entire city of Portland after the implementation of $\$ 1.65$ and $\$ 8$ toll cordons around the Central City compared to a no toll scenario in 2035 . 


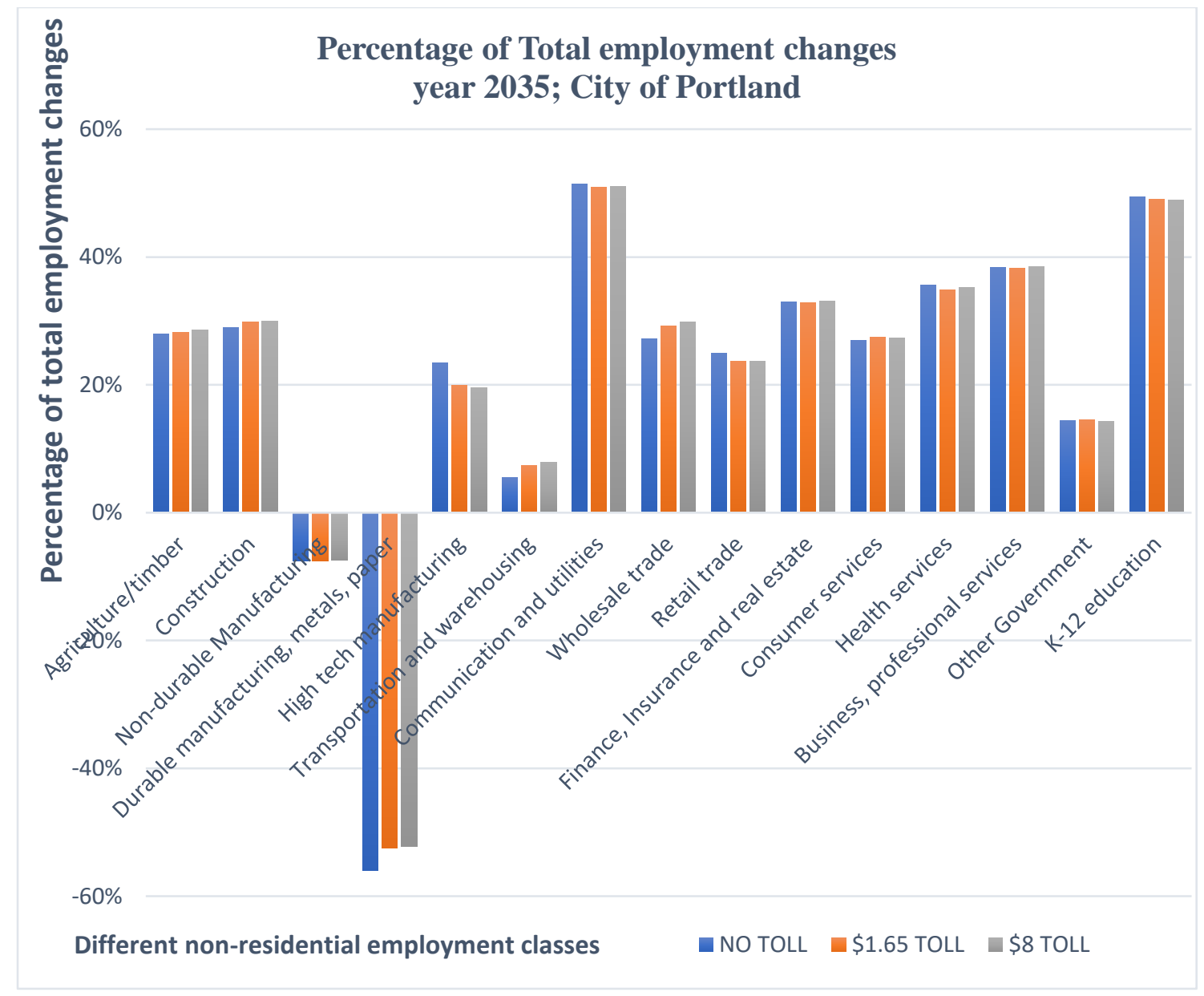

Figure 7.39

Under no toll, only Durable and Non-durable manufacturing industries are projected to a decline in employment, with a decline of $7.6 \%$ and $60 \%$, respectively. All the other industries have an increase in their employment. Moreover, higher-value economic activities are projected to the largest increase in their employment over time. In detail, employment for K-12 education increases by 49\%, while Communication/Utilities increase by $51 \%$. The class with the smallest increase in employment is Transportation/Warehousing (5.5\%).

Tolls negatively affect employment in four industries: Other government, Consumer services, K-12 education, and High-tech manufacturing. The percent 
difference is extremely small for the first three classes, while High-tech manufacturing reports a larger drop. Employment in all the other industries is positively influenced by tolls compared to no toll in 2035.

Overall, a Mid-cordon design seems to positively affect employment for the majority of industries within the entire city. It seem to encourage more development toward the center and right outside the boundaries compared to a Small cordon scheme.

\section{Percentage Changes in HH Location Demand}

Figure 7.40 shows how a Mid-cordon influences location demand for families without and with school-age children across the entire city of Portland compared to no toll in 2035.

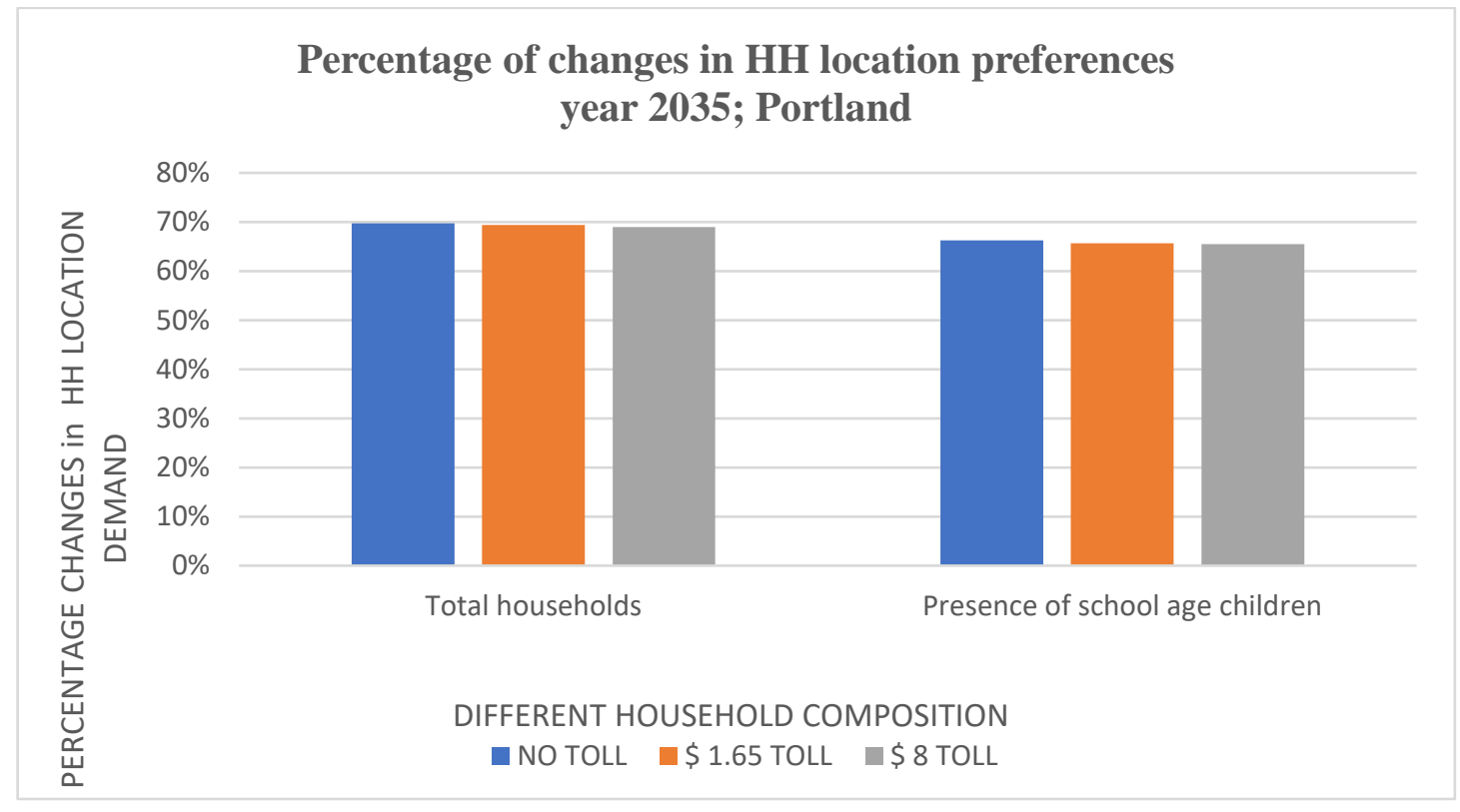

Figure 7.40 
In a no toll scenario, total households' demand for housing grows over time for both household types.

Once toll cordons are implemented, total household demand (with and without children) is projected to an overall $1 \%$ decline once $\$ 8$ is charged compared to the default scenario. Generally, a toll cordon minimally decreases hh demand for housing inside Portland compared to a no toll alternative.

\section{Total sqft Supply}

Figure 7.41 shows how a Mid-cordon influences total sqft supply inside the entire city of Portland compared to no toll in 2035.

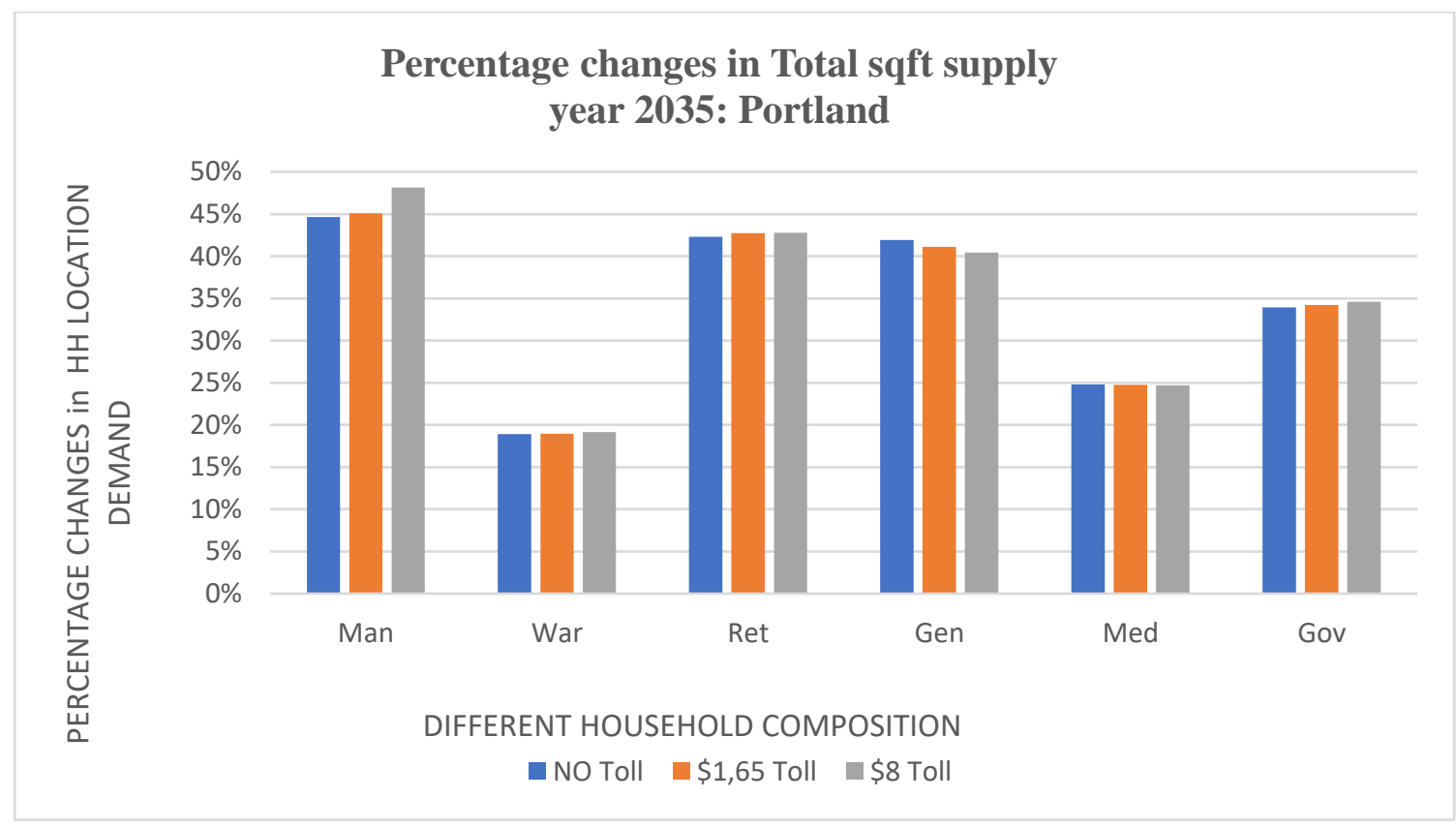

Figure 7.41

Under no toll, Manufacturing is projected to have the largest increase in total sqft supply (45\%), while Warehousing has the smallest amount of sqft supply available. Generally, sqft supply for commercial real estate is higher than for institutional real estate in 2035 . 
Once a cordon is implemented, only Manufacturing reports an increase in sqft available, at $4 \%$ under an $\$ 8$ toll, while total sqft supply did not report any change larger than $1 \%$ for any other scenario. Therefore, with the exception of changes in Manufacturing supply if a $\$ 8$ toll is implemented, there are not changes in sqft supply for any real estate type.

Generally, tolls do not affect sqft supply compared to no toll. Again, the presence of an UGB in the region makes supply behave as fixed.

\section{$\underline{\text { Residential Location Prices }}$}

Figure 7.42 shows percentage changes in residential location price within the entire city of Portland after the implementation of $\$ 1.65$ and $\$ 8$ toll cordons around the Central City compared to a no toll scenario in 2035.

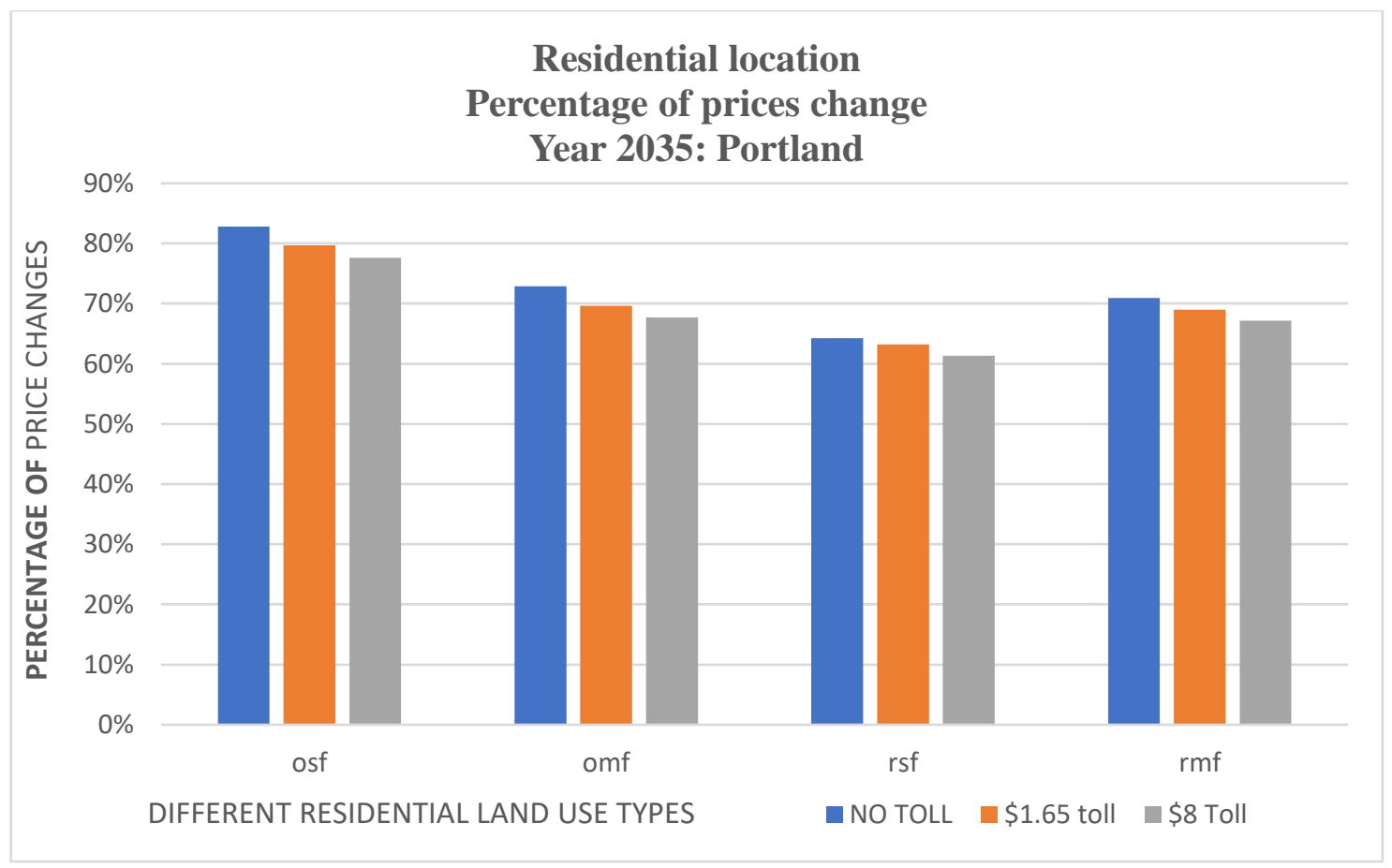

Figure 7.42 
In a no toll scenario, ownership classes are projected to the largest price index increase, in particular osf. Generally, all the residential real estate types show a large growth in demand versus supply that is reflected in relative increases in property values within the entirety of Portland.

After the implementation of $\$ 1.65$ and $\$ 8$ toll cordons around the Central City, prices still appreciate, but at a lower percentage compared to no toll; all 4 real estate classes have a relative loss in value compared to the default scenario. The higher the toll, the larger is relative price depreciation over time.

Generally, tolls reduce the demand for residential housing relative to the available supply, so that prices will decrease and adjust to the new demand and indirectly, through the new lower prices, supply and demand will find a new equilibrium. The higher the toll, the smaller the relative price appreciation over time.

\section{$\underline{\text { Total Households Supply }}$}

Figure 7.43 shows changes in residential supply within the entire city of Portland after the implementation of $\$ 1.65$ and $\$ 8$ toll cordons around the Central City, compared to a no toll scenario in 2035 . 


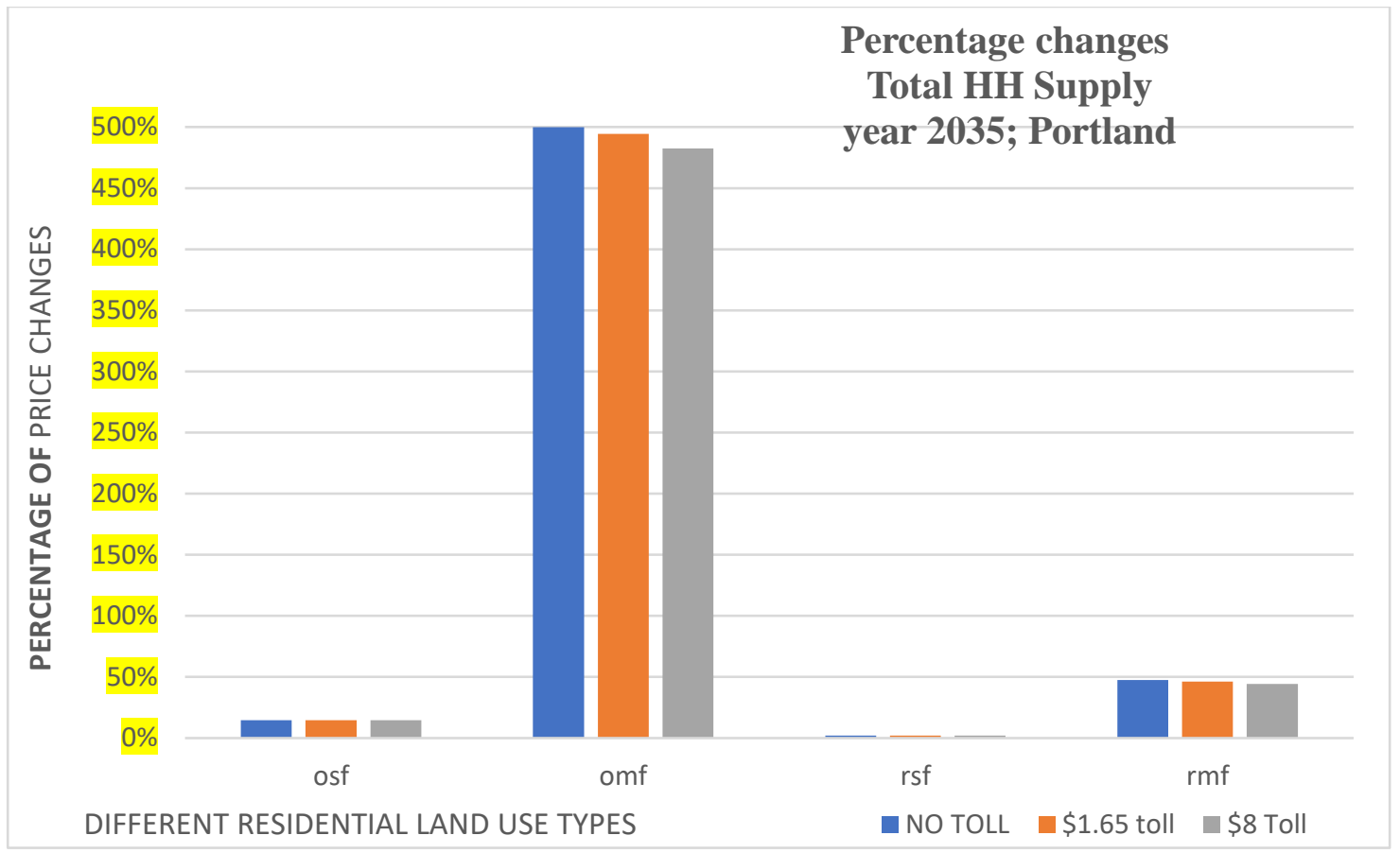

Figure 7.43

Under no toll, the entire city of Portland is projected to experience exponential growth in household supply of owner-occupied multifamily housing units in 2035. Rental of multifamily housing increases only $47 \%$, compared to a $499 \%$ increase in omf. Supply increase for single-family units is minimal.

After implementing toll cordons, rmf supply is forecast to drop 17\% and 5\%, respectively, under $\$ 1.65$ and $\$ 8$ tolls. Generally, the higher the price of the toll, the larger the decrease in omf supply compared to no toll. Tolls decrease supply for the other real estate classes as well, although at a marginal degree.

\section{Summarizing the Effects of the Central City Cordon:}

Generally, the implementation of a toll cordon around the Central City has a positive effect on demand for all non-residential real estate (except Manufacturing and 
Government) relative to supply, as is reflected in an increase in their relative property prices within the entire city of Portland compared to no toll in 2035.

The comparison of a toll cordon versus a no toll alternative shows that while demand for the majority of non-residential real estate declines in West of Portland; nevertheless, demand for all real estate raises within the ring (but Government), and demand for commercial real estate increases right outside the cordon in the Eastside.

Within the entire city, tolls positively affect employment for all industries, with the exception of High-tech manufacturing, Consumer and Government services, and K12 education compared to no toll in 2035.

Also, tolls boost employment for all classes (except K-12 education) inside the ring. Directly outside the West boundaries, employment in industrial activities grows, but at a very small percentage. Right outside the East side of the cordon, employment in Consumer services, and particularly in Transportation and Wholesale trade, is projected to increase compared to no toll in 2035.

Within the entire city, total household demand drops compared to a no toll scenario. Nevertheless, there is an increase in total household demand specifically in North and NE Portland.

Moreover, within the entire city, demand for residential housing relative to supply declines, triggering a relative price depreciation versus a no toll alternative in 2035.

Demand for residential real estate relative to supply declines within the ring as well as right outside the East side of the cordon, negatively impacting the price index, which only increases in the West side of Portland. 
Overall, supply is inelastic, so changes in demand affect prices the most. Also, the similarity between $\$ 1.65$ and $\$ 8$ results is very interesting; such different charges generate very similar outcomes. MetroScope is assumed to mitigate the impact of such different tolls by changing the distribution of the trips that are impacted by the tolls. Generally, the implementation of a Mid cordon positively affects economic growth within the entire city of Portland. Nevertheless, the movement of commercial activities toward the Eastside could generate some relocation of economic activities there. Compared to the Small cordon and a no toll alternative, a Mid cordon tends to concentrate activities more toward the core, both inside and outside the boundaries. Nevertheless, some activities (such as High-tech manufacturing) and households seem to disperse beyond the areas analyzed.

\section{Metro Areas Outside of Portland:}

The last part of the analysis focuses on land use changes in the metro cites surrounding Portland after a Central City cordon is implemented, compared to a no toll alternative in 2035 .

It is not the main target of this study to provide a comprehensive analysis of the metro area. This research focuses on the city of Portland, although a brief overview of changes in land use trends outside of Portland provides a broader overview of land use changes after a cordon around the Central City is implemented, compared to no toll in 2035.

After the implementation of toll cordons compared to a default alternative in 2035: 
Generally, non-residential location price indexes increase for many industries in the West part of the metro area. Tanasbourne/Bethany is projected to experience an overall price index appreciation in each industry, followed by Hillsboro/Orenco and Beaverton/Tigard, which report a relative drop in value only for General, Government, and Retail properties.

In the East side, Happy Valley/Milwaukie is projected to experience a relative price drop in all industries but Manufacturing and Government activities, while Gresham reports a relative price decline only in Warehousing and General offices.

Lake Oswego has a relative price drop for commercial properties, though at a very small degree after the implementation of a Mid-cordon.

Hillsboro/Orenco is projected to experience a larger increase in employment for all Manufacturing, Transportation, and Financial activities after the implementation of tolls compared to no toll. Generally, employment grows in almost all economic activities, with the exception of Construction and K-12 education. In detail, Transportation/Warehousing and Wholesale trades report the largest percentage increase in employment after a cordon is implemented compared to no toll.

Similar changes occur in Beaverton/Tigard and Tanasbourne/Bethany.

Also, Happy Valley accounts for a large number of industries projected to employment growth, with the exception of financial services and K-12.

Gresham has an increase in employment for higher-value economies.

It can be stated that the metro cities have an overall positive effect on nonresidential land use after the implementation of a cordon around the Central City compared to no toll. 
HH location demand increases only in Tanasbourne/Bethany and Gresham, as does residential location price indexes for all the housing types. Ownership of singlefamily units has the largest decrease in value.

Sqft supply does not provide any important changes after a toll implementation, although in Happy Valley/Milwaukie, there is a larger decline in sqft avalaiblity for Warehousing and General office after the Mid cordon is implemented versus no toll in 2035.

Generally, there is a decline in residential supply for the ownership of multifamily units in the entire Metro area as a result of a toll implementation. 


\section{Portland City Boundaries, or Big Cordon}

The "Big" cordon is designed around the boundaries of the city of Portland, Oregon (Figures 8.1 and 8.2), where a toll is charged each time a private vehicle crosses the city boundaries inbound. The effects of the implementation of $\$ 1.65$ and $\$ 8$ tolls are compared to the no toll scenario for all the non-residential and residential real estate categories after 25 years.

The design of a cordon around the city limits is valuable in providing an understanding of the overall effects that the implementation of a cordon charge has on non-residential and residential land use patterns in the city; thus, it can be of political interest. MetroScope forecasts economic activities and households' responses to the charge in the long term, enabling lawmakers to use the projected results to decide whether the use of a cordon toll around the city could enhance economic development. Will business and households stay inside Portland, or will they relocate elsewhere, and perhaps agglomerate, in the surrounding metro areas such as Tigard, Beaverton, Happy Valley, etc.? Which kind of economic activities will be affected the most by a cordon charge, or, instead, won't react to the new policy?

The projected output for the whole city of Portland is analyzed and compared to the same output for the cities located within the metro area but outside the cordon, such as Beaverton, Hillsboro, Tigard, Lake Oswego, and Clackamas (see Figure 8.2) versus a no toll alternative. 


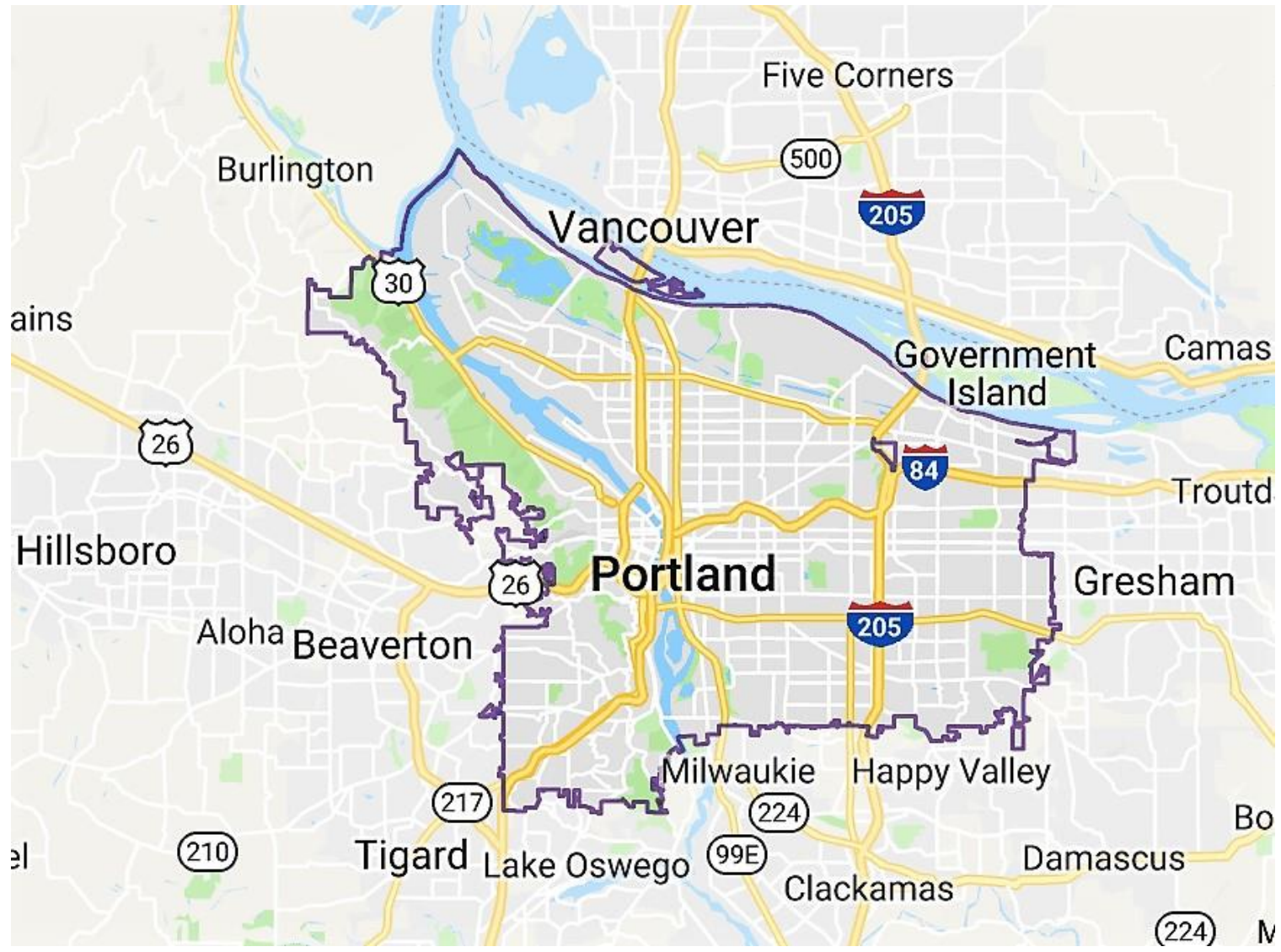

Figure 8.1 Portland, OR City Boundaries

Source: map data @2019 Google

The practical design of the borders of the "Big" cordon was the least challenging of the three scenarios; within MetroScope are 425 residential zones (rzones) and 72 employment zones (ezones); the largest 21 ezones are designed to perfectly overlap with the smallest 138 rzones that define the city of Portland. Nevertheless, the discrepancy between residential and employment zone sizes made the selection of the design of metro cities outside the cordon boundaries challenging.

The same variables used in the analysis of the Small and Mid-scenarios are used in the analysis of the larger cordon to enable the comparison among the three different cordon sizes. Again, one MetroScope year equals 5 actual years, where MetroScope year 0 is the baseline of 2010. As it was done for the other two cordon scenarios, if the results 
after 5 years and 15 years follow the same trend of the output after 25 years, then only the output after 25 years is discussed.

The metro area and city limit boundaries are represented in Figure 8.2.

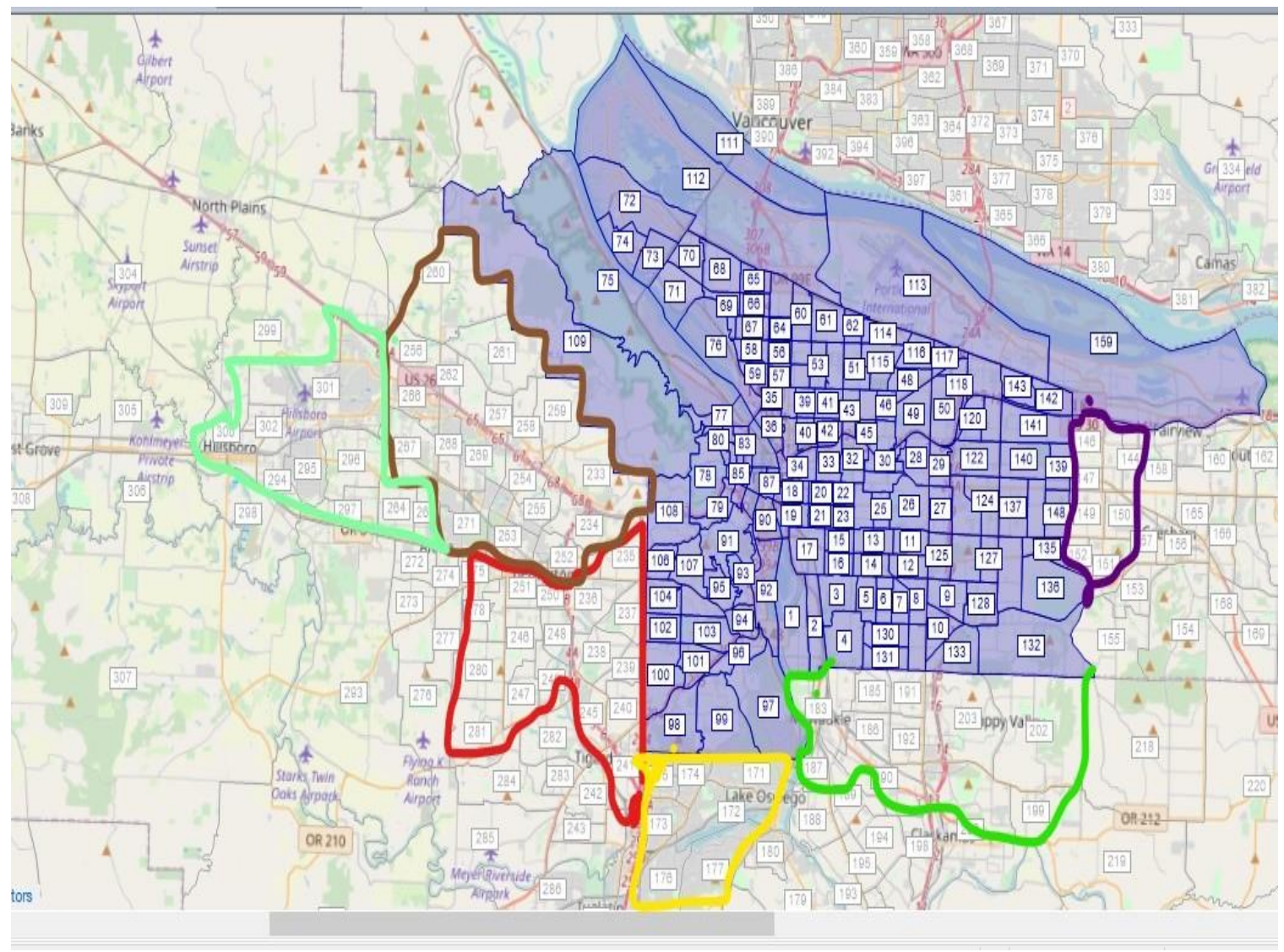

Figure 8.2 Big Cordon and Metro Areas Surrounding Portland City Boundaries

Source: PTV Visum (MetroScope)

From Figure 8.2:

Cordon zone (https://datausa.io/profile/):

Portland city boundaries: blue area. The largest industries in Portland are:

$\underline{\text { Healthcare \& social assistance, }} \underline{\text { Professional, Scientific, Tech services, }}$, and Retail

trade. 
Metro areas outside the cordon perimeter (https://datausa.io/profile/):

$>$ Gresham: area within the purple boundary. The largest industries are: $\underline{\text { Healthcare }}$ $\underline{\& \text { social assistance, }} \underline{\text { Retail trade, }}$, and Manufacturing.

$>$ Milwaukie and Happy Valley: areas within the green boundary. The largest industries are: $\underline{\text { Healthcare \& social assistance, }}$ Retail trade, and Manufacturing. Lake Oswego: area within the yellow boundary. The largest industries are: Healthcare \& social assistance, Professional, scientific, \& tech services, and Manufacturing.

$>$ Beaverton and Tigard: area within the red boundary. The largest industries are Manufacturing, Healthcare \& social assistance, Professional, scientific, \& tech services, and Retail trade.

Bethany and Tanasbourne: area within the brown boundary. The largest industries are Manufacturing, Healthcare \& social assistance, and Professional, scientific, \& tech services, and Retail trade.

Hillsboro and Orenco: area within the turquoise boundary. The largest industries are: Manufacturing, Healthcare \& social assistance, and Retail trade.

\subsection{Portland City Boundaries, or Big Cordon Output Analysis}

\section{Non-Residential Land Use:}

The analysis of the output focuses on the 7 geographical areas described above and shown in Figure 8.2. In detail, the first area analyzed is the area inside Portland, followed by the 6 metro areas located outside the cordon: Gresham, Happy Valley/Milwaukie, Lake Oswego, Beaverton/Tigard, Tanasbourne/Bethany, and Hillsboro/Orenco. 
From the non-residential real estate side, the first variable analyzed is the percentage changes in location price, followed by total employment percentage changes, percentage changes of total household and school-age households' location demand, and non-residential total sqft supply. Regarding residential real estate, the variables considered are the percentage changes in location prices and in total households' supply.

The analysis starts with the percentage changes in non-residential location prices for different industries before and after the implementation of a cordon toll $(\$ 1.65$ and $\$ 8$, respectively) inside Portland in 2035, followed by the report of the areas outside the cordon. With regards to the metro areas outside of Portland, each graph is intended to focus on the effects that a toll has on each industry across all cities.

As explained in previous sections, residential location price is not an actual price, but calculated from an index that reflects the match between supply and demand. If there is competition for real estate in a given zone, the unmet potential demand is reflected in higher location prices and vice versa. In detail, the level of supply and demand will affect prices accordingly. The new prices will bring a new equilibrium between new supply and demand, where the supply and demand calculations do not directly affect each other, but only indirectly through location prices.

\section{Non-Residential Location Prices}

Inside the Cordon:

Figure 8.3 shows non-residential location prices' response to the implementation of $\$ 1.65$ and $\$ 8$ cordon tolls versus no toll inside Portland in 2035. 


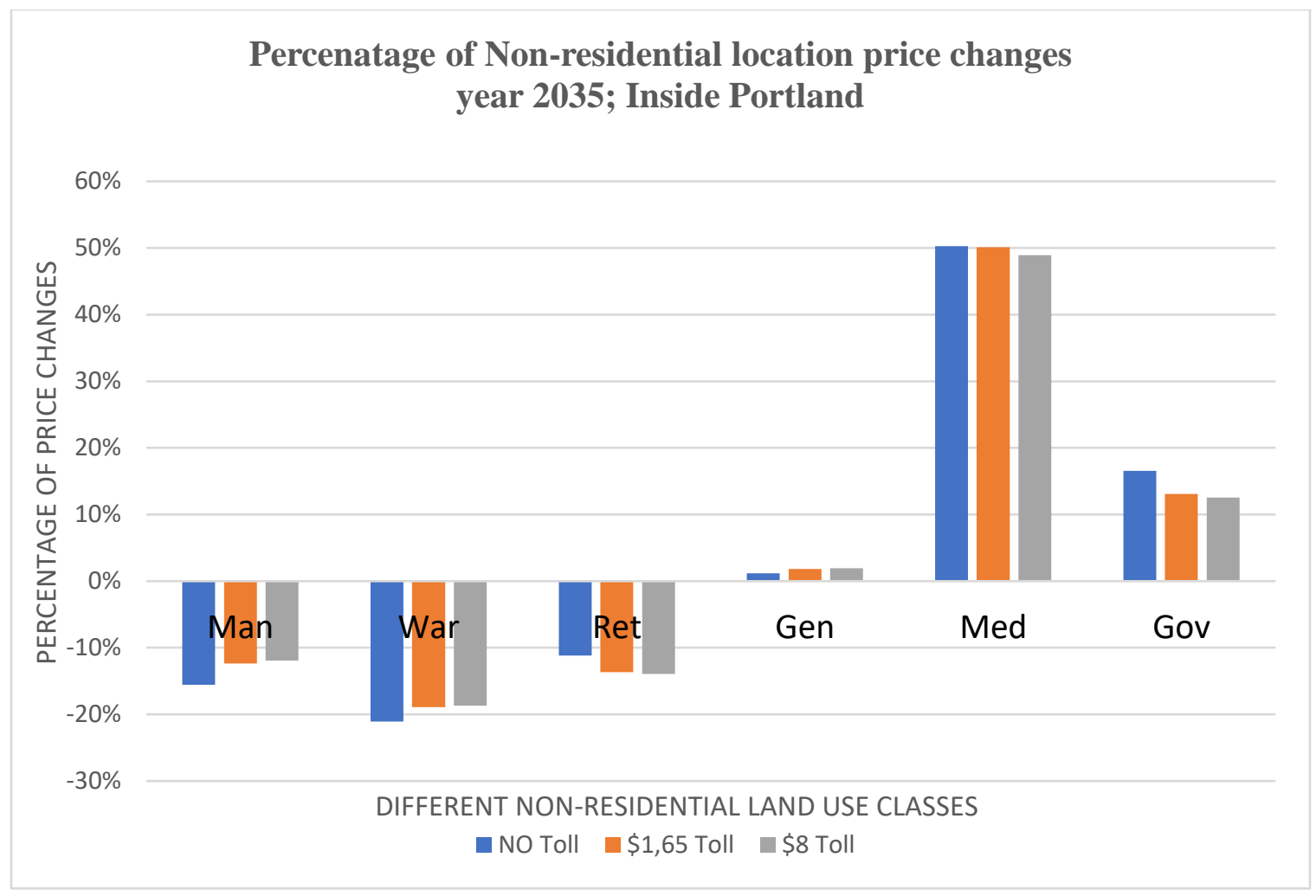

Figure 8.3

Under a no toll scenario, only Medical, Government, and General real estate are projected to a relative price appreciation. Industrial and Retail real estate report a relative price drop.

Once \$1.65 or \$8 tolls are applied to enter Portland, Medical offices, Government offices, and Retailers are projected to experience a relative price decline. All the other classes show a small increase in their price index over time.

Metro Areas Outside of Portland:

The following graphs report one industry at a time across all metropolitan cities before and after the cordon implementation in 2035: Manufacturing (Figure 8.4), Warehousing/distribution (Figure 8.5), Retailer/consumer services (Figure 8.6) General offices (Figure 8.7), Medical offices (Figure 8.8), and Government offices (Figure 8.9). 


\section{Portland vs Metro Areas}

Percentage of Non-residential location prices change in 2035 Manufacturing

\section{$10 \%$}

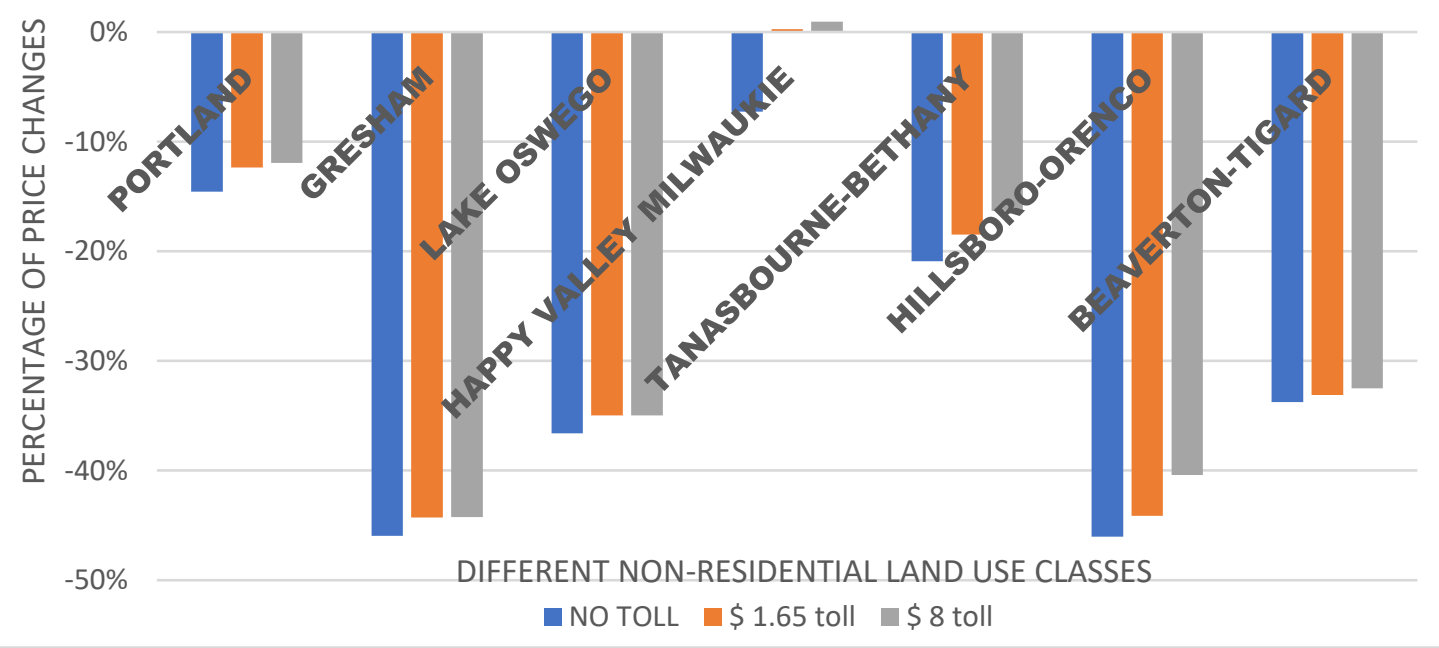

Figure 8.4 


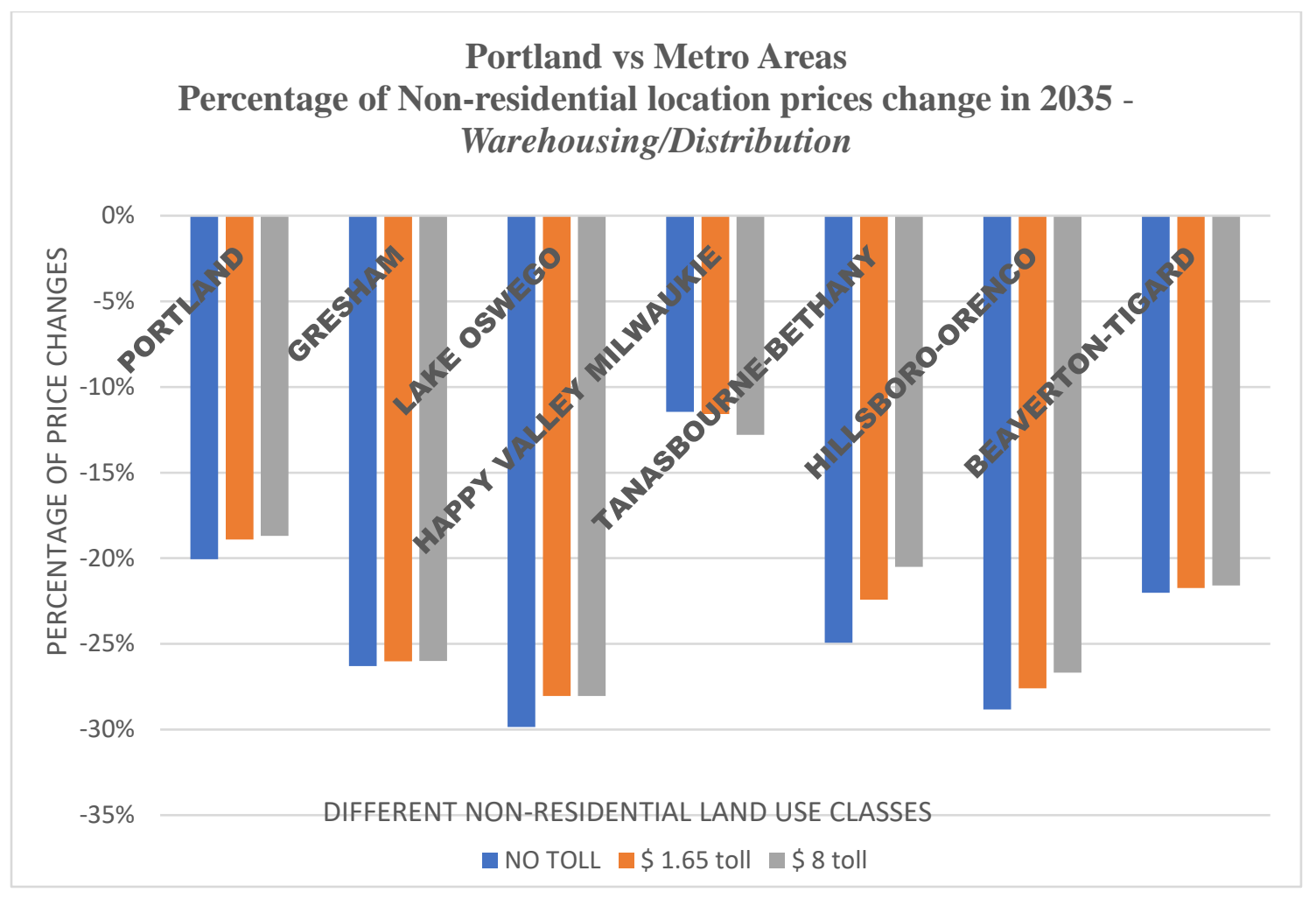

Figure 8.5

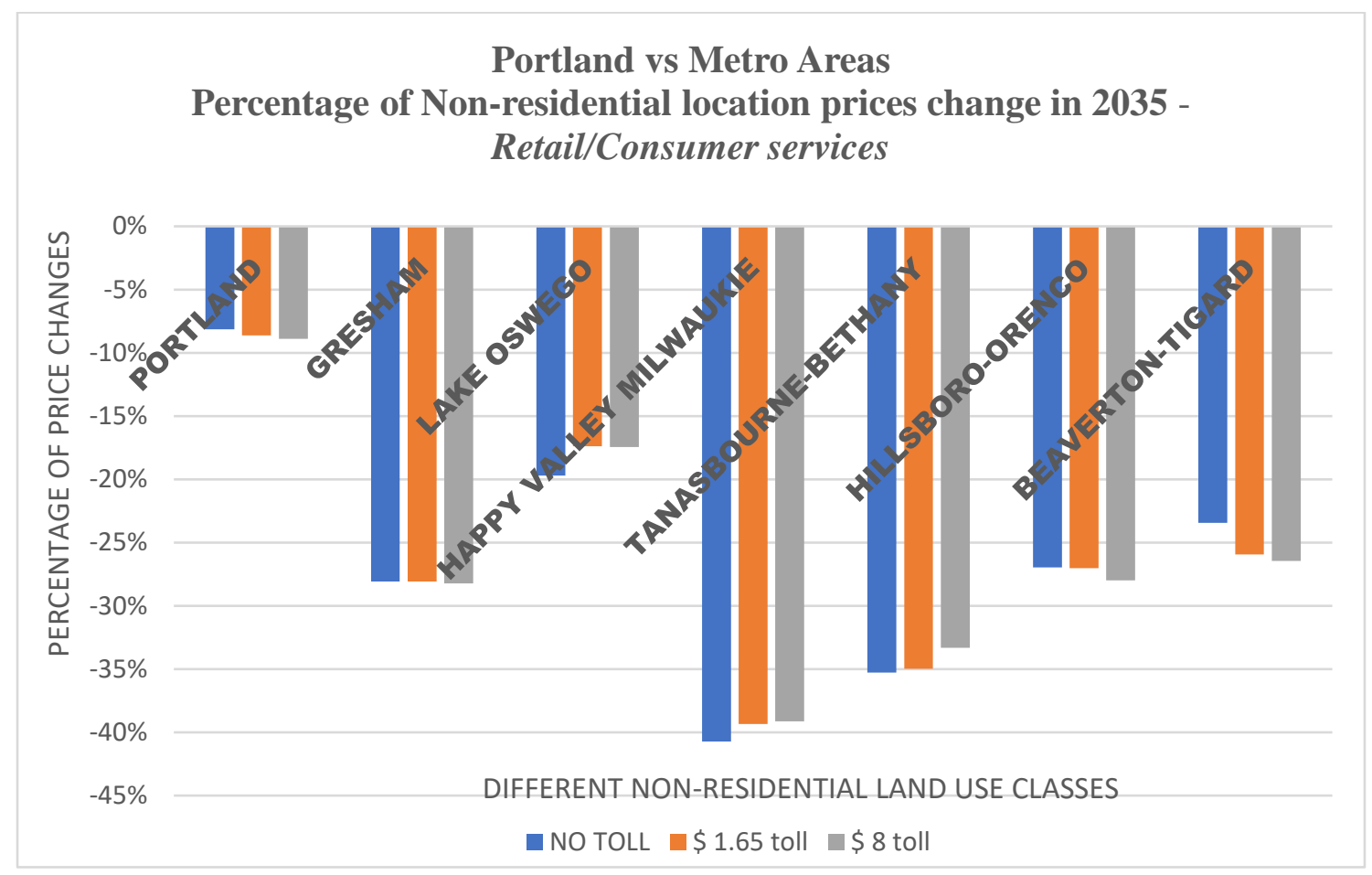

Figure 8.6 


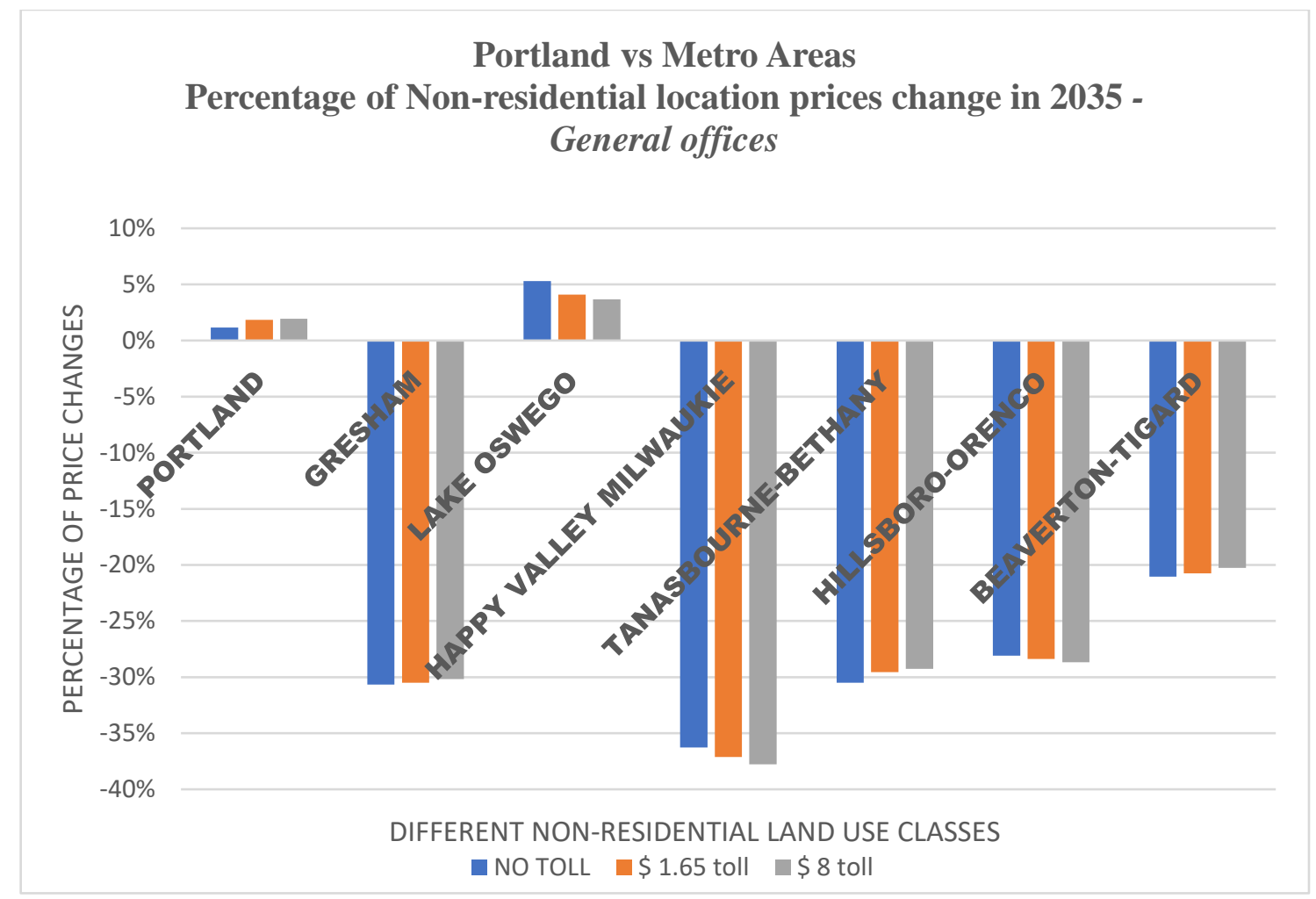

Figure 8.7 


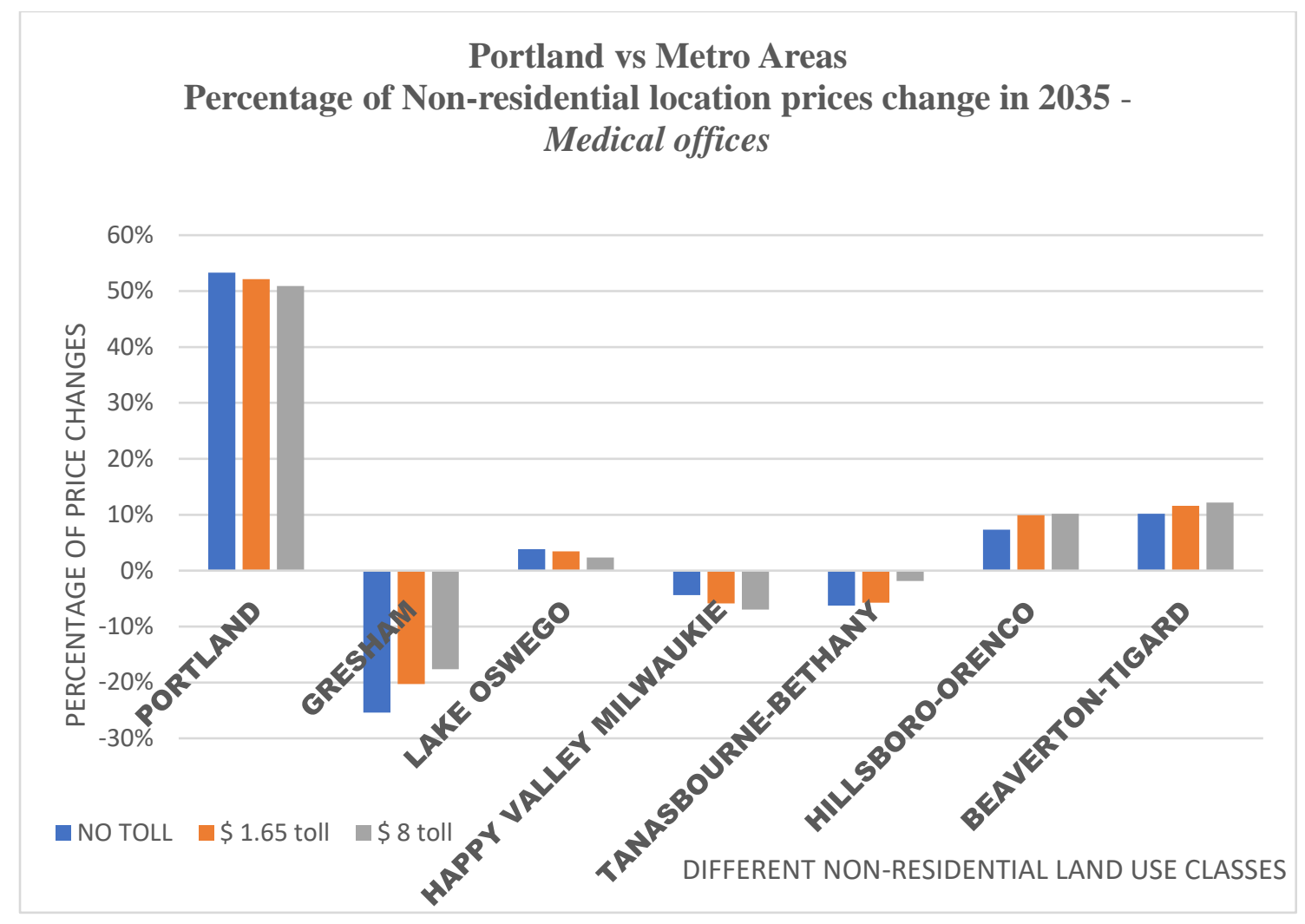

Figure 8.8 


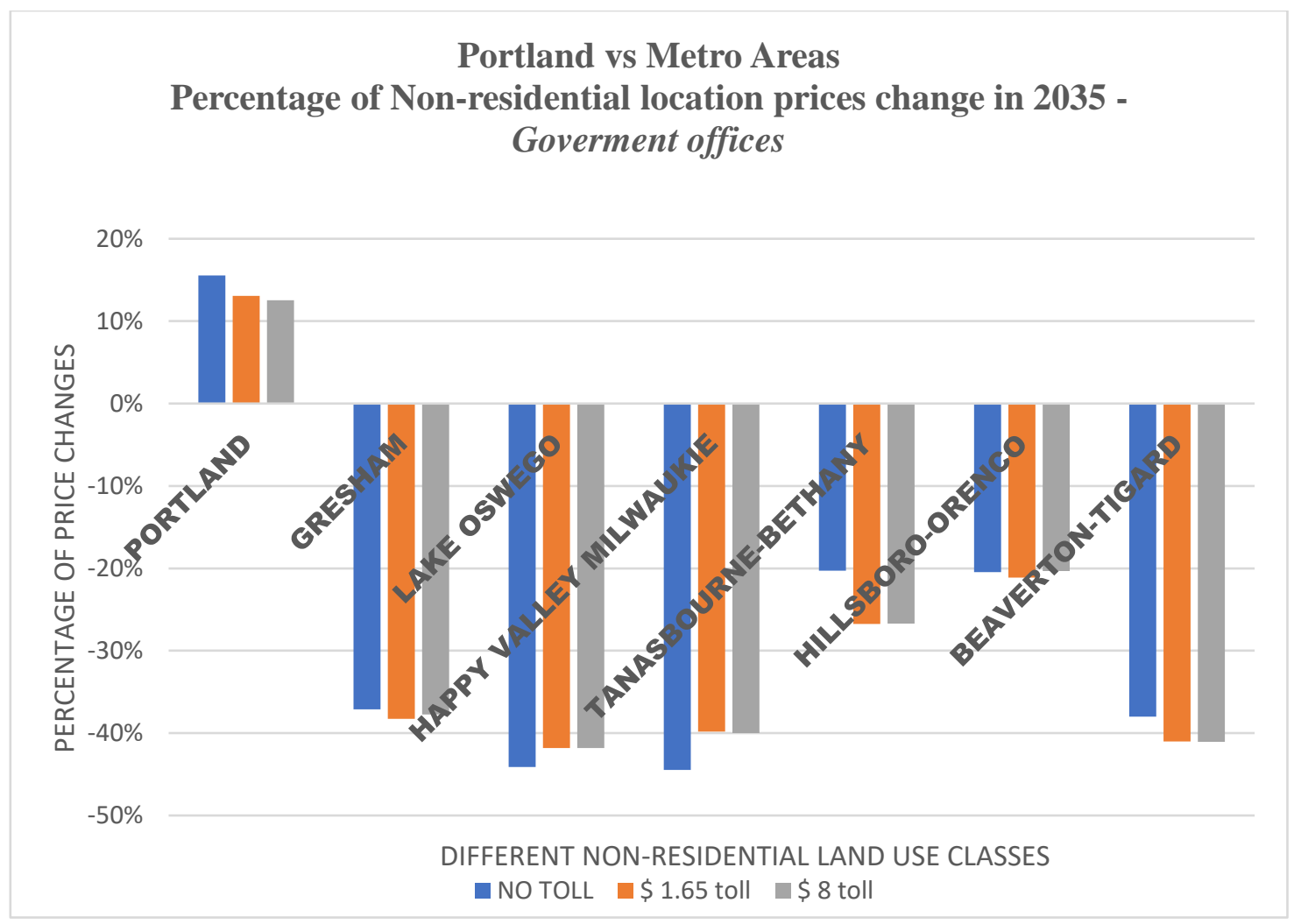

Figure 8.9

Manufacturing real estate has a relative price depreciation in each city outside of Portland, especially in Gresham (Eastside), and Hillsboro/Orenco (Westside) in a no toll scenario. A toll cordon has positive effects on demand for industrial land that is projected to a smaller decline relative to supply versus no toll overall in the metro area. As a consequence, prices will decrease at a smaller magnitude compared to the default alternative. In Happy Valley, a negative price index under no toll becomes a positive price index if a cordon is implemented instead.

Warehousing/Distribution is projected to a relative loss in property value in each city outside of Portland under no toll in 2035. The implementation of tolls dampen the relative price depreciation everywhere except Happy Valley/Milwaukie, which instead reports a further relative price reduction compared to no toll. After the implementation of 
$\$ 1.65$ and $\$ 8$ toll cordons around the Central City, prices still appreciate, but at a lower percentage compared to no toll;

Under no toll, Retail real estate is projected to experience a relatively large price depreciation outside of Portland. The implementation of tolls positively affects prices in Lake Oswego, Happy Valley/Milwaukie, and Tanasbourne/Bethany, dampening a relative value decline, while the other cities experience an additional price index decline.

In a no toll scenario, General offices show a relative price increase in Lake Oswego only, while relative property values for the other real estate decline, particularly in the East metro area. The implementation of tolls positively affects prices in Gresham, Tanasbourne/Bethany, and Beaverton/Tigard, dampening a relative value decline compared to no toll. In the other cities, location price is negatively affected by the tolls.

Medical real estate shows a significant price index appreciation overall in the Westside and Lake Oswego under no toll. The implementation of tolls positively affects prices in Gresham, Tanasbourne/Bethany, and Hillsboro, while a toll negatively affects the other cities.

Government offices' location price is projected to a relatively sharp decline in the whole metro area under no toll. The introduction of tolls significantly dampens relative price depreciation in Happy Valley/Milwaukie and Tanasbourne/Bethany only, while it has negative effects elsewhere.

The implementation of a Big cordon does affect location prices for industrial and commercial real estate inside and outside Portland. Table 9.1 shows how the location price index changes in each of real estate classes after a cordon is implemented compared to no toll in 2035 . The sign + indicates that a toll pushes relative prices to appreciate, 
while the sign - refers to a relative price reduction compared to no toll. The signs

highlighted in yellow represent a larger percentage change.

Table 8.1 Non-residential Location Price Changes Once a Toll Cordon Is Implememnted Versus No Toll

\begin{tabular}{|c|c|c|c|c|c|c|}
\hline Location prices changes & Man & War & Ret & Gen & Med & Gov \\
\hline Portland & + & + & $\cdot$ & + & $\cdot$ & $\cdot$ \\
\hline Gresham & + & + & $\cdot$ & + & + & + \\
\hline Lake 0sweg0 & + & + & + & $\cdot$ & $\cdot$ & $\cdot$ \\
\hline Happy Valley Milwaukie & + & - & + & $\cdot$ & - & + \\
\hline Tanasbourne-Bethany & + & + & + & + & + & $\cdot$ \\
\hline Hillsboro-0renco & + & + & - & $\cdot$ & + & + \\
\hline
\end{tabular}

Tanasbourne/Bethany is the city with the largest number of industries projected to experience a relative increase in price. Tolls seem to encourage the demand of economic activities to agglomerate within Tanasbourne/Bethany, contributing to the growth of the area.

Also, Industrial is the real estate class that benefits the most from a cordon compared to no toll.

Tolls do affect demand for industrial and commercial properties relative to the available supply, which is reflected in price changes.

Also, demand for Institutional real estate is strongly affected by the tolls, but in specific cities only. 


\section{Total Employment Changes}

Inside the Cordon:

Figure 8.10 shows changes in the percentage of Total employment inside Portland before and after toll cordon implementation in 2035.

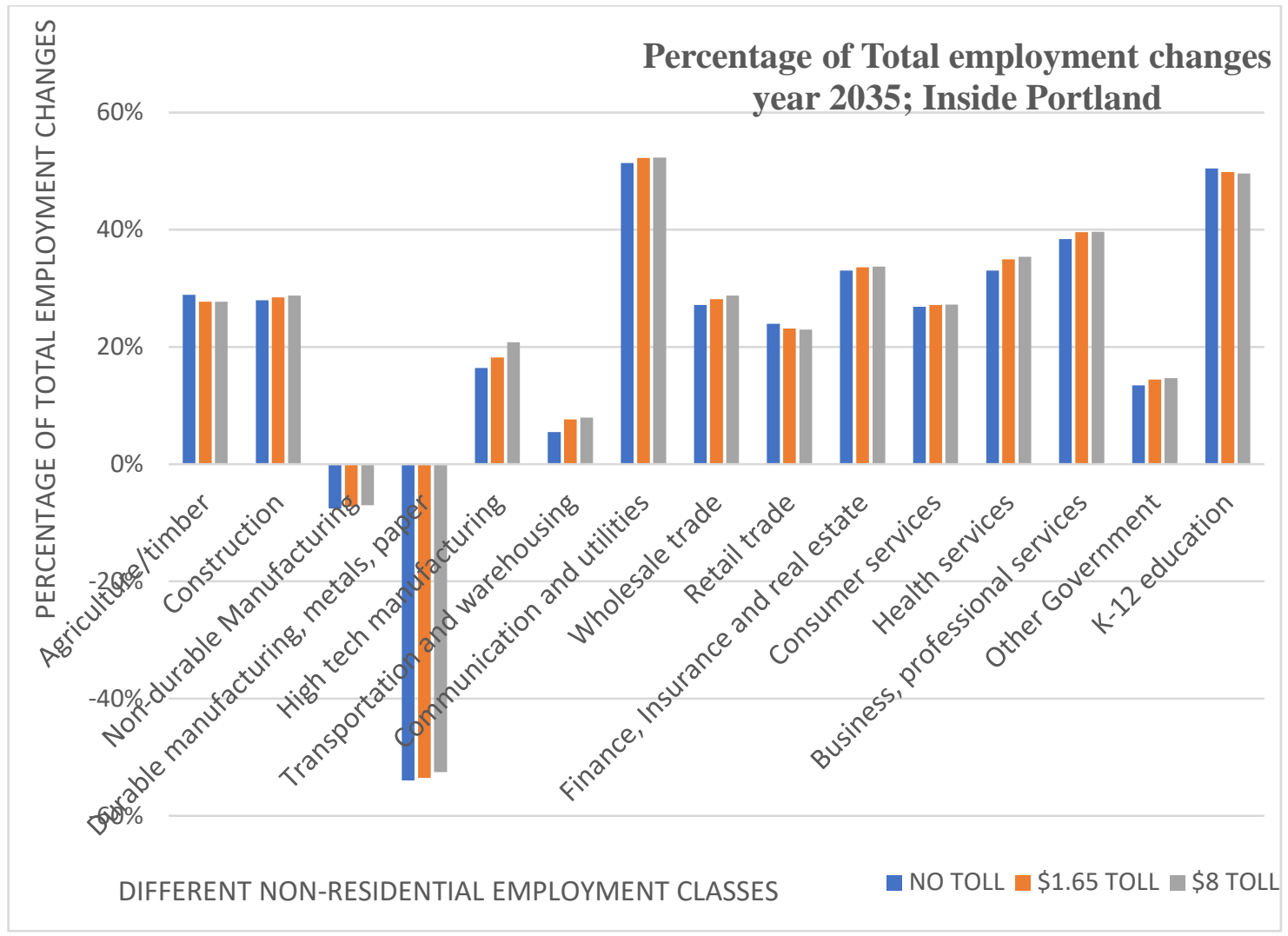

Figure 8.10

Under no toll, only Manufacturing industries are projected to a decline in employment, with a loss of 7.6\% in Durable and 54\% in Non-durable manufacturing, while all the other industries report positive employment. K-12 education and Communication/Utilities employment report the largest growth (50\% and 51\%, respectively), while Transportation/Warehousing reports the smallest (9.5\%) after 25 years. 
After a toll cordon is implemented, employment in K-12 declines. Additionally, employment for Agriculture/Timber and Retail slightly declines compared to no toll. All the other employment classes are projected to report growth compared to a default scenario.

Overall, a toll positively affects employment for the vast majority of employment classes within Portland if a Big cordon is implemented, increasing the likelihood of possible economy agglomeration as a consequence of the cordon.

Table 8.2 shows how each industry's employment reacts to the implementation of a cordon toll in Portland after a 25 -year period. The sign + indicates that a toll positively affects employment, while the sign - refers to a decline in employment after a toll cordon is implemented compared to no toll in 2035. The signs highlighted in yellow represent a larger percentage change.

Generally, a toll cordon is projected to boost employment for all industries with the exception of Agriculture, Retail trades, and K-12 education. High-tech manufacturing has the largest increase in employment resulting from a toll scheme. Overall, a toll positively affects employment for the great majority of the employment classes within Portland, increasing the likelihood of possible economy of agglomeration. 
Table 8.2 Percentage Changes in Employment After the Implementation of a Cordon Toll within Portland at the Year 2035

\begin{tabular}{|c|c|}
\hline INSIDE PORTLAND & \multirow{2}{*}{} \\
\hline Employment changes after a cordon is implemented & year \\
\hline Agriculture/timber & - \\
\hline Construction & + \\
\hline Non-durable manufacturing & + \\
\hline Durable manufacturing & + \\
\hline High tech manufacturing & + \\
\hline Transportation and warehousing & + \\
\hline Communication and utilities & + \\
\hline Wholesale trade & + \\
\hline Retail trades & - \\
\hline Finance, insurance/real estate & + \\
\hline Consumer services & + \\
\hline Health services & + \\
\hline Business, professional services & + \\
\hline Other government & + \\
\hline K-12 education & - \\
\hline
\end{tabular}

Metro Areas Outside of Portland, OR:

The following section focuses on changes in employment for the cities outside Portland after a toll cordon is implemented.

Each of the following graphs (Figures 8.11 to 8.16) shows the percentage changes in total employment in each city before and after the implementation of a cordon in 2035. 


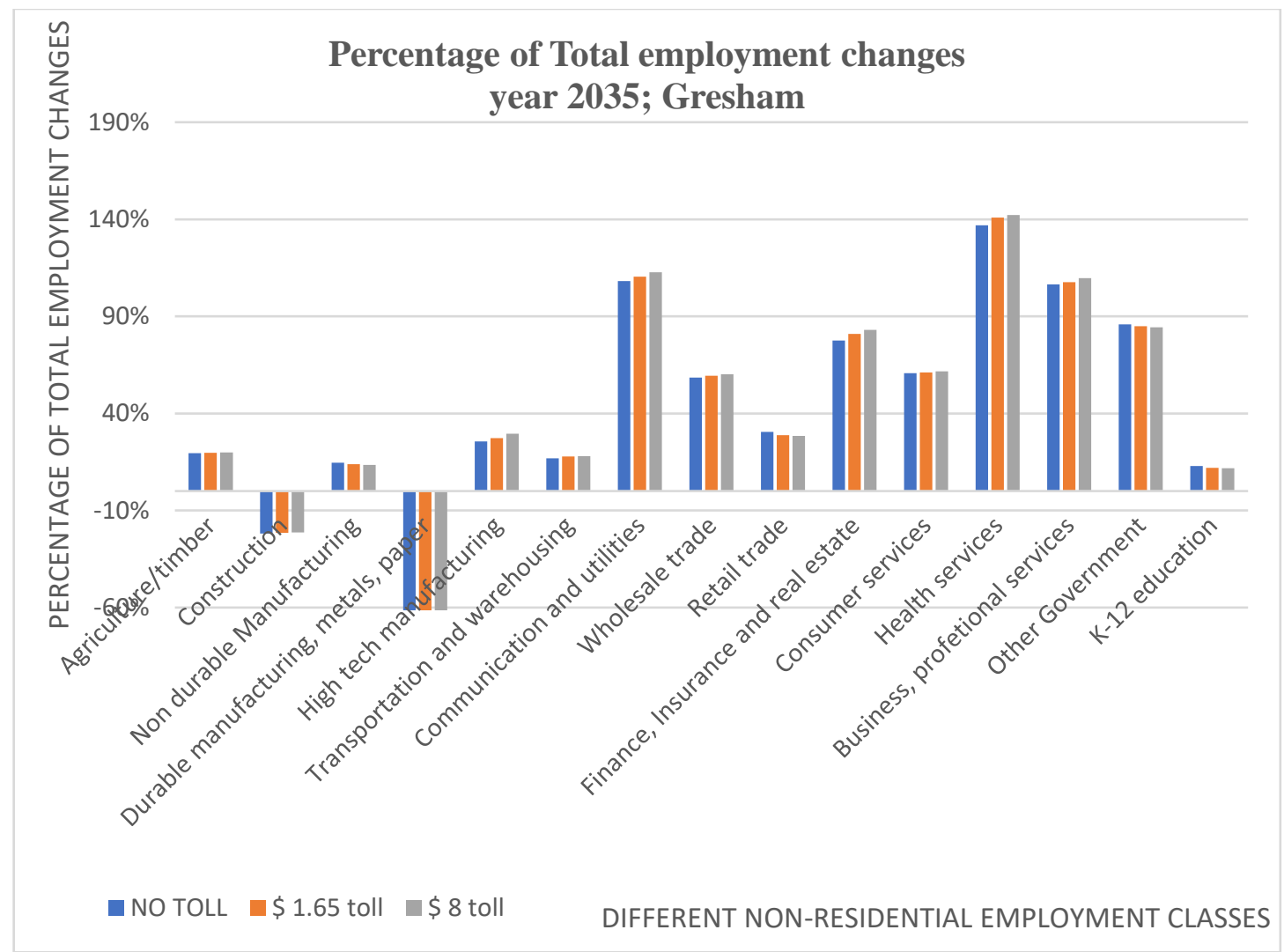

Figure 8.11 


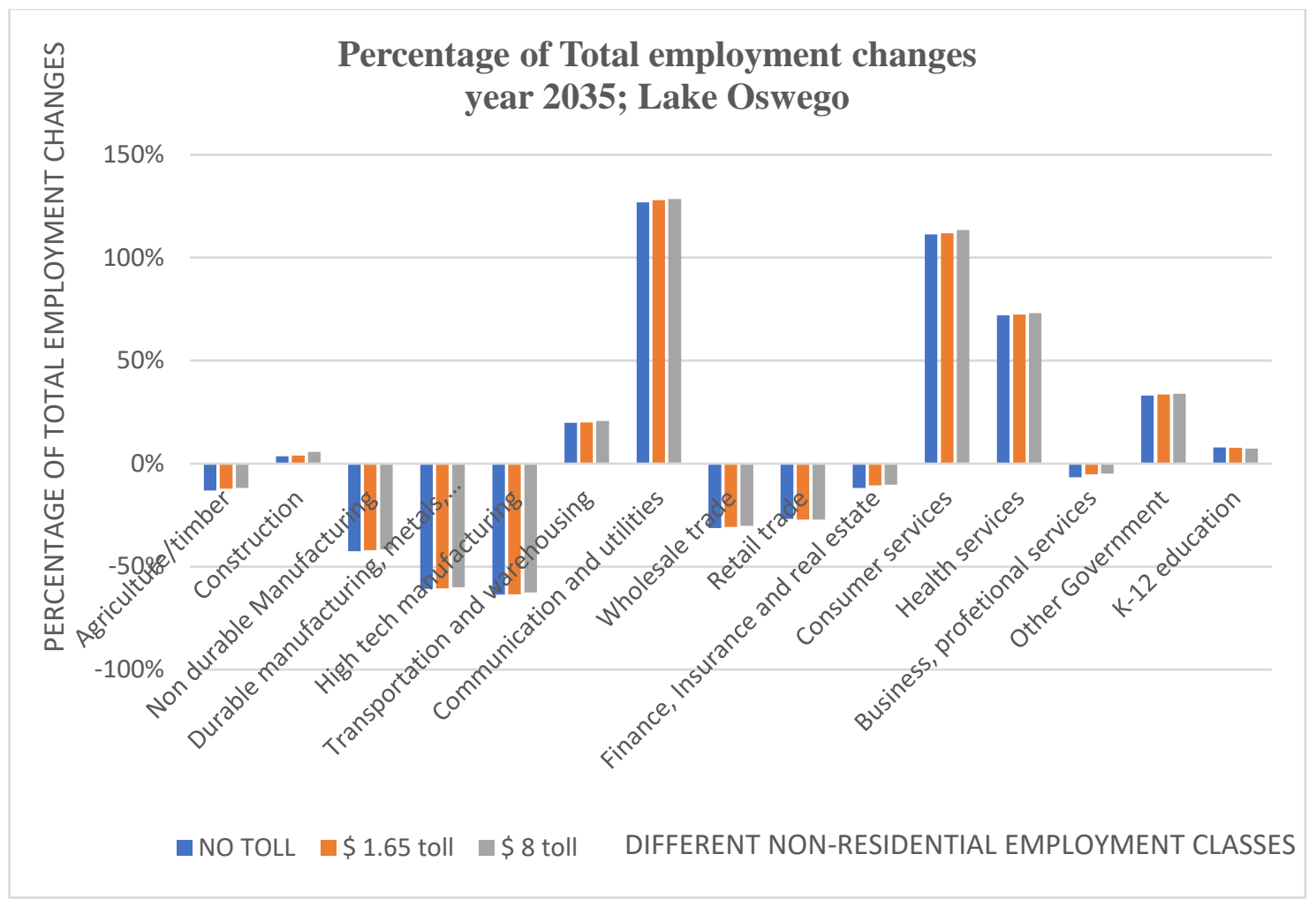

Figure 8.12 


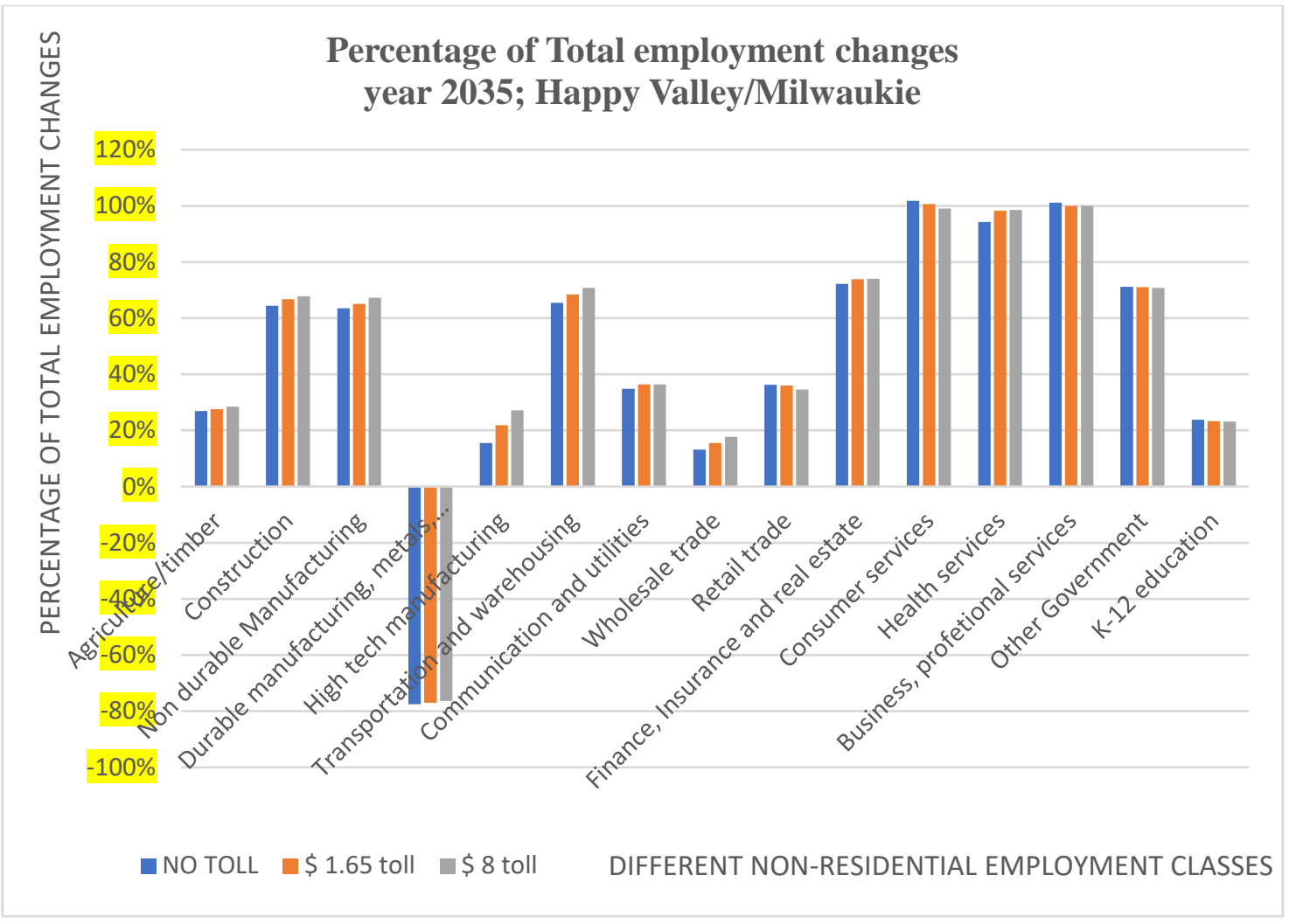

Figure 8.13 


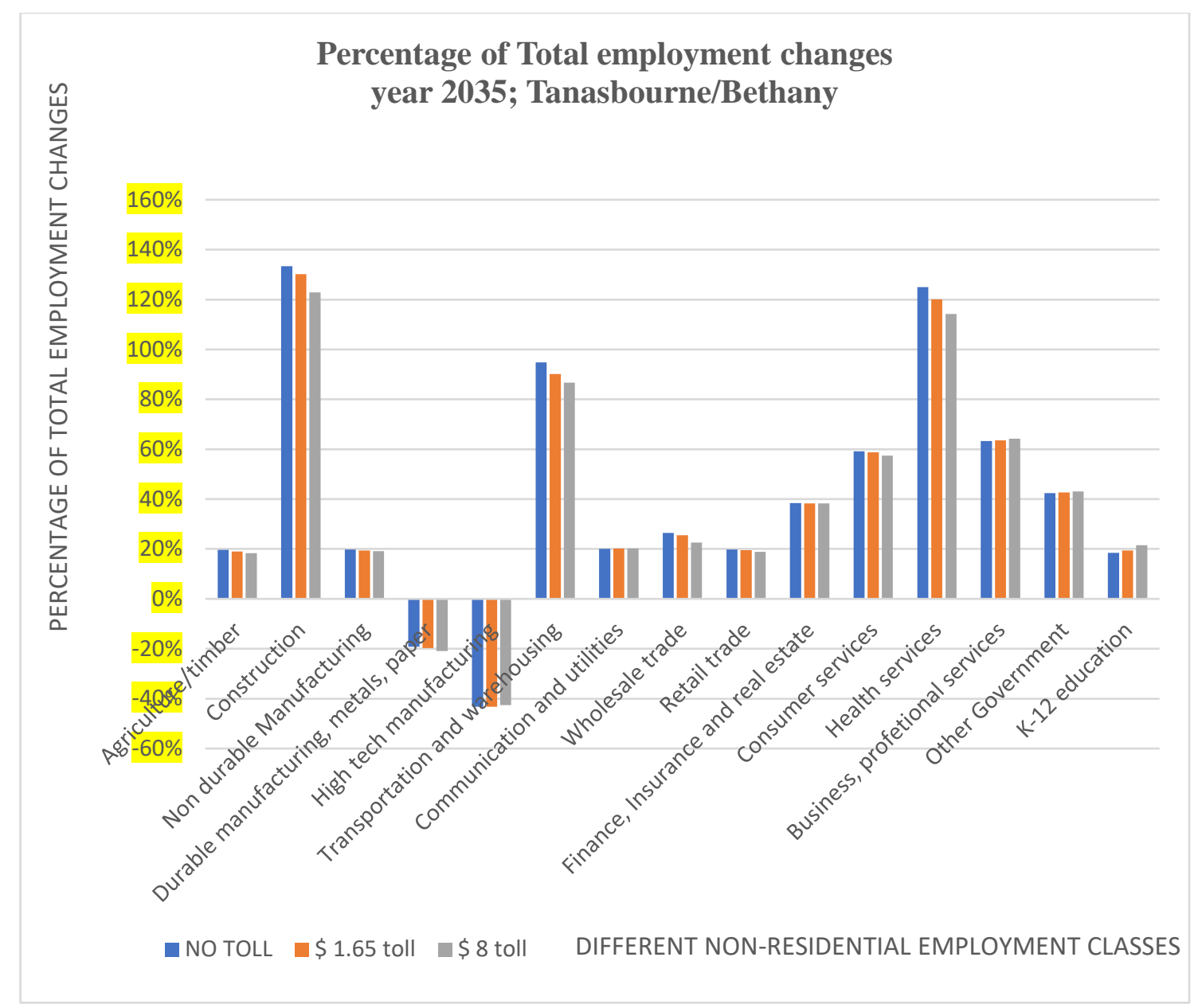

Figure 8.14 


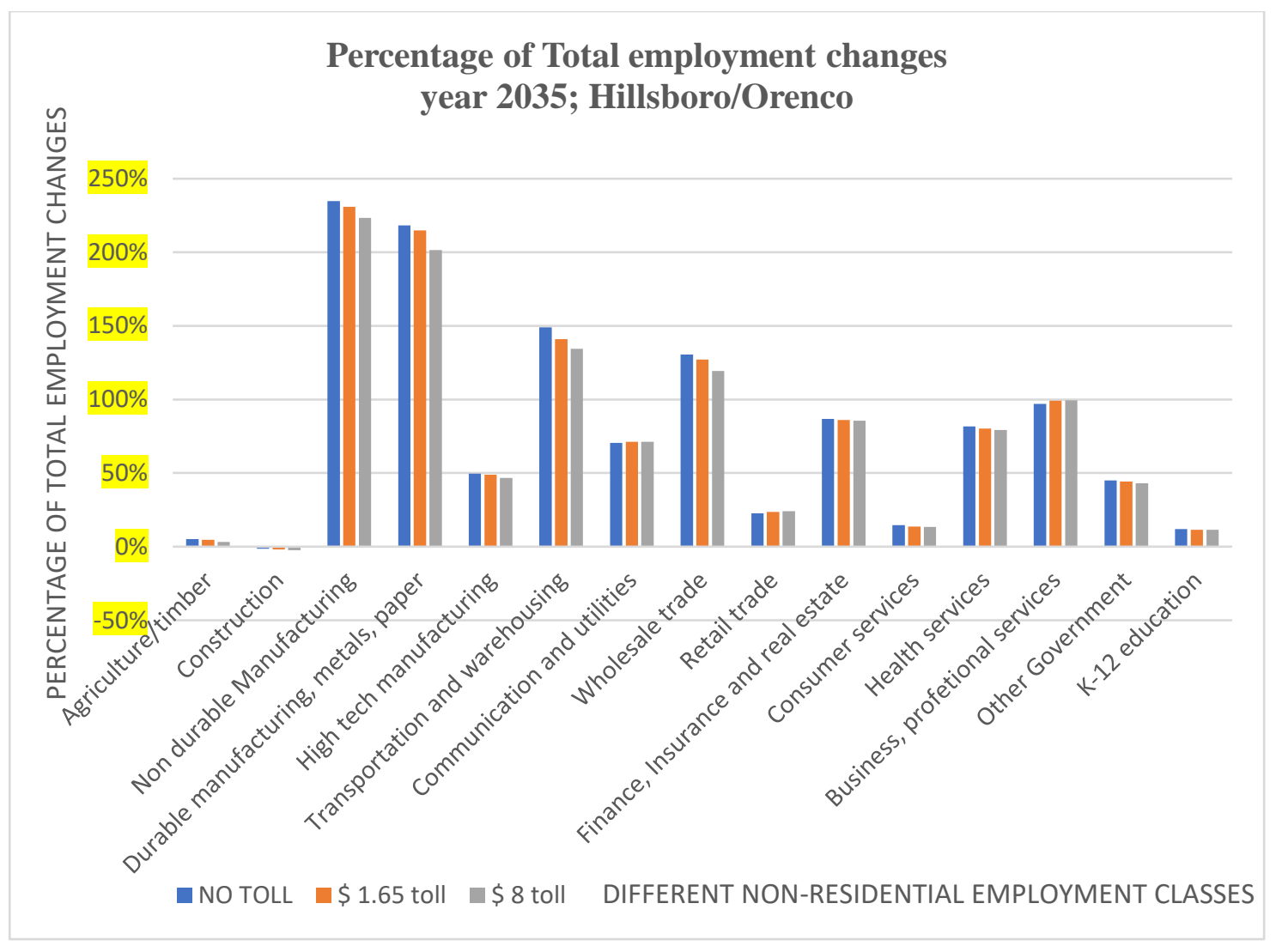

Figure 8.15 


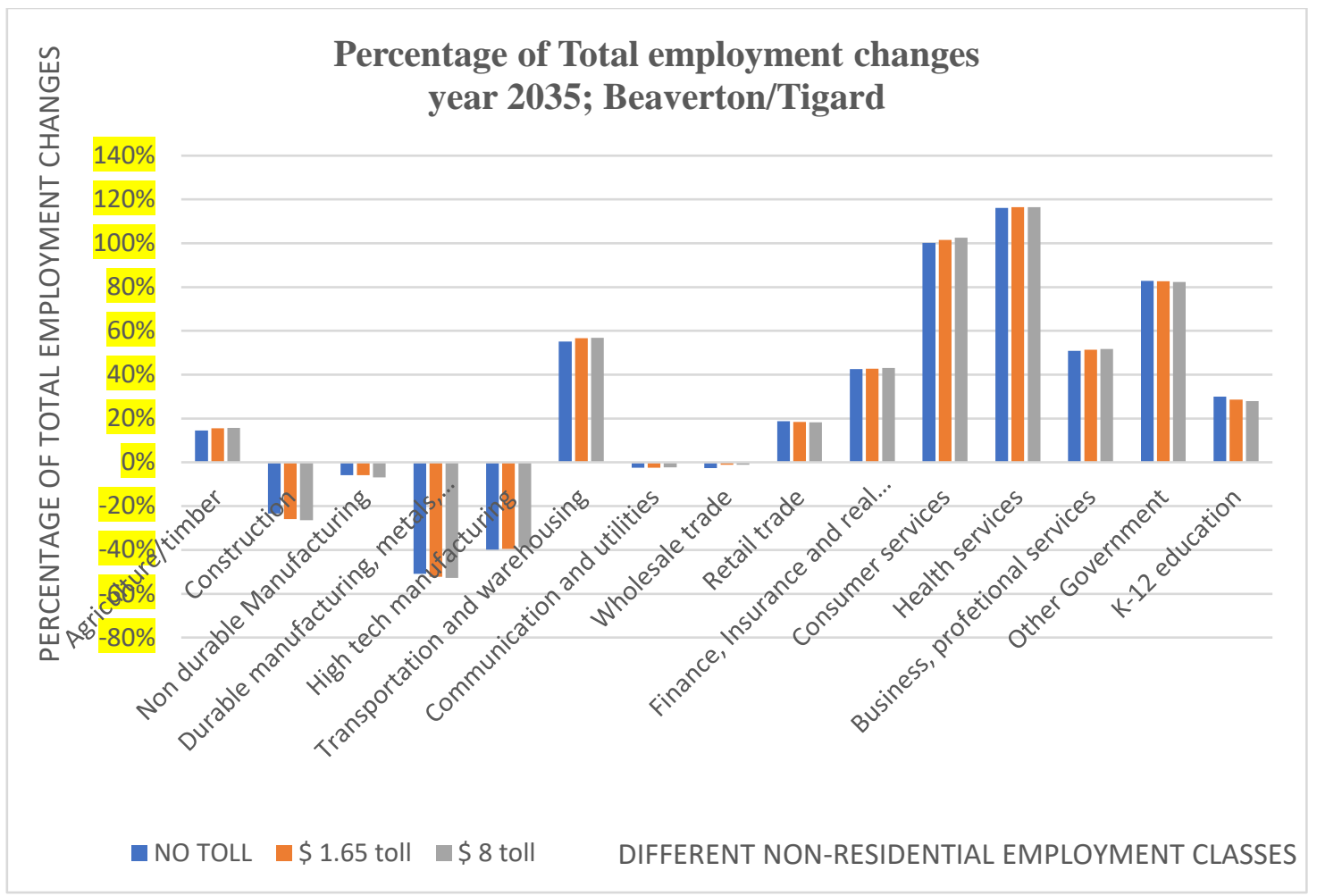

Figure 8.16

Under a no toll scenario, generally, higher-value economic activities have a positive increase in their employment in each of the metro areas except Lake Oswego, which loses employment in few commercial activities.

Transportation/warehousing, Consumer services, Health and Government services, and K-12 education are projected to an increase in their employment in each of the cities outside Portland under no toll at the year 2035. The largest increase in employment is in Non-durable manufacturing in Hillsboro, while the biggest decline is in Durable manufacturing in Happy Valley/Milwaukie and High-tech manufacturing in Lake Oswego.

After a cordon is implemented, each city outside Portland reacts differently to the new policy alternative. K-12 education and Retail trades are the industries projected to 
suffer the most after the toll is implemented, with an increase in their employment only in Tanasbourne/Bethany for K-12 education, and in Hillsboro/Orenco for Retail. In contrast, Communication and utilities is projected to an increase in employment in each city as a result of the cordon policy, followed by Business/professional services, with an increase in each area but Happy Valley/Milwaukie, and High-tech manufacturing, with an increase everywhere but in Hillsboro/Orenco.

The city projected to benefit the most from the toll is Lake Oswego, where employment grows in each industry except Retail and K-12 education, although the percentage changes are quite small.

On the contrary, Hillsboro/Orenco is forecasted to have the greatest decline in employment across industries if a cordon is implemented; only Communication/utilities, Business services, and Retail demand grows.

Table 8.3 shows changes in total employment after the implementation of a toll compared to no toll. The sign + indicates that a toll pushes employment to grow, while the sign - refers to a decline in employment after a toll cordon is implemented, compared to no toll. The signs highlighted in yellow represent a larger percentage change.

Overall, the implementation of a toll cordon has a large negative effect on employment in cities located in the West of Portland versus the Eastside.

Generally, Portland benefits the most from the cordon charge, with a positive effect on employment for almost all the industries but Agriculture/timber, 
Transportation/warehousing, Retail trades, and K-12 education. Lake Oswego

percentage changes in employment are extremely minor before and after the toll.

Table 8.3 Effects of the Implementation of a Cordon Toll around Portland on Non-residential Employment in Each City, at the Year 2035.

\begin{tabular}{|c|c|c|c|c|c|c|c|}
\hline $\begin{array}{c}\text { Employment } \\
\text { changes }\end{array}$ & Portland & Gresham & Lake Oswegd & Happy Valley & Tanasbourne & Hillsboro & Beaverton \\
\hline Agriculture & - & + & + & + & - & - & + \\
\hline Construction & + & + & + & + & - & - & - \\
\hline Non-dur Man & + & - & + & + & $\cdot$ & - & $\cdot$ \\
\hline Durable Man & + & - & + & + & - & - & - \\
\hline High tech Man & + & + & + & + & + & - & + \\
\hline $\begin{array}{l}\text { Transportation } \\
\end{array}$ & + & + & + & + & - & - & + \\
\hline Communication & + & + & + & + & + & + & + \\
\hline Wholesale trade & + & + & + & + & - & - & + \\
\hline Retail trade & - & - & - & - & - & + & - \\
\hline Finance & + & + & + & + & - & - & + \\
\hline Consumer services & + & + & + & - & - & - & + \\
\hline Health services & + & + & + & + & - & - & + \\
\hline Business services & + & + & + & - & + & + & + \\
\hline Other Government & + & - & + & - & + & - & - \\
\hline K-12 & - & - & - & - & + & - & - \\
\hline
\end{tabular}




\section{Percentage in Changes in HH Location Demand}

Inside the Cordon:

The following demand variable analyzed is Non-residential household demand for total households and households with school-age children to understand whether the presence of children is significant in demand for housing after a toll is implemented.

Figure 8.17 shows changes in location demand for families without and with school-age children inside Portland before and after the toll in 2035.

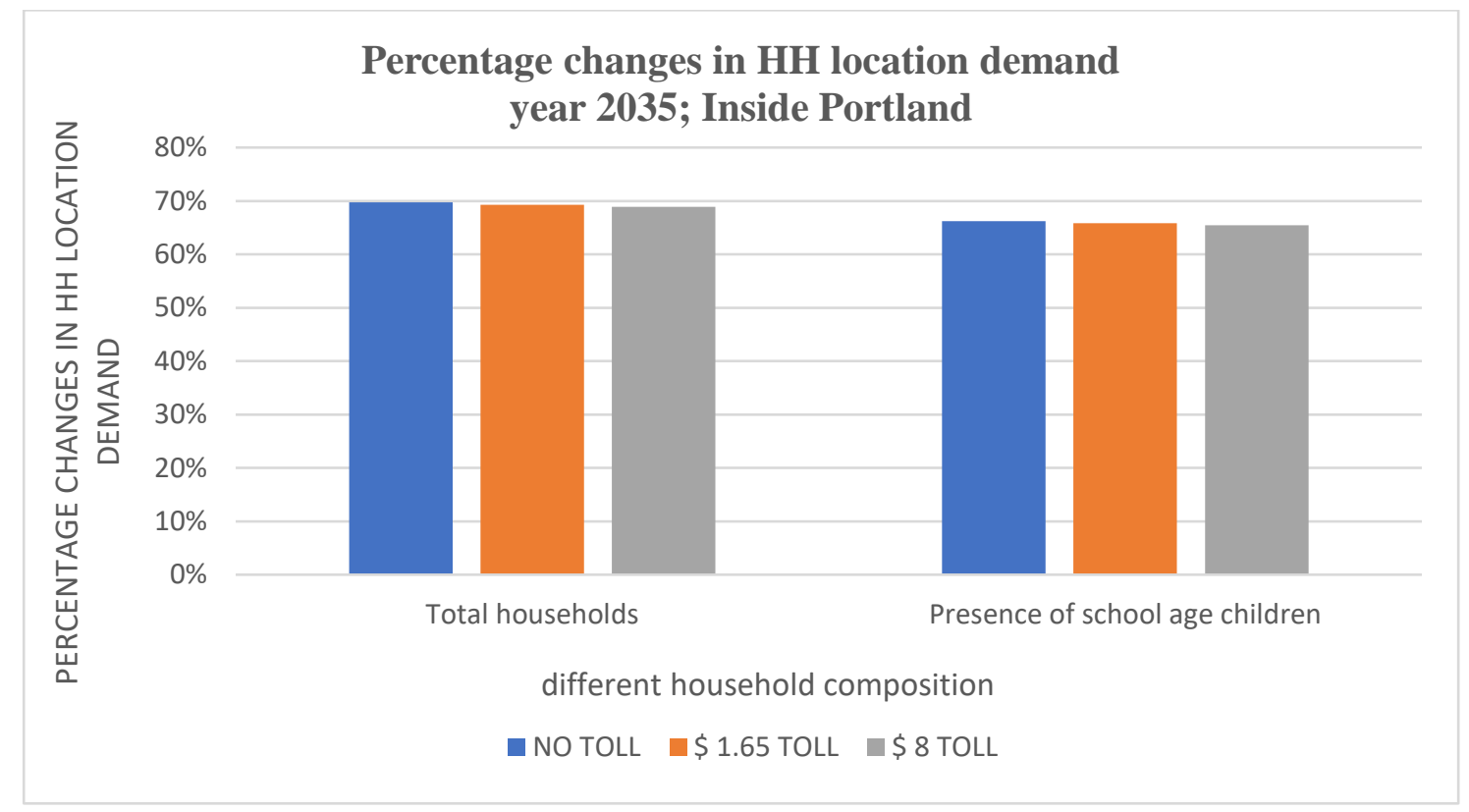

Figure 8.17

Under no toll, total households' demand for both classes grows over time, as shown in Figure 8.17.

Once a toll cordon is implemented, household demand is projected to a decline for both classes; percentage changes are slightly larger for an $\$ 8$ toll compared to $\$ 1.65$ toll. 
In detail, total hh demand declines slightly more than hh with school-age children once a toll cordon is implemented compared to no toll.

Generally, a toll decreases hh demand to locate inside Portland. Is hh demand projected to an increase outside of Portland? If so, in which metro cities?

\section{Metro Areas Outside Portland, OR:}

Figures 8.18 to 8.23 show changes in location demand for households with and without school-age children in each city outside of Portland after a cordon is implemented compared to no toll in 2035.

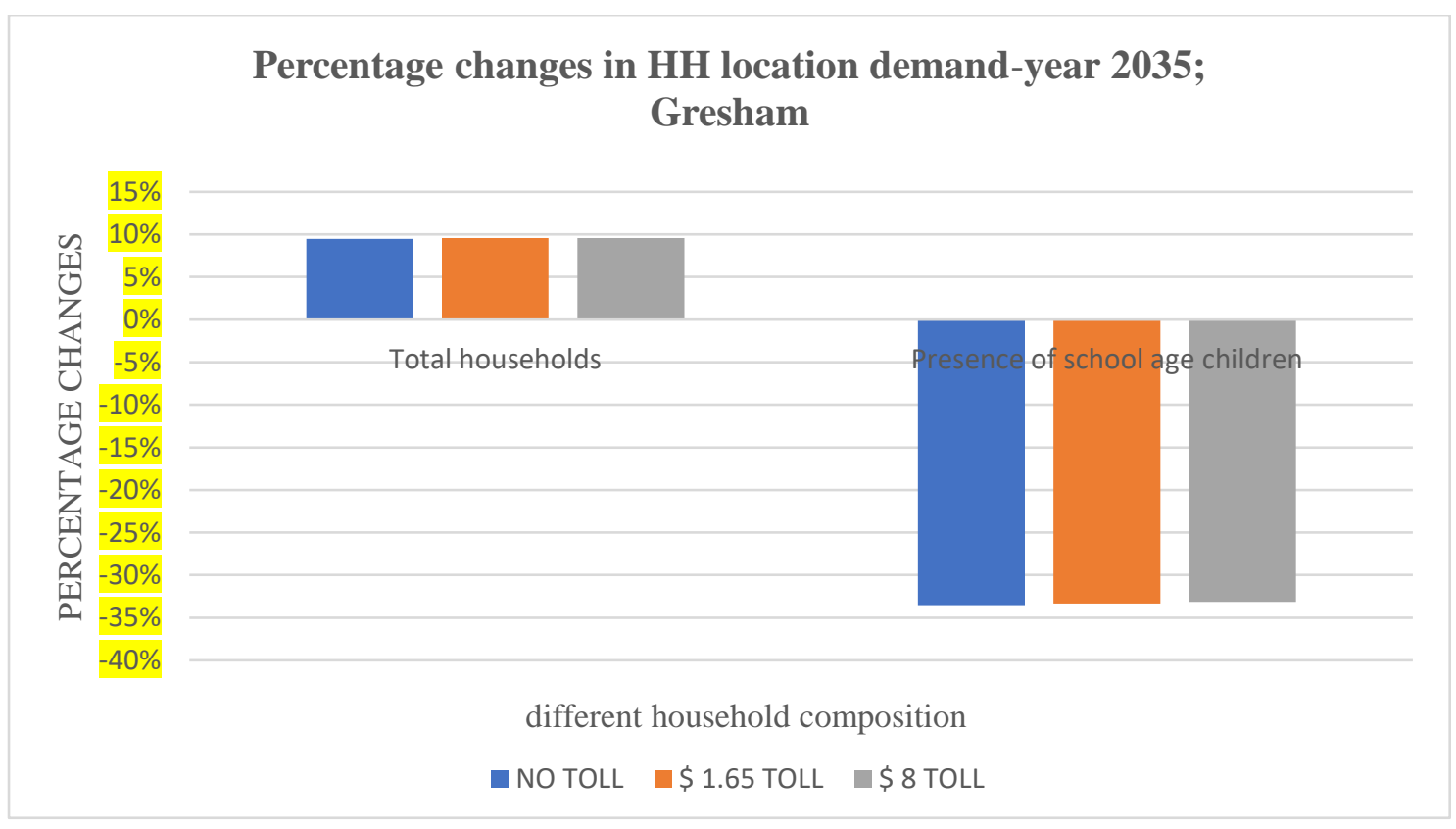

Figure 8.18 


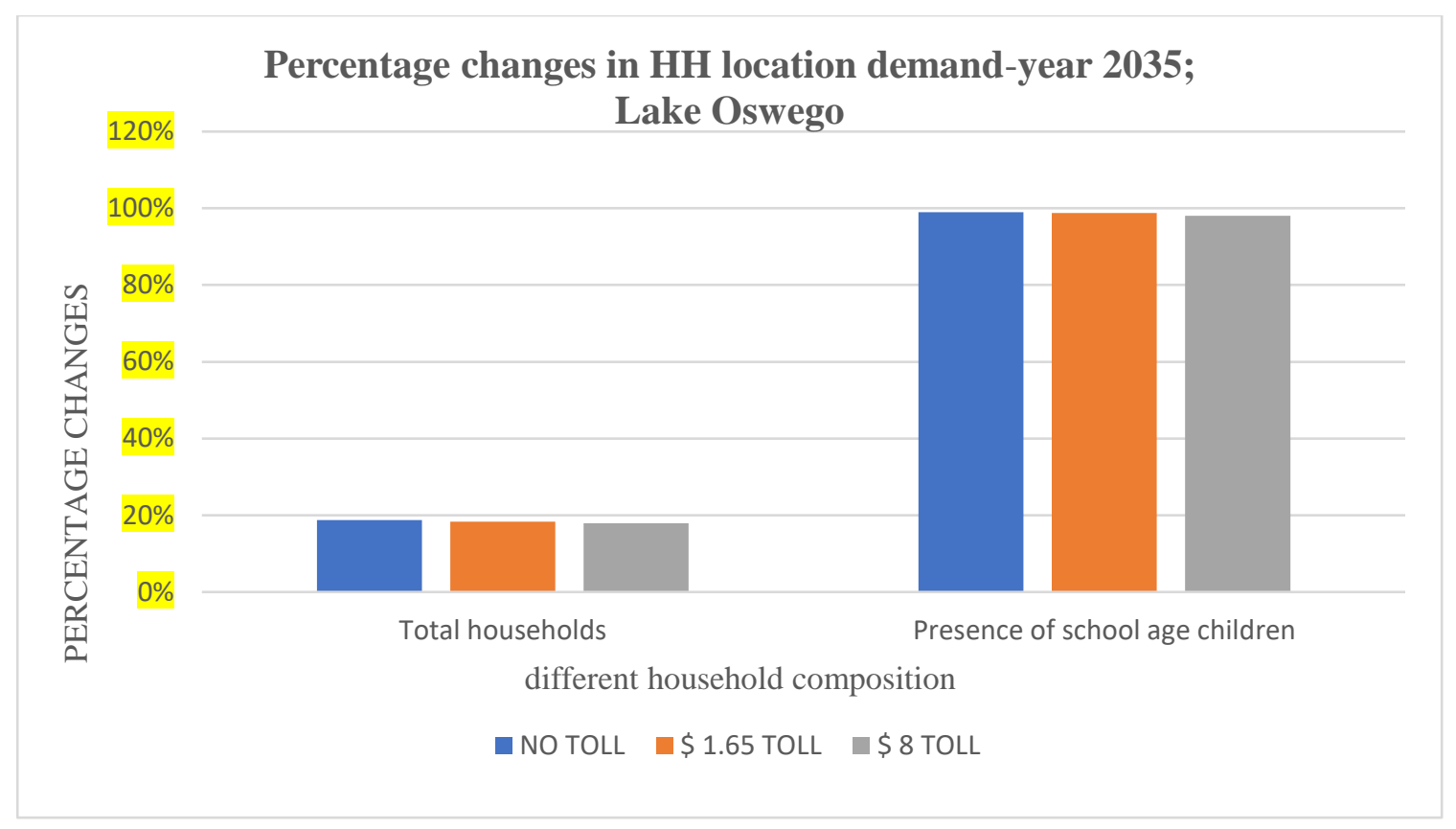

Figure 8.19

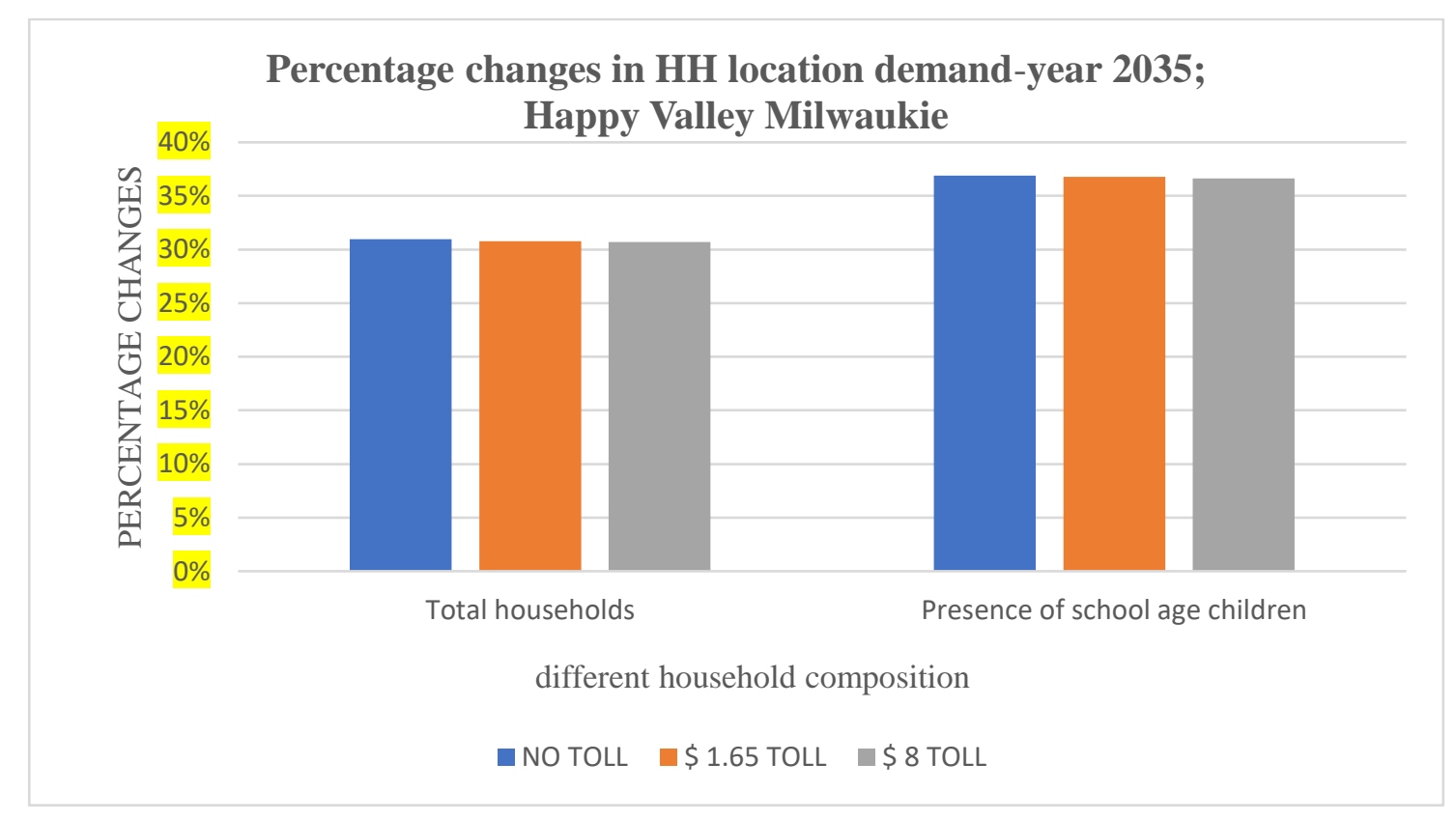

Figure 8.20 


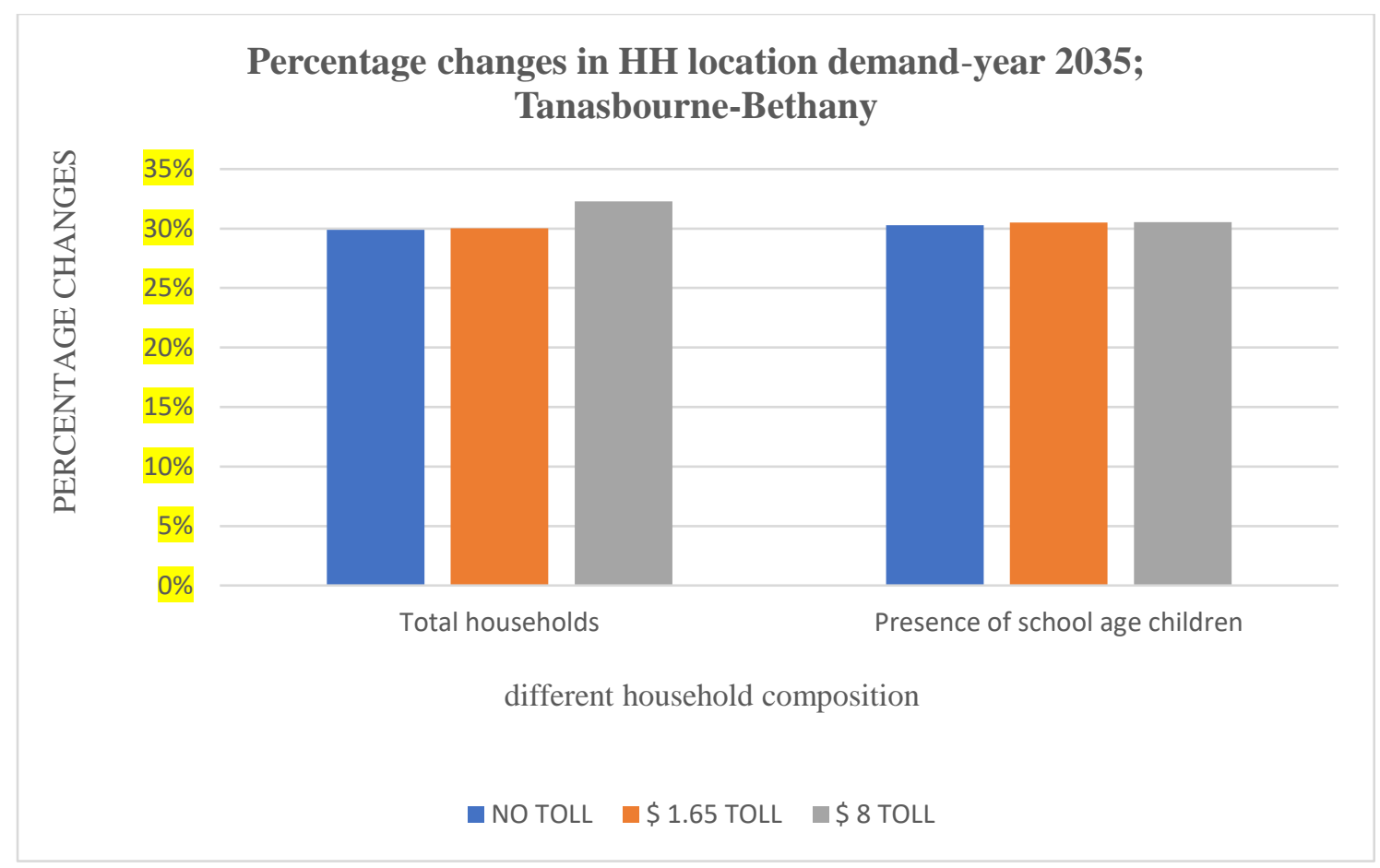

Figure 8.21

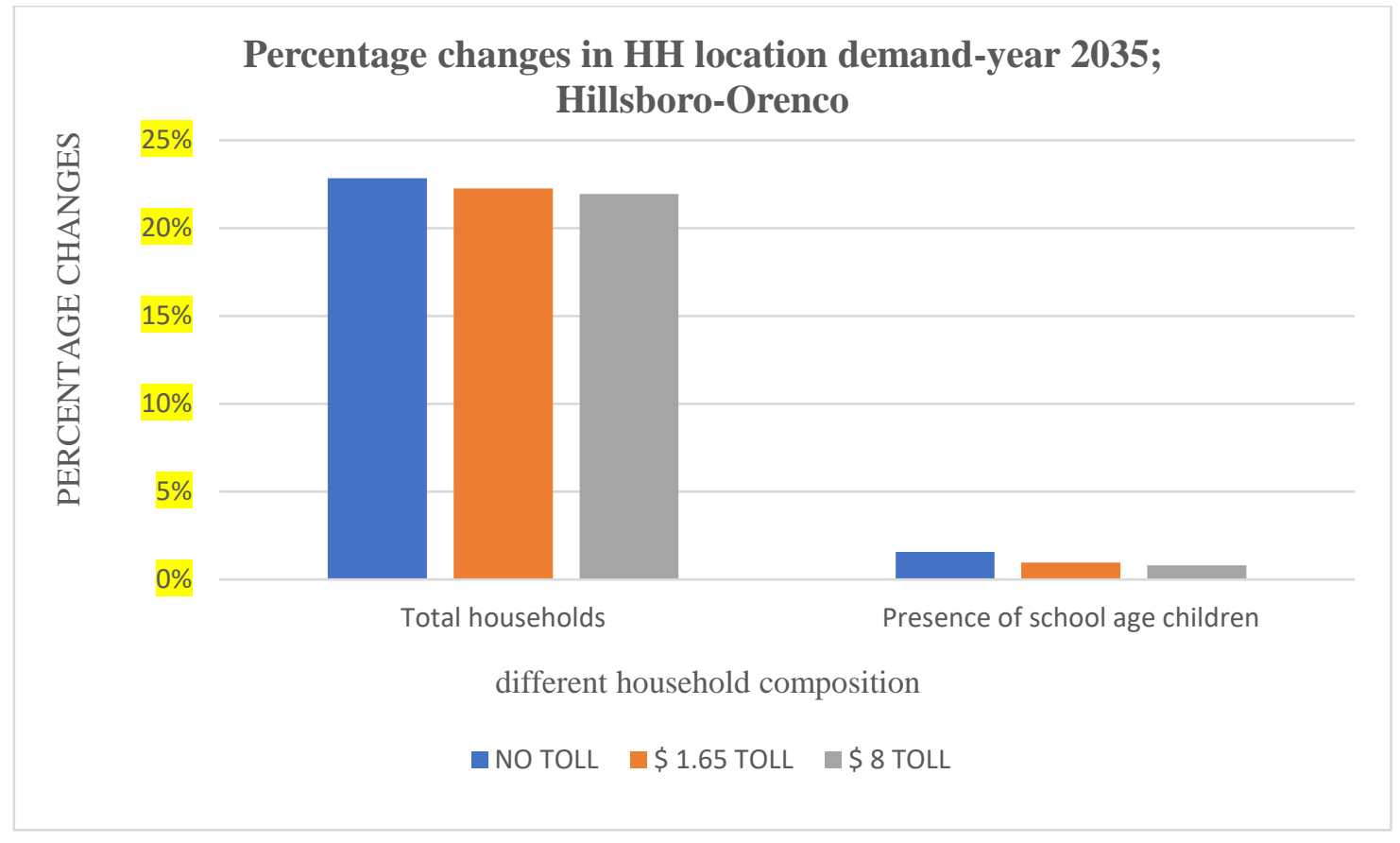

Figure 8.22 


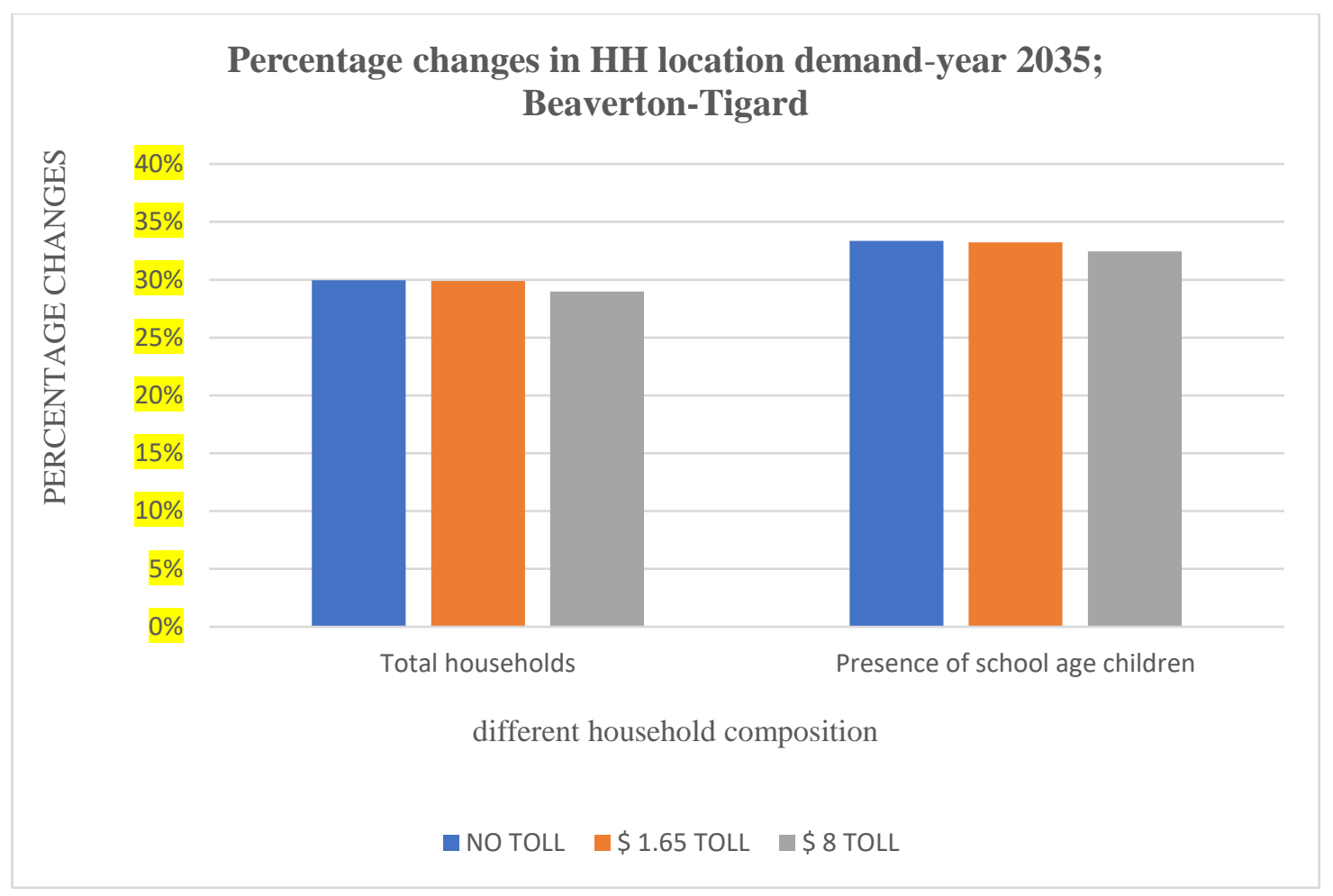

Figure 8.23

Under no toll, Lake Oswego is projected to double household demand for families with school-age children in 2035 . Once a toll cordon is in place, percentage changes of household demand for both classes is within $1 \%$ compared to no toll.

Under a no toll scenario, in Gresham, households without school-age children are projected to grow by $9 \%$, while households with children are projected to a $33 \%$ drop. The implementation of a Big cordon has a very small positive effect in increasing household demand in both classes. Similarly, Tanasbourne/Bethany is projected to a larger increase in demand for both hh types as a result from a toll cordon implementation compared to no toll. Generally, all the other cities report a decline in location demand after a toll implementation versus a default scenario in 2035. 
Generally, the implementation of a toll cordon reduces total household demand for Portland, as well as for the cities surrounding it, with the exclusion of Tanasbourne/Bethany ${ }^{8}$ and (very marginally) Gresham.

Table 8.4 resumes the effects after the implementation of a toll cordon on nonresidential household demand as described it above. The sign + indicates that a toll pushes hh demand to grow, while the sign - refers to a decline in demand over time after a toll cordon is implemented. The signs highlighted in yellow represent a larger percentage change.

Table 8.4 Changes in Non-residential Household Demand (With and Without School-Age Children) after a Toll Cordon is Implemented Versus No Toll in 2035

\begin{tabular}{|c||c||c|}
\hline Changes in HH demand after a toll is implemeted & Total hh & hh with children \\
\hline \hline Portland & - & - \\
\hline \hline Gresham & + & + \\
\hline \hline Lake 0swego & - & - \\
\hline \hline Happy Valley Milwaukie & - & - \\
\hline \hline Tanasbourne-Bethany & + & + \\
\hline \hline Hillsbor0-Orenco & - & - \\
\hline \hline Beaverton-Tigard & - & - \\
\hline
\end{tabular}

\footnotetext{
${ }^{8}$ One of the dimensions used in MetroScope for hh housing preferences is "child-friendly neighborhood score" that is implemented in the model and operates as an addition to the neighborhood score only for households that have schoolchildren present (Metro,2013).
} 
The next section explores percentage changes in non-residential total sqft supply inside the cordon boundaries, followed by changes in each of the cities outside Portland after a toll cordon is implemented compared to no toll in 2035.

As a reminder, all non-residential employment activities could locate in any of the 6 real estate classes identified in MetroScope, so that the use of any space by any employment type directly responds to the price for real estate classes being considered and the prices of all the competing classes (Metro, 2013). For example, any warehouse space can be occupied by a different work activity than originally intended.

\section{Total sqft Supply}

Inside the Cordon:

Figure 8.24 shows percentage changes in total sqft supply in different industries inside Portland before and after introducing \$1.65 and \$8 tolls against the default scenario in 2035. 


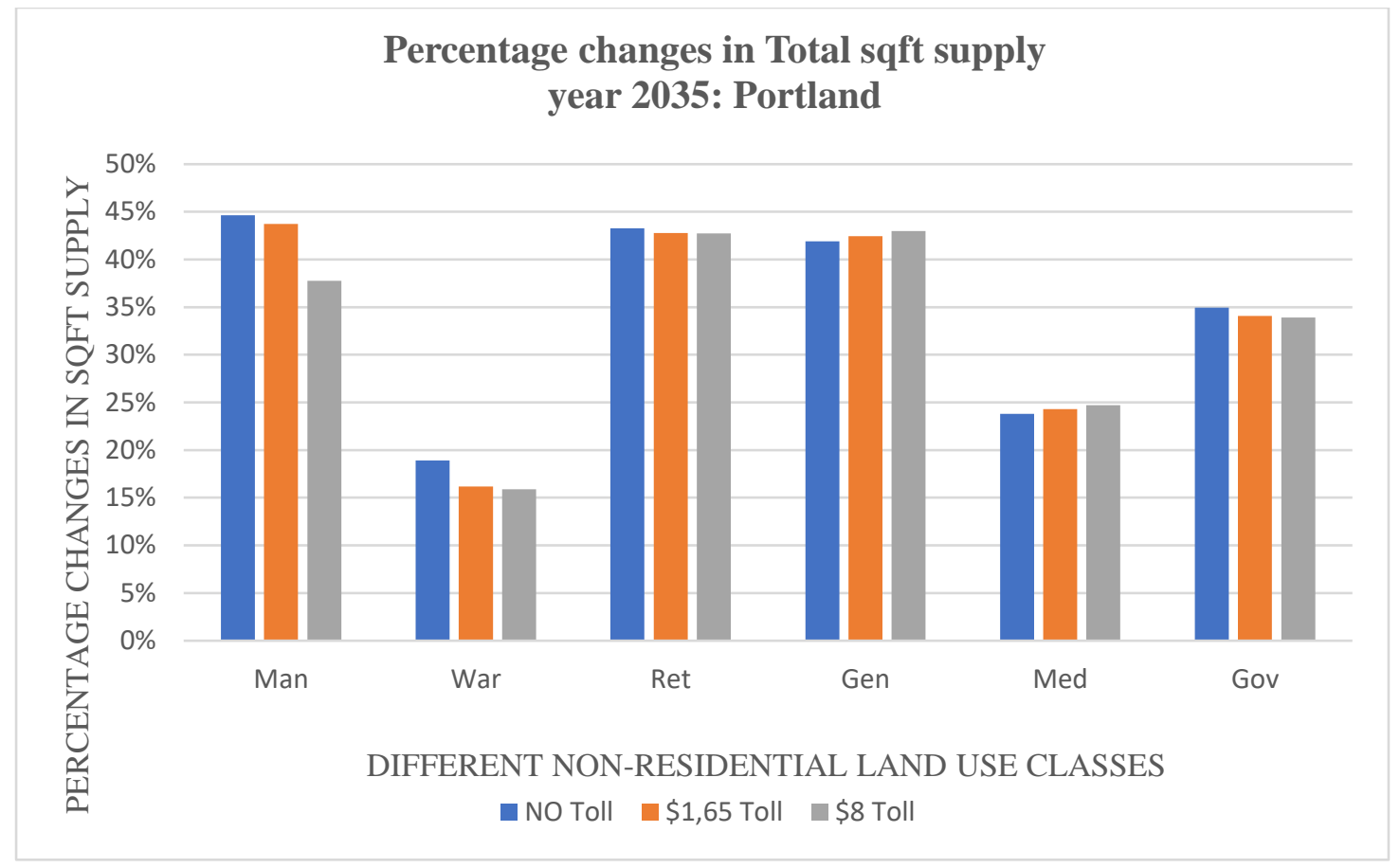

Figure 8.24

Under no toll, Manufacturing, General offices, and Retailers are projected to the largest increase in sqft supply (above 40\%), while Warehousing has the smallest growth.

Once that a cordon is implemented, only Manufacturing and Warehousing are forecast to a larger change in their sqft supply as a consequence of the toll; all the other industries are marginally affected. In detail, Manufacturing is the industry affected the most, with a significant drop in sqft supply; the higher the toll, the larger the decline in sqft supply. Also, Warehousing and Government offices are projected to a slight decline in supply. Medical and General offices are the only two industries anticipated to a small increase in sqft availability after a toll is in place compared to no toll in 2035.

It is important to point out how changes in sqft supply are similar for all nonresidential real estate types (except for Manufacturing) after the implementation of two different tolls, $\$ 1.65$ and $\$ 8$. 
Generally, the implementation of the tolls does not significantly influence sqft supply when compared to no toll. Supply is inelastic, so that changes in demand would mostly affect prices. Possibly, the presence of an UGB in the region makes supply less reactive.

Metro Areas Outside Portland, OR:

The following analysis and graphs focus on percentage changes in total sqft supply in each industry outside the cordon before and after the implementation of a toll cordon in 2035: Manufacturing (Figure 8.25), Warehousing/distribution (Figure 8.26), Retailers/consumer services (Figure 8.27), General offices (Figure 8.28), Medical offices (Figure 8.29), and Government offices (Figure 8.30).

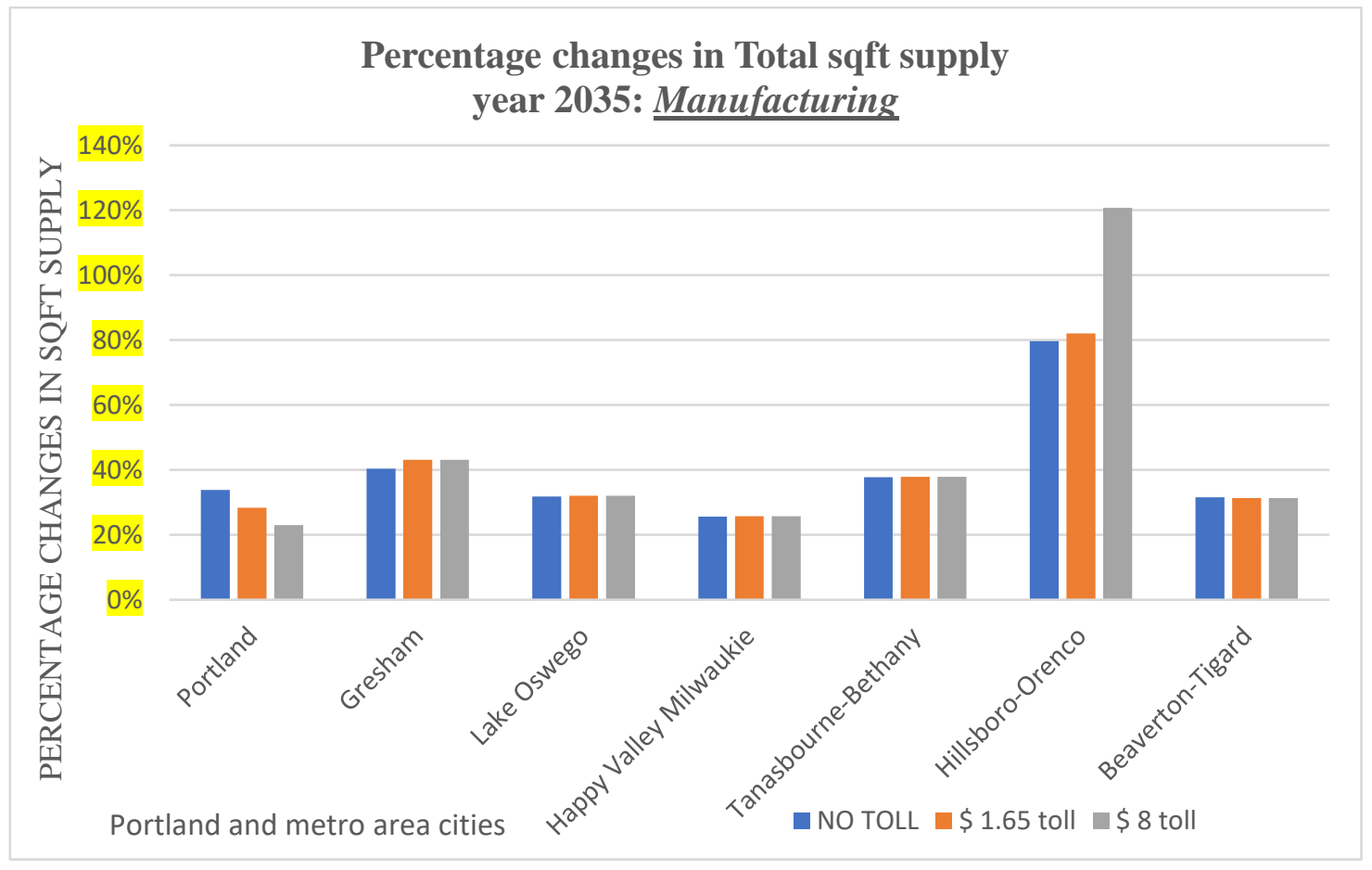

Figure 8.25 


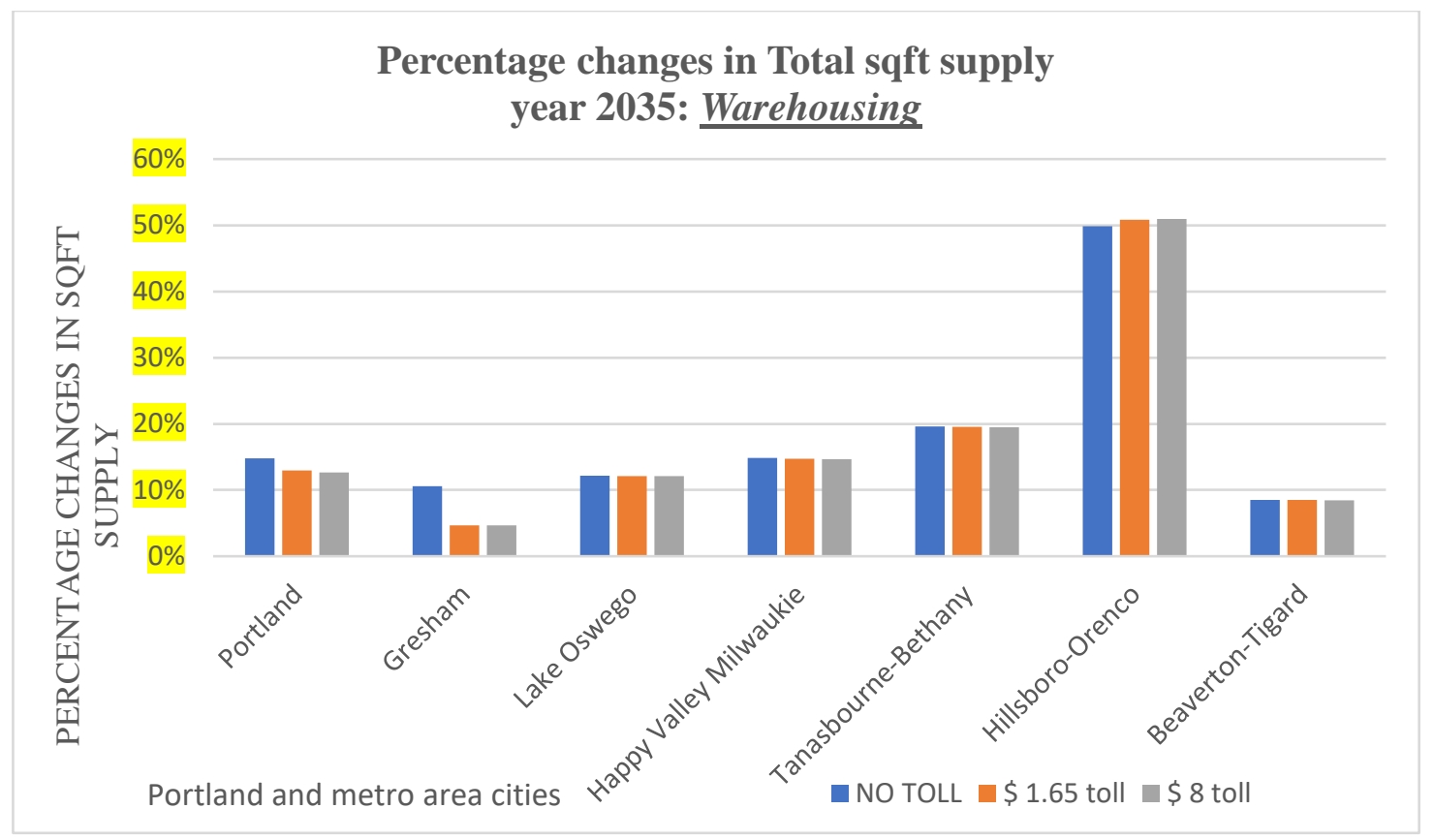

Figure 8.26

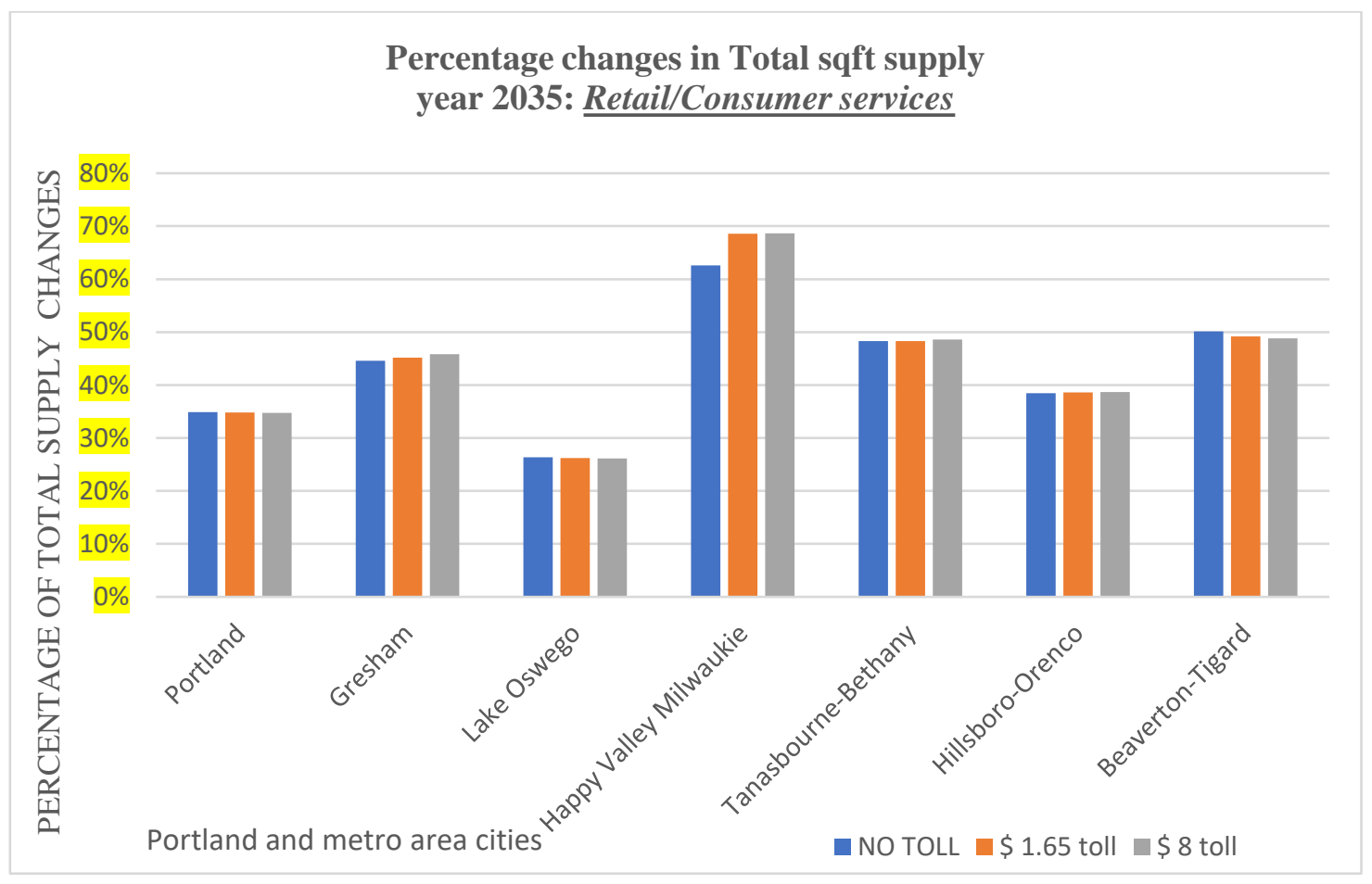

Figure 8.27 


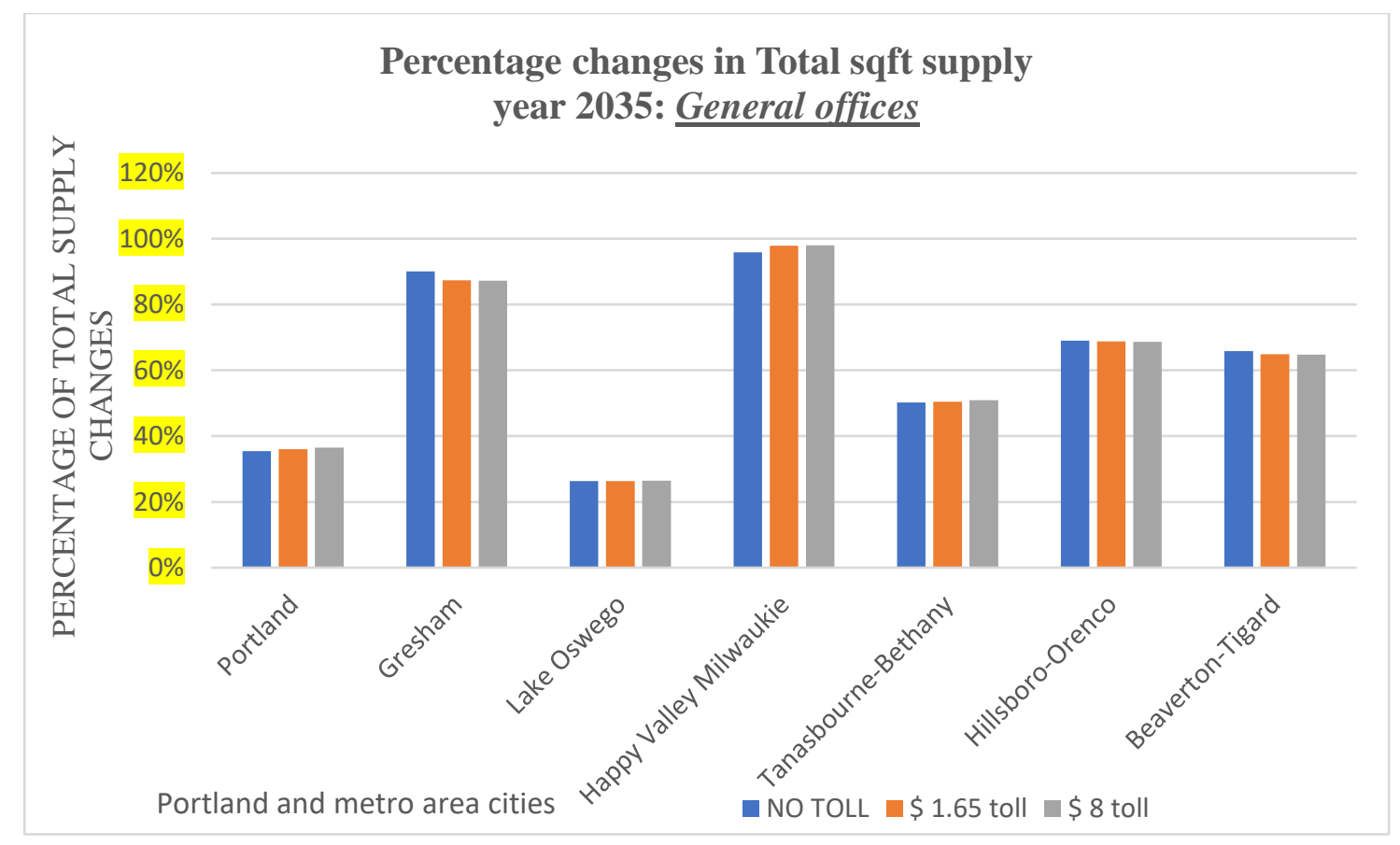

Figure 8.28

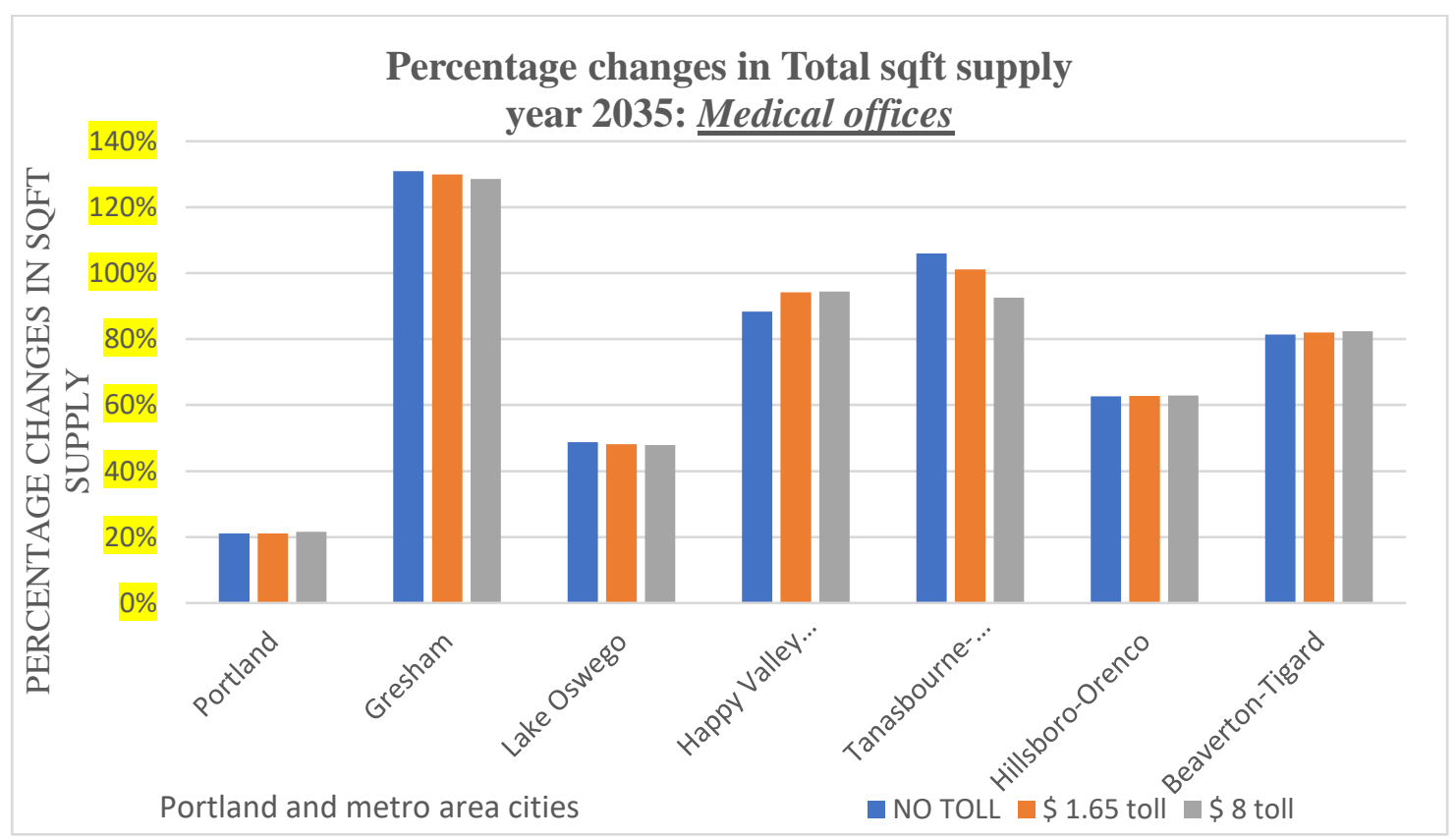

Figure 8.29 


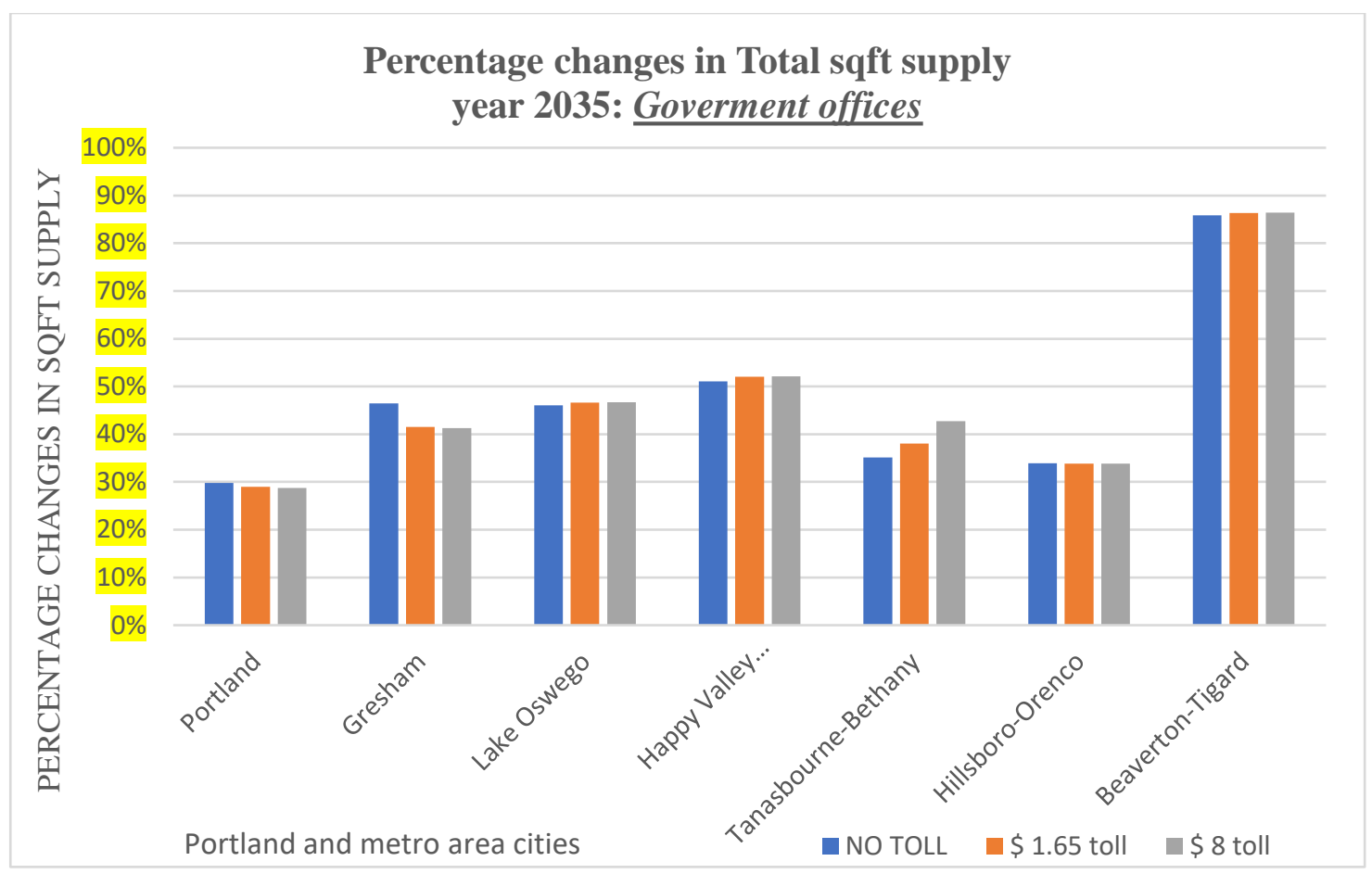

Figure 8.30

Total sqft supply is projected to increase in all industries after 25 years in the default scenario; the greatest increase is for Medical offices, which are projected to more than double the sqft supply available in Gresham and double it in Tanasbourne/Bethany. Also, General offices have an exponential increase in available sqft in the East of Portland (Gresham and Happy Valley/Milwaukie). On the contrary, Warehouse is the industry projected to have a smaller number of sqft available, especially in Gresham and Beaverton/Tigard in the default scenario in 2035.

After the implementation of $\$ 1.65$ and $\$ 8$ tolls, Medical offices still have the largest amount of sqft available over time, yet it also shows the largest decrease in supply (10\% and $13 \%$ less) in Tanasbourne/Bethany (Figure 8.29). Other industries with a large decline in sqft compared to no toll are Manufacturing in Portland and Warehousing and Government offices in Gresham. 
On the contrary, the biggest increase in available sqft is forecast to be in Happy Valley/Milwaukie for Medical, and in Hillsboro/Orenco for Manufacturing space. All the other industries do not show any noteworthy changes in available supply before and after tolls over time.

Overall, the cities affected the most by the implementation of tolls are: Gresham, with a significant decrease in sqft supply for Warehousing and Government offices; Happy Valley/Milwaukie, with a significant increase in available supply for Medical offices; Hillsboro/Orenco, with a large increase in sqft space for Manufacturing; and Tanasbourne/Bethany, with a big decrease in available Medical space.

Table 8.5 shows total sqft supply changes after the implementation of a Big cordon in 2035 . The sign + indicates that the cordon toll pushes for an increase in nonresidential supply in the selected city for a specific industry, while the sign - represents a decline in non-residential supply as a consequence of the toll at the year 2035.

Table 8.5 Effects of the Implementation of a Cordon Toll around Portland on Non-residential Total Supply in Each City at the Year 2035

\begin{tabular}{|c|c||c||c||c||c|c|}
\hline Changes in SQFT supply & Man & War & Ret & Gen & Med & Gov \\
\hline Portland & - & - & - & + & + & - \\
\hline Gresham & + & - & + & - & - & - \\
\hline Lake Oswego & + & - & - & + & - & + \\
\hline Happy Valley & + & - & + & + & + & + \\
\hline Tanasbourne & + & - & + & + & - & + \\
\hline Hillsboro & + & + & + & - & + & - \\
\hline Beaverton & - & - & - & - & + & + \\
\hline
\end{tabular}


The next analysis focuses on residential land use variables.

\section{Residential Land Use:}

Corresponding with the two previous cordon scenarios, for the Big cordon design, the 4 residential land use classes identified are osf, omf, rsf, and rmf. As explained in the previous session, households are assumed to locate where they can access a primary place of work. From each of the 72 ezones, households select a place of residence from among the 425 rzones according to their indirect utility functions embedded in MetroScope. Therefore, there is a connection between housing stock and place of employment (based on their willingness to pay and their consumer surplus).

Additionally, residential location price is not an actual price, but it is calculated from an index that reflects the match between supply and demand, which changes price accordingly. The new prices will affect supply and demand until they match (they do not directly affect each other, but only indirectly through the location price).

\section{$\underline{\text { Residential Location Prices }}$}

Inside the Cordon:

Residential location prices are analyzed before and after $\$ 1.65$ and $\$ 8$ tolls are implemented in 2035 .

Figure 8.31 shows percentage changes in residential location price inside Portland after the toll cordon scenarios are implemented against the no toll alternative. 


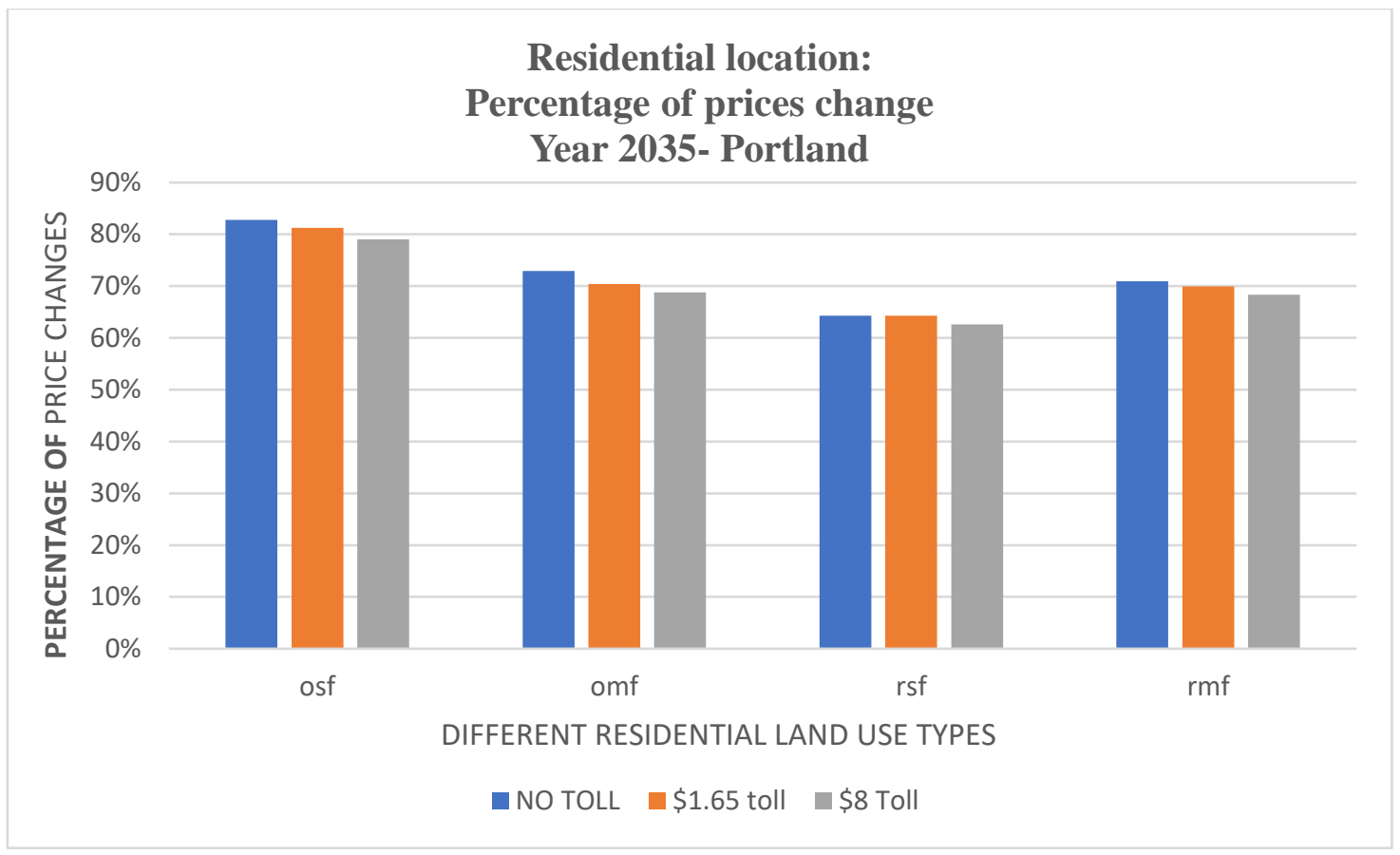

Figure 8.31

In a no toll scenario, ownership of single-family home is the real estate class with the highest increase. Although, generally all the residential real estate types are projected to a large increase in their relative property values.

After the implementation of $\$ 1.65$ and $\$ 8$ tolls, prices still appreciate, but at a lower percentage when compared to no toll; all 4 real estate classes have a relative loss in value compared to no toll. The higher the toll, the larger the relative price depreciation over time.

Generally, with the implementation of a toll, demand for residential housing relative to supply decreases, resulting in more available housing.

The higher the toll, the less the prices will appreciate over time. It could be assumed that the increased size of the cordon negatively affects residential property values inside the cordon boundaries. 


\section{Metro Areas Outside Portland, OR:}

The following graphs (Figures 8.32 to 8.37 ) show residential location price changes inside Portland by comparing the toll cordons against the default scenario for each city outside Portland in 2035. In detail, the graphs show the effects of a toll in Gresham (Figure 8.32) Lake Oswego (Figure 8.33), Happy Valley/Milwaukie (Figure 8.34), Tanasbourne/Bethany (Figure 8.35), Hillsboro/Orenco (Figure 8.36), and Beaverton/Tigard (Figure 8.37).

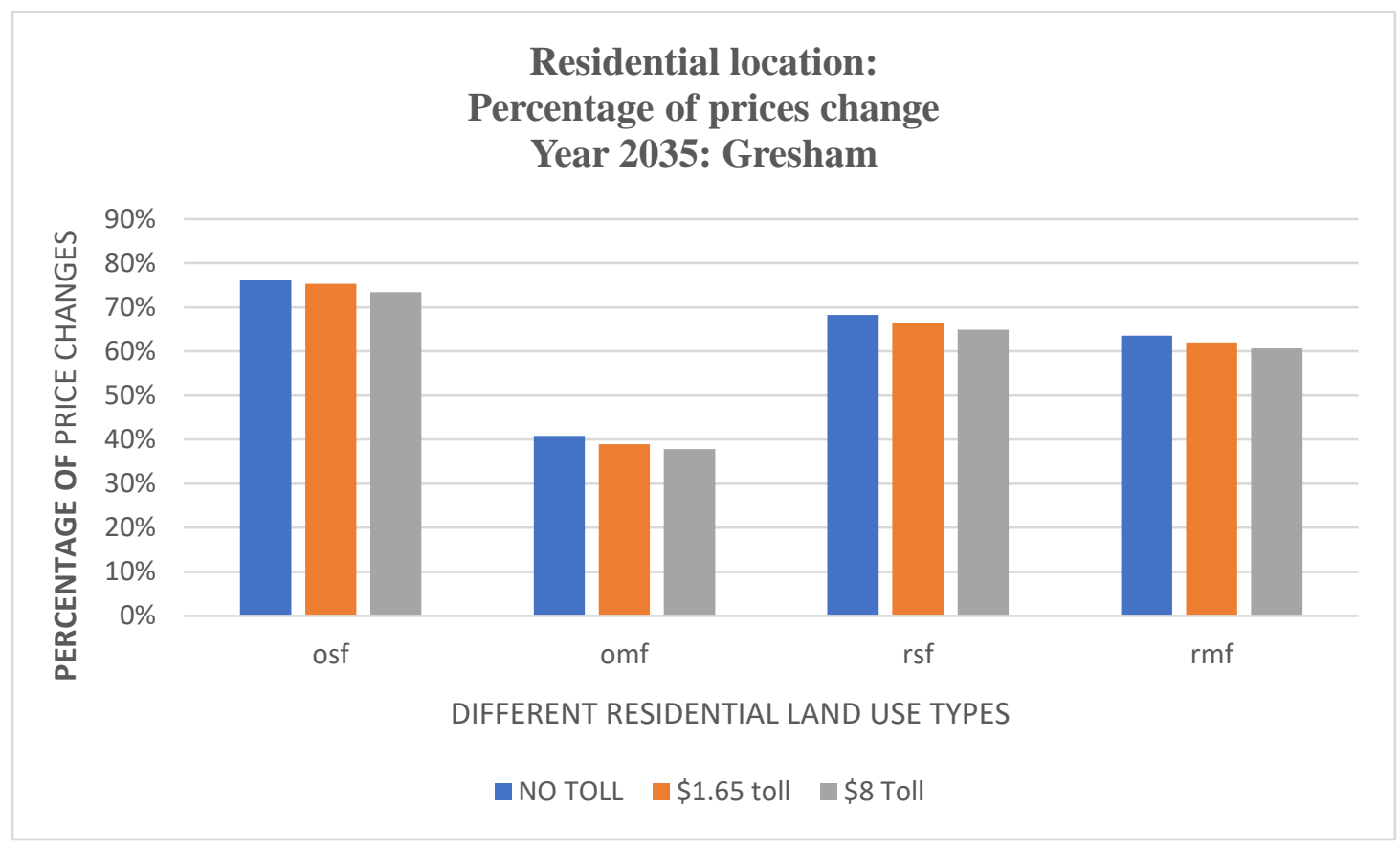

Figure 8.32 


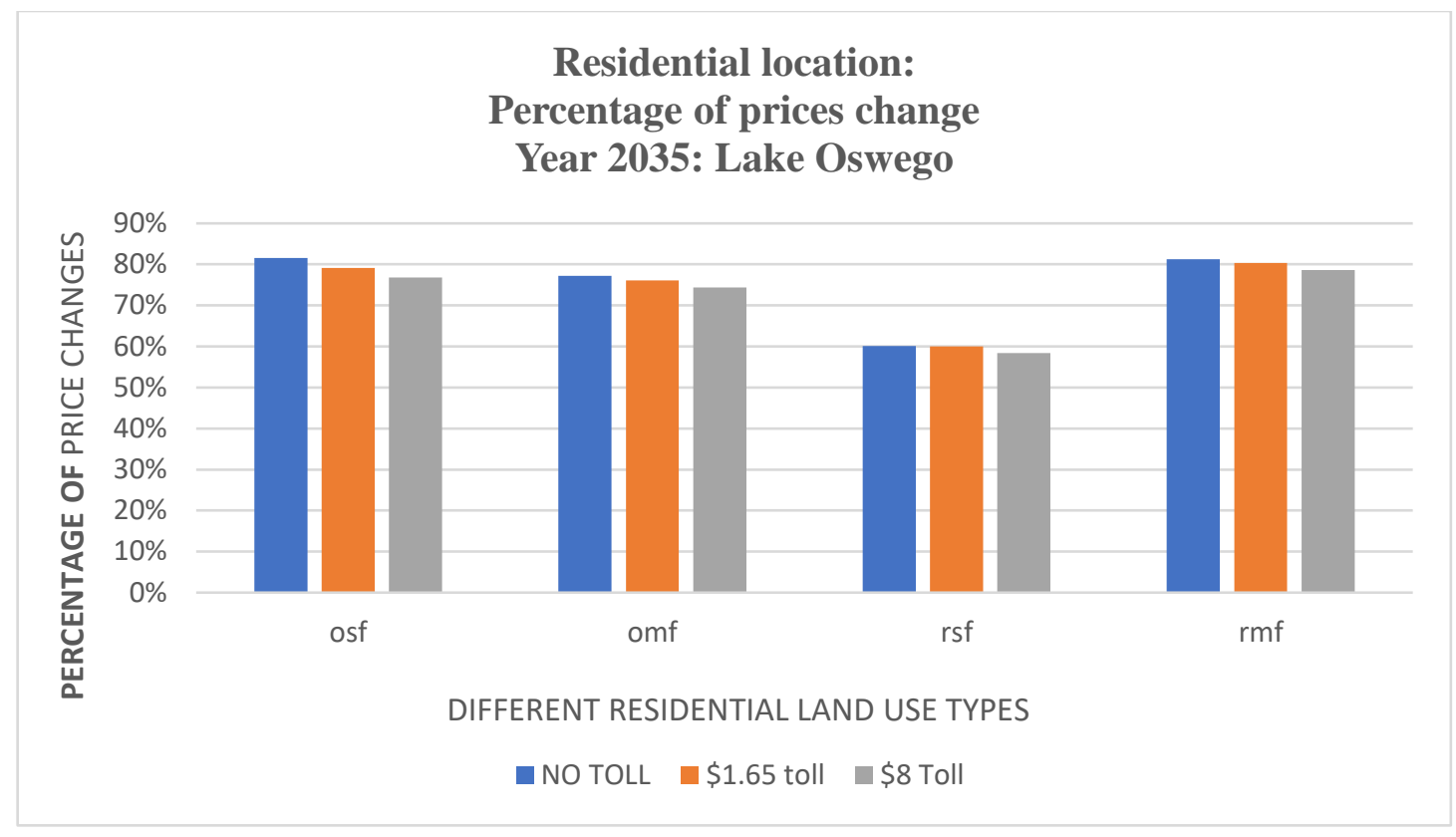

Figure 8.33

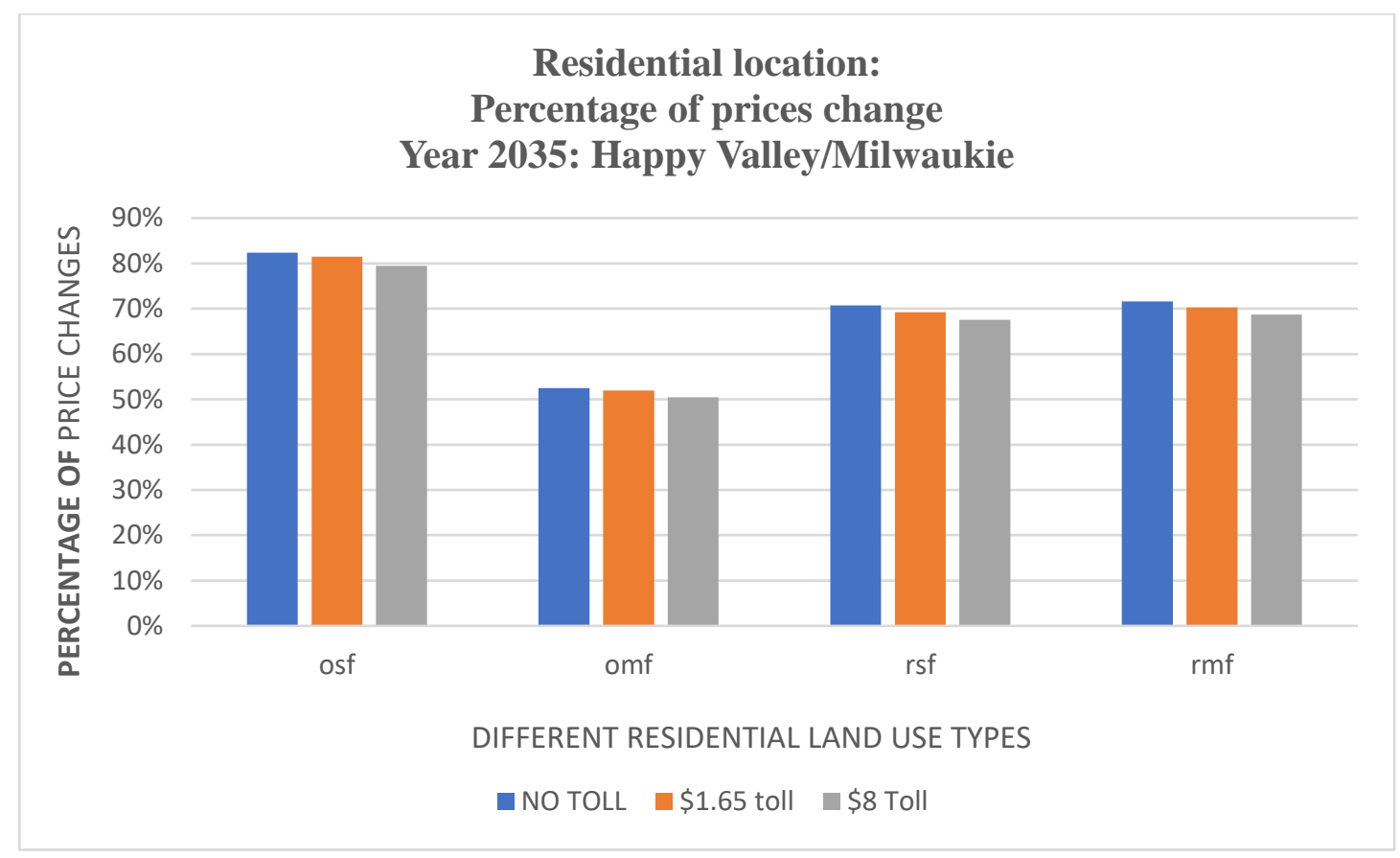

Figure 8.34 


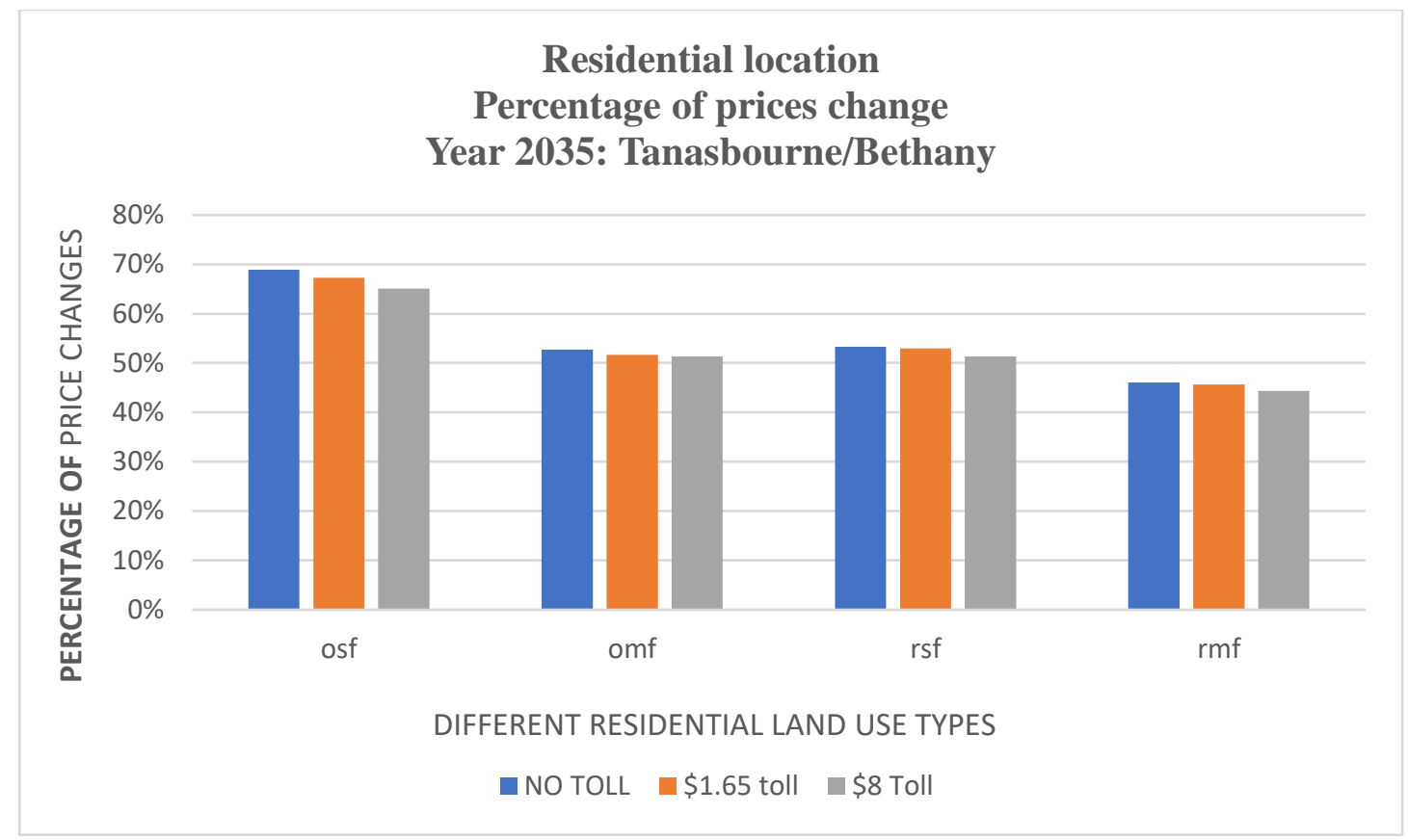

Figure 8.35

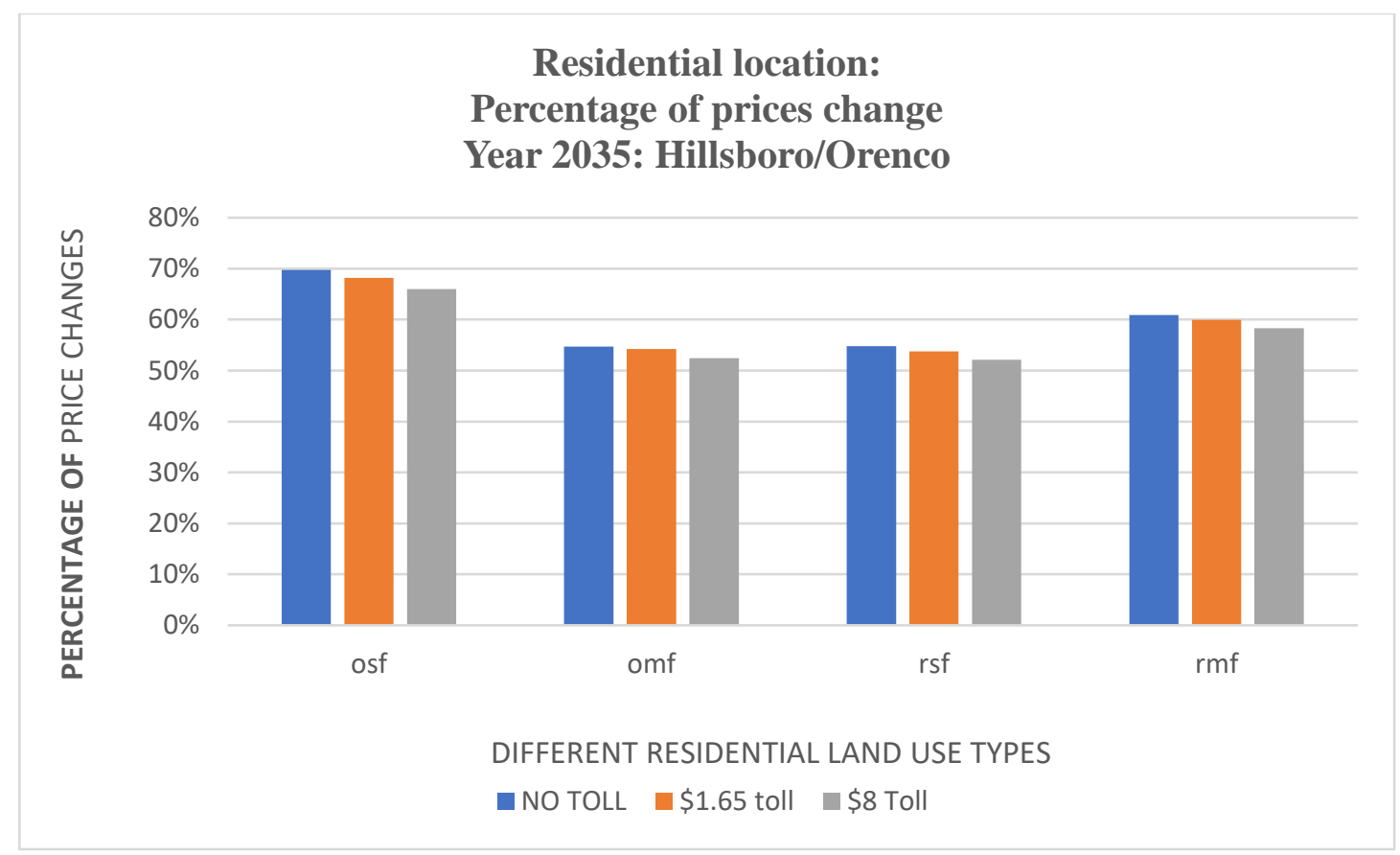

Figure 8.36 


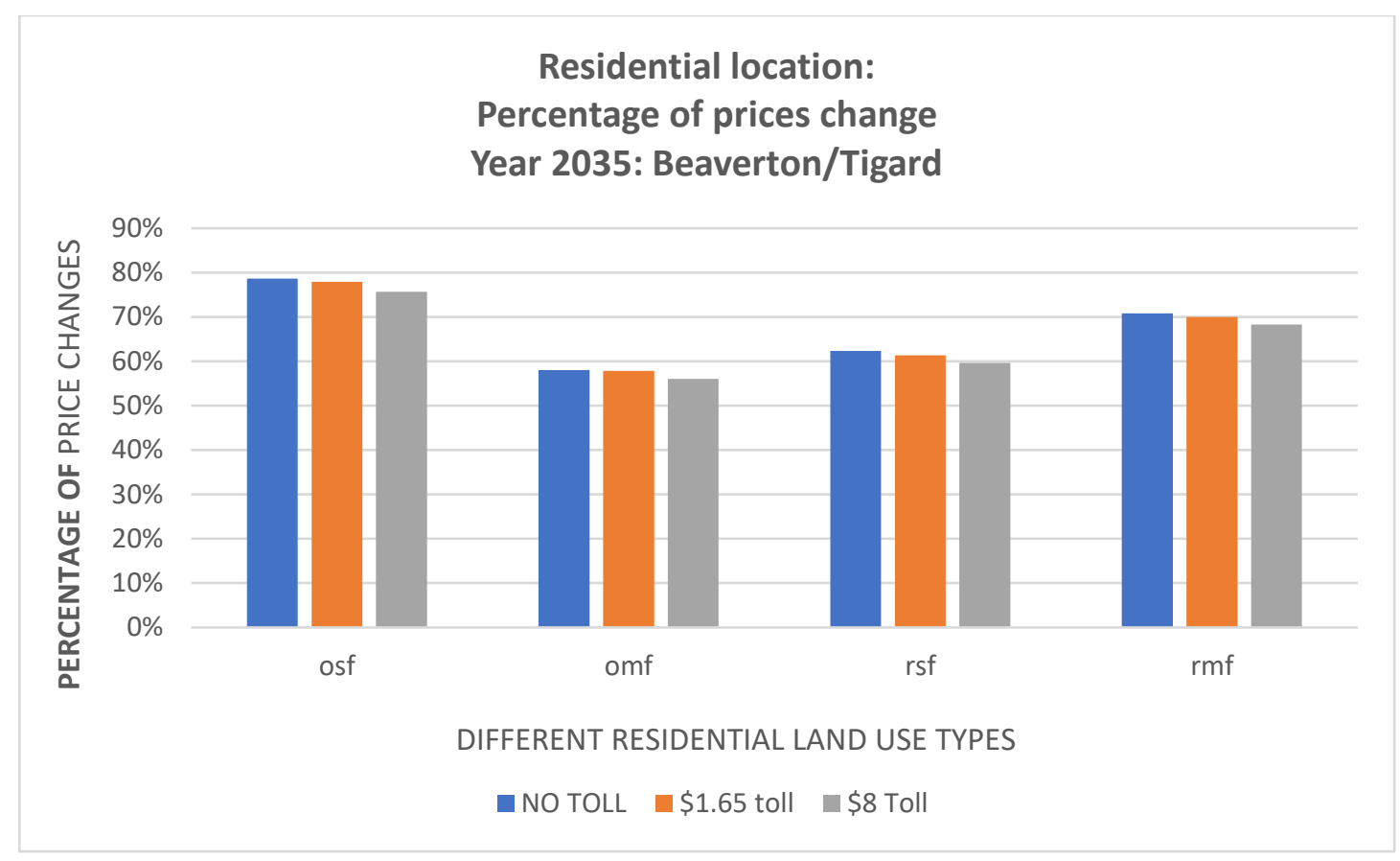

Figure 8.37

Under no toll, demand for ownership of single-family homes is the real estate projected to the largest increase in each of the cities outside of Portland. Overall, all residential real estate experiences a relative price appreciation in each city after 25 years.

The implementation of a toll cordon negatively affects the price indexes for residential real estate, which declines everywhere, causing a relative price depreciation in each city outside of Portland for any housing type compared to no toll in 2035. Further, the higher the toll, the larger is the relative loss in values in each city, compared to no toll.

Generally, a toll negatively affects demand for housing relative to supply for all residential real estate classes, especially for osf units, followed by rsf units. Portland and Lake Oswego showed a large increase in property value before the implementation of a toll, yet they show a slightly higher price depreciation than other cities when a toll is implemented compared to no toll. 
The next output analyzed is changes in the percentage of total households' supply before and after toll cordons are implemented in 2035.

\section{Total Households Supply}

Inside the Cordon:

Figure 8.38 shows the percentage changes in total households' supply inside the cordon boundaries after the implementation of toll cordons versus no toll after 25 years.

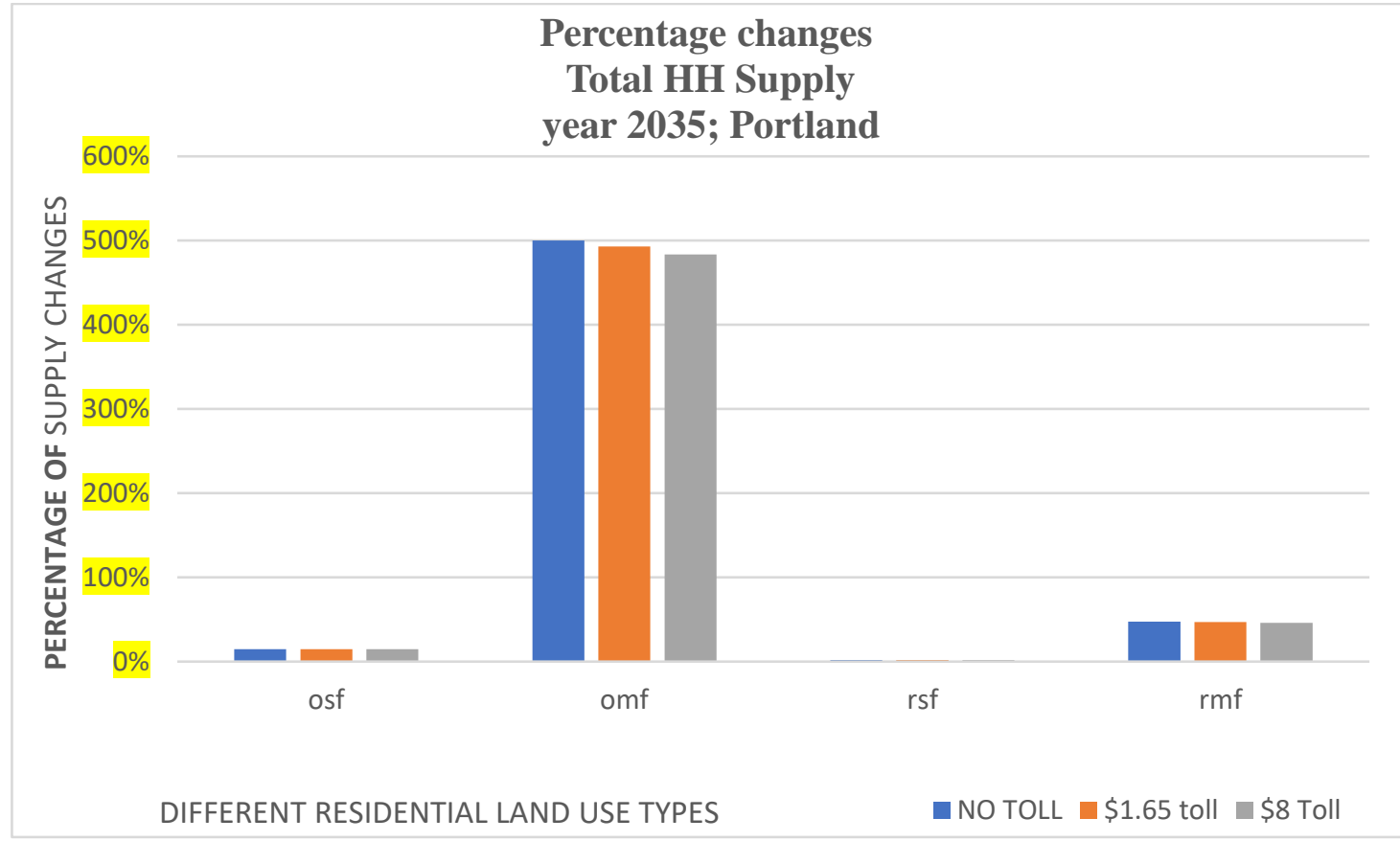

Figure 8.38

Under no toll, Portland is projected to a maximum growth in hh supply for owner occupied multifamily housing units in 2035. Rental of multifamily housing increases only $50 \%$, compared to a $499 \%$ increase in omf. The increase in ownership supply is minimal, especially for osf.

After implementing a toll cordon, it is noticeable that rmf supply is forecast to a significant drop; omf has the greatest drop in supply when $\$ 8$ toll is implemented compared to a $\$ 1.65$ toll, versus a default alternative. Generally, the higher the price of 
the toll, the larger the negative effect on total omf supply. Toll reduces the supply for the other real estate classes, but at very small percentage.

$\underline{\text { Metro Areas Outside Portland, OR: }}$

The following graphs represent changes in the percentage of total households' supply for residential real estate in Portland's subareas before and after the implementation of $\$ 1.65$ and $\$ 8$ cordon tolls versus no toll in 2035 . In detail, the graphs show: Gresham (Figure 8.39), Lake Oswego (Figure 8.40), Happy Valley/Milwaukie (Figure 8.41), Tanasbourne/Bethany (Figure 8.42), Hillsboro/Orenco (Figure 8.43) and Beaverton/Tigard (Figure 8.44).

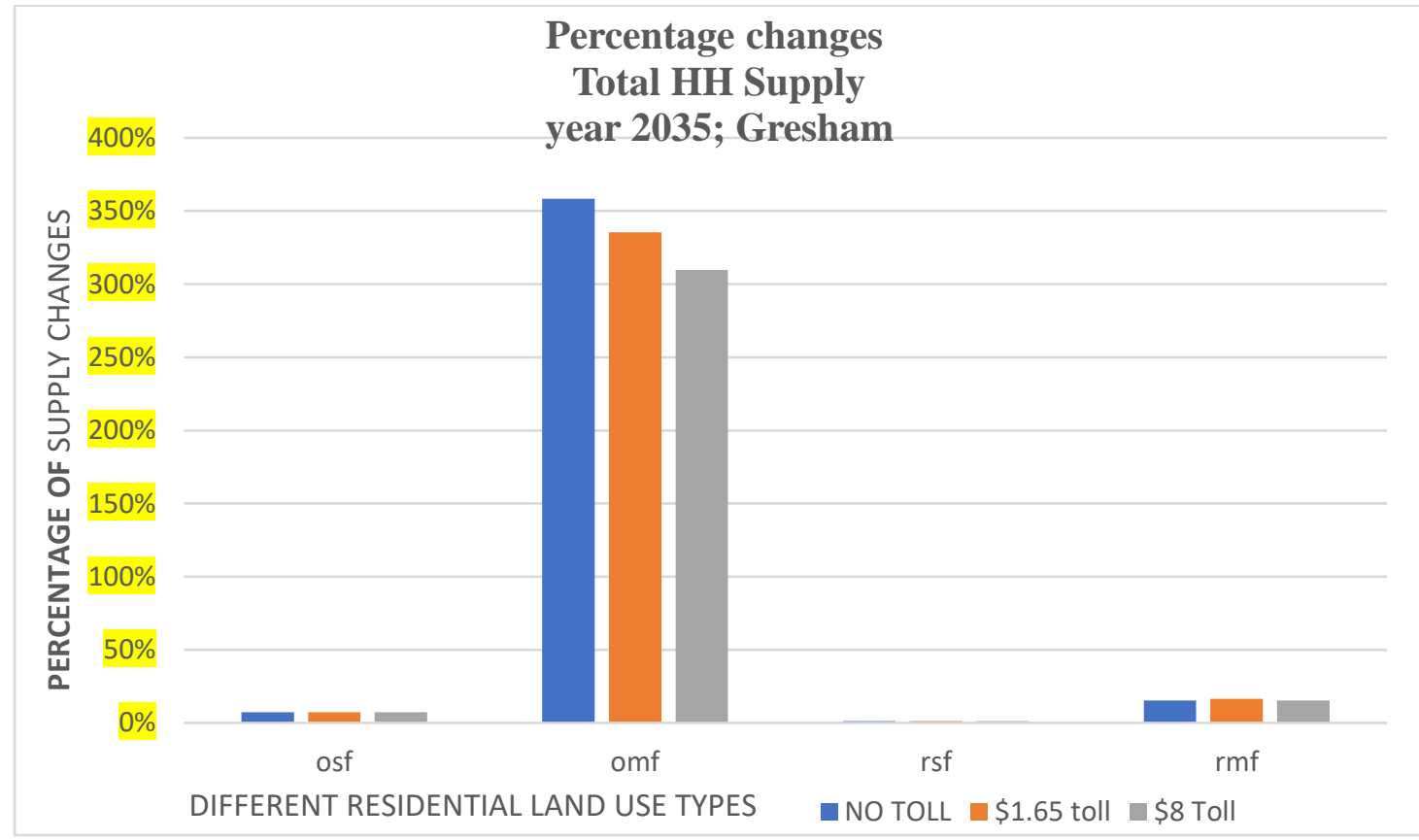

Figure 8.39 


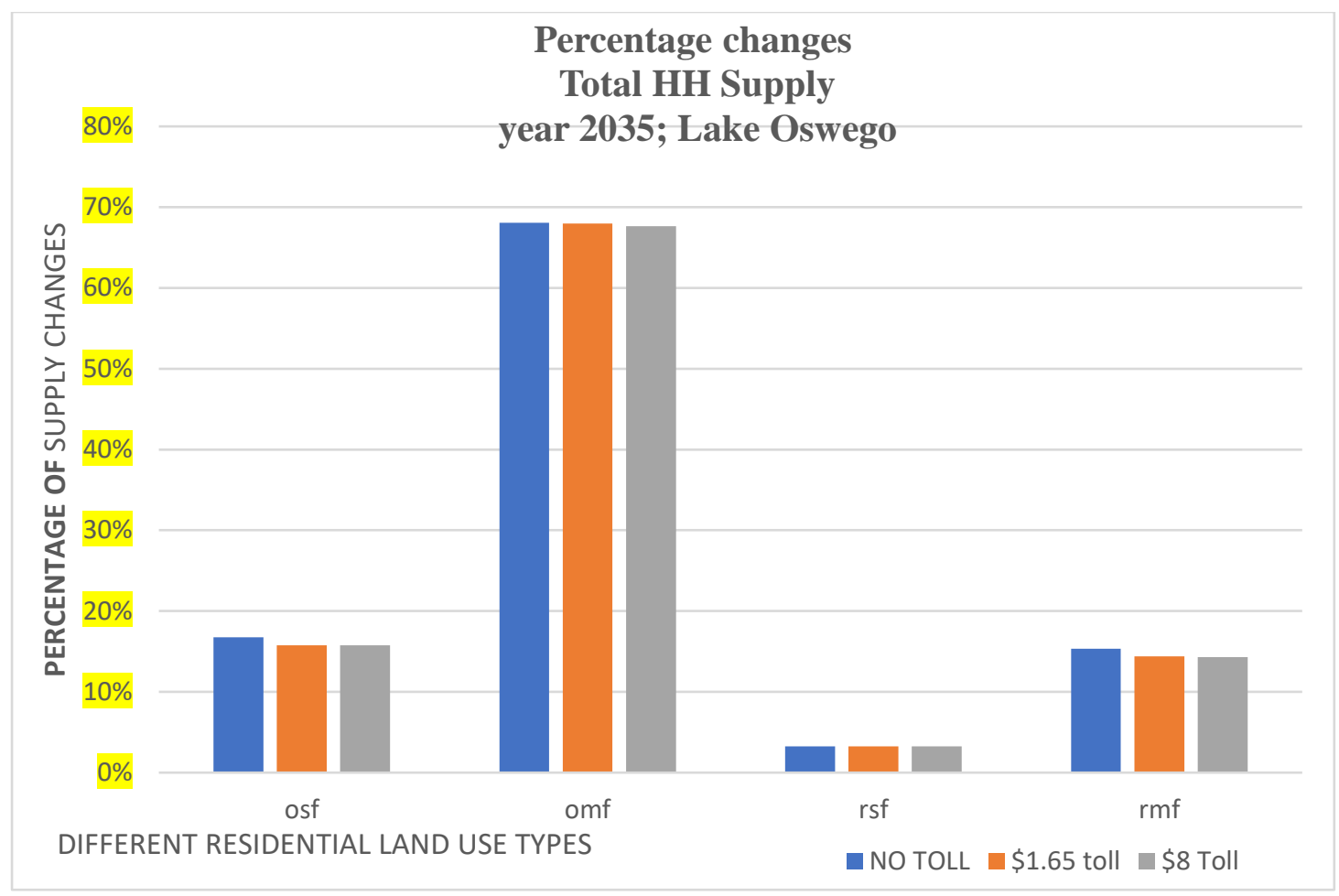

Figure 8.40

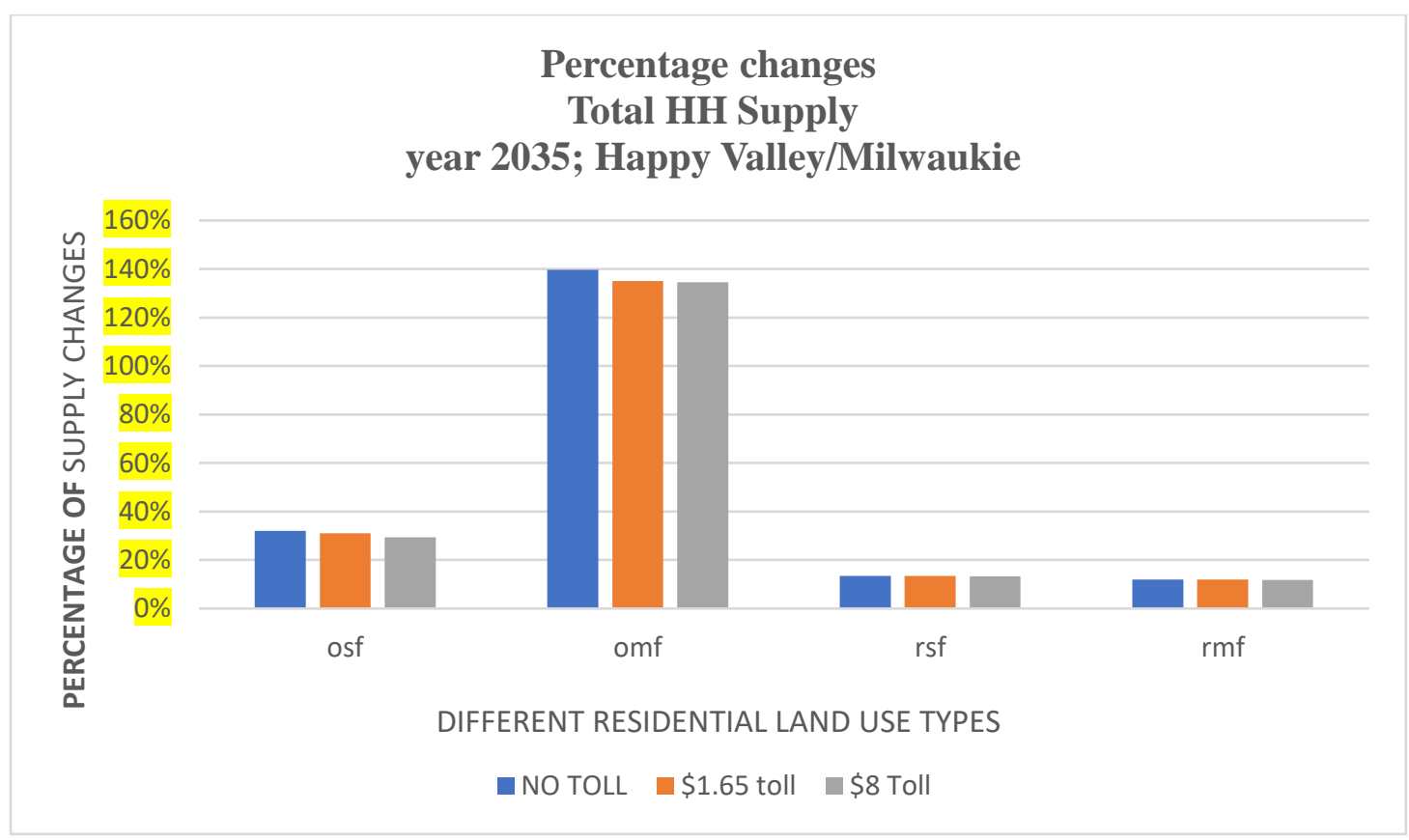

Figure 8.41 


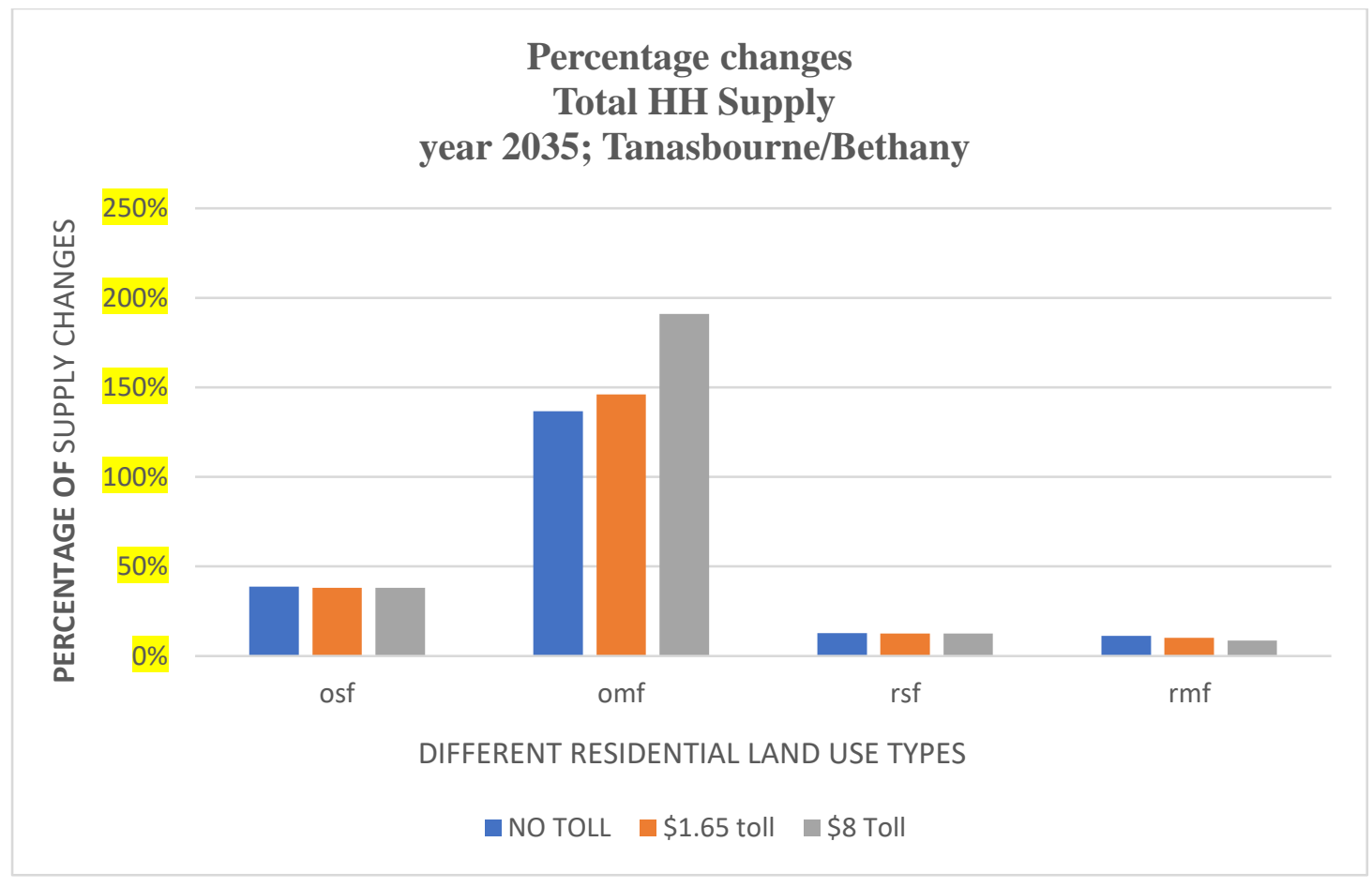

Figure 8.42

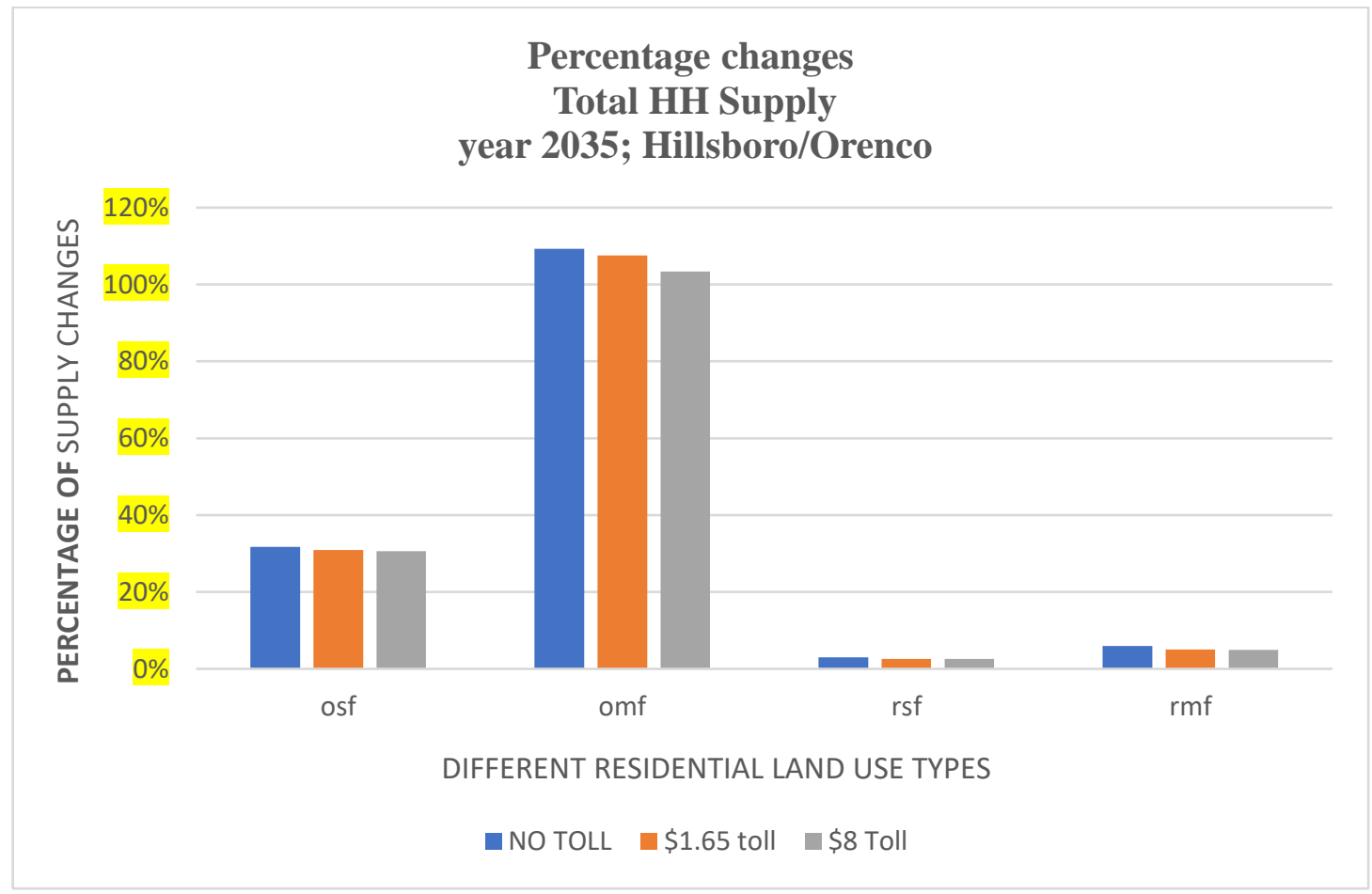

Figure 8.43 


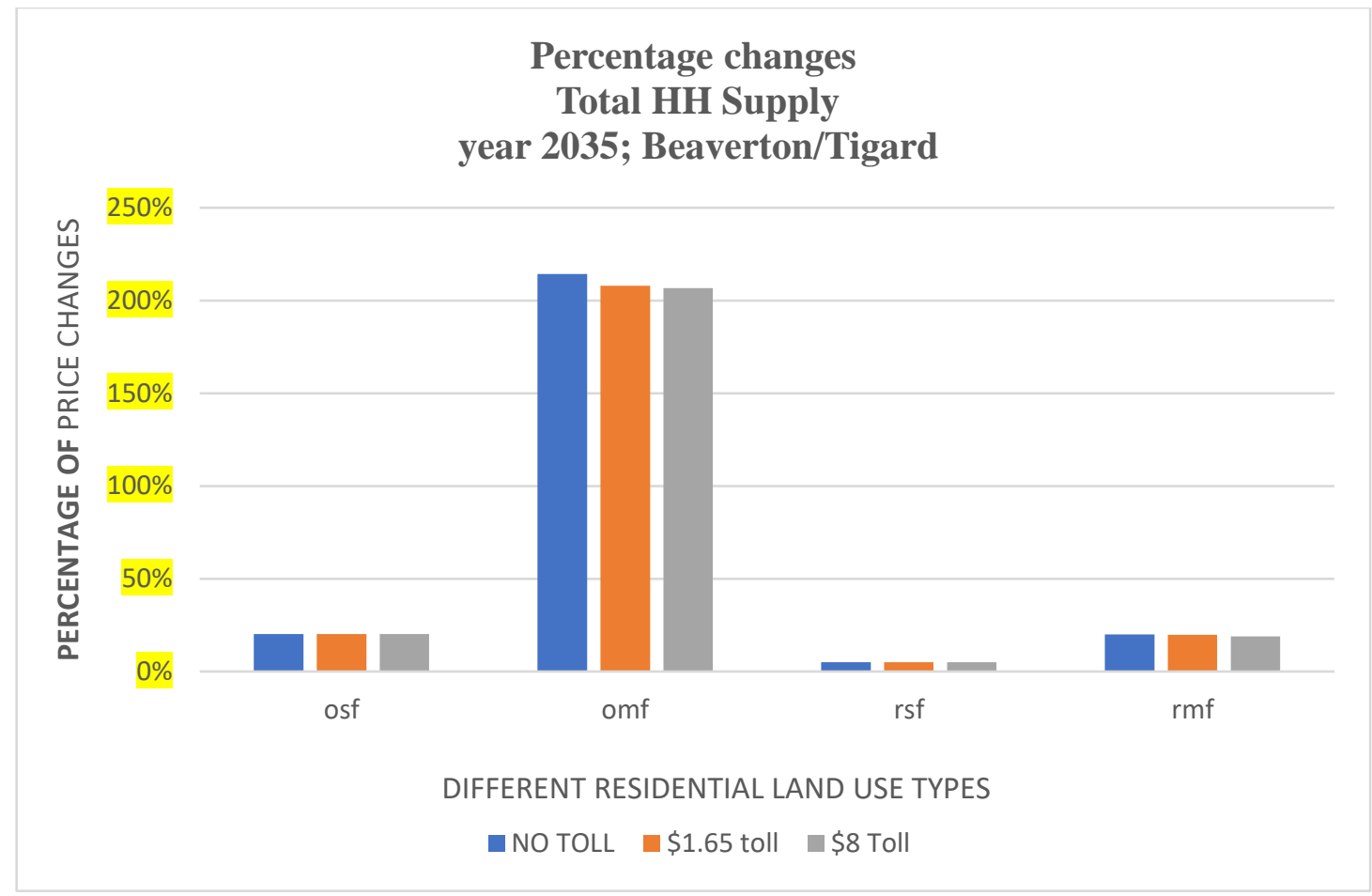

Figure 8.44

Under a no toll scenario, projections for all the Metro areas outside of Portland indicate a maximum growth for omf supply. Gresham has the larger growth in omf outside of Portland with a 358\% increase, followed by Beaverton/Tigard, forecasted to an additional $214 \%$ omf supply, then Tanasbourne/Bethany, with a growth of $137 \%$. In the other sub-cities, omf growth is between $150 \%$ and $100 \%$, with the exception of Lake Oswego, which accounts "only" for a $68 \%$ of omf supply increase.

Once the tolls are implemented, all the metro cities are projected to a decline in omf supply, with the biggest drop under $\$ 8$ toll compared to $\$ 1.65$ or no toll in 2035 . The city projected to the largest percentage drop in omf supply is Gresham, with a $23 \%$ and $49 \%$ decline once $\$ 1.65$ and $\$ 8$ tolls are implemented, respectively, compared to no toll. 


\section{Summarizing the Effects of Big Cordon:}

Inside the entire city of Portland, the implementation of a Big cordon positively affects employment in all the different classes with the exclusion of Agriculture, Transportation, Retail, and K-12 education. Demand for Industrial real estate increases, while demand for any class of residential housing declines, as does total household demand after a toll is implemented compared to no toll in 2035. Supply is inelastic and doesn't react as much to the implementation of toll cordons, making demand affect prices the most. Overall, today Portland's economy is based primarily on Health, Social, Professional, and Tech services, as well as Retail, and tolls push for further growth of all of those activities except Retail.

It is interesting to observe how activities are projected to move around the metro area once that the Big cordon is in place. The presence of a cordon affects non-residential supply and demand variables more that the dollar amount charged. Therefore, it can be stated that the presence of a cordon can potentially affect non-residential location patterns and investments. The model is not very sensitive to travel time; $\$ 1.65$ and $\$ 8$ tolls produce similar results. Tolls are calculated adding extra minutes, so that MetroScope mitigates the impact of such tolls by changing the redistribution of all trips that are impacted by the tolls. Drivers adjust their trip to the higher transportation costs.

Outside of Portland: Generally, in the East side of Portland, tolls positively affect employment for higher-value economic activities and Construction, specifically in Gresham. Also, industrial and commercial properties show an increase in relative land prices (except in Retail and Government). As today, Gresham's economy is based mainly on lower-value activities such as Manufacturing industries and Health services, yet tolls 
significantly push for employment in Finance, Insurance, Real Estate, Business, and Consumer services besides Construction, Transportation services, and High-tech manufacturing. Therefore, Gresham might have a shift in types of economies after the implementation of a Big cordon. Happy Valley/Milwaukie reports an increase in employment for mainly Industrial activities. The majority of non-residential real estate shows a decline in relative land prices. Overall, residential real estate have a relative price decline.

On the contrary, in the West part of the metro area (especially in Tanasbourne/Bethany and Hillsboro/Orenco), tolls reduce employment in all the Manufacturing activities but High tech, while only a few commercial economies have an increase in some commercial and consumer services. Non-residential property price is projected to a relative price appreciation for almost all the industries in Tanasbourne/Bethany. Today, Tanasbourne's economy is based in Manufacturing and Professional, scientific and tech services. The introduction of a Big cordon might intensify Manufacturing activities over higher-value economic activities compared to no toll in 2035.

Beaverton/Tigard reports an increase in commercial and consumer activities, as well as Transportation/warehousing and Communication/utilities once a toll is in place. K-12 education increases employment only in Tanasbourne/Bethany. Generally, residential housing has a relative price depreciation.

Summarizing the effects that each cordon has within the entire city of Portland after a toll is implemented compared to a no toll alternative in 2035 : 
Table 8.6 provides a visual comparison of the effects that each of the three cordons has on non-residential and residential land use patterns compared to a default alternative 25 years after the implementation. The sign + indicates that a toll pushes land use variables to grow, while the sign - refers to a decline in land use variables over time, compared to no toll.

It is noticeable that the number of non-residential properties is projected to relative price depreciation as the size of the cordon increases versus a no toll alternative. Employment reacts similarly in each of the three scenarios. Household demand is positively affected only in a Small cordon alternative. Additionally, residential real estate price indexes increase only for ownership of multifamily units at the entire city level only if a Small cordon is implemented.

Supply is less affected from cordon policies than demand; supply is inelastic so that changes in demand mostly affect prices. The UGB makes supply act as fixed.

More detailed evaluations and assumptions with regard to the impact of each cordon on land use patterns are expanded in following two chapters: Main Findings and Final Evaluations. 
Table 8.6 Recaps and Compares the Effect that Each Cordon Has within the Entire City of Portland After a Toll is Implemented Compared to a No Toll Alternative in 2035

\section{Comparison of Difierent Cordon scenarios on land use variables \\ within the entire city compared to no toll}

Non-residential location prices

CBD Central C PDX

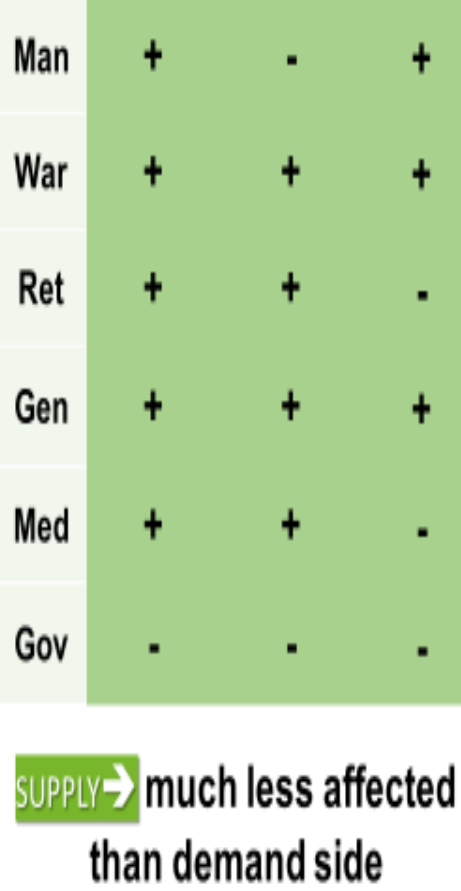

Residential location prices

Total employment Changes

\begin{tabular}{|c|c|c|c|}
\hline & CBD & Central C & PDX \\
\hline Agriculture & + & + & - \\
\hline Construction & + & + & + \\
\hline Non-dur Man & + & + & + \\
\hline Dur Manufact & + & + & + \\
\hline High tech Man & - & - & + \\
\hline Transportation & + & + & + \\
\hline Communication & + & + & + \\
\hline Wholesale trade & + & + & + \\
\hline Retail trade & . & + & - \\
\hline Financellnsurance & + & + & + \\
\hline Consumer services & + & - & + \\
\hline Health services & + & + & + \\
\hline Business & + & + & + \\
\hline Other Government & + & - & + \\
\hline$K-12$ & . & . & . \\
\hline
\end{tabular}




\section{Main Findings}

\subsection{Summary of the Main Findings}

The previous chapters presented data, graphs, and tables documenting the growth in terms of residential and non-residential land use projections within the areas inside and outside the three cordons for the entire city of Portland and the neighboring towns before and after the tolls, compared to a no toll alternative in 2035. Each chapter discussed how industries, employment, and household patterns are projected to change if a toll cordon is applied. MetroScope output is analyzed and compared to the default scenario after the implementation of a toll cordon around the CBD (Small), Central City (Mid) and Portland City Limits (Big). Toll rates of \$1.65 and \$8 were charged to cross inbound. Since MetroScope produces such a large amount of output, this chapter recaps the key findings with regard to non-residential and residential land use changes and will attempt to explain them. The main questions are: which scenario (if any) brings the greatest benefits to Portland? Does a specific size (Small, Mid, or Big) of a toll cordon affect development more? What challenges are possible?

In an attempt to answer these questions, the next section of this paper provides a recap of the key effects of implementing each of the three cordons compared to the default scenario.

$>$ Changes in land use patterns within the entire city of Portland in a no toll scenario in 2035:

Industrial and Retail real estate price indexes decline. Conversely, Medical, General, and Government offices relative prices appreciate. 
Employment for all economic activities grows, with the exclusions of durable and non-durable manufacturing.

Demand for housing shows a substantial increase at the city level (as well as within the downtown) in 2035.

Price indexes for all types of housing raise, especially for ownership of both single and multifamily units, at the entire city level and at the areas equivalent to the CBD and Central City.

Overall, non-residential land use variables grow at the entire city level.

Under the same no toll scenario, the areas equivalent to the Small and Mid-cordon perimeters report a decline in non-residential properties except Medical offices. In Eastern Portland, Industrial real estate reports a relative price decline, while Commercial real estate has an increase in relative value.

Changes in employment within the CBD and Central City show a decline in Manufacturing industries and Wholesale trades, while Wholesale is positive at the city level.

Non-residential land use variables experience an overall increase at the city level. Residential real estate shows an appreciation both at the city level as well as within the downtown area. Sqft supply for industrial space increases at the city level, causing a relative price depreciation.

Changes in land use patterns within the entire city of Portland after a cordon implementation versus no toll in 2035:

The number of non-residential land use classes projected to a relative price appreciation diminishes as the size of the cordon increases. 
- At the entire city level, the implementation of a Small cordon boosts a relative price appreciation for non-residential spaces for all the land use classes (except Government).

- In a Mid-cordon scenario, in addition to Government real estate that is projected to a relative price depreciation, also Manufacturing spaces have a relative price decline.

- In a Big cordon, additionally to those variables, Retailer and Medical spaces have a relative price drop.

Employment performs similarly in each of the three scenarios; nevertheless, a few employment classes perform differently depending on the size of the cordon toll compared to no toll.

- A Small cordon is projected to increase in employment in almost all economic activities, with the exception of Retailers, K-12 education, and High-tech manufacturing.

- A Mid-cordon is projected to increase in employment for the same activities as the Small cordon, with the exception of Government and Consumer offices.

- A Big cordon is projected to increase in employment in almost all economic activities, with the exception of Agriculture/Timber, Retailers, and K-12 education.

- Employment in High tech is projected to increase only if a Big cordon is implemented. 
Household demand for housing increases only in a Small cordon, while there are slight declines in a Mid or a Big cordon scenario compared to no toll.

Overall, non-residential sqft supply does not significantly change in any real estate class.

Residential land use: the increase in relative price for residential housing slightly diminished as the size of the cordon increases compared to no toll in 2035 . The implementation of any of the three cordons shows a relative price depreciation for ownership of single-family units. Differently, multifamily units' relative value grows only under a Small cordon scenario.

Total household supply for omf increases in a Small cordon scenario.

Land use changes inside the cordon boundaries:

- Within the Mid-cordon perimeter, non-residential real estate and employment have a bigger appreciation compared to the other two toll scenarios versus no toll. Further, even when the area of the Mid cordon is divided into West and East, the West still performs better than the equivalent ${ }^{9}$ Small cordon area.

- Within the Small cordon perimeter, only a very few economic activities are projected to a minor increase in employment, and nearly all the nonresidential properties have a relative decline in prices.

Similarly, household demand for housing increases in the Eastside if a Midcordon is implemented but declines if a Small cordon is implemented.

${ }^{9}$ The West area of the Mid-cordon perfectly overlaps with and therefore is equivalent to the Small cordon area. 
Residential demand for housing declines inside the Mid cordon, where the additional available supply is reflected in relative lower location prices.

Conversely, residential real estate is projected to a relative price growth inside the Small cordon boundaries.

Land use changes right outside the cordon boundaries:

Tolls boost demand for commercial properties relative to the available supply, triggering a relative price appreciation in the Eastern neighborhoods when a Small or a Mid cordon is employed. On the contrary, Western neighborhoods report a relative loss in industrial and commercial property values.

Both a Small and a Mid cordon positively affect employment in high-value activities, especially for Transportation and Warehousing in the Eastside. Generally, residential real estate price indexes (ownership especially) are projected to a growth in West Portland, both under a Small or Mid cordon scheme.

East Portland, ${ }^{10}$ is projected to an overall increase in real estate price indexes only if a Small cordon is applied.

Total household demand increases in North and East Portland under both scenarios.

Changes in land use for the cities outside of Portland:

Non-residential location price patterns are projected to a similar outcome in each of the three scenarios compared to no toll.

\footnotetext{
${ }^{10}$ Central East/Hawthorne and Lloyd district
} 
West of Portland, ${ }^{11}$ Tanasbourne/Bethany is projected to an overall increase in real estate price indexes under each of the three cordons compared to no toll. Retailers show a relative decline in prices only in Hillsboro/Orenco and Beaverton/Tigard if a Mid or a Big cordon scenario is implemented. East of Portland, ${ }^{12}$ the number of industries projected to a relative decline in property values is larger than in the West metro area, regardless of the size of the cordon, compared to a no toll alternative. Happy Valley is projected to incur the largest relative real estate price depreciation under any cordon scheme versus no toll.

- Cities in the eastern side of Portland report an overall larger number of industries projected to an increase in their employment if a Big cordon is implemented. In the western side of Portland, employment for industries and businesses does not increase as much as in the East metro area under a Big cordon.

- Differently, a Mid cordon scheme positively influences employment in the western neighborhoods.

- A Small cordon scheme does not have much impact on employment outside of Portland compared to the other scenarios against a default alternative.

Households' location demand increases most in Tanasbourne/Bethany, followed by Gresham, in all the three scenarios versus no toll.

\footnotetext{
${ }^{11}$ Western side of Portland includes Tanasbourne/Bethany, Beaverton/Tigard, and Hillsboro/Orenco

${ }^{12}$ Eastern side of Portland includes Happy Valley/Milwaukie, and Gresham
} 
Generally, total sqft supply is reported to behave similarly in all the scenarios. Residential demand for housing has a relative decline in property values for all the real estate classes in each scenario compared to no toll.

Household supply has a similar behavior among all areas and scenarios.

Compared to other cities, Lake Oswego did not report any important land use changes after the implementation of toll cordons versus no toll.

\subsection{Final Evaluations}

Changes in land use patterns described above identify the main effects caused by the implementation of each different cordon policy compared to a no toll alternative in 2035. It is predicted that the size and location of a cordon is critical in affecting economic development and household patterns. As the timeframe for the evaluation of the no toll scenario is 2035, the MetroScope model assumes that the existing policies, investment patterns, and trends continue. MetroScope inputs were changed to for each cordon policy scenario, creating a basis for comparing them against a default alternative.

Overall, the imposition of a toll affects demand side variables greatly, while supply does not react as significantly to the implementation of different toll cordons. Supply is assumed to be less reactive because of the presence of Urban Growth Boundaries (UGB) in the region that makes supply behave as "fixed." Metro's approach to estimating land supply includes various estimates of already existing vacant land and individual tax lots which have the potential to redevelop (Metro, 2013). Nevertheless, MetroScope does not allow implementation of any additional supply into the model.

The presence and size of a cordon caused alterations in residential and nonresidential land use patterns, although the similarity between $\$ 1.65$ and $\$ 8$ results is very 
interesting. Such different charges generate similar outcomes. One assumption is that MetroScope mitigates the impact of such different tolls by changing the distribution of the trips that are impacted by the tolls. In fact, MetroScope calculates tolls as an increase in travel minutes, so that households adjust their travel to the higher transportation costs, triggering a change in distribution of all trips. Hence, the traffic adjusts based on tolling making the model less sensitive to travel time, and any changes get distributed over the whole system. Nevertheless, the use of a different cordon size alternatives influences economic growth inside and outside the boundaries. Moreover, MetroScope was run to calculate the effects of the implementation of 15 minutes - or a $\$ 5$ toll-for each of the three cordons as well. The results were not worth reporting since the $\$ 1.65$ and $\$ 8$ tolls produce very similar outcomes, as explained above. Nevertheless, it is reasonable to speculate that if the model would provide modal shifts, then the produced results would, to a certain degree, mitigate the dispersion effects that the analysis found, considering that none of the alternatives would be subject to the tolls.

The MetroScope simplified version does not allow forecasting changes in mode choices, but only predicts private transportation mode. However, the model provides valuable land use information to be used to examine whether and which size of a cordon could be used to enhance economic development in Portland, Oregon.

Importantly, while analyzing the results, it has to be taken into consideration that MetroScope's location price is not a value, but an index that reflects the match between Supply and Demand; therefore, if there is a competition for real estate in each given zone, the unmet potential demand is reflected in a higher location price. The produced values 
indicate how the land supply will converge to its demand and can predict whether supply is falling behind real estate demand resulting in higher location prices or vice versa.

Location price index measures the housing price relative to 2010 calculated on a "hedonic" table, that is, the matrix with the actual price paid for housing in 2010 dollars. Because price is an index, price decline is relative to supply and demand, which together determine price and quantity; therefore, prices will increase even in the case where the price index declines.

This research focuses on the city of Portland and tries to account for the questions formulated at the beginning of this study with regard to which size of cordon design, if any, brings the greatest economic benefits to Portland.

It appears that the design of a Small or Mid cordon scheme provides overall economic benefits at the entire city level, although they might create dispersion of employment and household activities within the city. In more details for each cordon:

The implementation of a toll cordon around the CBD positively affects both nonresidential real estate and employment for almost all economic activities at the city level. Not only does household demand for housing increase within Portland, but also relative changes in prices for residential real estate reports a relative smaller depreciation compared to the other two cordon schemes versus the default scenario in 2035. Businessoriented activities are projected to an increase in employment and in real estate demand in East Portland.

The same variables are negatively affected inside the ring by the toll against a no toll scenario, advancing the assumption of some redistribution of businesses economies moving from the core to East Portland. However, the majority of economic activities do 
not account for relocating outside the boundaries in East Portland either. It could be speculated that the CBD cordon generally causes dispersion of employment beyond those areas. Yet, the totals for the entire city of Portland show a likely increase in economic investments.

Generally, in the areas right outside the boundaries, a CBD cordon produces a relative price appreciation in all residential classes in the West and East districts. Households living there would avoid paying the toll but still be close to the downtown and its opportunities.

The western part of Portland is surrounded by hills and Forest Park on one side and the downtown from the other side, where a concentration of higher-income households (City of Portland, 2015) reside. The increased costs brought by the tolls is assumed to be less significant in affecting location choices within high-income neighborhoods. From one side, households are facing the cost of crossing the cordon line to enter the city center or to go to East Portland, yet they appreciate the "residentially" and "elite" characteristics of the area. Some households may not be affected by the tolls on a daily commute; in fact, professionals who work in industries such as Intel or Nike could commute to their offices in Beaverton, Tigard, or Hillsboro without crossing the cordon line, while maintaining the advantage of being close to the downtown that can be accessed sporadically for amusement.

Households located in the eastside could still access job opportunities outside the cordon, while still being close to the CBD. Although east of Portland has the largest number of affordable housing units and is home to a large number of families with children, the area does not have many family-wage jobs, as the city of Portland (2009) 
states. Therefore, a cordon around the downtown raises equity issues in terms of limiting their access to the CBD and its opportunities.

Generally, a cordon around the CBD has positive effects on growth at the entire city level; nevertheless, it could produce a dispersion of economic activities and households while raising horizontal and vertical equity issues for lower income groups.

Similar considerations about household location patterns are as well true in the Mid cordon scheme. Demand for housing declines both inside the cordon and outside the east boundaries. Households located outside the east boundaries would experience the same equity issues explained above with regard to a decreased accessibility to the central city and its opportunities. Conversely, many higher-income households reside in West Portland (City of Portland, 2009). Within the westside, demand for housing increases since a toll around the Central City is assumed to be less significant in affecting location choices within high-income neighborhoods.

Overall, within the cordon boundaries, demand for non-residential real estate and employment increase, triggering a relative price increase. It is speculated that businesses located inside the cordon are less transport-dependent, so they would experience a smaller cost increase due to the charge that would be offset by the expected (theoretical) improvement in travel time; higher-value economic activities experience a larger increase in their employment and real estate. Retailers do not show any major impact from the toll; it could be because they are more sensitive to population. On the contrary, industries more dependent on transport, such as Manufacturing and Transportation/Warehousing, will be more affected by the toll; therefore, they would appreciate proximity to their sources, corridors nearby airports and major transportation hubs located primarily in the 
east side. While a toll boosts employment and non-residential location prices inside the ring and outside the eastern part of the Mid cordon, the increased commercial desirability is not reflected in higher property values for residential real estate, which, instead decline in those areas. However, a relative price depreciation does not necessarily cause a decline in employment and consumption. These variables are related to broader economic growth trends as well.

At the city level, totals show that overall demand for non-residential real estate and employment increase, with the exception of a few service/consumer-oriented activities that report a decline (the same variables would have a positive trend in the Small cordon scheme).

Supposedly, a Mid cordon brings potential economic growth to the entire city of Portland, perhaps at a slightly more minor degree than the Small cordon if one looks at the totals of the entire city. Nevertheless, an increase in non-residential employment and real estate demand towards the east side could generate some relocation of economic activities there. Compared to the Small cordon, it can be speculated that the Mid cordon generates more concentration of activities toward the core, both inside and outside the boundaries. Nevertheless, some activities and households seem to disperse beyond the areas analyzed. Therefore, horizontal and vertical equity issues need to be assessed if a cordon is considered as a potential policy tool to enhancement development.

Generally, a cordon around Portland city boundaries has positive effects on nonresidential real estate and employment for almost all the non-residential variables.

However, the number of non-residential properties projected to a relative price appreciation diminishes as the size of the cordon increases. 
Overall, real estate demand relative to supply declines inside Portland, as does the number of households within the city. The increase in relative location prices for residential real estate properties diminishes as the size of the cordon increases compared to no toll in 2035. Within Portland, there is an excess supply for Medical and Government spaces that seems unutilized. It could be speculated that some of the space once used for these activities would be converted to meet other investment needs. Supply becomes substitutable between purposes.

With the implementation of a Big cordon, the cities outside Portland are projected to an increase in non-residential real estate demand and employment. In detail, the larger the cordon size, the higher the number of industries projected to increase in their employment compared to no toll, especially in the eastern metro area. Generally, industrial activities are projected to an increase in employment and relative property values in the east. Activities such as Manufacturing and Transportation are more sensitive to increased transportation costs and congestion; consequently, they would value proximity to transport hubs and airports. Hence, by locating in the east side, they would accommodate such needs of proximity while being free from the toll. Moreover, not only industrial economies are projected to grow there, but also commercial and consumers activities as well, in both the east and west areas. These results are in line with the projected growth of households in Gresham and Tanasbourne/Bethany, likely attracted by the increased accessibility to employment while avoiding the toll, favoring the connection between housing stock and place of employment.

Generally, it could be speculated that a cordon would produce dispersions of employment and households relative to a no toll policy alternative, and this dispersion 
could be expected to extend beyond the areas studied. Because of the provinciality of Portland, compared to world capitals where toll cordons are implemented, a Small cordon particularly has a much stronger influence on an economically fragile downtown. It has to be taken into consideration that the implementation of a toll cordon in Portland could create equity issues with regards to limiting access to the downtown for lower income groups. The unequal impact from the tolling scheme across different socio-economic groups, as well as on different geographical areas of the population, raises fairness concerns that are also critical for acceptance. Politicians are resistant to the introduction of something that voters oppose. Policymakers need to ensure that any new policies could support all communities without limiting access to any areas and without discriminating against any household types. Also, lawmakers need to ensure that the new pricing policy will be able to accommodate not only growing economic activities, but facilitate the connection between workers and jobs, increase the number of educated workforces, and ensure that all communities are accessible and prosperous. It is important for legislators to carefully assess whether new policies will support economic development without amplifying the gap between different socio-economic groups, discriminating the housing market, and limiting access to certain zones. It becomes a matter of not only whether a cordon brings growth but also how the growth will happen and who is affected.

The east of Portland is characterized by the largest number of affordable housing units and families with children (City of Portland, 2009), although many of those households do not enter the group of families with wage-jobs (City of Portland, 2009). Traveling from the east to major job centers can be challenging for them. The implementation of a cordon could further limit access to their job opportunities. In fact, it 
is crucial for lawmakers to assess growth not only at the entire city level but also evaluate how well each cordon policy performs at the district scale. Although in-depth horizontal and vertical equity issues are of utmost importance to urban and regional success, they will not be further discussed in this paper.

Moreover, an implementation of a toll cordon without new road construction will generate lots of income to the relevant government. The importance of the debate over the intended use of revenue is recognized; in fact, much of the debate over the use of congestion pricing centers on the intended use of revenue. The collected revenue could be used efficiently either by providing additional benefits and/or transportation investments or by lowering other transportation taxes. Although economic theory supports utilizing this revenue to provide additional benefits to the society, such as lowering taxes or making other transportation investments, part of the literature argues that the revenue should be used to subsidize transit. The debate on the potential use and related issues of the collected income is not assessed in this study due to the inability of MetroScope to provide any information on the amount of revenue that could be produced.

The simplified version of MetroScope limits to test a single cordon line, for a single mode, and assumes a flat toll for a 24/7 period. If the full version of MetroScope could be used, the accounting of modal shifts would likely mitigate the dispersion effects that this study had found, considering that none of the alternative modes would be subjected to the tolls. It could be reasonable to speculate that the implementation of a dynamic cordon where tolls vary by time of the day would differently affect residential and non-residential land use patterns. The implementation of dynamic pricing into the full version of MetroScope would overcome a main limitation and provide additional 
information and more accurate predictions on land use changes and households response, as well information on modal share. By applying a toll only at certain times of the day and/or certain days of the week, the issue of limited accessibility faced by lower income groups could be mitigated as well. Moreover, based on the observations of existing dynamic cordons, it could be speculated that the ability to vary tolls could also lower traffic congestion, vehicle miles traveled (VMT), and emissions. The great majority of cordon and area schemes enforced in world capitals are dynamic pricing. London is currently assessing the possibility to switch from a flat fee to dynamic pricing to ease traffic and improve revenue. 


\section{Conclusions}

The results reported offer more of an introduction into the analysis of the effect of implementing a cordon charge on residential and non-residential land use than any conclusive understanding. As explained in the methodology chapter, MetroScope was a simplified version of the full model ran by Metro, which may have biased some results. Nevertheless, the findings are informative with respect to the likely impact of cordon tolling on land use and some other factors that may influence land value, investment decisions, and households' location preferences. The most important conclusion is that the size of the cordon caused alterations in residential and non-residential land use decisions.

The performance of each cordon compared to the default scenario advocates for a debate on its relationship with land use and call for future research on cordon charges as a policy tool to advance employment, housing, transportation, urban design, congestion management, and land use patterns. Even though regional growth depends on additional factors, this report addresses the likelihood of a cordon toll to influence future industrial, commercial, and residential markets and could provide the city of Portland with a demand forecast and supply estimates to determine future land needs. Nevertheless, as Metro stated, the outcome should be used to gauge growth in the area and to make general assessments. The results should be used along with other tools to make complete evaluations.

Regional growth depends on a range of variables such as an educated workforce, general economic conditions, accessibility to jobs, freight mobility, specialized infrastructure and technology development, etc.; therefore, more refined research is 
suggested to probe the existing relationship between cordon sizes and non-residential and residential land use variations and related issues. The use of the full version of MetroScope will lead to a more comprehensive and accurate understanding of the connections between employing the right cordon size to economic development and residential location choices. Further, the use of the full version of MetroScope will account for all transportation mode shifts as a result of the new policy. It must be acknowledged that the forecast outputs could diverge from the actual future trends because of a certain level of uncertainty due to rapid technological changes, other innovations, and new political regulations that could cause shifts from current assumptions. Lastly, in MetroScope, a toll is represented only by an equivalent travel time; hence a modification of the model to simulate and assess the revenue originated by a cordon is of utmost interest for lawmakers.

\subsection{Limitations and Future Research}

The estimated findings are considered noteworthy and may lead to more refined research on the relationship between cordon sizes and changes in economic development, travel behavior, and households' location decisions. Implementing dynamic cordon pricing into MetroScope would provide a more relevant forecast and would seek to respond to additional questions initiated from the course of this study. Dynamic pricing that would vary by time of day and/or day of the week would likely provide additional information and more accurate predictions on land use changes and households' response to a cordon scheme. Moreover, the analysis of mode shifts would add another layer of complexity that should yield important insights and offer some further understanding into factors that are likely to affect these responses. 
Further, MetroScope does not provide any information about the potential revenue collected, yet it would be of foremost interest to have such an estimate. Future research on this subject and all the related issues is remarkably important for politicians.

This study did not examine the cost or type of technology necessary to implement the cordon scheme, nor any related issues. In fact, thanks to the improvement in toll collection, including electronic toll detection and satellite surveillance, camera-based recognition, radio frequency identification, etc., detecting and collecting fees has become easier. It is well-understood that the number and locations of access points and the type of technology chosen could impact the cost of establishing and operating the cordon network. In future research, it will be worthwhile to focus on technology aimed to improve cordon performance and to lower costs.

Additional research addressing equity issues may be important to preserve accessibility for disadvantaged groups. Further, studies on the environmental impacts of cordon charges is another aspect of equity that is worthwhile to be investigated. To end, the implementation of cordon schemes may raise privacy concerns that are noteworthy to be addressed by policymakers.

It should not be dismissed that MetroScope is based on a set of assumptions that are more likely to develop in the Portland-Vancouver MSA. As such, the simulations were conducted for a particular metropolitan area, for specific congestion pricing policies, and the results are limited by the simplified version of MetroScope. Possible extensions of this research are all noteworthy. 


\section{Bibliography}

Ahmadi Azari, K., Arintono, S., Hamid, H., \& Davoodi, S.: 2013 Evaluation of Demand for Different Trip Purposes Under Various Congestion Pricing Scenarios, Journal of Transport Geography Vol.29, pp:43-51.

Ahmadi Azari, K., Arintono, S., Hamid, H., \& Rahmat, R.: 2013 Modelling Demand under Parking and Cordon Pricing Policy, Transport Policy Vol.25, pp:1-9.

Ambühl, L, Loder, A., Becker H., Menendez, M., \& Axhausen, K., 2018, Evaluating London's Congestion Charge - an Approach Using the Macroscopic Fundamental Diagram, Proceedings of 7th Transport Research Arena TRA 2018, April 16-19. (Institute for Transport Planning and Systems).

Anas, A. \& Hiramatsu, T.: 2013: The Economics of Cordon Tolling: General Equilibrium and Welfare Analysis, Economic of Transportation Vol.2, Issue 1 pp:18-37.

Anas, A. \& Hiramatsu, T.: 2011-09: RELU-TRAN-Application and Challenges, Economic of Transportation Vol.2, Issue 1 pp:18-37. Citation 16(1) pp.: 153-162, Osaka University http://hdl.handle.net/11094/23035.

Budstuper, A. 2018: London Congestion Charge: Why it's Time to Reconsider One of The City's Great Successes, The Conversation, Academic Rigor, Journalist Flair. https://theconversation.com/london-congestion-charge-what-worked-what-didnt$\underline{\text { what-next-92478 }}$

Brueckner, J. 2014; Cordon Tolling in a City with Congested Bridges, https://pdfs.semanticscholar.org/0582/855fe34ea9c7def816d1670b6e941829d5fa.pdf 
CityLab; 2018 London Congestion Charges is showing its age,

https://www.citylab.com/transportation/2018/04/londons-congestion-charge-needsupdating/557699/

CityMetric; 2018 London Congestion Charges it has been a huge Success, it's time to change it now https://www.citymetric.com/transport/london-congestion-charge-hasbeen-huge-success-it-s-time-change-it.

City of Portland, 2015: Employment demand analysis: Urban Growth Report. Appendix 6, 2014.

City of Portland, 2015: Growth Scenarios Report, (July 2015).

City of Portland, 2009: Household Demand and Supply Projections: (July 12, 2011).

De Borger, B, Russo, A.: 2018 - The Political Economy of Cordon Tolls, Journal of Urban Economics Vol. 105, pp. 133-148.

Eliasson, J., 2009: A cost-benefit analysis of the Stockholm congestion charging system, Transportation Research Part A 43, pp: 468-480.

Eliasson, J., et al 2009; The Stockholm congestion - charging trial 2006: Overview of Effect. Transportation Research Part A 43 pp:240-250.

Gomez-Ibanez, J., Tye, W., Winston, C.,1999; Essay in Transportation Economics and Policy. Brookings Institution Press, Washington, DC.

Ho, H.W., Wong, S.C., Yang, H., Loo, B.P.Y., 2005: Cordon-based congestion pricing in a continuum traffic equilibrium system. Transportation Research A, Vol.39(7-9), pp:813-834.

Metro, Cser, J.: MetroScope Gen 3.5 Overview (2013). 
Leape, Jonathan, 2006: The London Congestion Charge. Journal of Economic Perspectives-Vol. 20, No. 4, pp: 157-176.

Metro: MetroScope: A forecast Allocation Model and Policy Assessment Toll: A brief Model description (2004).

Metro: MetroScope Documentation_(2007).

Metro: MetroScope: 3.0 Generalized Design and Equation Specifications as Implemented at Portland Metro (July 10, 2009).

Mun, S., Konishi, K. and Yoshikawa, K, 2003: Optimal Cordon Pricing, Journal of Urban Economics, Vol. 54 pp:21-38.

Mun, S., Konishi, K. and Yoshikawa, K, 2005: Optimal Cordon Pricing in a nonMonocentric City, Transportation Research Part A, Vol. 39 pp:723-736.

Prud'homme R., \& Bocarejo, J.P., 2005 The London Congestion Charge: A Tentative Economic Appraisal, Transport Policy, Vol. 12, No. 3, pp:279-287; and response by Peter Mackie, pp. 288-290.

Ribalta, A. Gómez, S \& Arena, A.; 2018: Decongestion of Urban Areas with Hotspot Pricing, Networks and Spatial Economics, Issue 1, pp 33-50

Rufolo, A.; 2010. “Transportation Economics,” in 21 ${ }^{\text {st }}$ Century Economics: A Reference

Safirova E., et al; October 2006: Long Term Consequences of Congestion Pricing. Resources for the Future, RFF DP 06-42.

Santos, G, 2004: Urban congestion charging: a second-best alternative. Journal of Transport Economics and Policy 38 (3), pp: 345-369.

Schaller, B, 2010: New York City's Congestion Pricing Experience and Implications for Road Pricing Acceptance in the United States. Transport Policy 17, pp: 266-273. 
Short, John R. 2018: Are Traffic-Clogged US cities ready for Congestion Pricing? The Conversation Academic Rigor, Journalist Flair. https://theconversation.com/aretraffic-clogged-us-cities-ready-for-congestion-pricing-90814

Small, K. Gomez-Ibanez, J. 1999; Urban Transportation Handbook of Regional and Urban Economics, 1999, vol. 3, pp 1937-1999 from Elsevier.

Sumalee, A., 2004: Optimal road user charging cordon design: a heuristic optimization approach. Computer-Aided Civil and Infrastructure Engineering 19, pp:377-392.

Takuya Maruyama a, Agachai Sumalee 2007: Efficiency and equity comparison of cordon-and area-based road pricing schemes using a trip-chain equilibrium model, Transportation Research Part A 41 pp: 655-671.

Verhoef, E.T., 2002: Second Best Congestion Pricing in General Networks: heuristic algorithms for finding second best optimal toll levels and toll points. Transportation Research Part B 36, p: 707-729.

Victoria Transport Policy Institute (November 24 $\left.{ }^{\text {th }}, 2011\right)$ : London Congestion Pricing, www.vtpi.org.

Zhang, X., Shing, H.F., 2006: The London Congestion charge and Property Prices: An Evaluation of the Impact on Property Prices Inside and Outside the Zone. London School of Economic MPRA Paper No. 4050, posted 13. July 2007.

Zhang, X., Yang, H., 2004: The optimal cordon-based network congestion pricing problem. Transportation Research 38B (6), pp: 517-537. 